Florida International University FIU Digital Commons

6-12-2003

\title{
A new algorithm for electroencephalogram functional brain mapping based on an auditory- comprehension process
}

Mercedes Cabrerizo

Florida International University

DOI: $10.25148 /$ etd.FI14052523

Follow this and additional works at: https://digitalcommons.fiu.edu/etd

Part of the Computer Engineering Commons

\section{Recommended Citation}

Cabrerizo, Mercedes, "A new algorithm for electroencephalogram functional brain mapping based on an auditory-comprehension process" (2003). FIU Electronic Theses and Dissertations. 1959.

https://digitalcommons.fiu.edu/etd/1959 
Miami, Florida

\section{A NEW ALGORITHM FOR ELECTROENCEPHALOGRAM FUNCTIONAL BRAIN MAPPING BASED ON AN AUDITORY-COMPREHENSION PROCESS}

A thesis submitted in partial fulfillment of the requirements for the degree of MASTER OF SCIENCE in COMPUTER ENGINEERING

by

Mercedes Cabrerizo 
To: Dean Vish Prasad

College of Engineering

This thesis, written by Mercedes Cabrerizo, and entitled A New Algorithm for Electroencephalogram Functional Brain Mapping Based on an Auditory-Comprehension Process, having been approved in respect to style and intellectual content, is referred to you for judgment.

We have read this thesis and recommend that it be approved.

Prasanna Jayakar

Ilker Yaylali

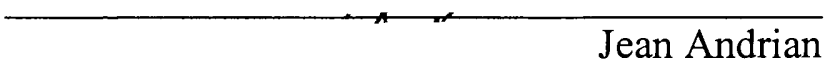

Malek Adjouadi, Major Professor

Date of Defense: June 12, 2003

The thesis of Mercedes Cabrerizo is approved.

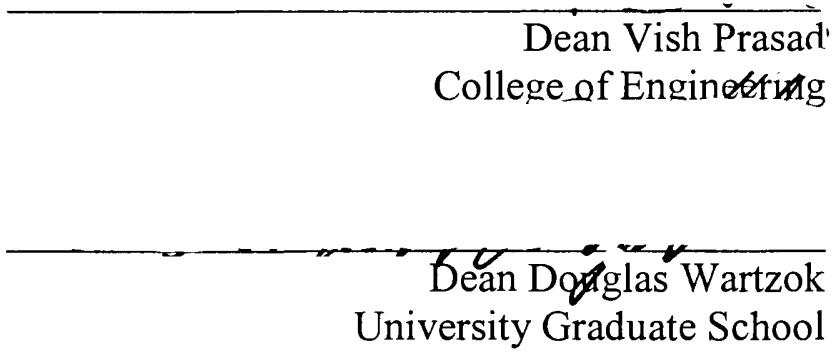

Florida International University, 2003

ii 


\section{DEDICATION}

I dedicate this thesis to my family. Without their patience, understanding, support, and most of all love, the completion of this work would not have been possible. 


\section{ACKNOWLEDGMENTS}

I wish to thank the members of my committee for their support and patience. Dr. Ilker Yaylali and Prasanna Jayakar for the many discussions we had, their insightful ideas, and comments that made this thesis more concise. I would like to give special thanks to Dr. Ilker Yaylali, who also provided me with all the needed literature about my research. I thank Dr. Jean Andrian for being a member of my master thesis committee and for his valuable comments for my research. I am most grateful and forever indebted to my major professor Dr. Malek Adjouadi. He has been extremely helpful in identifying my thesis topic, developing the ideas, publishing the papers, and helping me with the thesis. His appreciation of my work and encouragements were important in completing my thesis. Working with him has been a great pleasure for me.

I wish to thank the National Science Foundation and the Office of Naval Research for their support provided under grants EIA-9906600 and N-000149910952, and my deepest appreciation also goes to the National Science Foundation Graduate Fellowship Program for the prestigious fellowship that is allowing me to pursue my Ph.D. studies. The support of Miami Children's Hospital has been critical in carrying out the experimental work of this thesis.

I thank my parents for their unconditional support and love that keep me persevering in my work. My thanks also go to Ernesto for his moral support. 


\title{
ABSTRACT OF THE THESIS
}

\section{A NEW ALGORITHM FOR ELECTROENCEPHALOGRAM FUNCTIONAL BRAIN}

\section{MAPPING BASED ON AN AUDITORY-COMPREHENSION PROCESS}

by

\author{
Mercedes Cabrerizo
}

Florida International University, 2003

Miami, Florida

Professor Malek Adjouadi, Major Professor

The main objective of this thesis is to gain insight on the dynamics of the human brain through electroencephalography (EEG) analysis, with emphasis placed on the characterization of the effects of an Auditory/Comprehension task. A thorough examination of the EEG recordings was accomplished through the use of the most common brain waves (Alpha, Beta, Delta, and Theta). Conceivably, as the EEG recordings based on these tasks become better understood, their use as a helpful tool in mapping the different functions of the brain will become more effective. The EEG data was collected from 15 patients at Miami Children's Hospital using the ESI-256 system. A final evaluation of spectral arrays is performed based on comprehensive color topographic maps of the various induced brain activities. This representation allows us to bring out how different patients react under different circumstances, and to detect consequently neurological disorders such as the Attention Deficit Disorder (ADD). 
I. INTRODUCTION

II. DESCRIPTION OF THE ELECTRIC SOURCE IMAGING (ESI-256) EXPERIMENTAL SETUP FOR INITIAL EVALUATIONS OF EEG

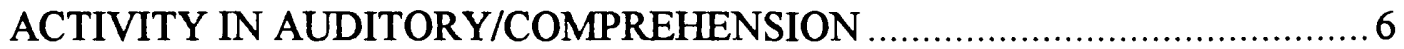

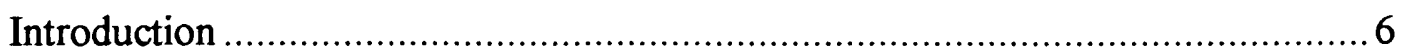

Principal Components and Description of the ESI-256 System........................ 7

Description of the Software in the ESI-256 ..................................................9

Description of the Setup for the MCN Configuration with The ESI-256

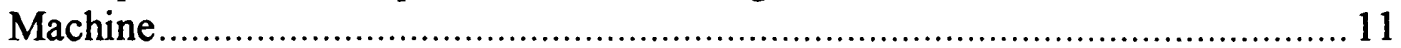

Data Acquisition Process Using the ESI-256 ................................................ 12

System Setup and Technical Requirements for our Research.......................... 14

Signal Pre-Processing Step to the Acquired EEG Data .................................... 17

Statistical Analysis of the Pre-Processed EEG Data ......................................... 18

III. EEG SIGNALS AND THEIR RELEVANCE TO AUDITORY

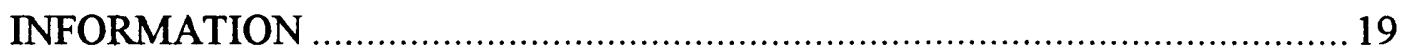

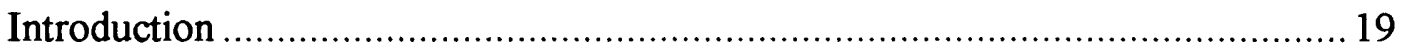

Frequency Contents of the EEG and its Significance..................................... 19

Advantages of EEG in Comparison to High Technology Brain Imaging

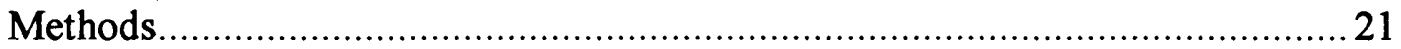

A Caution on Artifactual Activity in the EEG ............................................. 23

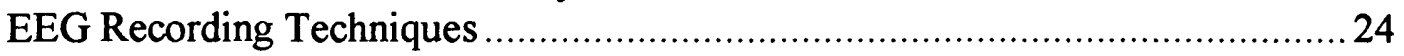

Montage Based on the Modified Combinatorial Nomenclature (MCN) ............26

IV. AUDITORY/COMPREHENSION AND THEIR CHARACTERIZING

FEATURES IN EEG RECORDINGS ….................................................... 30

Background on Auditory Cortex and Related EEG Activity ............................30

Regions Related to Language Comprehension ............................................ 31

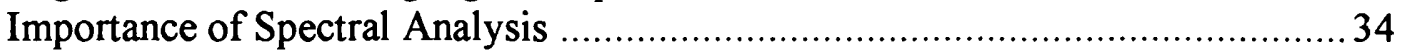

The Function and Analysis of EEG Frequency Bands .................................... 36

Different Approaches Used in Cognitive Processes......................................... 39

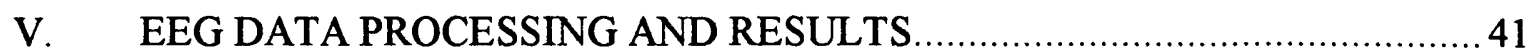

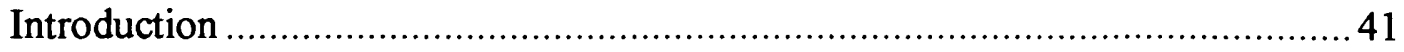

Noise Reduction of the EEG Signals ............................................................. 42

Analysis in Frequency Domain of the De-Noised EEG Signal.........................4 47

Analysis in Time Domain of the De-Noise EEG Signal.................................... 49

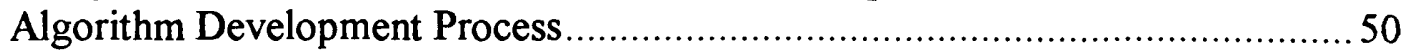

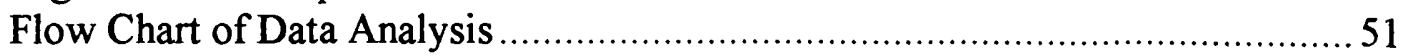

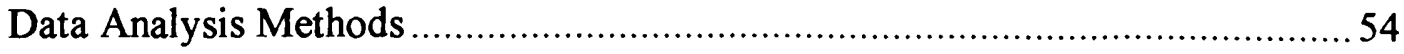


Spectral Analysis Using the Fast Fourier Transform

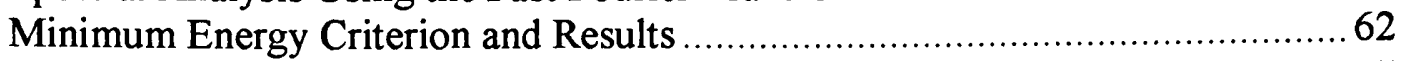

Root Mean Square

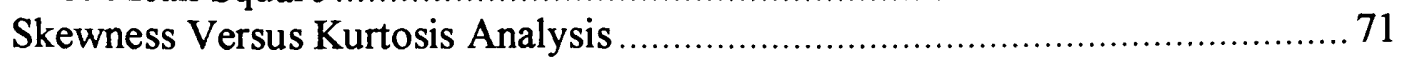

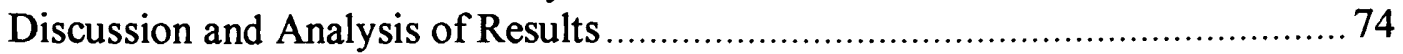

Cumulative Results Related to a Positive Change of Activity in the

Auditory/Comprehension Task ................................................................. 79

Cumulative Results related to a Negative Change of Activity in the

Auditory/Comprehension Task

Cumulative Results Related to a Positive and Negative Change of Activity in the Answering Task

Tabulated Results of the Auditory/Comprehension Task ................................ 90

Tabulated Results of the Answering Task .................................................... 101

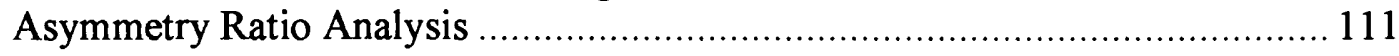

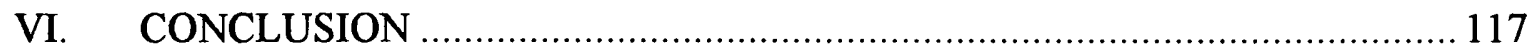

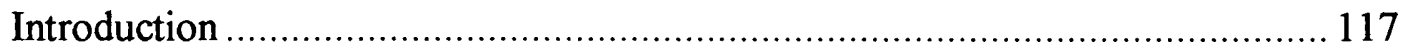

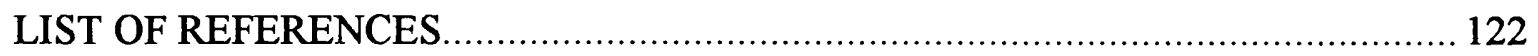

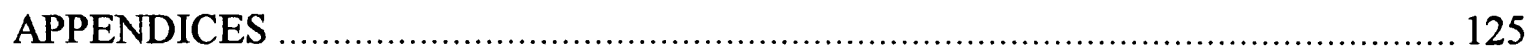




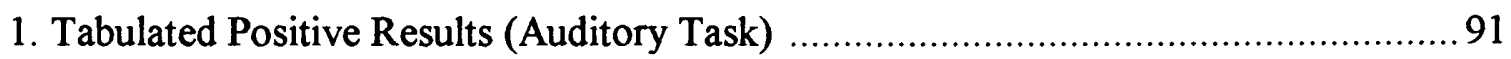

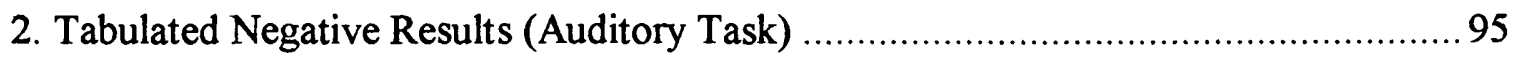

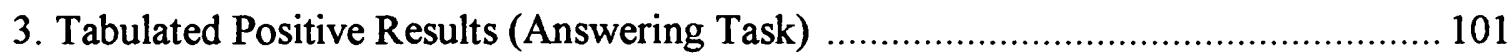

4. Tabulated Negative Results (Answering Task)............................................ 106

5. Asymmetry Ratio (Listening Task Positive Values) ....................................... 112

6. Asymmetry Ratio (Auditory/Comprehension Task Cumulative Values) ................. 113

7. Asymmetry Ratio (Answer Task Cumulative Values) ................................... 113

8. Auditory/Comprehension Task (Activity Localization) …............................... 114

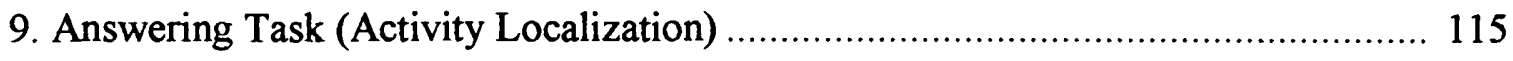




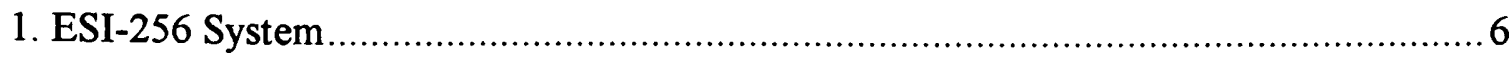

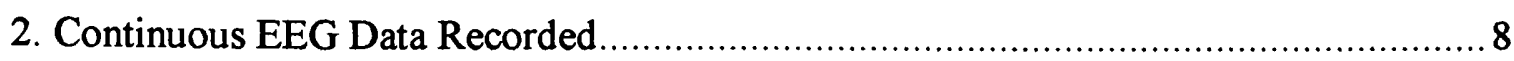

3. Interface Showing the Parameters of the ESI-256 Machine Used in the

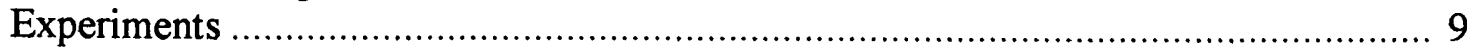

4. Interface Showing Electrode Labels Used in the Experiment ............................... 11

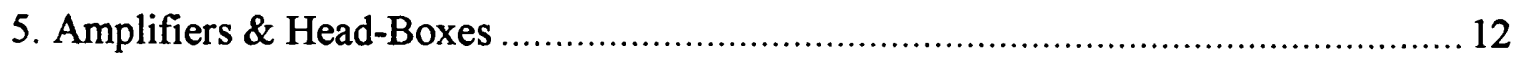

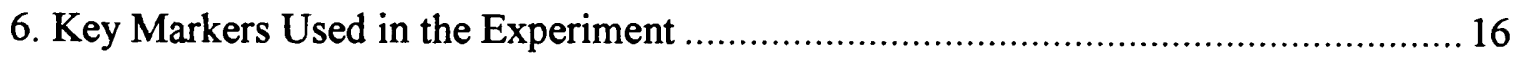

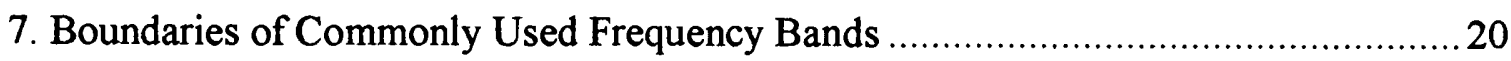

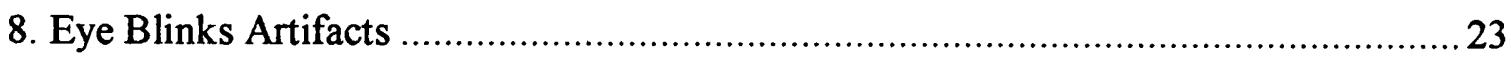

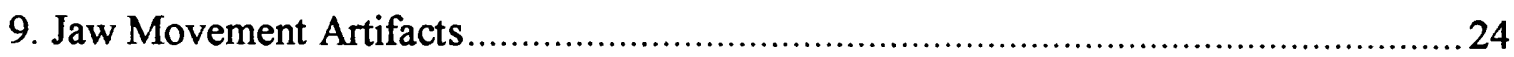

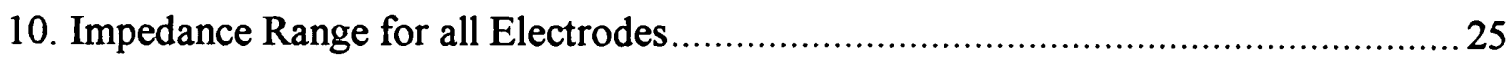

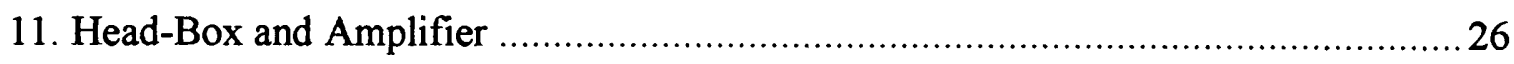

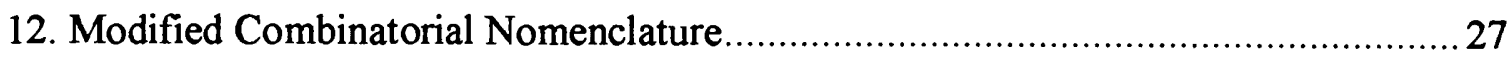

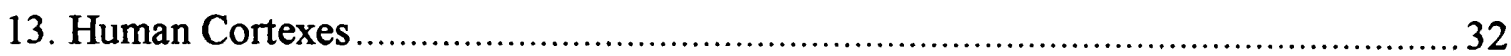

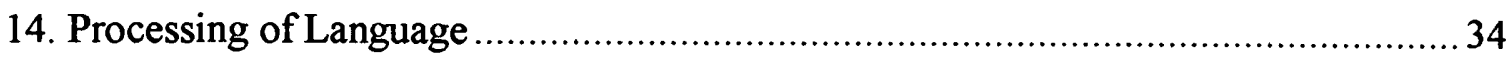

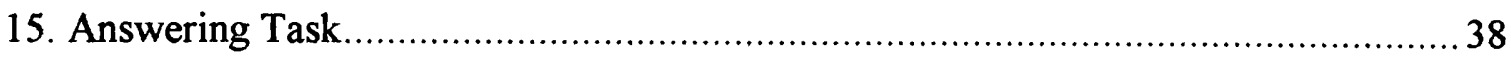

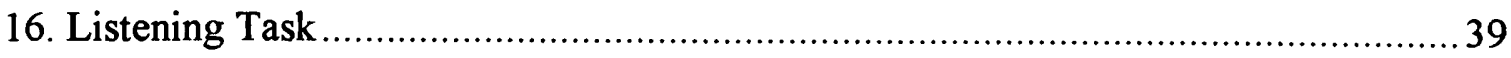

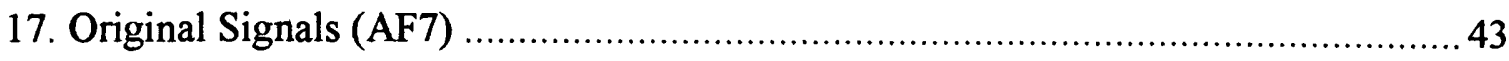

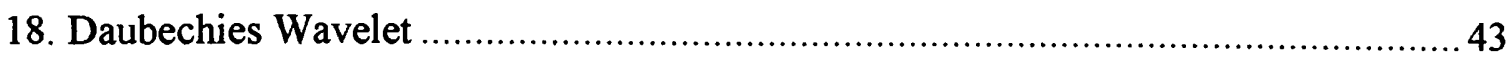

19. Different Steps in Reconstructing the EEG Signal ........................................ 45

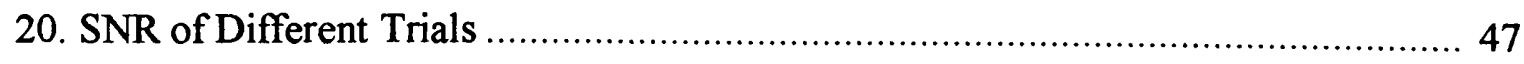


21. Differences in the Fourier Transform

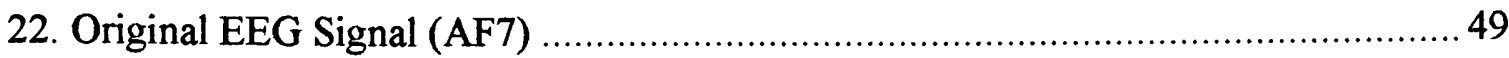

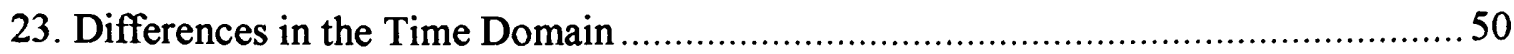

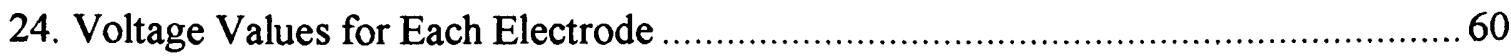

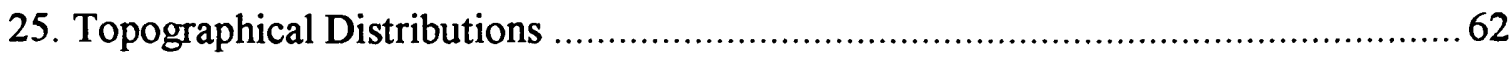

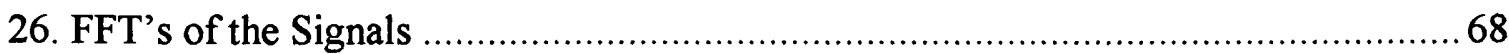

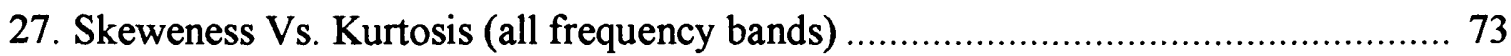

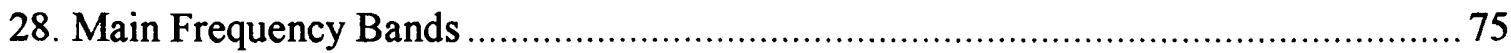

29. EEG Frequency Bands of a Raw Auditory EEG................................................ 78

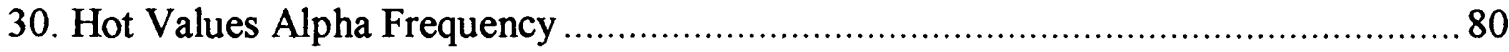

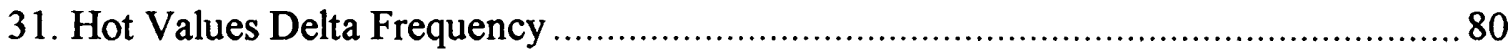

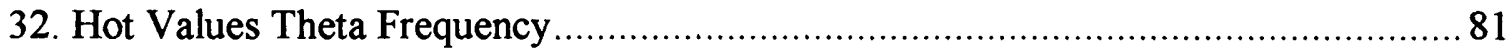

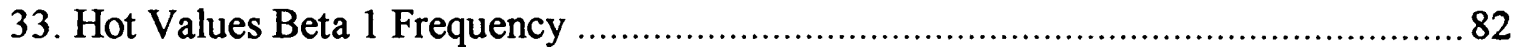

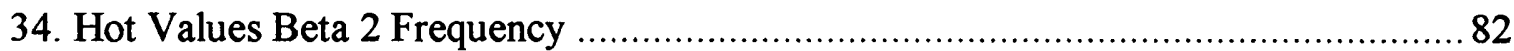

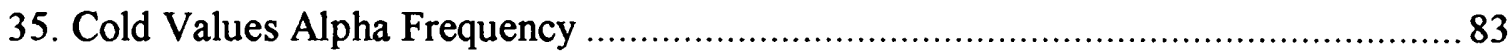

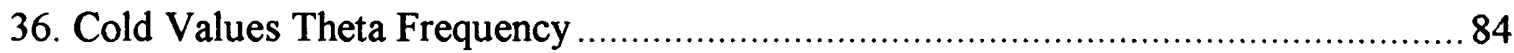

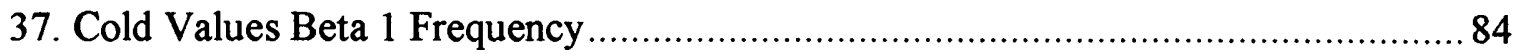

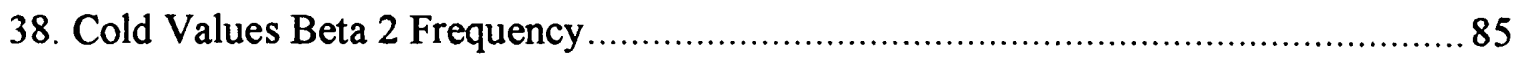

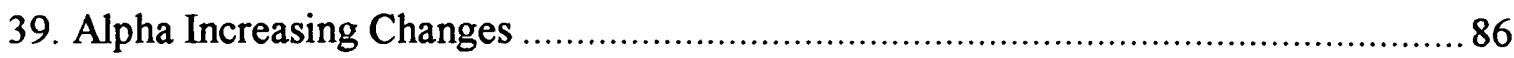

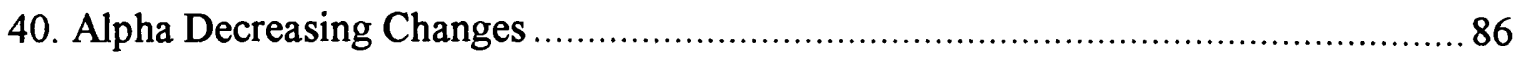

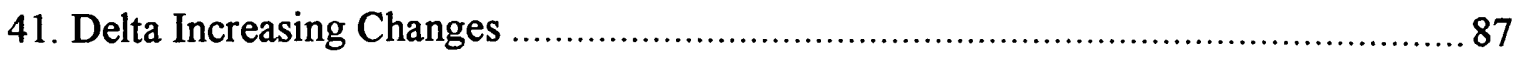

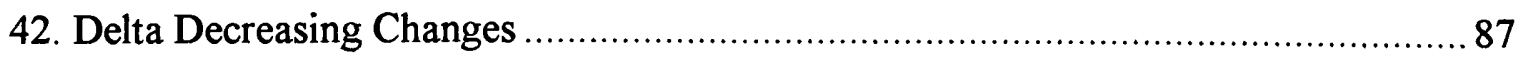

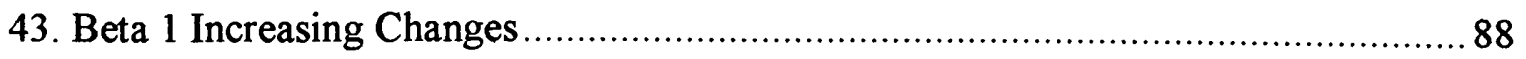




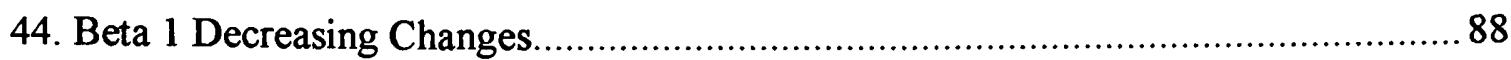

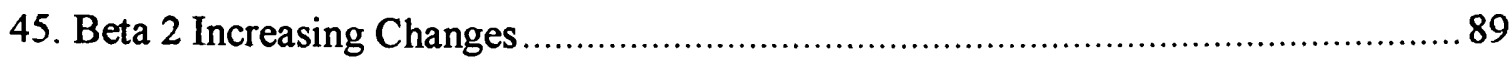

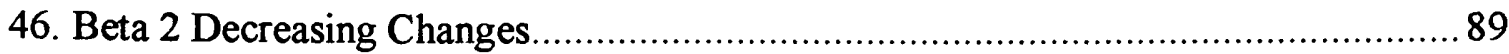

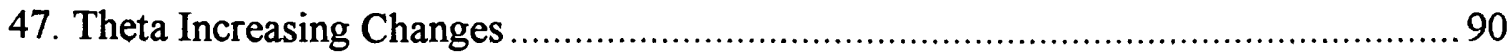

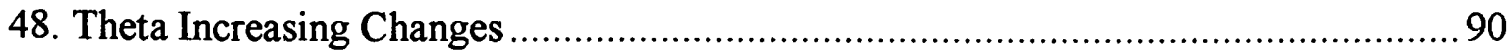




\section{CHAPTER I}

\subsection{Introduction}

This research focuses on EEG brain research in order to characterize brain functional mappings based on auditory/comprehension tests. This research has been conducted by using the ESI-256 (Electrical Source Imaging) machine. This system performs high-resolution external recordings of Electroencephalogram (EEG) activity up to 256 channels. The main objective is to gain a better understanding of the dynamics of the human brain through a study of EEG signals under well-conceived Auditory/Comprehension tasks. In addition, localization of brain behavior activity with respect to auditory-comprehension or response time will be provided. This relationship allows us to bring out how different patients react under different circumstances and to detect neurological disorders such as attention and comprehension disorders in the brain.

The aim is to develop an automated algorithm that will find patterns of dynamic brain behavior during monitoring of these processes in order to interpret and characterize EEG activities while focusing on trend (like behavior between patients) and anomalies that may shed light on attention and other auditory/comprehension disorders in the human brain. EEG reactions could vary depending of the subject. The frequency changes in the brain could be localized in different regions of the scalp depending of the type of listening/comprehension or response task. A computer program developed in this thesis will produce detailed head topography in order to show the frequency changes that take place in the brain during specific Auditory/Comprehension tests. In addition, the 
program will compare the EEG signals of any new patient to be potentially included in the study with the rest of the patients used in this study, in order to evaluate similar/dissimilar behaviors. The software implemented would be general, both in its implementation structure as well as in characterizing EEG brain behavior, in order to cope with what is expected to be a multitude of elusive brain behavioral characteristics. A main challenge is the ability to provide meaningful assessments of such EEG behaviors within the context of controlled tasks such the auditory/comprehension task.

The research problem is divided in 2 important parts. The first part will describe the behavior of EEG signals during the Auditory/Comprehension test applied to the subjects. In order to assure an accurate data acquisition, an EEG technician at Miami Children's Hospital has helped ensure that the same test is applied several times for each subject. This way an association between the task and the corresponding EEG activities using the ESI-256 machine will be studied. The second part will involve the implementation and processing of the frequency components of EEG signals in order to assess relevant brain wave changes in the subjects as they respond to several comprehensive questions. The algorithm will localize and find patterns of activity in the brain. A statistical analysis is conducted and comparative assessments were performed. The auditory/comprehensive test followed the strict guidelines on human-subject protocols. N.I.H. (National Institutes of Health) examination and I.R.B. (Institutional Review Board) have been secured for this research.

The analysis of the frequency components of EEG data will help us define changes in critical regions of the cortex during tasks such as listening activity and speech. 
This will enable us to accurately and safely define relevant regions of the brain. By implementing our method, EEG aspects of even complex cognitive processes, which underlie mental events such as mental arithmetic, watching pictures, reading and performing special creative processes can now be visualized through topographical displays and other specific signal processing ways created in this thesis. In addition, scalp measured EEG activity is non-invasive and may be applied to patients, including children, without any health risks. This non-invasive technique based on EEG data will come to complement other non-invasive techniques such as the Magnetic Resonance Imaging (MRI) and the Computer Topography Imaging (CT scan) for an integrated approach, where accuracy in diagnosis is deemed critical.

An essential goal of the pre-surgical evaluation is to map critical regions of the brain controlling speech and language functions so that these regions can be preserved during surgery. Mapping performed by electrically stimulating the cortex via subdurally implanted electrodes, although highly effective, introduces a small risk for cortical tissue injury, and is used only for extreme cases. Mapping the brain with our technique is effective albeit not to the higher resolution and less noisy aspects of the subdural approach, but does not present any risk to the patient.

Understanding whether some specific frequency components increase or decrease is important for modeling and understanding the systems giving rise to the signals, and may also have important clinical implications. As an example, frequency analysis may be applied to the treatment of disturbed language acquisition and to the improvement of a second language acquisition. The analysis of the mean voltage and relative mean power 
of different frequency bands will describe the localization in the brain, where a certain task, in this case listening and response, takes place. Therefore, the information (e.g. Left and Right Positive vectors, and Left and Right Negative vectors) generated by the different frequency bands will be used to both identify and evaluate the existence of a significant or relevant change in the brain during such tasks. A statistical approach is thus designed based on such characteristic vectors. The method developed in this study can then be extended to analyze other complex cognitive processing. Experimental observations made by medical doctors used to reinforce the identification and characterization of EEG activity in support of subsequent decision making processes.

Spectrum Analysis by a Fast Fourier Transform (FFT) is performed on sections of EEG data to determine the power content of the four main frequency bands. The resulting waveforms are displayed as a brain map, which will show the scalp distribution of the power within each frequency band. The amplitude of the different waveforms at a single point is also displayed in a similar format. This type of display provides a more objective analysis of the EEG activity and can serve as a platform for enhanced visualization.

This thesis is structure in the following logical manner:

Chapter 2 provides a description of the experimental setup used in conducting the experiments involving the 15 subjects. This chapter outlines a procedure for usage so that other researchers can pursue similar recording sessions for other type of research.

Chapter 3 discusses the EEG data content in direct relation to auditory information. It provides the nomenclature used in the recording apparatus in order to 
view the electrodes responses in context with their respective locations for more accurate brain functional mappings.

Chapter 4 provides a background on the auditory cortex within the context of the assigned or performed tasks. EEG recordings are shown to ensure that our experimental setup is operational.

Chapter 5 describes the processing steps that were undertaken and the results that were obtained. A detailed flow diagram is presented to show the interrelationship between the different processing methods that were implemented in this thesis.

Chapter 6 provides concluding remarks on the results obtained and on the procedure that yielded such results. 


\section{CHAPTER II}

\section{Description of the Electric Source Imaging (ESI-256) \\ Experimental Setup for Initial Evaluations of EEG \\ Activity in Auditory/Comprehension}

\subsection{Introduction}

The experiments conducted in this study involve the use of the ESI-256 EEG brain research machine. The ESI_256 system allows us to acquire data using large electrode arrays up to 256 channels. In addition, this system can be used in other research areas through the use of evoked potentials, and event-related potentials. Another important feature of this valuable machine is that it can be integrated with other input modalities like MRI (Magnetic Resonance Imaging) and SPECT (Single-photon emission computed tomography). An illustration of this machine is shown in Figure 2.1.

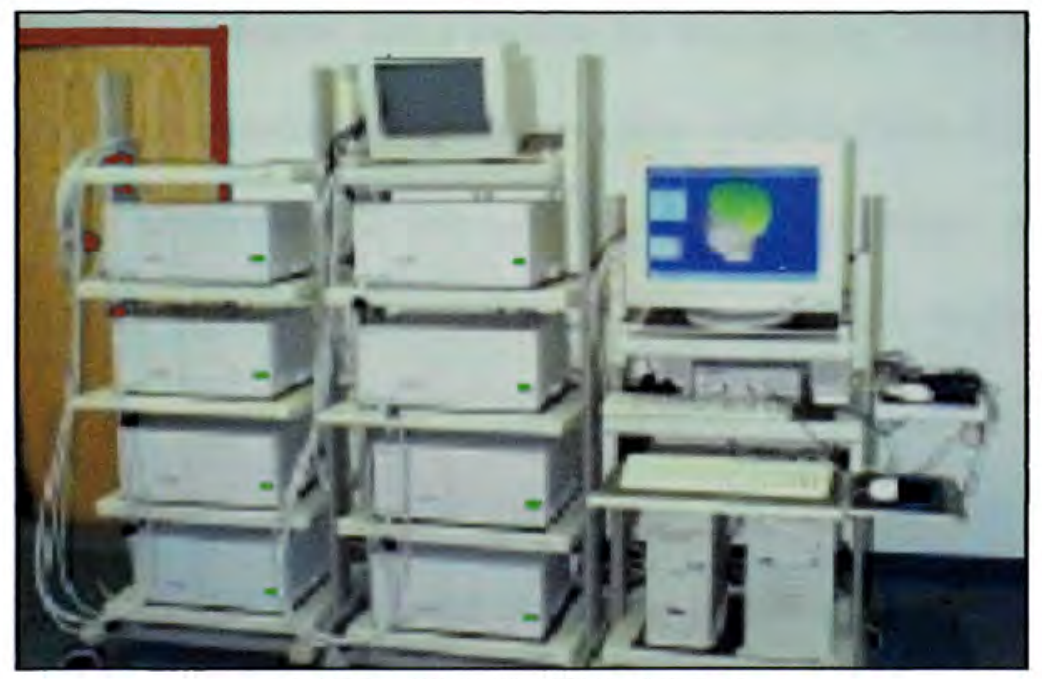

Figure 2.1 ESI-256 System 
The main modules of the system consist of 8 synamps (synchronous amplifiers), which are connected to a headbox. Each head box can accommodate up to 32 channels. The first synamp stage is in the head box. Each signal coming out from different electrodes is amplified with a gain of 150 . This configuration decreases susceptibility due to radiated noise sources. Also, each headbox comes with a circuitry able to perform DC offset correction, impedance checking and calibration. The ESI software support consists of the Acquire program. The host computer executing this program controls the data acquisiton of the SynAmp. This program performs all the acquisition process. It also controls, displays, and storages of the data recorded.

In this chapter, an overview to the ESI-256 system and a description of the components used for the development of this thesis are provided.

\subsection{Principal Components and Description of the ESI-256 System}

The main modules of the ESI-256 system consists 8 SynAmps EEG amplifiers, a host computer, the Scan software, and a monitor for data display. The 8 Synamp include an array of 8 head-boxes associated with each amplifier. Each headbox accommodates up to 32 channels. The headbox is the first gain stage since each channel is configured in order to amplify the signal coming from each electrode. The headbox should be positioned close to the subject in order to reduce radiated noise sources coming from the power lines and the outside environment. EEG signals are amplified with a gain of 150 . Most of the channels of each amplifier are monopolar channels (1 to 28) and the rest are bipolar channels (29 to 32 ). The electrodes are connected to the corresponding 
headboxes, which relate and transmit data to the host computer through the synamp amplifiers.

The SynAmp amplifiers provide the online digital signal processing, amplification and digitization of the EEG signals recorded from the electrodes. Also, they transfer the digitized data to the host computer through a SCSI interface. The Acquire program, which is installed in the host computer, provides the acquisition of the EEG data, and displays the signals coming from each electrode in continuous mode on the screen. An illustration of such data acquisition is provided in Figure 2.2.

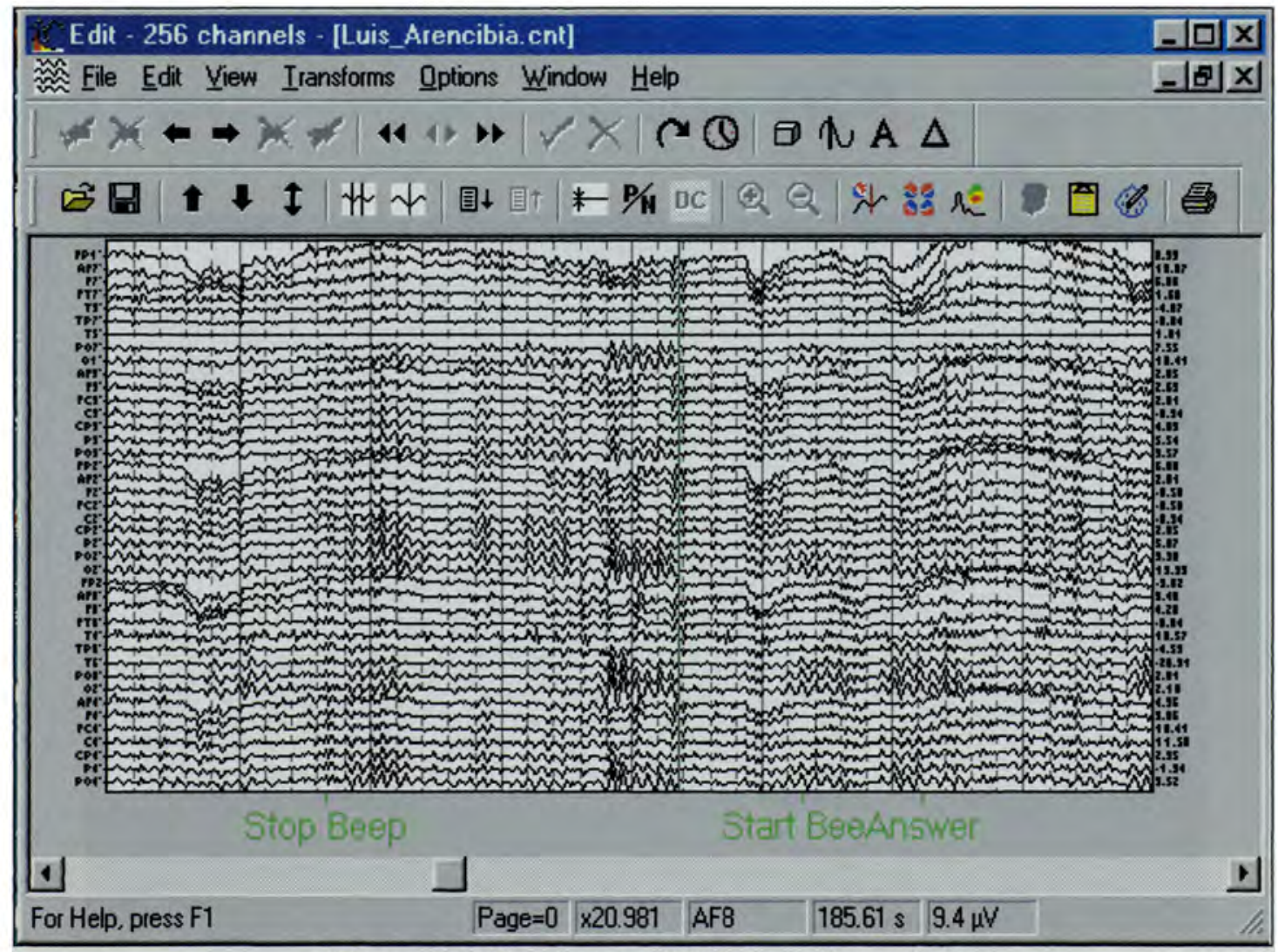

Figure2.2 Continuous EEG Data Recorded 


\subsection{Description of the Software in the ESI-256}

The ESI-256 machine comes with the SCAN software for the acquisition and analysis of the EEG data collected. This software is divided into several modules such as Acquire, Edit and 3D Space. The Acquire module, as the name implies, is used for the acquisition and on line processing of the EEG signals. The initial setup of the number of amplifiers used in this study, the impedance checks of all the electrodes, as well as the setting of the overall parameters of the amplifiers and the channel assignment table are obtained using this module.

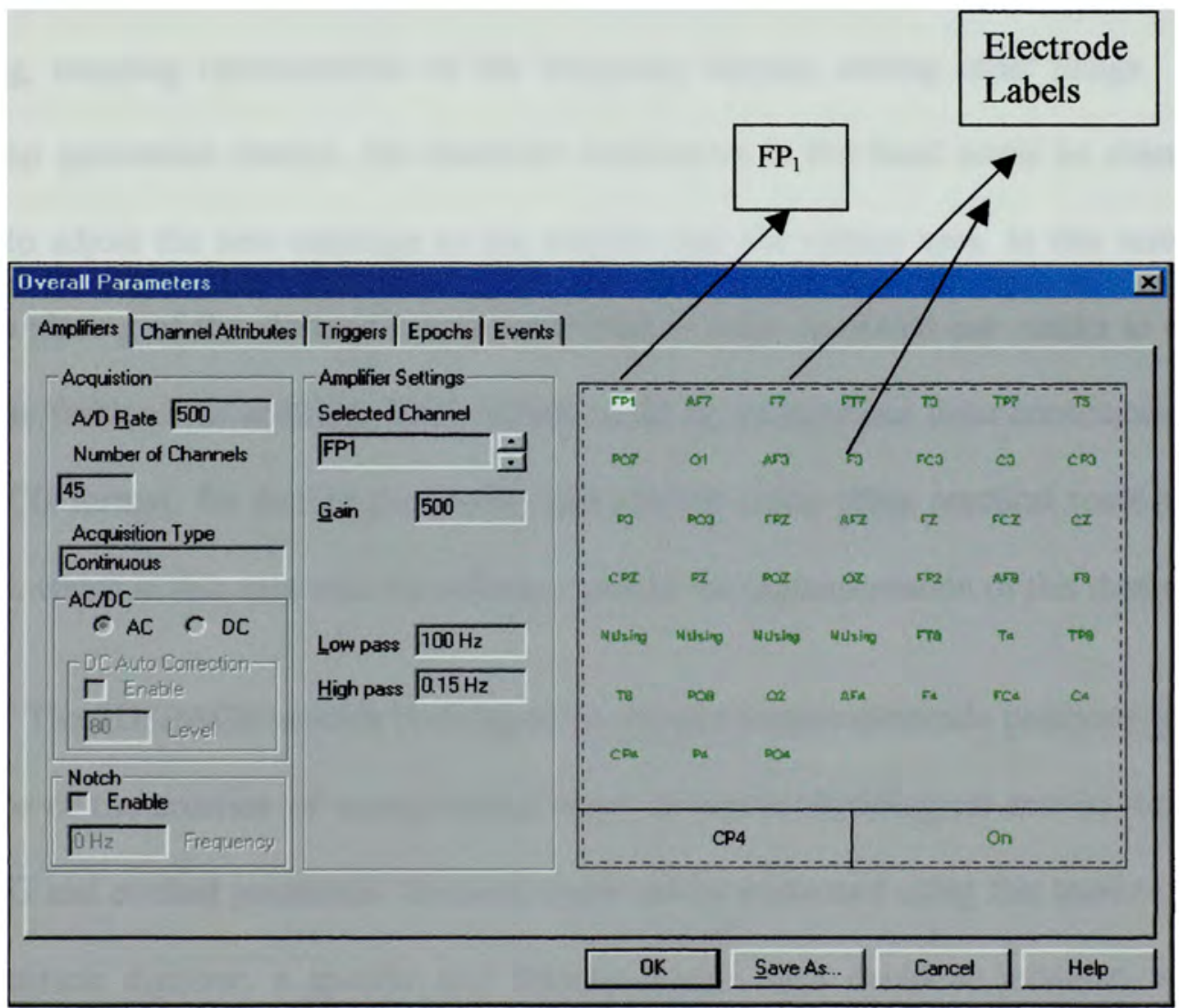

Figure 2.3 Interface Showing the Parameters of the ESI-256

Machine Used in the Experiments 
In Figure 2.3, the box where all the parameters could be altered is shown. In our research the selected parameters are: $500 \mathrm{~Hz}$ sampling rate, the used 41 channels, a notch filter was marked, continuous AC recording and a gain of 100 . The continuous EEG signal from each electrode is displayed in the monitor of the host computer. Also, markers could be placed in the data to define specific tasks, as shown earlier in Figure 2.2 .

The Edit module allows us to do off-line analysis and processing of the recorded EEG data. This module provides ways to save blocks of data where the focus of attention should be placed, where reduction of artifacts is needed; or for DC offset correction, filtering, mapping representation of the frequency domain, among other things. Using the Map generation feature, the electrode localization in the head could be changed in order to adjust the new montage to the analysis that the system uses. In this research a precise placing of the electrodes was performed in order to obtain our results in a more accurate fashion. In addition, EEG signals could be transformed from continuous mode to ASCII format, for further processing and analysis using other practical tools such as Matlab, which in this case was the software used in the implementation of this thesis.

The 3DSPACE module is designed to digitize precise electrode positions with the purpose of the creation of topographical maps of electrophysiological activity measured by EEG and evoked potentials. Dynamic maps can be generated using this module. Using the Fastrack digitizer, a specific and detailed human head could be modeled; then by superimposing the maps on the head, a clear view of the EEG activity could be observed. 
The modules used for this thesis were the Acquire and Edit sub-modules. In this type of research, these two modules were sufficient for our needs since they provided sufficient ways to deal with the different phases of the analysis and preprocessing of the EEG data.

\subsection{Description of the Setup for the MCN Configuration with The ESI-256 Machine}

Each SynAmp, has an input up to 32 channels. Since the system has 8 amplifiers, you can go up to 256 channels. The user by modifying the setup selected could vary the number of channels to use in a specific study. Figure 2.4 shows the channel assignment table of the Edit or Acquire sub-modules is displayed. The user could enter at any time the number of electrodes desired as well as the labels corresponding to each one of hem. The conducted study was performed using the MCN (Modified Combinatorial Nomenclature), with a total of 41 electrodes placed in key locations of the scalp.

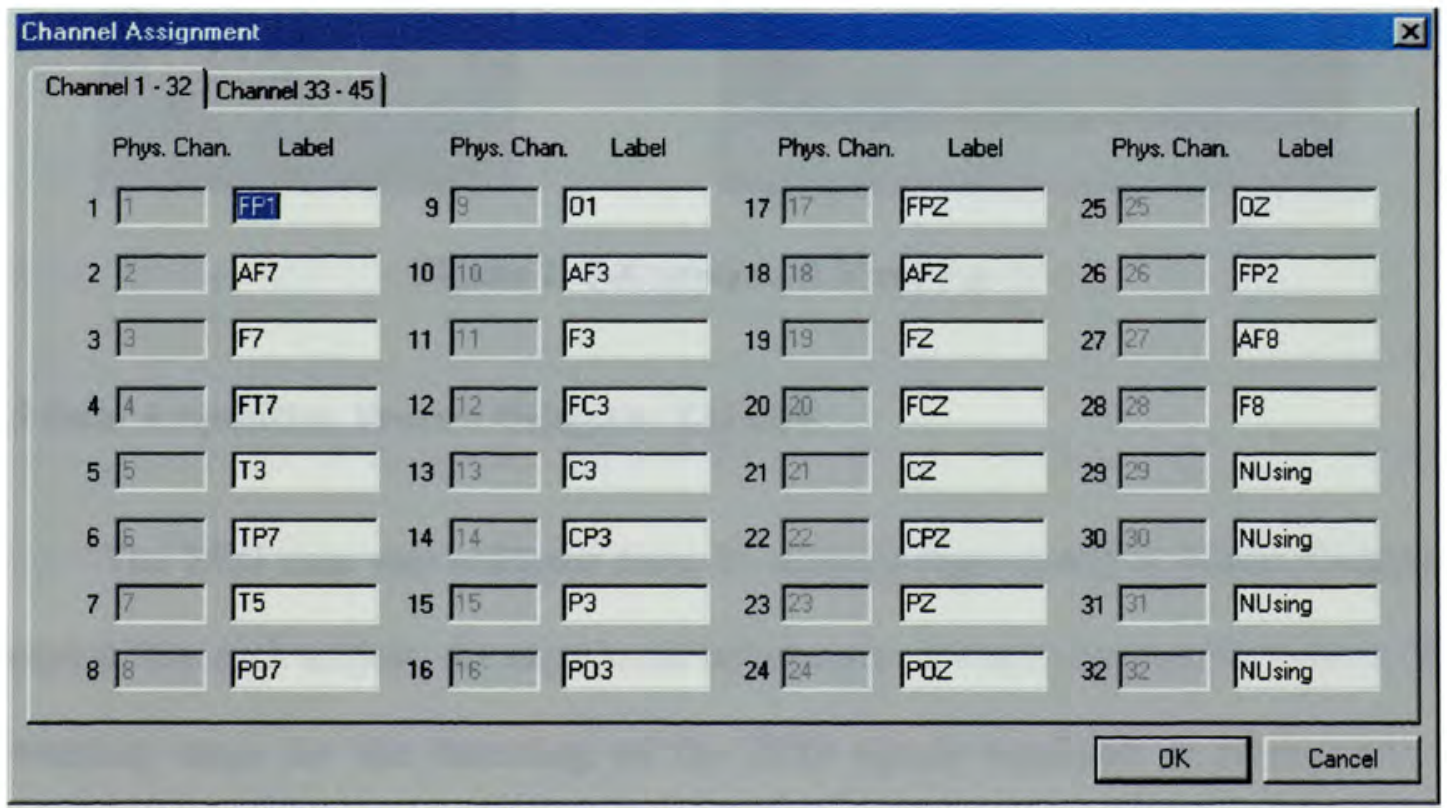

Figure 2.4 Interface Showing Electrode Labels Used in the Experiment 
Two amplifiers and head-boxes were used, as illustrated in Figure 2.5, for the experiment conducted in this thesis, which resulted in using 41 electrodes given the chosen MCN setup. The electrodes were connected to the corresponding head-boxes starting at channel 1 through 28 in the first head-box and starting at channel 1 through 13 in the second head-box. An electrode positioned in the forehead was selected as ground. This electrode was connected to the GROUND channel as specified in the head-box.
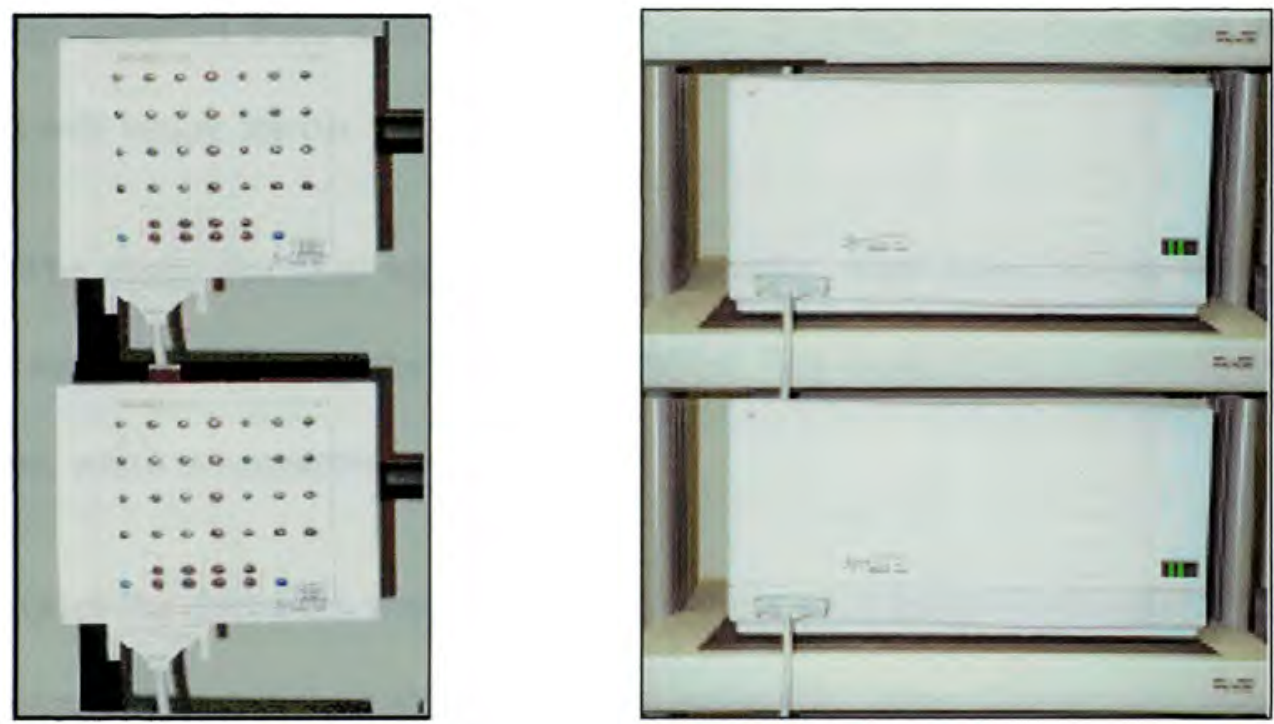

Figure 2. 5 Amplifiers \& Head-Boxes

\subsection{Data Acquisition Process Using the ESI-256}

The EEG data was collected from 15 subjects (age 23-42) at Miami Children's Hospital. For each subject, the experiment lasted on an average close to 20 minutes. The pre-testing steps for the recording of the EEG signals consisted in placing the 41 electrodes based on the Modified Combinatorial Nomenclature (MCN) montage 
described in the previous chapter. Since the ESI-256 system is situated in the Neuroscience Center at Miami Children's Hospital under the supervision of Dr. Prasanna Jayakar and Dr. Ilker Yaylali, a specific and well-documented training about EEG signals was provided by Eva Capote, an EEG specialist, who was the technician in charge for placing the electrodes on the scalp and ensuring the proper conduct of the experiment. The subjects used included 10 males and 3 females varying in age between 23 and 42 . Most of the subjects were males because in our experiments the hair interferes with the effective point of contact between the subject's scalp and the electrode. Therefore, the recordings obtained from subjects who had very short hair were clearer than those of subjects with longer haircut.

The electrodes after been placed in the scalp, were connected to the first and second amplifier following the same localization. The localization is done through the head-box, which is connected to the amplifier.

Once the electrodes were placed, the subjects were asked to relax and lay down in a very comfortable bed from the hospital. An explanation about the test was given to the subject before starting with the procedure. The test, which takes no more than ten minutes, is an auditory comprehension test, where the subject listens to thirty-four sentences and has to complete each one (See appendix F). It was required from the subject to have his/her eyes closed and to maintain the maximum possible relaxation in order to reduce the effect of artifacts in the EEG signal such as eye blinking, movements, among others. Thirty to forty seconds of normal brain activity of the relaxed subject was 
recorded prior to administering the test in order to have a baseline of each patient to be used for better analysis.

EEG signals were collected with the high spatial resolution of the ESI-256 machine. The Acquire software sub-module of the Scan 4.0 interface was used to record continuous EEG data while testing each subject at a sampling frequency of $500 \mathrm{~Hz}$ per channel. This yields a total of $500 \times 41$ data points collected per second per subject. Each of these data files generated consisted as a whole of 500 data samples/second-channel $\mathbf{x}$ 600 seconds $\times 41$ channels $=12.3 \times 10^{6}$ data samples per experiment. Therefore, the amount of computer memory storage that each subject would require is about $504 \mathrm{MB}$. Our host computer has 2 additional drives of $40 \mathrm{~GB}$, to ensure that all of our experiments could be saved for further analysis.

Appendix $\mathrm{A}$ and $\mathrm{C}$ provides for future references a precise outline of the steps followed when using the ESI-256 machine in data. This guide provides the basic steps in order to acquire, collect, and retrieve the EEG data, and will allow future students to do a quick setup of the machine for other type of data collection and analysis.

\subsection{System Setup and Technical Requirements for our Research}

The Acquire module of Scan 4.0 provides different options for the user to set up the system. The parameters used included the gain and on-line filters of the amplifiers. For this specific research endeavor, the gain of both amplifiers was set to a 100 and the cut off frequencies for the filters were $0.15 \mathrm{~Hz}$ for the high pass filter and $100 \mathrm{~Hz}$ for the low pass filter. This range allows us to eliminate some unwanted frequency components 
and at the same time fit our data to this spectrum range, which is more characteristic of EEG signals.

The data was collected in continuous mode. This way, the electrical activity coming from different locations in the scalp could be appreciated in order to look for patterns in the data during different activities. Also, using continuous data allows placing online event markers, so the signal is divided into different parts according to a certain task. This allows for a more detailed analysis during the off-line digital processing using the Edit module of the ESI-256 machine, and subsequent processing using the Matlab 6.5 program. The F1 through F11 event keys are included by default in the software. The Keys shown in Figure 2.6 were used for our research: F2 (Stop of listening), F7 (start of listening), F10 (Answer), and F11 (No response). With the use of these event markers, the EEG data collected could be separated in blocks representing different activities, so it could be analyzed further in more details. (See also Appendix B).

Once the data is separated into blocks, the files were converted from continuous format (*.cnt) to ASCII format, so it could be processed in Matlab 6.5. The ASCII files are divided in columns depending of the number of electrodes used, so the files consist of 41 columns and the rows represent the number of samples taken per channel. The samples could vary depending on how many seconds of EEG are analyzed. A total of 13 ASCII files per subject were collected, 6 containing auditory/comprehension activity, 6 with answer activity, and 1 with the baseline behavior of the subject. Our goal with the processing of these ASCII files is to generate an algorithm that performs a spectral visual representation in the brain of the active regions at a given task. Also, a database of all the 
patients could be established and stored in order to compare future patients that have similar/dissimilar behaviors during the same task.

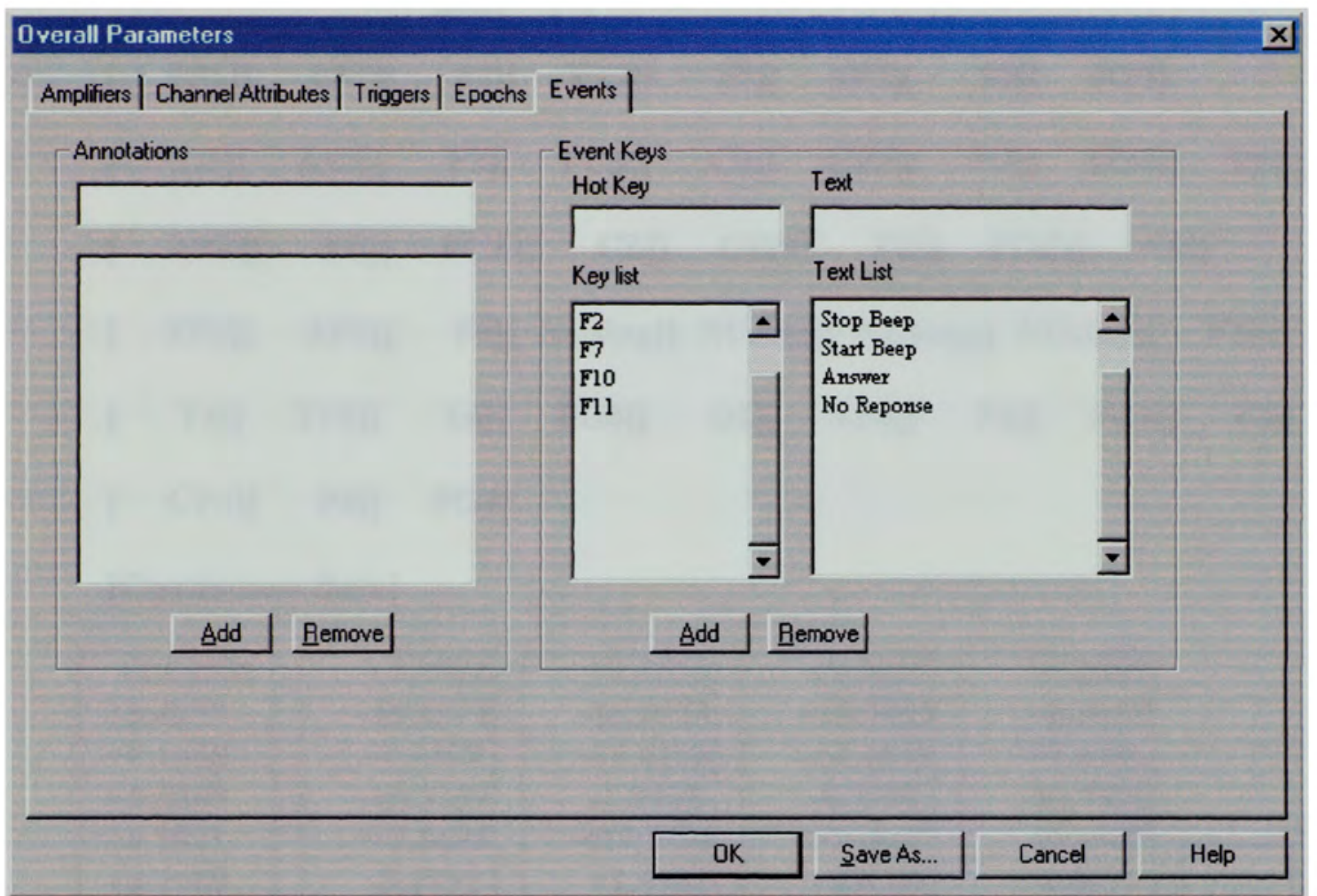

Figure 2.6 Key Markers Used in the Experiment

Example of an ASCII file

[Subject]

[Date] 05/07/2002

[Time] 16:57:57

[Channels] 45

[Rate] 500.000000

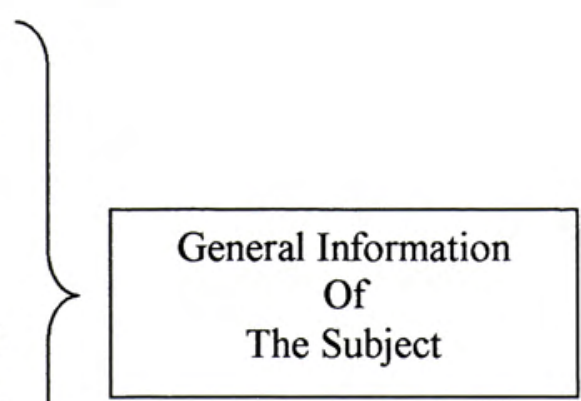

[Type] Continuous

[Rows]Points

[Electrode Labels] 


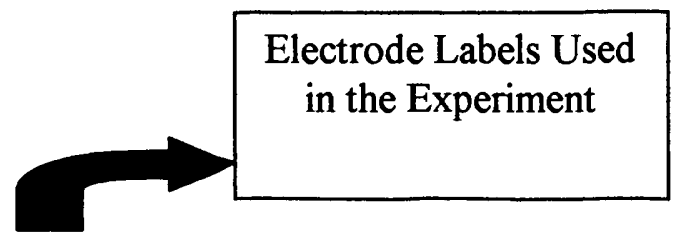

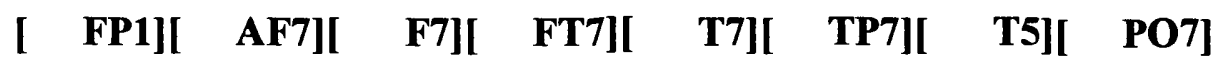

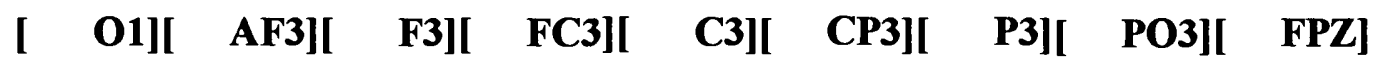

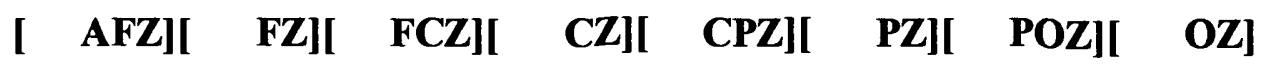

[ FP2][ AF8][ F8][ NUsing][ NUsing][ NUsing][ NUsing][ FT8]

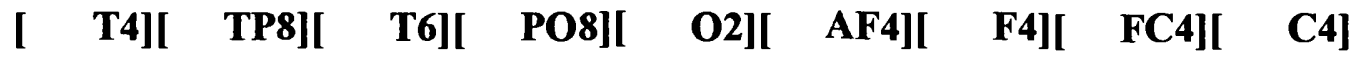

$\left[\begin{array}{lll}\text { CP4] } & \text { P4] } & \text { PO4}\end{array}\right]$

[Continuous Data]

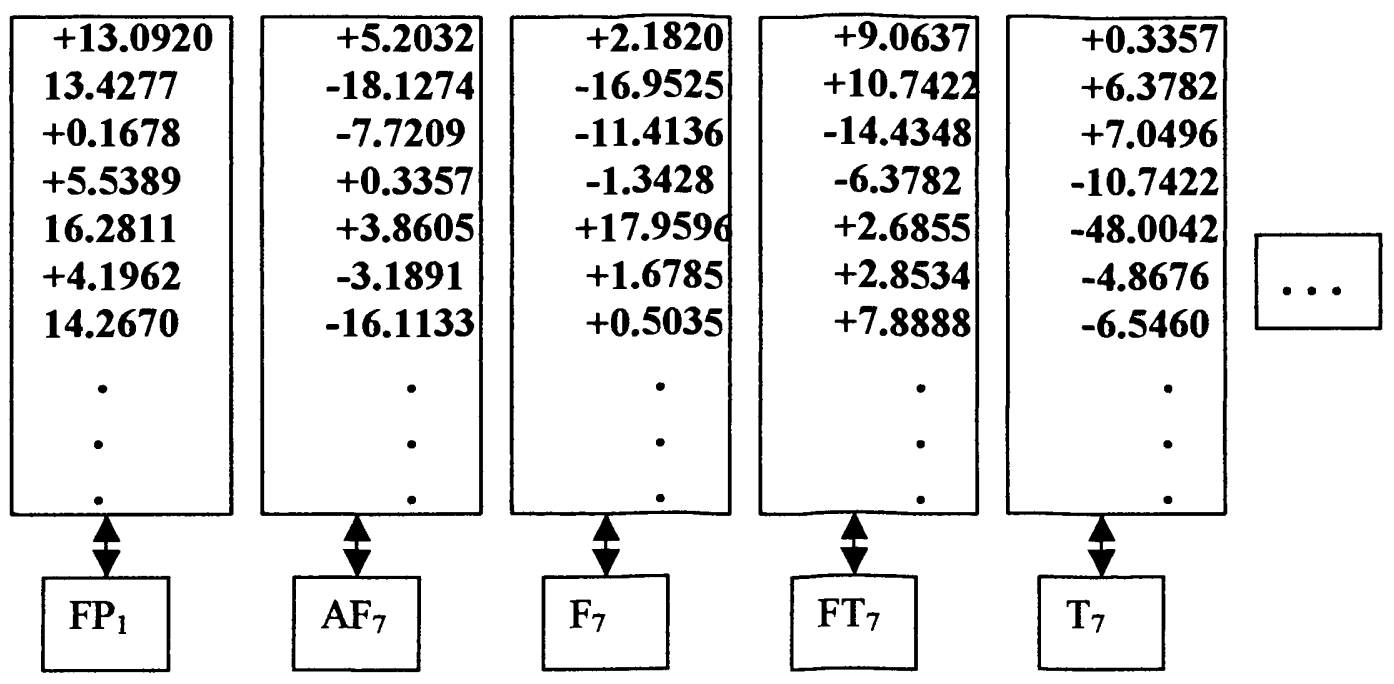

2.7 Signal Pre-Processing Step to the Acquired EEG Data

The recorded continuous EEG data was first viewed in all 41 electrodes. To reduce unwanted noise added to the data by the external environment, the data was 
digitally filtered with a low pass filter set below $60 \mathrm{~Hz}$. The separated files were saved in ASCII format with the Stats sub-module of the Scan 4.0 Interface. A program was written in Matlab in order to perform the second set of off-line digital signal processing to the EEG data. The four main frequencies were analyzed for each region of the brain in each of the hemispheres (left/right). There are four broad spectral bands of clinical interest: delta $(0-4 \mathrm{~Hz})$, theta $(4-8 \mathrm{~Hz})$, alpha $(8-12 \mathrm{~Hz})$, and beta $(12-30 \mathrm{~Hz})$. The boundaries of the beta band were subdivided into 2 new boundaries. Beta 1 was considered from 12 to $20 \mathrm{~Hz}$ and Beta 2 from 20 to $30 \mathrm{~Hz}$. This way a concise analysis could be narrow down and patterns could be found more consistent when comparing subjects.

\subsection{Statistical Analysis of the Pre-Processed EEG Data}

The absolute mean power and mean voltage values of each frequency band taken into consideration obtained for each subject and from each region of the brain were used to analyze the EEG signals. Tables are provided representing each region of the brain, considering the division left and right. These tables show the number of active electrodes present in every region during a given task. Therefore, a comparison could be established for all the patients. The skewness values and the kurtosis values are graphically represented in order to find regions where these values pertaining to a specific frequency band are located. 


\section{CHAPTER III}

\section{EEG Signals and their Relevance to Auditory Information}

\subsection{Introduction}

Since the research of this thesis involves recordings and processing of the Electroencephalogram (EEG), a background on the nature of this signal is necessary. The EEG, recorded in the scalp, is generated by changes in the electrical charge of the membrane of cortical nerve cells. These changes fluctuate as a result of impulses arriving from other neurons at contact points, or synapses. This electrical activity creates electrical dipoles, which result from the depolarization and hyperpolarizations of the postsynaptic membrane of the cortical pyramidal neurons. The voltage created by the electrical dipoles, measured on the brain tissue, is the Electrocorticogram (ECoG), with amplitude in the range of millivolts. However, the EEG measured on the scalp is in the microvolts range (generally lies between 10 and 100 micro-volts), since the amplitude of the cortical signal is reduced by the resistance imposed on it by the leptomeninges, cerebrospinal fluid, dura mater, bone, galea, and the scalp [Spehlmann, 1988; Clark, 1998]. EEG is a most convenient and cost effective way in measuring brainwave activity in the outer layer of the brain.

\subsection{Frequency Contents of the EEG and its Significance}

EEG of humans either at rest or awake commonly contains rhythmical potential changes. These rhythms are called brainwaves and they are measured in frequency (speed of electrical pulses) and in amplitude (intensity of the brainwave). Frequency is 
measured in cycles per second, or Hertz $(\mathrm{Hz})$. Thus, one frequency is one cycle, or one pulse per second. The frequencies of the EEG signal range from 0.5 to $100 \mathrm{~Hz}$, depending on the degree and type of activity of the brain, such as alertness and sleep. Electrical activity emanates from the brain in the form of brainwaves. There are four brainwave states that range from the low amplitude/high frequency Beta to the high amplitude/low frequency Delta. Research has shown that according to the activity level of an individual, one brainwave state may be dominant at any given time, even though all brainwave states will remain present at minimal levels. The frequency of EEG waves is divided into four groups of frequency bands. These divisions are shown in Figure 3.1.

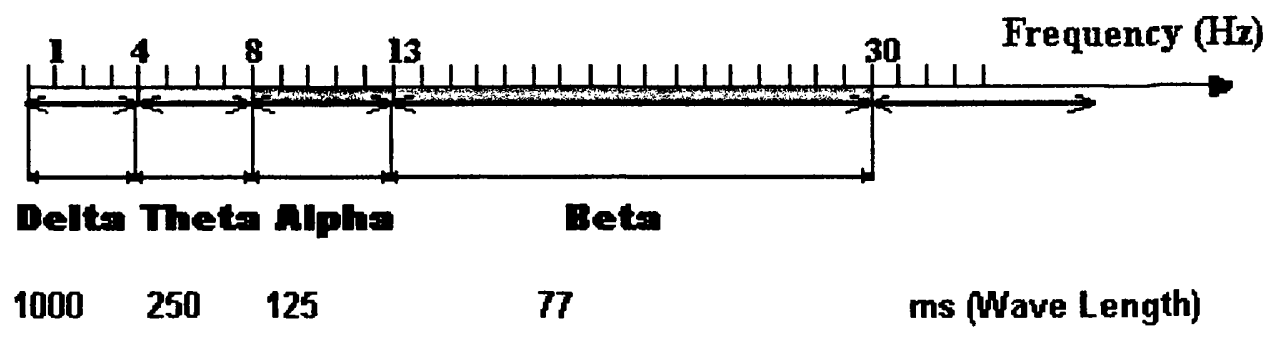

Figure 3.1 Boundaries of Commonly Used Frequency Bands

The four main brain waves are alpha, beta, delta and theta. Alpha waves are those between 8 and $13(\mathrm{~Hz})$. It is the major rhythm seen in normal relaxed adults, and occurs whenever the person is alert, but not actively processing information. In general, alpha waves decrease when the subjects have their eyes opened and are attentive to external stimuli. Beta activity is 'fast' activity. It has a frequency of $13 \mathrm{~Hz}$ and greater. It is generally the dominant rhythm in those who are alert or anxious or who have their eyes 
opened, and are listening and thinking during analytical problem solving, judgment, decision making and processing information. The lowest frequencies are delta, these are less than $4 \mathrm{~Hz}$, and occurs in deep sleep. It reflects unconscious mind. We increase delta waves in order to decrease our awareness of the physical world. Theta activity has a frequency of 4 to $8 \mathrm{~Hz}$ and is considered as slow activity. Theta waves are strong during internal focus and meditation. It is seen in connection with creativity and intuition.

\subsection{Advantages of EEG in Comparison to High Technology Brain Imaging Methods}

EEG posses a high temporal resolution, simple in use, and does not disturb a subject in most of the cases provided that the recording apparatus is comfortably connected to the subject. The EEG can be recorded near the patient, while he/she is lying down in a comfortable chair or bed, and can be used for long-term monitoring of many stages of the mind, such as, during sleep, during a period of brain malfunction (epilepsy), or during the administering of different tasks such as the auditory/comprehension task. EEG can reveal one of the main parameters of the neural activity in the brain, which is the rhythmic property that reflects the essence of neural excitation. Therefore while recording electrical (as well as magnetic) field patterns, the physiologist has access to the actual mechanisms of the brain information processing.

The principal effects of this study can lead to the discovery of the functional mapping of human brain processes, revealing not only in what region of the human cortex, but how information is processed in the brain in real time by assessing the make up of these pattern activities. Thus, EEG, which previously was treated as a result of 
simple and sometimes sporadic summation of the activity of enormous masses of neurons, is nowadays an efficient tool in exploring the intimate mechanisms of informational processing in human brain. With the advent of even higher resolution in spatial recordings and the newer technological developments, EEG data analysis will see for the near future far greater enhancements.

Expected such advances will be most welcome since electroencephalograms (EEG) provide information about the health and function of the brain. The EEG can help diagnose conditions such as epilepsy, brain tumors, brain injury, stroke, and liver or kidney disease, which leads to specific metabolic conditions. EEG can help physicians find the source of other problems such as headaches, weakness, blackouts, dizziness, or auditory/comprehension problems. It can also be used in patients, who are deeply unconscious, to distinguish between brain death and possible reversible conditions.

Sleep deficiency is another frequent disorder that currently affects millions of people of all walks of life. Electroencephalograms have been used to research bright light therapy and its effectiveness in order to alleviate this common problem. In addition, electroencephalography has become a major tool in aiding physicians to look closer at the origins of alcoholism, along with its often-devastating effects.

The diverse examples mentioned above represent only a small number of applications of electroencephalograph-based technology. Today, EEGs are at the forefront of medical diagnosis and treatments. Continual research on possible applications of the EEG signals will assuredly lead to new ways of fighting common and 
other as yet to be understood diseases such as Alzheimer, Parkinson's disease just to name a few.

\subsection{A Caution on Artifactual Activity in the EEG}

When recording EEG, artifacts may appear and they are not generated by cerebral activity. They may be due to other physiological activity originating from the subject, for instance eye blink, body movement (EMG), and heart beat (EKG). Also, interference from power lines and electrical sources from the ESI (256) machine could as well affect the recordings of EEG signals of some of the electrodes. Artifacts must be avoided as much as possible because they may mimic or obscure cerebral activity. Artifacts such as eye movement were observed to be the most common in our recorded EEG data; even though the subject's eyes were closed, some eye movements can usually be seen. In Figure 3.2 , an example of the artifact activity generated by eye blink may be observed. Also, other artifacts such as jaw movement are illustrated as well in Figure 3.3.

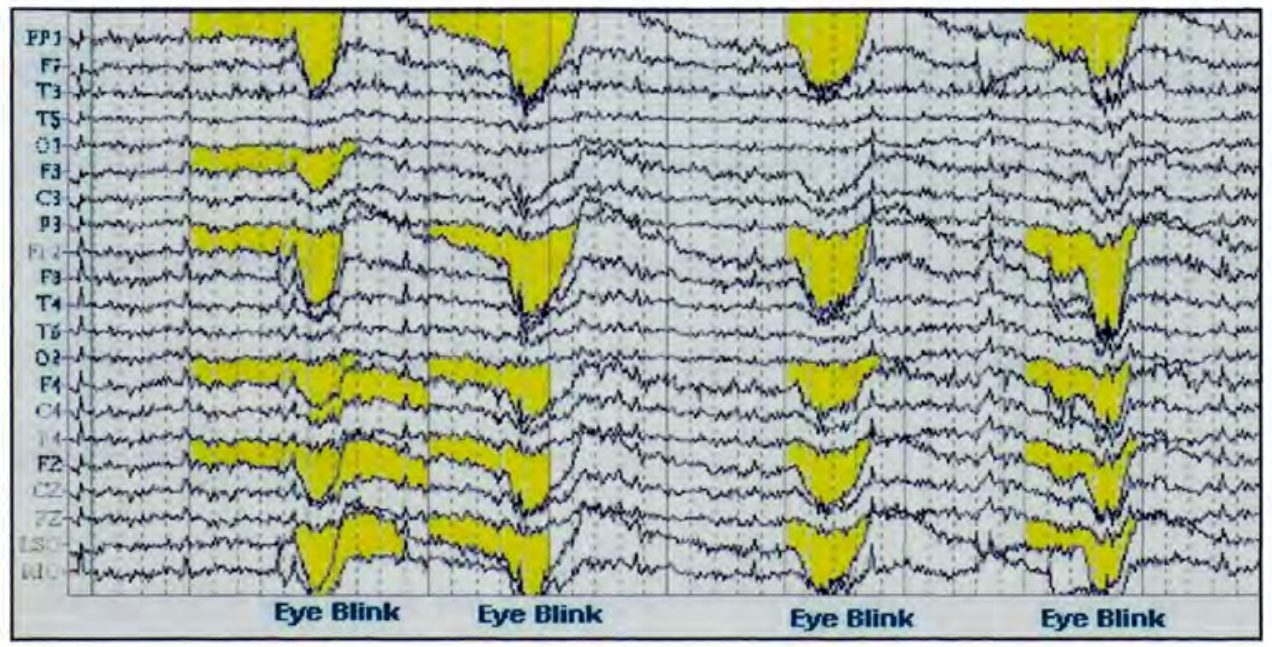

Figure 3.2 Eye Blinks Artifacts 


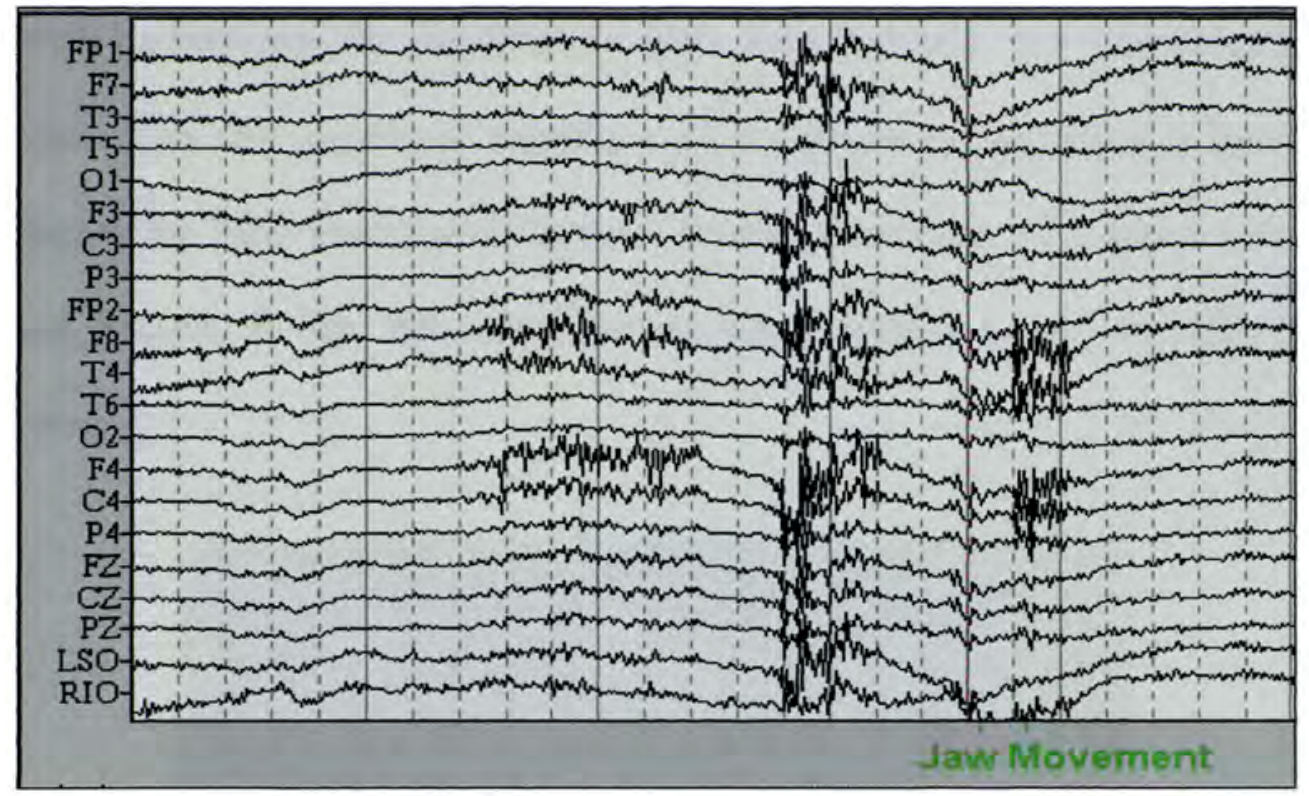

Figure 3.3 Jaw Movement Artifacts

\subsection{EEG Recording Techniques}

The EEG is recorded from electrodes placed on key locations on the scalp. Electrodes consist of a conductor connected by a lead wire and plug to the input of the recording machine, in this case the ESI (256) machine. The instrument picks up electrical impulses in the brain and records them. Scalp electrodes are applied with a conductive gel or paste after determining the precise location and after preparing the scalp to reduce electrical impedance. As can be observed in Figure 3.4, the ESI (256) machine provides the following box, so the user can check during the recording, the impedance of any electrode.

The gel helps to reduce the impedance between the scalp and the electrode. The impedance of each electrode should be measured routinely before every EEG recording 
and should be between 100 and $5000 \Omega$. Both very high and very low impedance are undesirable. Very low impedance acts like a shunt between the recording electrodes and short-circuits the EEG potential differences. On the other hand, very high impedance is unwanted because it can attenuate the recordings leading to the so-called $60 \mathrm{~Hz}$ interference.

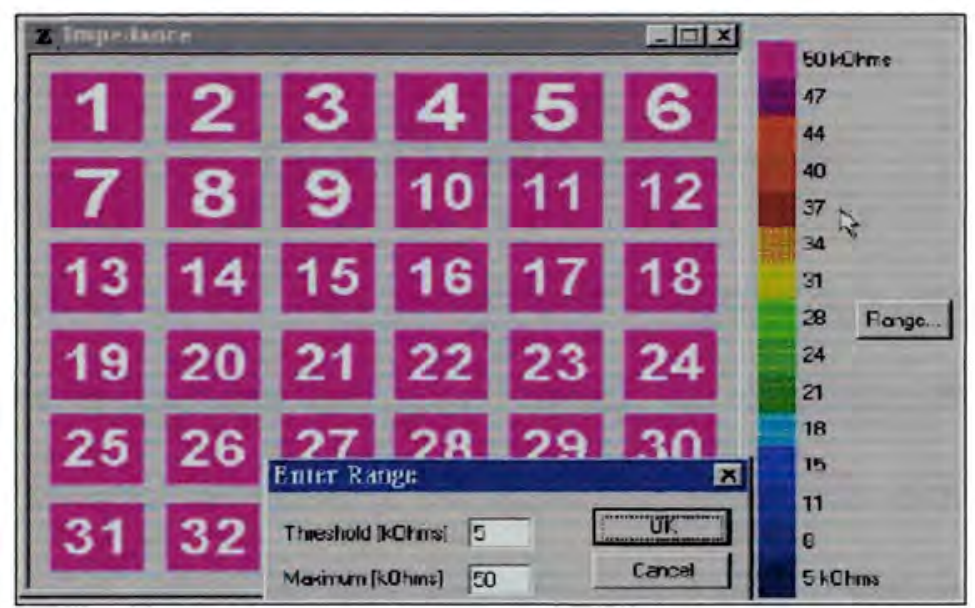

Figure 3.4 Impedance Range for all Electrodes

The hardware setup for the recording of EEG includes an input head box and amplifiers connected to the host computer (see Figure 3.5). In this study two head boxes were used since each box provides input up to 32 channels. The electrodes from the scalp of the subject are directly connected to the head box. Each head-box is connected to the designated amplifier. EEG amplifiers act as differential amplifiers. They pick up the difference of electrical potentials between the electrodes connected to the two inputs and increase that size of the potential difference. The ESI-256 machine is equipped for different filtering methods to be applied to the signals. In this study, a notch filter of 60 $\mathrm{Hz}$ is used in order to eliminate all the $60 \mathrm{~Hz}$ interference. 

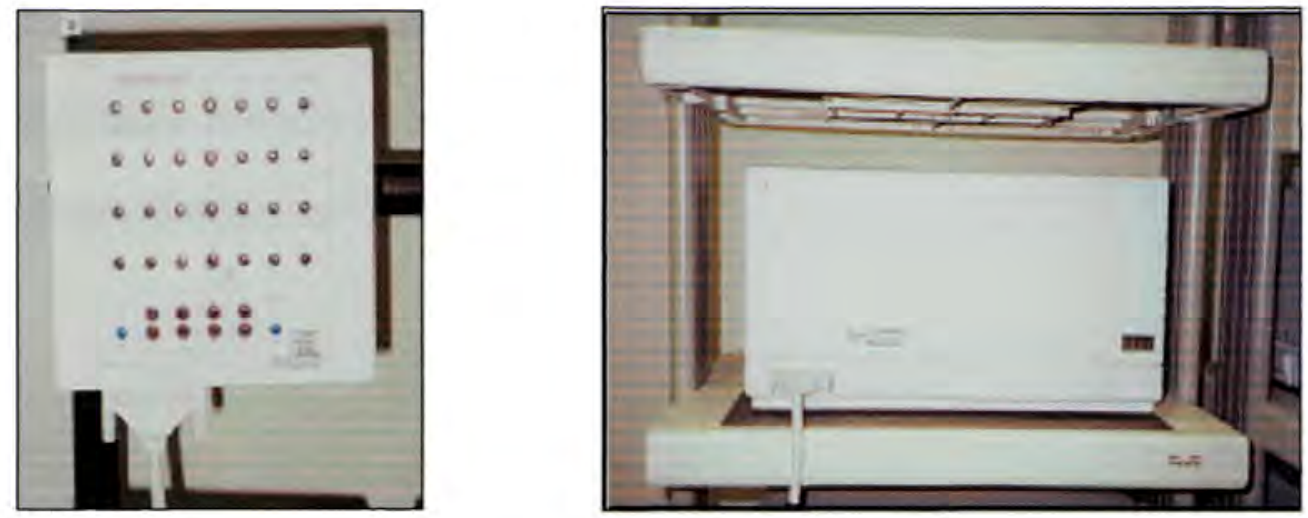

Figure 3.5 Head-Box and Amplifier

The electrodes on the scalp are arranged in general as a particular montage. Montages can be divided into two types: bipolar and referential. Bipolar montages connect pairs of different electrodes to the inputs of the amplifiers. Bipolar montage can localize circumscribed potentials more precisely than with a referential montage; they however, distort the shape and amplitude of potentials.

Referential montage, measures the potentials changes with respect to one common electrode used as a reference. This referential recording can give an undistorted display of the shape of the potential changes. It is useful for recording that has a wide distribution of potentials. However, a disadvantage is that it is usually impossible to find a reference electrode that is completely inactive.

\subsection{Montage Based on the Modified Combinatorial Nomenclature (MCN)}

The pattern of connections between the electrodes and the recording channels is known as a montage. EEG montages vary according to the monitored procedure and the 
number of recording channels available. EEG montages are design to be symmetrical about the midline in order to obtain information of the left and right hemisphere relating to amplitude and difference of the phases.

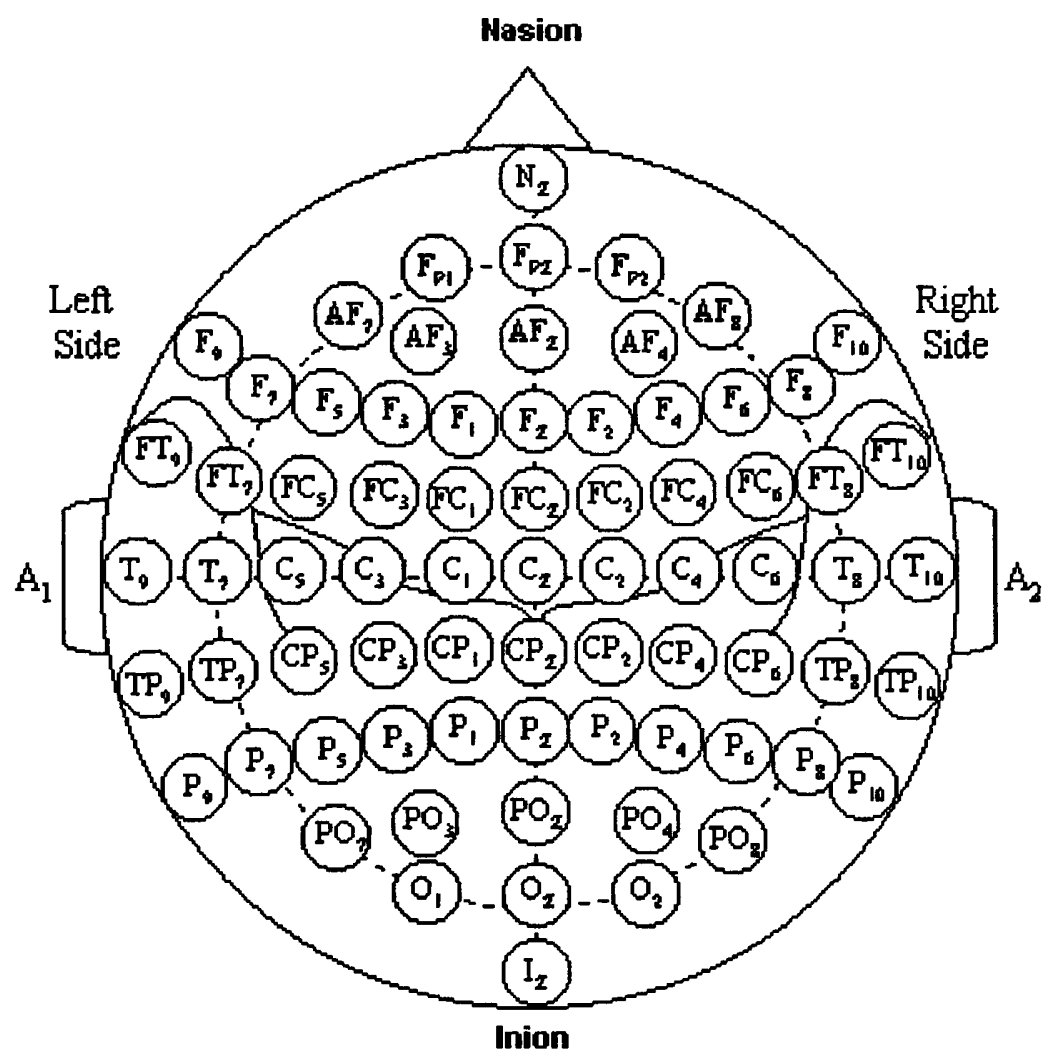

Figure 3.6 Modified Combinatorial Nomenclature

The 10-20 system is the most common used montage. The "10" and "20" (10-20 system) refers to the $10 \%$ and $20 \%$ inter-electrode distance. This system could be expanded to use more electrodes in order to obtain more information from specific areas of the scalp and to improve electroencephalographic spatial resolution. Taking this into consideration, the American Clinical Neurophysiology Society (ACNS) has developed a 
more extensive placement scheme using modified combinatorial nomenclature (MCN). With the use of this scheme, which is illustrated in Figure 3.6, more recording electrodes are used, which yield a higher spatial resolution and improved signal quality.

When recording a more detailed EEG with more electrodes, extra electrodes are added utilizing the spaces in-between the existing 10-20 system. This MCN system uses $1,3,5,7$, and 9 for the left hemisphere, which represents $10 \%, 20 \%, 30 \%, 40 \%$, and $50 \%$ of the inion-to-nasion distance respectively; and 2, 4, 6, 8, 10 are used to represent the right hemisphere. Electrode between two 10-20-system electrode use combination of capital letters, for instance, FC between $\mathrm{F}$ and $\mathrm{C}$. Even numbers $(2,4,6,8)$ refer to the right hemisphere and odd numbers $(1,3,5,7)$ refer to the left hemisphere. " $Z$ " refers to an electrode placed on the midline. The smaller the enumeration of the electrode, the closer is the position of it to the midline. Each electrode site has a letter identifying its sub-cranial lobe and a number, or another letter identifying its hemispherical location. For example, "FP" as the Front-polar or prefrontal lobe, "F" as Frontal lobe, "T" as Temporal lobe, "C" as Central lobe, "P" as Parietal lobe, and "O" as Occipital lobe. Nasion, which is in the front of the head, is the point between the forehead and nose. Inion is the bump at the back of the skull. In order to avoid any type of confusion, the work presented MCN configuration, where electrodes T7, T8, P7 and P8 are used in place of $\mathrm{T} 3, \mathrm{~T} 4, \mathrm{~T} 5$ and $\mathrm{T} 6$.

Furthermore, with the need for higher spatial resolution, systems have been created such that a larger number of electrodes are already arranged in a cap, which is then placed on the scalp of the subjects. The most common caps contain 32,64 , or 128 
electrodes. Systems for a cap with 256 electrodes also exist, but are not very common in the market. As a matter of fact, the system of our lab (Center for Advanced Technology and Education (CATE)) has a 256-electrode recording capability, but requires a timeconsuming process for setting up a subject for experimental studies. This system was used for the research described in this thesis; a detailed description of such recording system was given in Chapter 2. 


\section{CHAPTER IV}

\section{Auditory/Comprehension and their Characterizing Features in EEG Recordings}

\subsection{Background on Auditory Cortex and Related EEG Activity}

The functional organization of the primary human language skills (talking and listening) is often referred to as the cognitive architecture of human language. The acquisition of these complex language skills is so important that it constitutes the central topic of psycholinguistic research.

Research about auditory and comprehension include several important issues that relate to the processing mechanism of the structure that constitutes a sentence, the integration of individual words into a higher-order meaning depiction, the cognitivefunctional issues of comprehension, and the cognitive and neural flexibility of language comprehension. There exist different types of language disorders. Aphasia is one of them and is a disturbance due mainly to damage in the cortical brain areas involved in language processing. As an example, Broca's Aphasia is when the patient understands but is not fluent and Wernicke's Aphasia is the reverse, when the patient is fluent, but has impaired comprehension.

Attention Deficit/Hyperactivity Disorder (ADHD) is one of the most prevalent disorders of childhood years and is estimated to affect three to five percent of school-age

children (American Psychiatric Association, 1994, p. 82). ADHD can lead to emotional and behavioral problems. This disorder exists in all countries and it is a persistent lifelong 
disorder, which is not curable although it could be manageable in some cases. Through the years, the drug therapy has been effective in treating some of the symptoms of $\mathrm{ADHD}$, but have been relatively ineffective in treating attentional deficits, high distractibility, low frustration tolerance, and information processing (Tansey \& Bruner, 1983). Research also indicates that long term effects of the widely used stimulant medication Ritalin on certain academic or cognitive tasks such as reading are limited (Barkley \& Cunningham, 1978). In addition, when stimulant drug therapy is discontinued and the medication is out of the body, ADD/ADHD behaviors return (Lubar \& Lubar, 1999).

Nowadays, there exists a lot of concern over the omnipresent use of medication as a treatment for $\mathrm{ADHD}$ since an enormous quantity of children are currently taking stimulant medications in order to control hyperactivity and inattention. Although these medications deal with the problem temporarily, they do not provide a cure. When we talk about drug therapy, we have to think about the side effects associated with it; that is why it is very important that the research about cognitive processes such as auditory comprehension is ongoing in order to create more effective therapies to be available for the treatment of $\mathrm{ADHD}$ among others.

\subsection{Regions Related to Language Comprehension}

The regions of the human brain associated with language comprehension and language production continue to be widely studied. Functional topographical imaging is a great tool to search for explanations of how the brain interacts with language. Since we still know so little about how the parts of the brain interact with each other, being able to 
analyze the changes taking place on the brain during an auditory/comprehension test could potentially shed light in understanding some of the brain activities. The research on patients that have deficit in sentence comprehension is very important in terms of explaining some aspects of language processing.

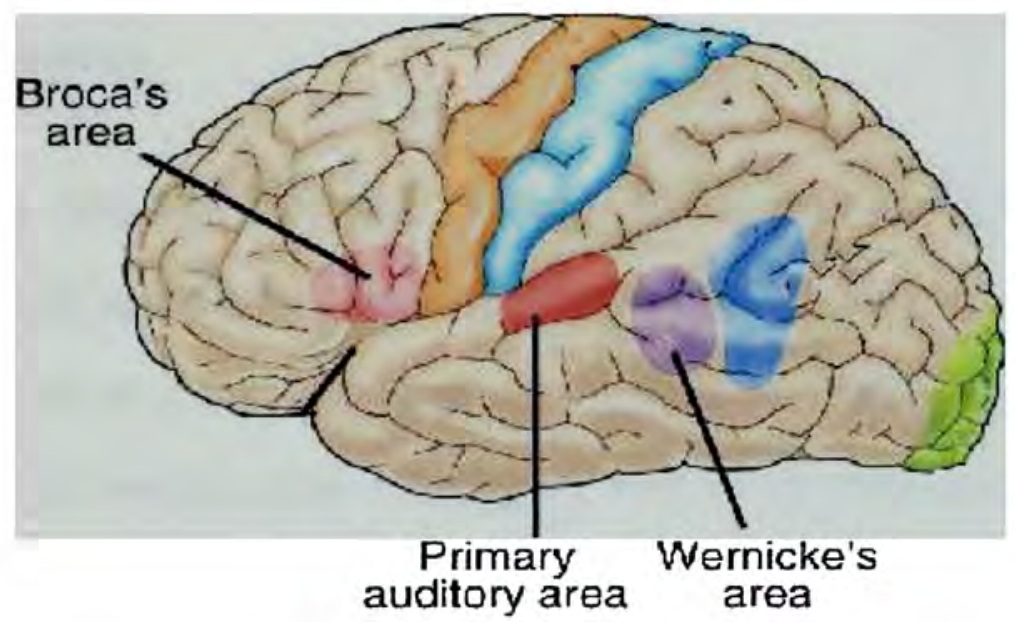

Figure 4.1 Human Cortexes

The language comprehension area is just adjacent to auditory cortex, where the parietal lobe meets the temporal lobe. Wernicke discovered this area in 1874 , by studying patients with comprehension deficits, which are called aphasias. Regions around this area have also been suggested to be involved in short time memory. Broca gave the first evidence of brain laterality and its connection with speech in 1861 . He found out that a lesion in the frontal lobe of the left hemisphere limited the patient to understand speech, 
but on the other hand that patient had no problem talking correctly. The area described is the Broca's area, which is the cortical area in charge of language production. The illustration in Figure 4.1 shows the different areas in charge of the auditory/comprehension process. Language is far too complex to be broken down into discrete cortical areas. Language seems to be located probably all over the brain. The discrete areas of Broca and Wernicke may be necessary for language, but they are certainly not sufficient.

During language processing numerous distributed cortical and subcortical neuronal systems are activated. They have to collaborate and according to a specific task demand, they act as a single functional system. The areas of the brain responsible for recognizing and receiving sounds are closely linked with language processing. It is evident that without a correct auditory input, language comprehension cannot occur at any circumstances. Also, there is evidence that when people speak, they do listen to themselves as they are speaking in order to make sure they are pronouncing the words correctly.

In Figure 4.2 , it is shown that auditory inputs travel from the ear to the auditory cortex, and from the cortex to the auditory association cortex. From the association areas, the signals are projected to Wernicke's area, where comprehension is carried out. The information is then projected to Broca's area, where the speech is generated. This information is sent to the frontal cortex and the premotor areas for processing prior to be sent to the motor cortex, where the words are produced. Knowledge of these pathways is relevant in order to better understand the functional maps of brain activities. 


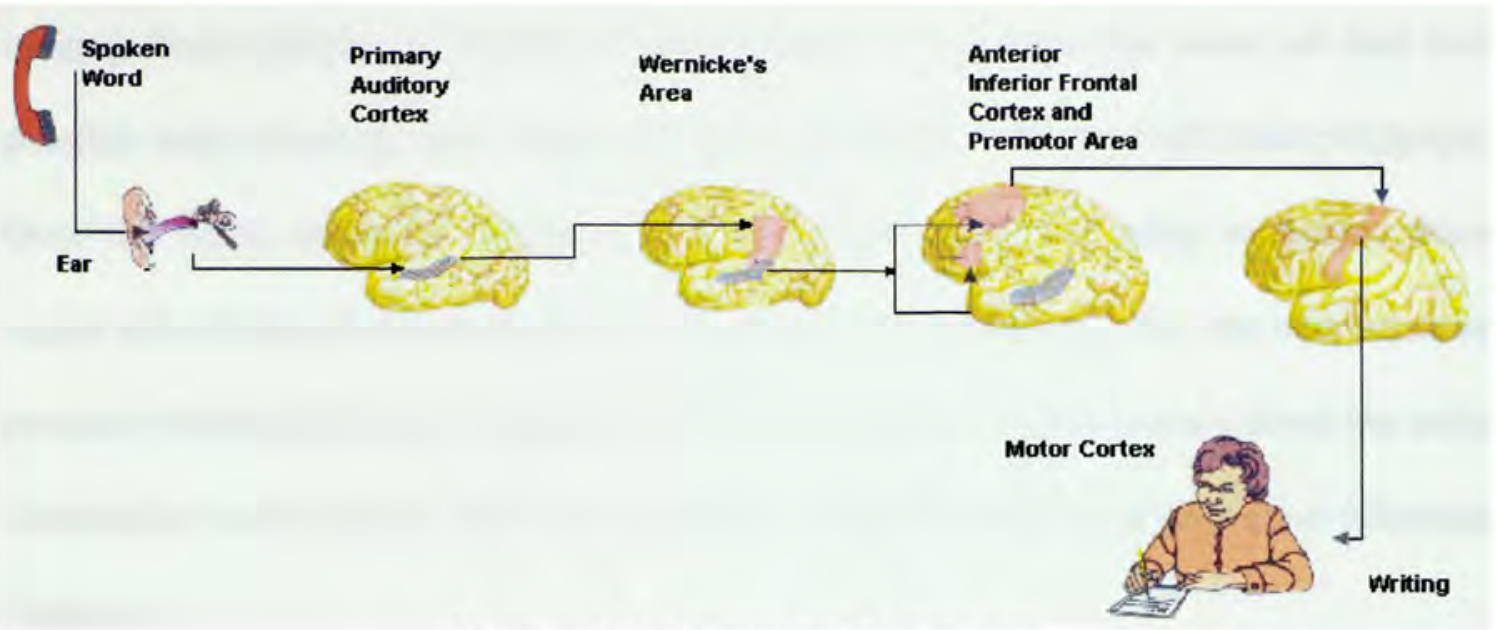

Figure 4.2 Processing of Language

\subsection{Importance of Spectral Analysis}

The brain proves to contain an immense wealth of information. One research platform for its detection and explanation can be through by spectral analysis. For example, the presence of alpha waves can show the existence of an awake, but resting state. If the eyes are opened and the voltage of the signal is high enough, we could indicate the presence of an inattentive dreamy state. In fact we often see this sign in adolescents and adults with attentional disorders. When we get mentally busy, we should see alpha reduce significantly in size. In its place we see mostly smaller, quicker beta brain waves. The beta family of waves happens at frequencies from 13 to $30 \mathrm{~Hz}$. Delta and theta waves are relatively slow. Delta usually defines waves as occurring from 1 to 4 . Theta waves occur at 4 to $8 \mathrm{~Hz}$. During drowsiness, first alpha disappears, and then the size of theta waves begins to increase. As sleep begins, theta waves get larger, then become mixed, and eventually give way to slower delta waves. It is also noted that high amplitude slow waves can be signs of various neurological and psychological problems, 
ranging from epilepsy to ADHD (Attention Deficit Disorders). For years, all that was possible was recording these frequency waves on paper with the traditional polygraph. Over the years, advances in signal processing have made it possible to sample these waves many times per second and to analyze them in various ways. We can now measure precisely the amplitude and frequency of waves of interest, be fairly exact about the scalp distribution of the waves, and even compare a patient's EEG to a normative reference database.

This is particularly interesting for studying children with learning and attentional deficits. Some researches affirm that often a good activation of the EEG can be noticed during some tasks (e.g., drawing, playing a musical instrument), but very poor activation is observed during listening, reading or math. It can usually be deduced which type of task is hardest for the child to do, based on the presence of slow brain waves. Research has shown that brain waves in individuals with Attention Deficit Disorder (ADD) usually contain excessive slow waves (theta) and not enough fast wave activity (beta) during activities requiring concentration and learning. Usually, for individuals with $\mathrm{ADD}$, they must decrease their slow wave (theta) activity and increase their fast wave (beta) activity. In order to help clarify the diagnosis of minimal brain dysfunction, neurologists search for abnormalities within the EEG records. This decision could be made based primarily in terms of slow EEG activity (4 - 8 Hertz).

In this research work we focus on which areas of the brain cause a particular function (e.g., comprehension processing, speech process). The main aim is to display these brain activities through statistically verified EEG results. Beside basic research on 
the relation between brain function, cognition and language processing, the results of these experiments can be applied in different fields of medicine towards the treatment of disturbed language acquisition in children and to the improvement of second language acquisition. In addition, the spectral components of EEG signals constitute an important tool for the investigation of the physiology of language representation and gives new insights into the functional relationship between participating neuronal networks during language processing.

Spectral analysis of the EEG has merit, since it can guide prognosis and intervention. It could be used as a tool to aid in the clinical diagnosis of various dysfunctional states but not as a substitute for clinical judgment and medical opinion. This technique should be combined with other medical, psychological and neuropsychological data to best aid the patient.

\subsection{The Function and Analysis of EEG Frequency Bands}

EEG is produced due to electrical potentials generated by nerve cells in the cerebral cortex in response to different inputs. In order to analyze diverse patterns of the EEG signals, several features have to be analyzed carefully, such as frequency, amplitude of the waveform, distribution and repetition of data patterns, among others. Frequency refers to the number of times a certain wave is repeated within one second. For instance, a wave completing 8 cycles in one second is called a wave of $8 \mathrm{Hertz}(\mathrm{Hz})$.

Brainwaves are measured in $\mathrm{Hertz}(\mathrm{Hz})$, or cycles per second and are usually divided into four major frequency bands. The classic names for these EEG frequency 
bands mentioned before are beta (12-30), alpha $(8-13 \mathrm{~Hz})$, theta $(4-8 \mathrm{~Hz})$, and delta $(1-$ $4 \mathrm{~Hz}$ ). Analyzing the frequency domain of these EEG signals is one of the most important criteria for assessing abnormality in clinical EEG, such as comprehension or auditory disorders. Each frequency band is traditionally associated with generalized behavioral correlates. Band waves less than $8 \mathrm{~Hz}$ are called slow waves; on the other end of the spectrum, waves greater than $13 \mathrm{~Hz}$ are called fast waves. For example, the fastest frequency band, beta, is associated with focused attention, active concentration, and is considered a high arousal level. Alpha, a non-drowsy state, is associated with relief from attention and concentration. Theta is associated with drowsiness and dreaming, and is considered a low arousal level. The slowest frequency band, delta, is normally associated with deep, dreamless sleep.

A thorough study of these different frequency bands is performed over the EEG signal intervals, where the auditory and response time take place. We use methods with high temporal resolution such as EEG to reveal the precise time-course of cortical activity as questions are being processed. Time course information is crucial to the investigation of language comprehension, because it is a dynamic process that involves the integration of various types of information (phonological, syntactic, semantic, etc) over a very short time interval.

In Figure 4.3, a block of the EEG signal during the response time is depicted. The EEG data collected in continuous time during 5 seconds has two markers. The stop beep is when the question is asked and the subject has to start answering the question. The answer marker is when the subject responds to the question. There are some evident 
fluctuations in the EEG signal at the time when the subject actually talks due to some articulation movements. The frontal and temporal lobes show activity since they are directly related to the speech production.

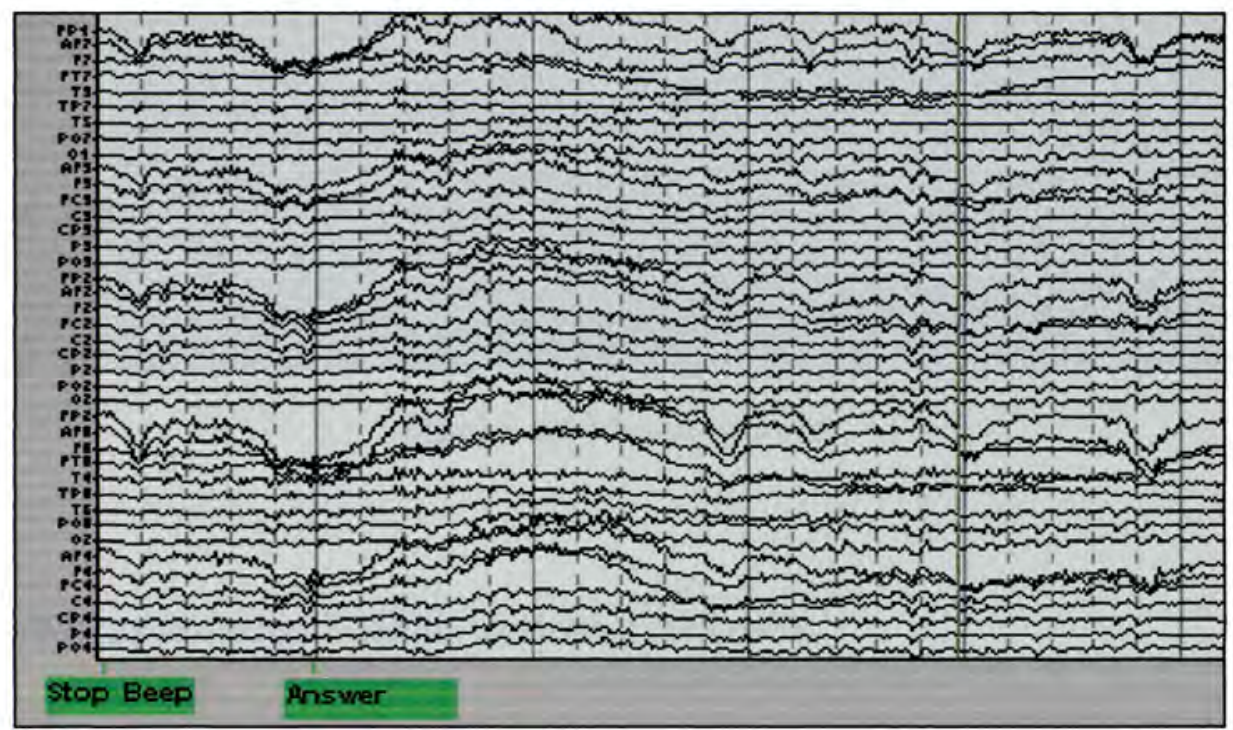

Figure 4.3 Answering Task

In Figure 4.4 a block of continuous EEG is showing the recorded time when the subject is paying attention to a comprehensive question. The labels on the left identify the 41 electrodes used in this recording. Each vertical line represents 500 samples of the original signal, which is equivalent to 1 second. In this case we have 8 seconds of recording of EEG signal during this specific task. It is noted that the artifacts due to the eye movement of the subject are avoid since the eyes of the subject were kept closed during the auditory test in order not to distort the final analysis of the EEG behavior and its frequency components. 


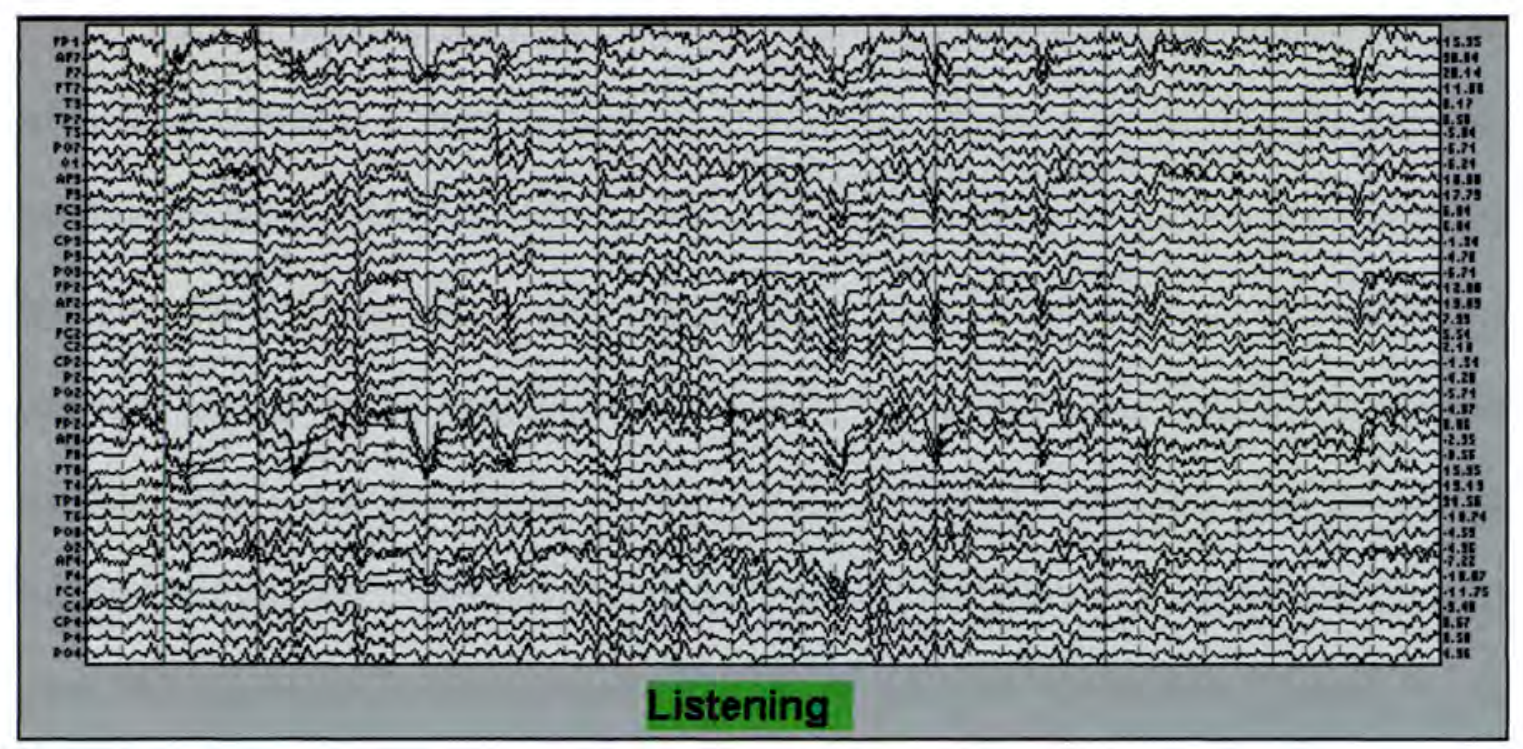

Figure 4.4 Listening Task

\subsection{Different Approaches Used in Cognitive Processes}

The different approaches that have been considered in previous research for the topographical mapping of cognitive tasks, are performed embracing the following major themes $[1,4,5,6,11,12]$ :

- Using the power distribution: Calculating the power of each frequency band relative to the skull.

- Using coherence: Differences in power spectra coherence between the left and right hemispheres.

- Using neural networks: Training power values for each frequency band to look for a pattern of different behavior of EEG. 
Each of these methods shows merit in their application and meet different degrees of success. Clearly, a central characteristic binding all of these themes has been the localization in the brain where these different tasks take place. In our method in order to interpret EEG during an auditory/comprehension task, a detailed activity mapping is provided as well as the similarities/dissimilarities with respect to a database of different patients. The work introduced in this thesis attempts to compare similar/dissimilar behaviors of the EEG during an auditory/comprehension task and the respective response time. The innovation in the implementation of this approach, described in Chapter 5, is in creating different hemispheric vectors and based on the minimum energy criterion, a conclusion about EEG frequency spectrum similar/dissimilar behaviors is displayed topographically using different and descriptive color-coding. 


\section{CHAPTER V}

\section{EEG Data Processing and Results}

\subsection{Introduction}

The research focuses primarily on exploring the human brain mechanisms responsible for auditory language and answering functions. The purpose of this study is also to examine some of the EEG and the subjective effects of these tasks alone and in combination with the most common band-frequency brain waves. Conceivably, as the EEG and subjective effects of these tasks become better understood, their use as a helpful tool in mapping the different functions of the brain will become more effective. The study involved fifteen subjects (age 23-42) with 12 males and 3 females. The EEG of each patient was recorded during the Auditory/Comprehension test from 41 scalp sites. The electrodes were placed according to the Modified Combinatorial Nomenclature (MCN) in order to test brain regions involved in this task. Each signal, coming from each of the channels, was meticulously observed in order to eliminate unwanted artifacts and the background noise. The original EEG signals were divided in different blocks in order to differentiate distinct tasks, involving the auditory/comprehension and the response time. Also, a background EEG in the state of calm alertness was recorded with the eyes closed for 40 seconds in order to obtain a point of reference for each subject. After recording the background, the subject started listening to 34 questions and proceeded in answering them. The fluctuations of changes in the frequency spectrum are topographically displayed for both tasks. By means of complex digital analysis, an 
evaluation of spectral arrays is shown in a comprehensive color topographic maps illustrating the resulting brain activities.

\subsection{Noise Reduction of the EEG signals}

EEG signals have played an important role in the modeling of the brain's cortical dynamics and have been analyzed over the past decades with much effort towards a better understanding of the function of the brain. Representations based on Fourier Transforms are a powerful tool in these matters. This approach is based on the EEG spectrum that falls primarily within four-frequency bands-alpha $(8-13 \mathrm{~Hz})$, beta $1(13-20 \mathrm{~Hz})$, beta 2 (20-30 Hz), delta (1-4), and theta $(4-8 \mathrm{~Hz})$. Such approach has been a proper way for some EEG characteristics, but suffers from large noise sensitivity.

An optimal approach to alleviate or filter the effects of noise in a given EEG signal is necessary in order to eliminate unwanted frequency components. The noise is distinguished by high frequency and low amplitude characteristics. A factor that may have contributed to the production of noise is the low sampling rate. Even though a higher sampling rate will eliminate some noise in the signal, but it will, on the other hand generate large data files. From the plot in Figure 5.1, a superimposed noise can be observed. It was necessary at this point to develop a procedure for the smoothing of the EEG signal as a preprocessing step. This preprocessing step is set not to distort the original signal, but to only eliminate the high frequency components greater than $60 \mathrm{~Hz}$.

The recorded signal as shown in Figure 5.1 for one of the electrodes of a given subject is used to contrast the merits of different wavelet transforms (Haar and the 
Daubechies family). As you can notice, the EEG signal is corrupted with some noise due to different factors, such as the environment, the equipment that was used to record the signal, among others.

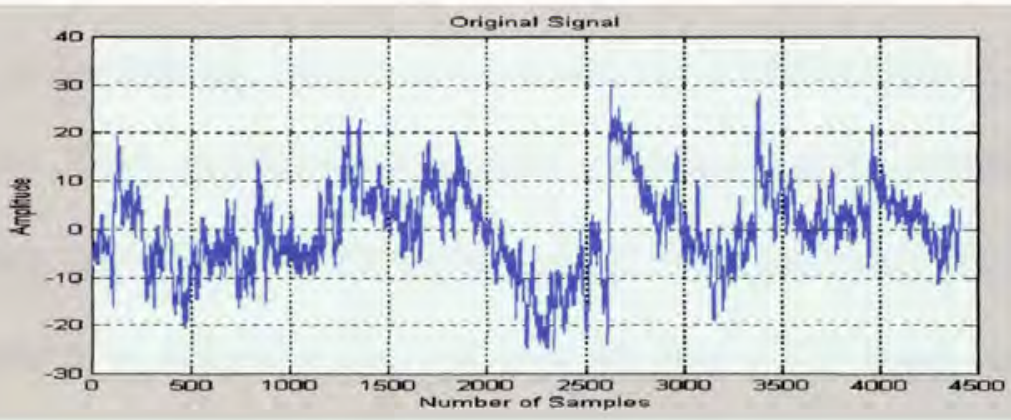

Figure 5.1. Original Signal (AF7)

The wavelet Daubechies 14 was selected as the optimal solution to denoise the signals recorded. Figure 5.2 displays a wavelet from the Daubechies family of wavelet functions. The compact support of the wavelet basis functions allows the Wavelet Transform to efficiently represent signals with localized features. The shape of this wavelet is similar to the shape of the EEG signal. Since the shape is similar to the EEG behavior, a better match is made and the final results will be better in comparison with other wavelets like the Haar, which is a square waveform.

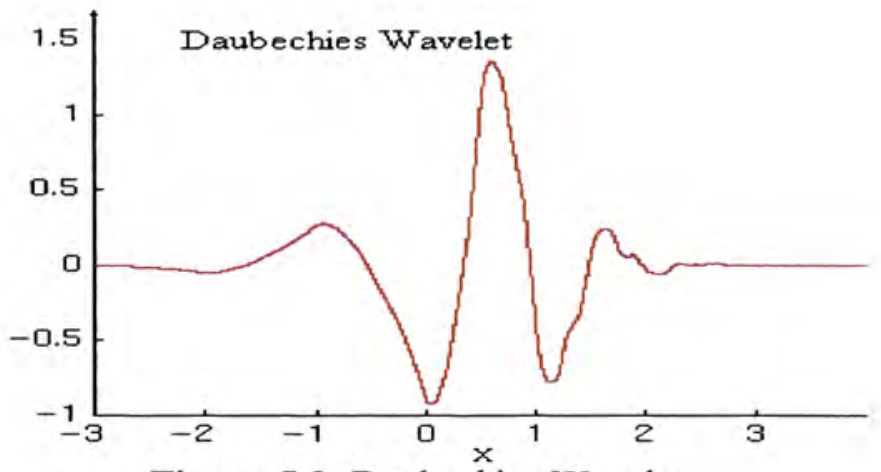

Figure 5.2. Daubechies Wavelet 
When data is decomposed using wavelets, some filters act as averaging filters (approximation coefficients) and others produce details. If the details are small, they might be omitted without substantially affecting the main features of the data set. Figures 5.3 (b) and (c) show the reconstructed approximation output and the reconstructed detail output. The idea of thresholding, then, is to set to zero all coefficients that are less than a particular threshold. These coefficients are used in an inverse wavelet transformation to reconstruct the data set [28]. The continuous wavelet transform implemented for noise removal in $x(t)$ and it is defined as the sum over all time of the signal multiplied by scaled, shifted versions of the wavelet function $\psi(t)$ :

$$
C W T(\tau, s)=\int_{-\infty}^{\infty} x(t) \psi\left(\frac{t-\tau}{s}\right) d t
$$

Where $\tau$ and $s$ are translation and scale parameters, respectively and the result of the CWT are many wavelet coefficients, which are a function of scale and position.

An implementation example using the EEG signal at electrode AF7 is shown in Figure 5.3.

(a) Original EEG Signal (Electrode AF7)

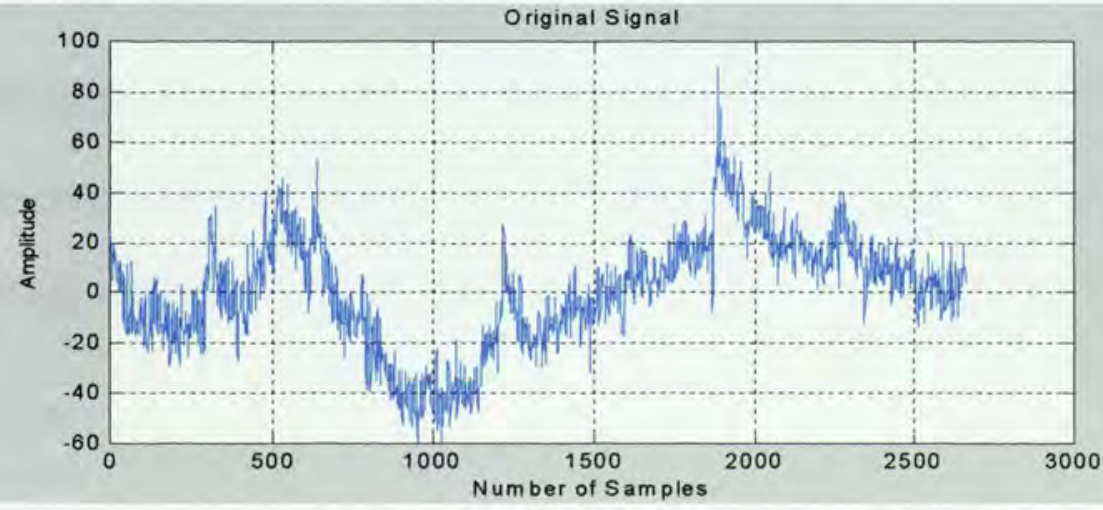


(b) Approximation Output (Electrode AF7)

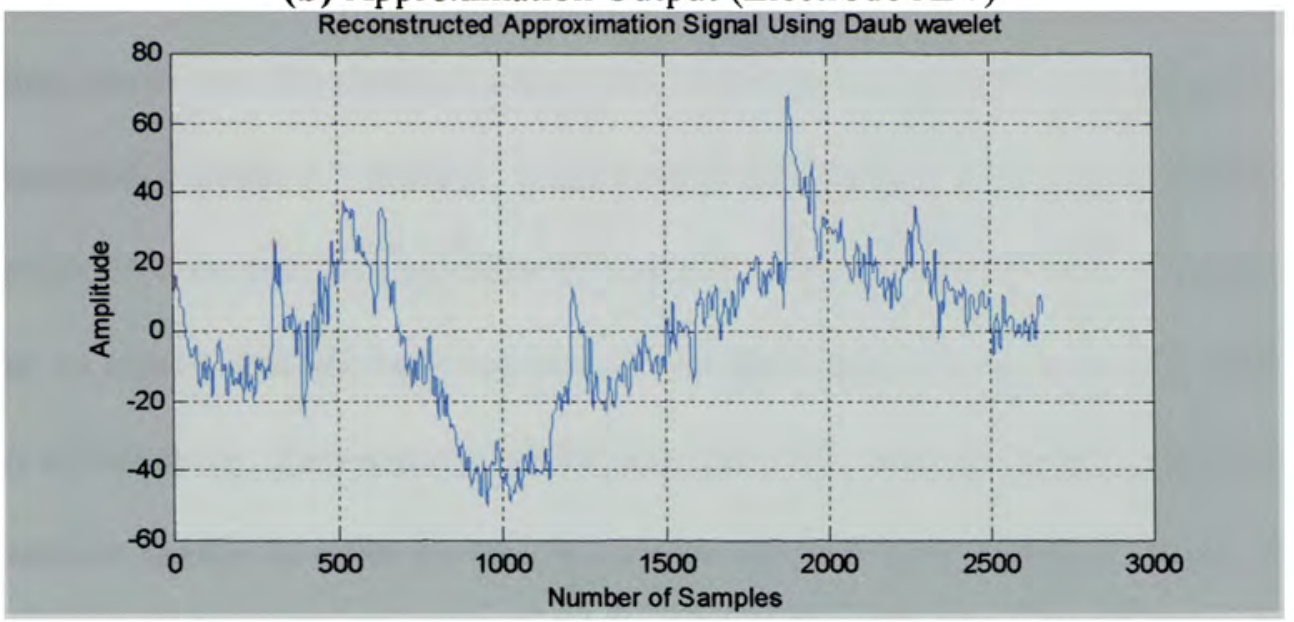

(c) Detail Output (Electrode AF7)

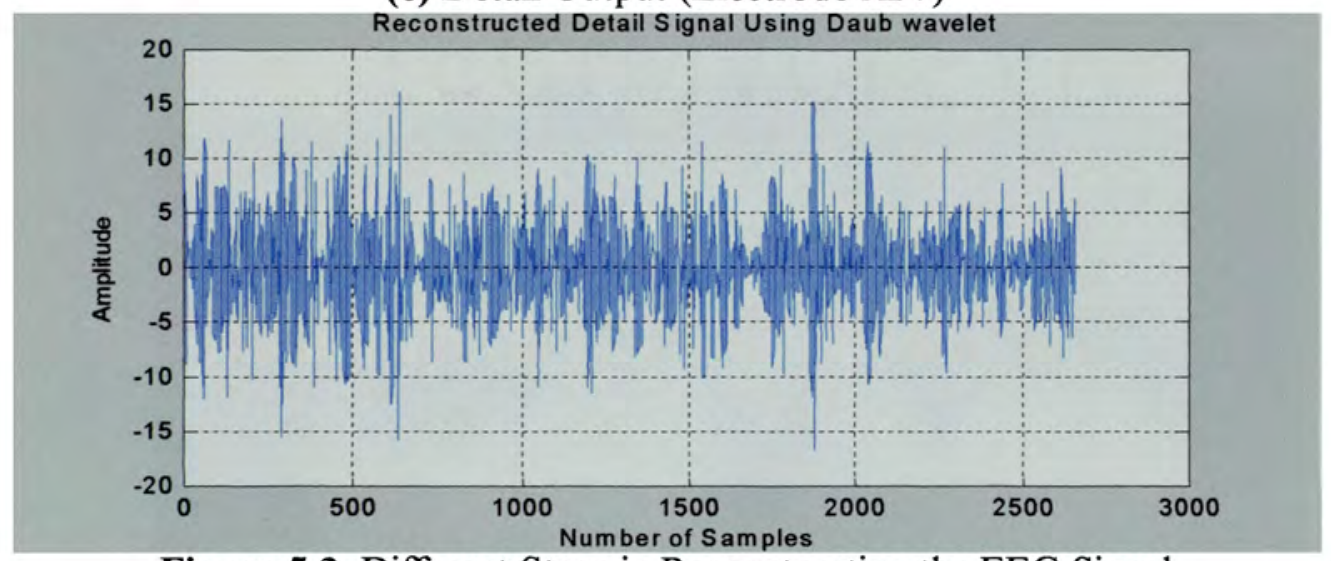

Figure 5.3. Different Steps in Reconstructing the EEG Signal

The most significant characteristic of the wavelet transform is that it dilates and contracts as the transform is computed for every single spectral component. The transformed signal becomes a function of the transnational and the scale parameters ( $\tau$ and $s$ ). The term translation is related to the location of the window, as the window is shifted through the signal and the scale parameter is inversely proportional to frequency $(1 / f)$. 
Figure 5.4 (a), the reconstructed signal after applying the Daubechies wavelet transform, shows that the signal to noise ratio (SNR) is the highest if you compare it with the subsequent Figures 5.4 (b)-(d). Even though the resultant EEG signal after applying Daubechies 14 does not look so different from the others, different trials were performed in order to assure that the best wavelet of the Daubechies family has been selected in support of our study, since in most all the cases the SNR was the higher compared to the other wavelet family. In other words, because the signal-to-noise ration is higher, most of the signal was recovered after applying the wavelet transformation.

(a) $\mathrm{Db} 14 \mathrm{SNR}=1.0129$

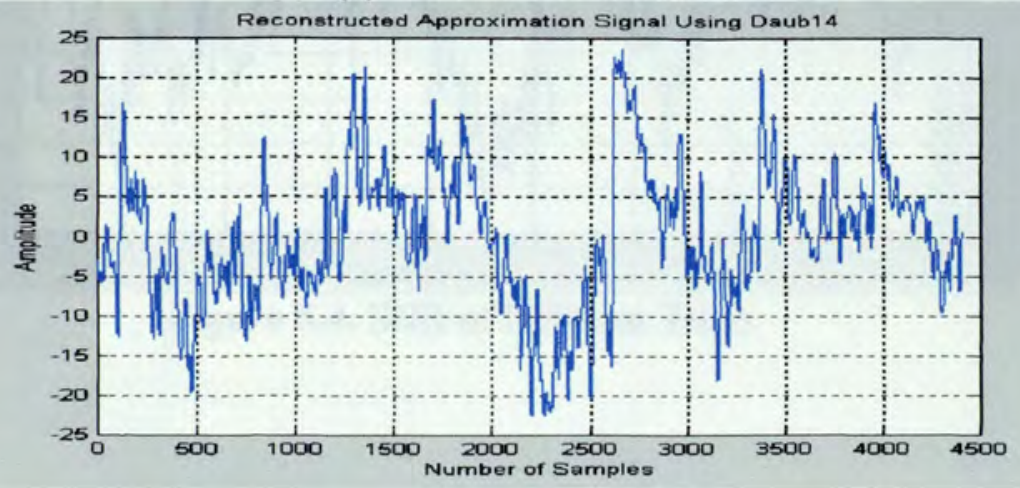

(b) $\mathrm{Db} 2 \mathrm{SNR}=1.0125$

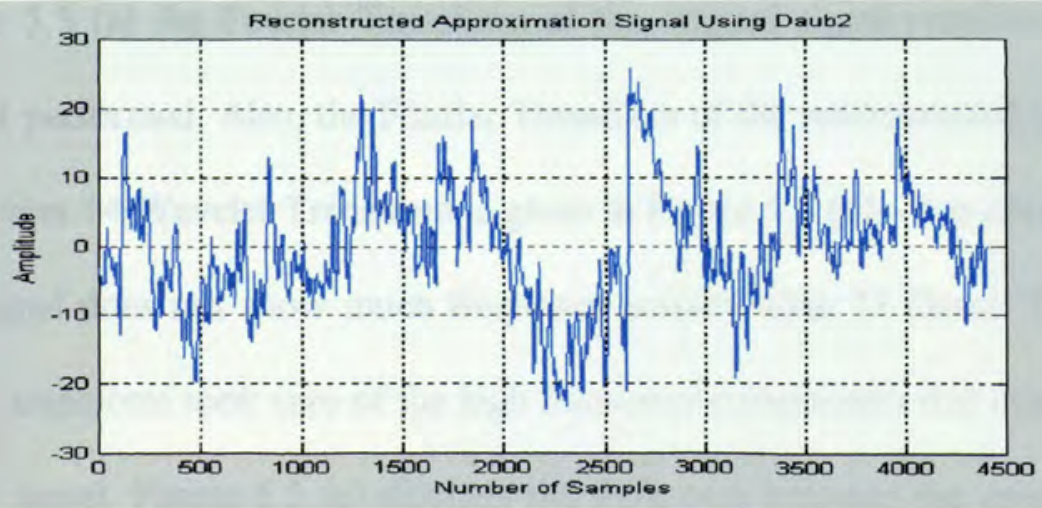


(c) $\mathrm{Db} 10 \mathrm{SNR}=1.0029$

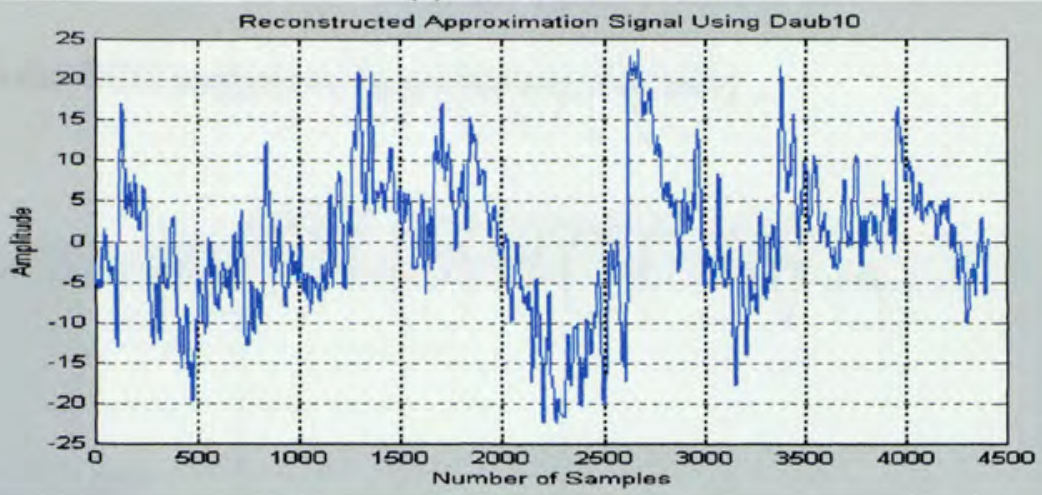

(d) Haar $\mathrm{SNR}=0.9926$

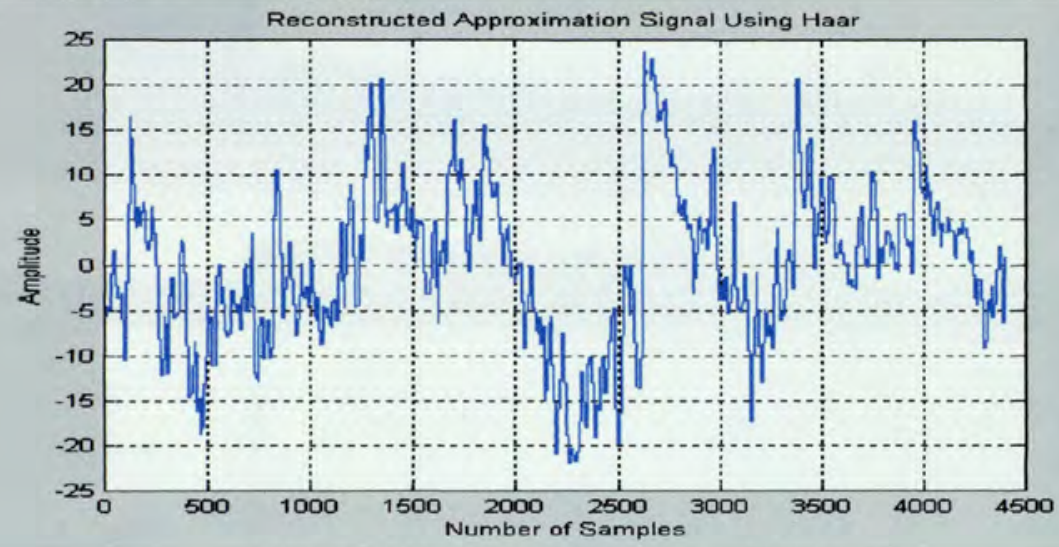

Figure 5.4. SNR of Different Trials

\subsection{Analysis in Frequency Domain of the De-Noised EEG Signal}

In Figure 5.5 (a) the Fourier Transform of the original signal provided earlier in Figure 5.1 is first performed. Also, the Fourier Transform of the reconstructed signal after applying Daubechies 14 Wavelet Transform is given in Figure 5.5 (b). It is noted that the reconstructed signal does not show much frequency activity after $35 \mathrm{Hertz}$. This means that the Wavelet transform took care of the high frequency components that constitute the noise in a given signal. Figure 5.5 (c) displays the difference between the original signal and the reconstructed EEG signal in order to corroborate that the frequency components 
that are indeed eliminated are in the range higher than $30 \mathrm{Hertz}$, which should not have any effect on the EEG analysis to be performed thereafter.

(a) FFT of the Original EEG Signal

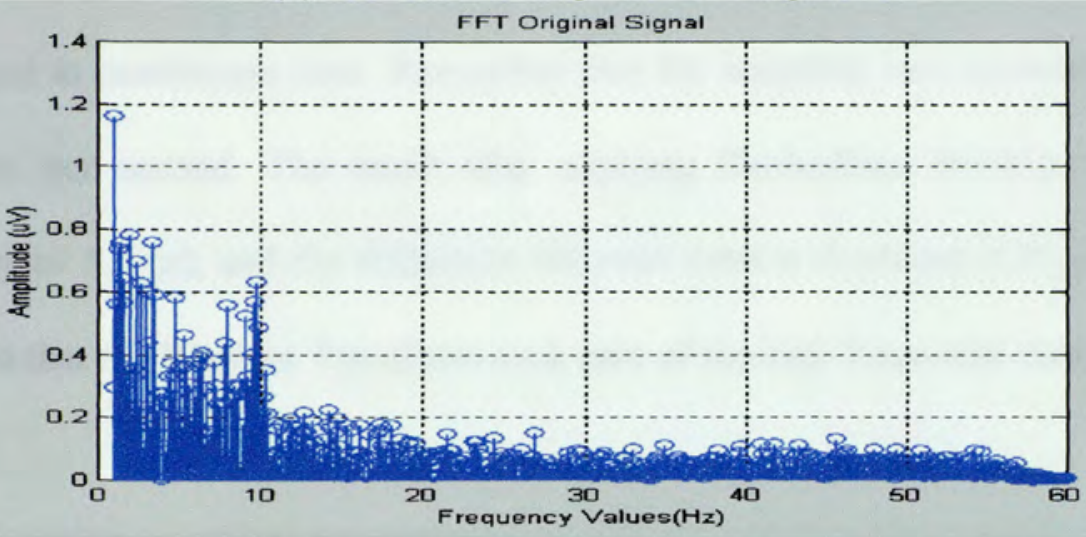

(b) FFT (Reconstructed EEG) Signal

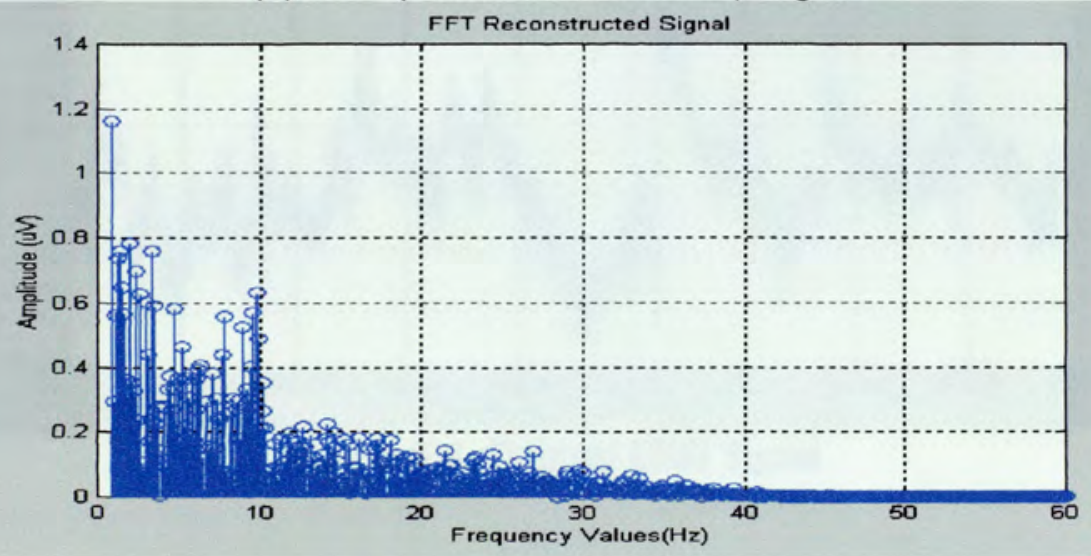

(c) FFT Difference Signal

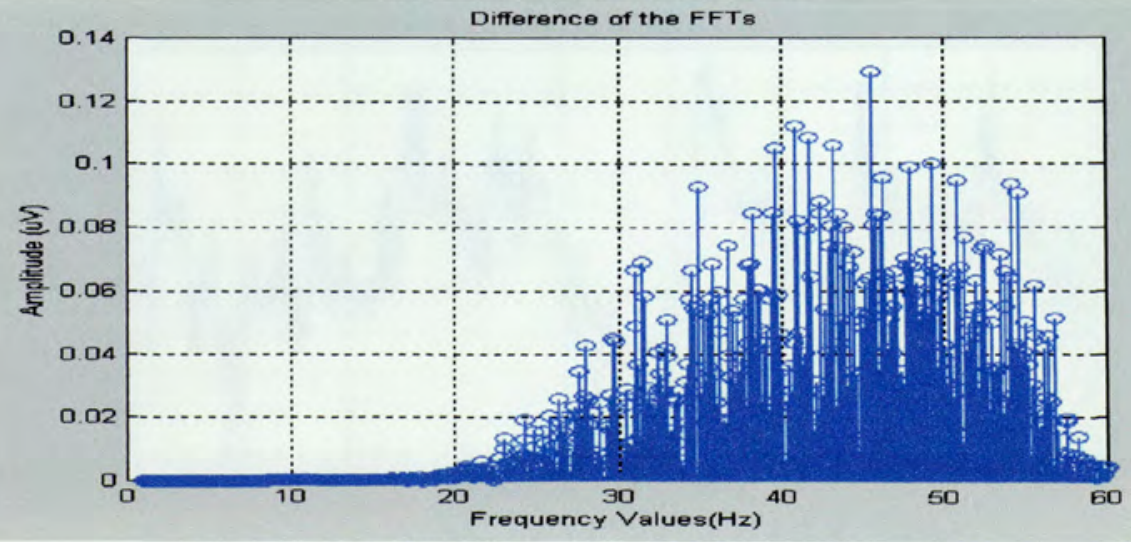

Figure 5.5. Differences in the Fourier Transform 


\subsection{Analysis in Time Domain of the De-Noise EEG Signal}

An analysis is performed in the time domain in order to visualize better the reduction of noise in real time data. In Figure 5.6 nine seconds of the original EEG signal is represented in continuous time. Remember that the sampling rate considered is that of 500 samples per second. The result after applying Daubechies Wavelet Transform is shown in figure $5.7(\mathrm{a})$, and the difference between them is displayed in Figure 5.7 (b). It is also noted that the Wavelet Transform took care of the high frequency components.

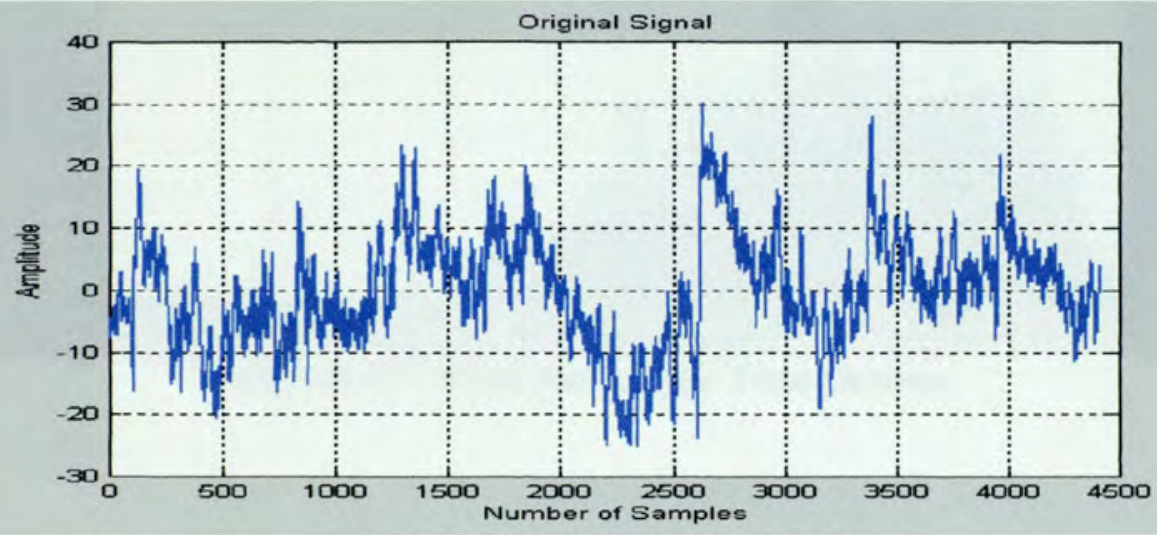

Figure 5.6. Original EEG Signal

(a) Reconstructed Signal After Daubechies 14

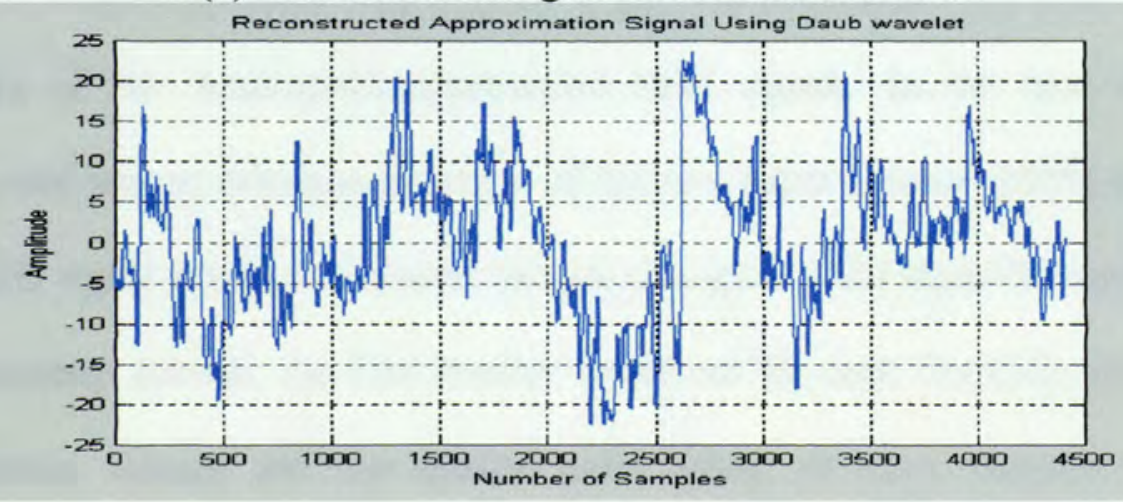


(b) Original Minus Reconstructed Signal

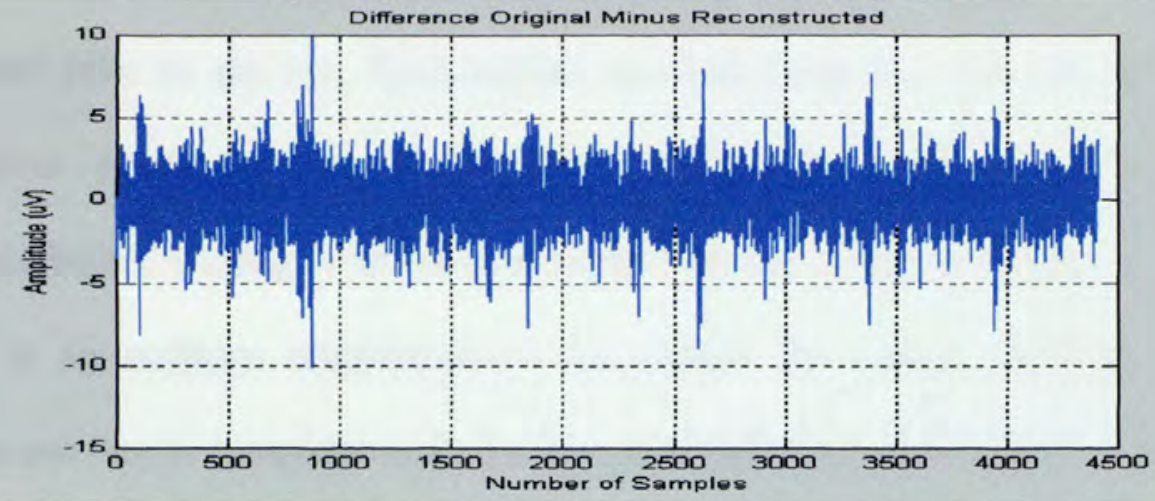

(c) FFT Original Minus Reconstructed Signal

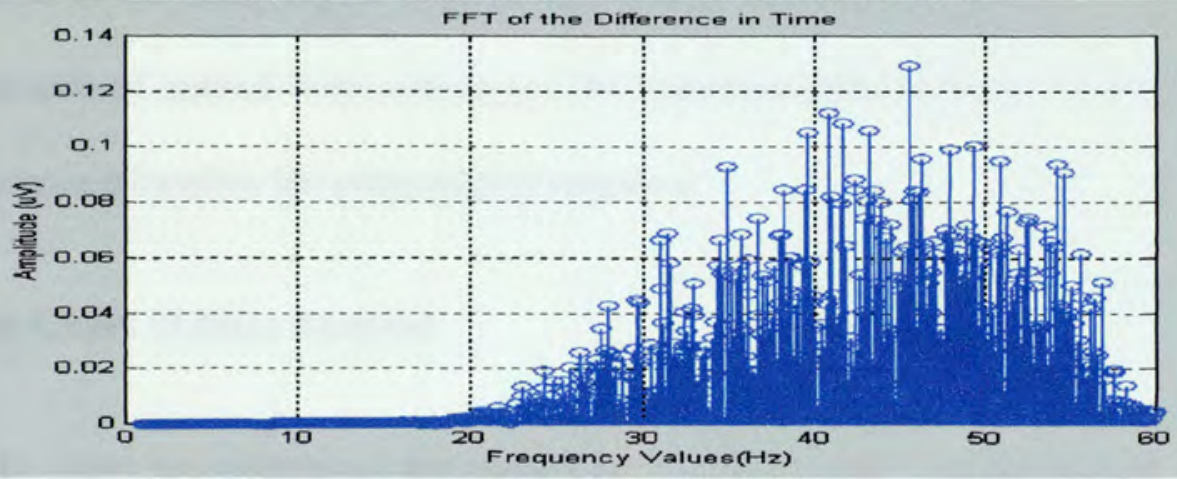

Figure 5.7 Differences in the Time Domain

\subsection{Algorithm Development Process}

Two approaches were used in order to perform the analysis and draw insight from the spectra of the Auditory/Comprehension EEG signals. In the time domain, the approach used was to calculate the ratios of the root mean squares (RMS) values of the filtered EEG signal versus the original version of a given EEG signal for each electrode. In the frequency domain, the Fast Fourier Transform for each electrode was calculated and the mean voltage and the relative mean power of every frequency band was 
considered. As mentioned earlier 15 subjects took part in the experiment. There was no requirement prior to the test. Each subject was laid down in a bed with 41 electrodes connected to specific locations in the scalp. An explanation about the test was given to the subject before starting with the procedure. The test, which takes no more than ten minutes, is an auditory comprehension test, where the subject listens to thirty-four sentences and has to complete each one. It was required from the subject to have his/her eyes closed and to maintain the maximum possible relaxation in order to reduce the effect of artifacts in the EEG signal such as eye blinks, movements, among others. Thirty to forty seconds of normal brain activity of the relaxed subject is recorded prior the test in order to have a baseline for comparative purposes.

\subsection{Flow Chart of Data Analysis}

In order to understand the integrated algorithm that was established in order to analyze and interpret the EEG data, a structure of the steps undertaken and a flow chart of tasks are provided. The following steps describe the structure of the algorithm developed.

1)-Six listening/answering sessions for each patient.

2)-One baseline of (30-60 Seconds) for each patient.

3)-Eliminate the DC offset by taking the mean and subtracting it form each point of the file.

4)-Perform FFT for each listening/answering session. 
5)-Perform FFT to the baseline session.

6)-Average the FFT of the six listening.

7)-Subtract the FFT of the baseline from the average FFT of the listening/answering files.

8)-The result from this subtraction is divided into 5 different frequency bands: Alpha (813HZ), Beta1 (13-20HZ), Beta2 (20-30HZ), Delta (1-4HZ), and Theta (4-8HZ).

9)-Mean voltage and relative mean power for each band is calculated.

10)- Calculating two thresholds of 1 and 2 standard deviation(s) $\left(T_{1}\right.$ and $\left.T_{2}\right)$ in the positive and negative directions with respect to the absolute mean voltage of the signal in order to consider only those values within the following ranges: $\left[\begin{array}{ll}+T_{1} & +T_{2}\end{array}\right]$ and $\left[>T_{2}\right]$ and $\left[-\mathrm{T}_{1}-\mathrm{T}_{2}\right]$ and $\left[<-\mathrm{T}_{2}\right]$.

11)- Creating specific data arrays that contain the number of active electrodes in each hemisphere for each frequency band mentioned earlier.

12) -Applying the minimum energy difference criterion to these arrays in order to attain similarities/dissimilarities between different subjects.

13) -Performing topographical representations using a color-coding scheme in order to enhance locations in the brain that reflects increasing and decreasing changes.

The flowchart of tasks considered follows: 


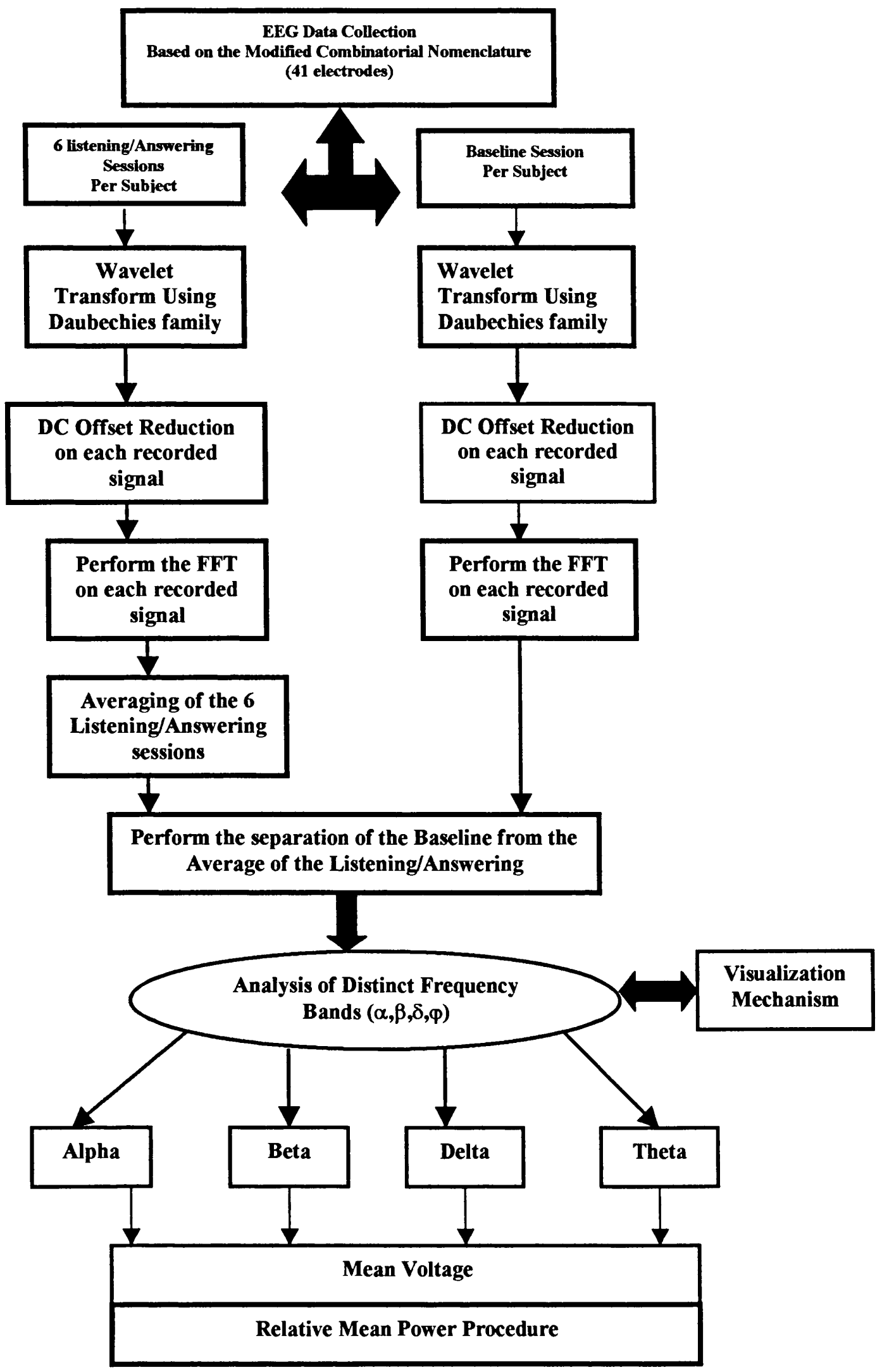




\subsection{Data Analysis Methods}

\subsubsection{Spectral Analysis Using the Fast Fourier Transform}

In order to perform spectrum analysis, a fast Fourier Transform (FFT) is performed on sections of the EEG data to determine the power content of the four main frequency bands. The resulting waveforms are displayed as a brain map, which will show the power distribution within each frequency band. In this case the FFT is applied to six different auditory/comprehension blocks of the EEG signals (these signals are obtained from the same subject, and during the same task, either listening or answering). For each subject, 34 recordings were considered, out of which 6 were used for analysis. These 6 signals chosen were void of eye blinks and body movement. Functional mappings of the brain must be made accurate; therefore this EEG pre-selection process is only to enhance the representation and not to distort the results. Once the signals were carefully chosen, a conversion to ASCII files was performed for compatibility in the processing. The ASCII files consist of a matrix with 41 columns. Each column represents digitized data recorded from a single electrode. The first prepossessing performed to the EEG signals was the noise reduction algorithm. After the signals were cleaned of the effects of noise, the DC offset reduction is also performed. With the digital files, we can measure the component at $0 \mathrm{~Hz}$ by measuring what the average sample value is and how much it has drifted from zero. Most files that have been recorded through analog equipment should have little, if any, DC offset. That is why in this case DC offset is reduced from each electrode by subtracting the average of each column from each point of the column itself. 
Two different procedures are realized in order to compare and get the best results. In the first one, the FFT of the baseline and the six listening/answering files are calculated by the formula 5.2. The Fourier transform of a finite-energy discrete-time signal $x_{(n)}$ is defined as

$$
X_{(w)} \equiv F\{X(w)\}=\sum_{n=0}^{N-1} x_{(n)} e^{-j 2 \pi n w / N}
$$

Physically, $X_{(w)}$ represents the frequency content of the signal $x_{(n)}$. In other words, $X_{(w)}$ is a decomposition of $x_{(n)}$ into its frequency components. $N$ is the total number of samples and $w$ is within the following range: $0 \leq w \geq N-1$

The final values used and further processes are the positive values of the FFT. The $\mathrm{N}$ stands for the total number of samples.

$$
X^{\prime}(w)^{\prime}=\frac{X_{(w)}}{2} \cdot \frac{1}{N}
$$

After that, we separated the frequency components for each file in the above mentioned 5 different bands: Alpha $(8-13 \mathrm{~Hz})$, Beta-I $(13-20 \mathrm{~Hz})$, Beta-II $(20-30 \mathrm{~Hz})$, Delta $(1-4 \mathrm{~Hz})$ and Theta $(4-8 \mathrm{~Hz})$. The mean voltage amplitude $(\bar{V})$ and the relative mean power for each band were calculated using ratios 5.4 and 5.5 for the mean voltage.

$$
\bar{V}=\frac{1}{N} \sum_{w=i}^{w=j} X^{\prime}(w)
$$


Where, $i=f_{c 1} \frac{N}{2} \cdot 2 \cdot f_{s} \quad$ and $\quad j=f_{c 2} \frac{N}{2} \cdot 2 \cdot f_{s}$

In this case $N$ is the total number of samples, $f_{c 1}$ and $f_{c 2}$ are the cut off frequencies, $f_{S}$ is the sampling frequency and $X_{(w)}^{\prime}$ is the vector containing the real values of the Fourier Transform

The relative mean power is calculated by

$$
\overline{P_{r}}=\frac{\frac{1}{N} \sum x(i)^{2}}{\frac{1}{N} \sum y(i)^{2}}
$$

Where $\overline{P_{r}}$ stands for relative mean, $x$ represents the voltage values for a specific band and the $y$ values represent the voltage values for all the bands and $N$ is the total number of samples.

With these equations set, an average of the six different mean voltages for each band is performed. The mean amplitude of each band of the baseline $Y_{(n)}$ is subtracted from each band of the six-listening/answering files $X_{(w)}$. The difference is stored in $D$.

$$
D=\frac{1}{N} \sum_{w=i}^{w=j} X(w)-\frac{1}{N} \sum_{n=i}^{n=j} Y_{(n)}
$$


Finally, a Gaussian distribution is applied to those values. Calculating two thresholds of 1 and 2 standard deviation(s) $\left(T_{1}\right.$ and $\left.T_{2}\right)$ in the positive and negative directions with respect to the absolute mean voltage of the signal in order to consider only those values within the following ranges: $\left[+T_{1}+T_{2}\right]$ and $\left[>T_{2}\right]$ and $\left[-T_{1}-T_{2}\right]$ and $\left[<-T_{2}\right]$.

The process of visualization was another integral task of this research endeavor. The visual graph proposed represents the shape of a human head with its 41 electrodes positioned in the same MCN order. In order to have an understanding of the behavior of the brain, a Gaussian distribution was applied to the final values of each electrode. Two thresholds were established. The values shown in red and orange are the ones that belong to the positive threshold of 2 standard deviations (2) or higher and where the values in orange are the ones that are higher than the positive threshold of 1 , but less than 2 . The same reasoning was followed for the negative threshold of 2 and higher. Also, a table was made in order to show the percentages of activity for each region of the brain, which are: frontal, temporal, parietal, occipital, and central. A table for each band was created, so a final analysis is made based on the percentages belonging to each cortex region of the brain. The final values are graphically represented with different colors according to one and two standard deviation in the negative and positive directions with respect to the mean. At first, we averaged the six EEG signals in the time domain and then apply the Fourier Transform, but it was not a convincing approach because it missed a lot of information of the signals with this procedure. The average of the EEG signals was therefore accomplished in the frequency domain instead of the time domain since the 
registration of records does not begin at the same time of the task; there is a minimum time delay (time lag), which could skew the analysis. At the beginning of each task, either answering or listening, a marker on the continuous data on the screen is set at the beginning and at the end of the given task.

With this reasoning and after applying the Fourier Transform to the 6 listening/answering and baseline files, an average of the 6 Fourier Transform of the 6listening/answering files is done. Then, the Fourier Transform of the baseline is subtracted from the Fourier transform of the listening/answering files. A mean voltage, which is the average absolute magnitude (as defined in microvolts) of a band over the entire epoch, is calculated for each band of the listening/answering file and the graphical representation is provided to portray the final results of the EEG brain activities.

An example of the graphs produdced by the program is illustrated. These graphs only belong to one frequency band, so the same analysis is performed for the other bands as well (See appendix D-E). It is noted that the first graph of Figure 5.8 that is generated by the program is the detailed distribution of absolute mean voltages values for each electrode. They have different colors according to our color bar provided on the side. The calculation of the skewness and kurtosis values as provided in equations 5.10 and 5.11 are also computed for enhanced statistical studies.

Skewness is a measure of the asymmetry of the data around the sample mean. If skewness is negative, the data are spread out more to the left of the mean than to the right. If skewness is positive, the data are spread out more to the right. The skewness of 
the normal distribution (or any perfectly symmetric distribution) is zero. In order to visualize better the actual meaning of this value, the skewness will be calculated for the histogram illustrated in Figure 5.8 (a),

Kurtosis is a measure of how outlier-prone a distribution is. The kurtosis of the normal distribution is 3 . Distributions that are more outlier-prone than the normal distribution have kurtosis greater than 3; distributions that are less outlier-prone have kurtosis less than 3 .

(a) Voltage Values for each Electrode

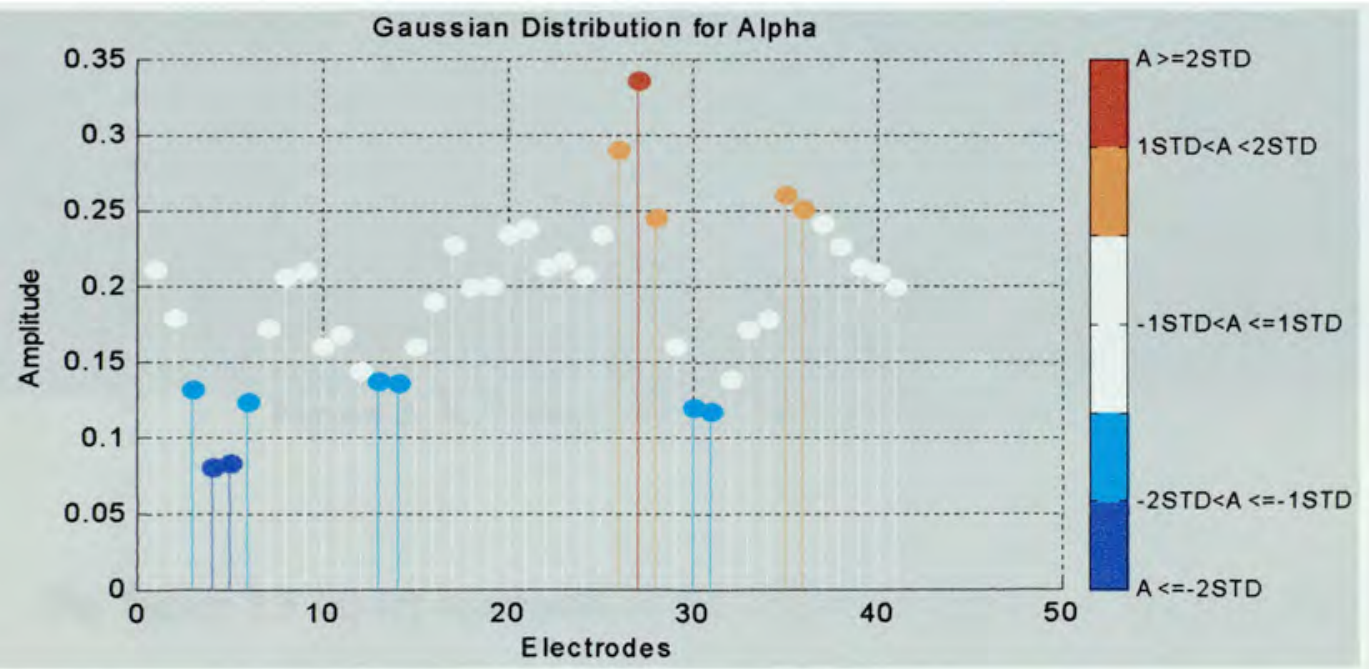

Skew_hot $=-5.5968$

Kurtosis_hot $=-38.6404$

The following two graphs represent the hot and cold values. This is done in order to see the shape of the histogram that these values yield. It is noted that the calculation of the kurtosis and skewness values are shown above in Figure 5.8 (a). 


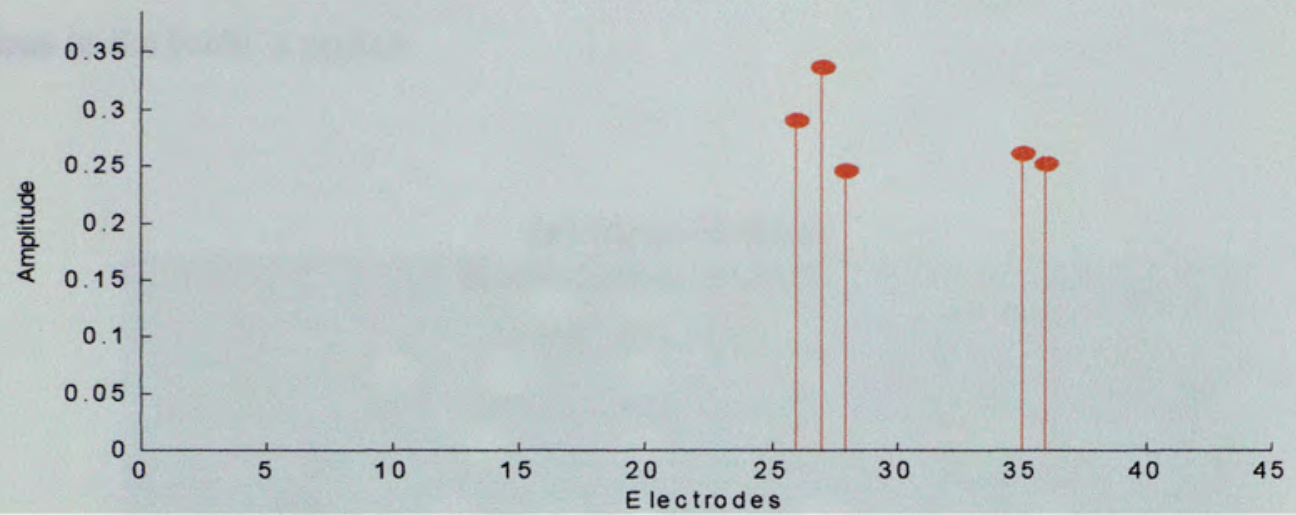

(c) Cold Values

Cold Values for A Ipha

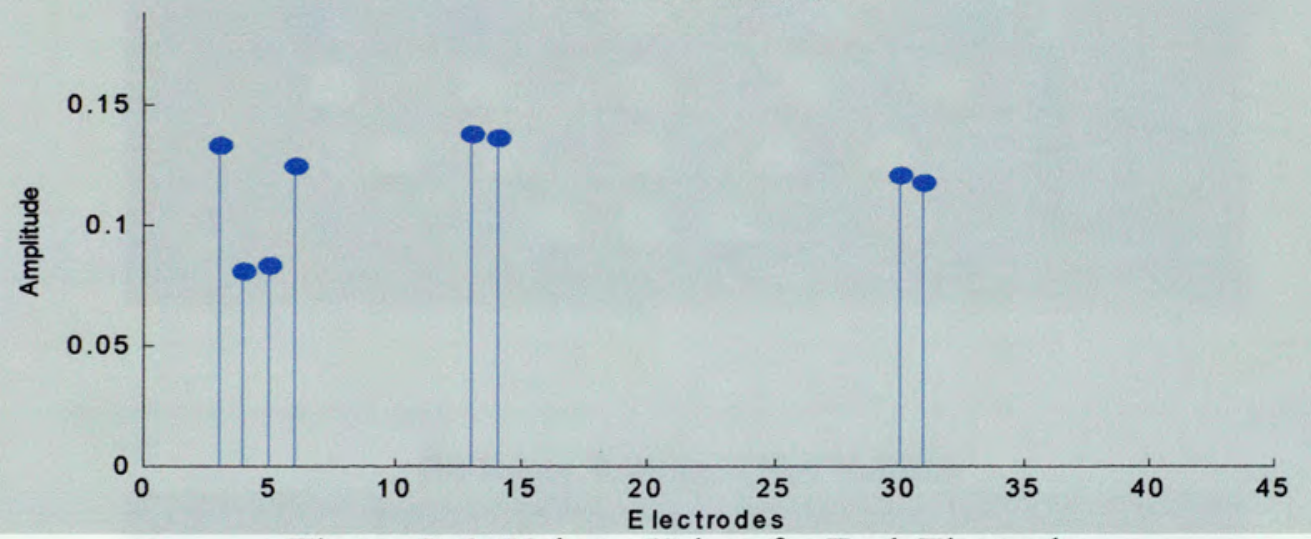

Figure 5. 8. Voltage Values for Each Electrode

The Figure 5.9 (a)-(c) represents all the electrodes placed on the scalp that we used in this study. The different colors are used in order to represent the various significant changes in the positive or negative direction with respect to the mean. The circles of activity shown in red and orange depict the hot values, which means values increasing with respect to mean, and the bullets in dark and light blue depict those values that decrease with respect to the mean voltage of all the voltages values for the entire array of electrodes. It is noted that a detailed representation of the head is displayed as 
well as the labels of the electrodes used in order to be able to pin point important active regions in the brain 's cortex.

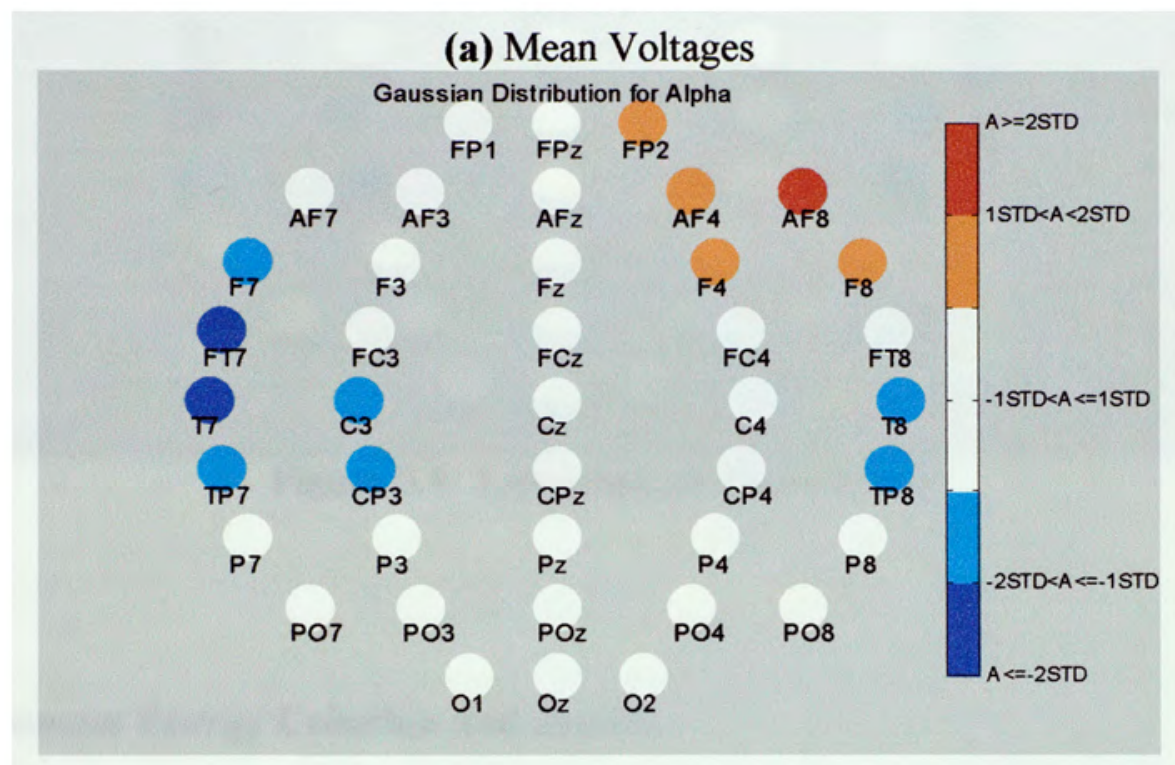

(b) Mean Voltages (Hot Values)

Gaussian Distribution for Alpha (HOT Values)

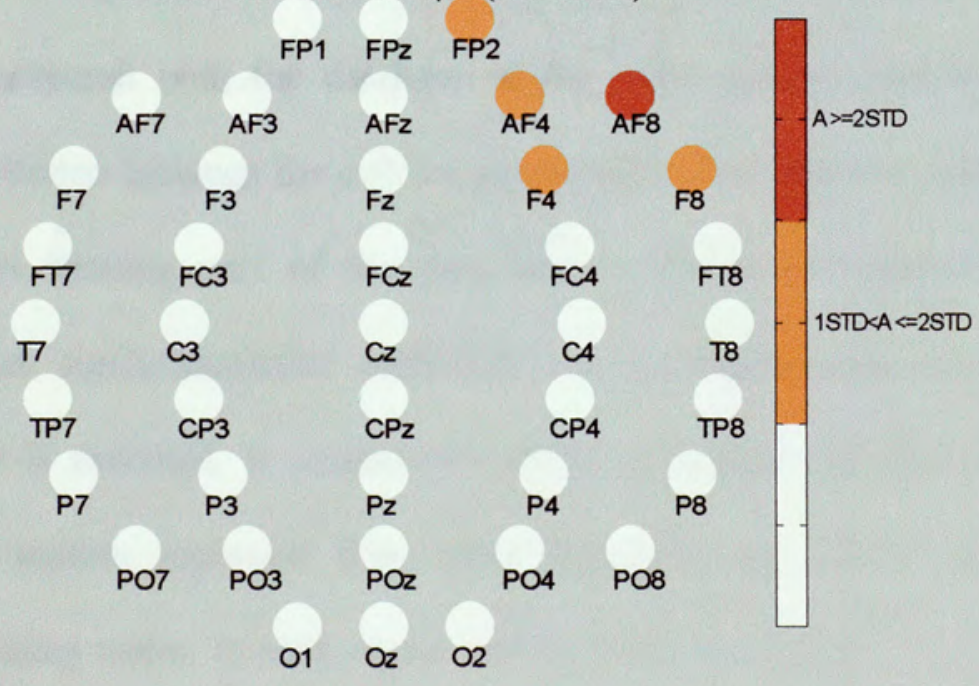




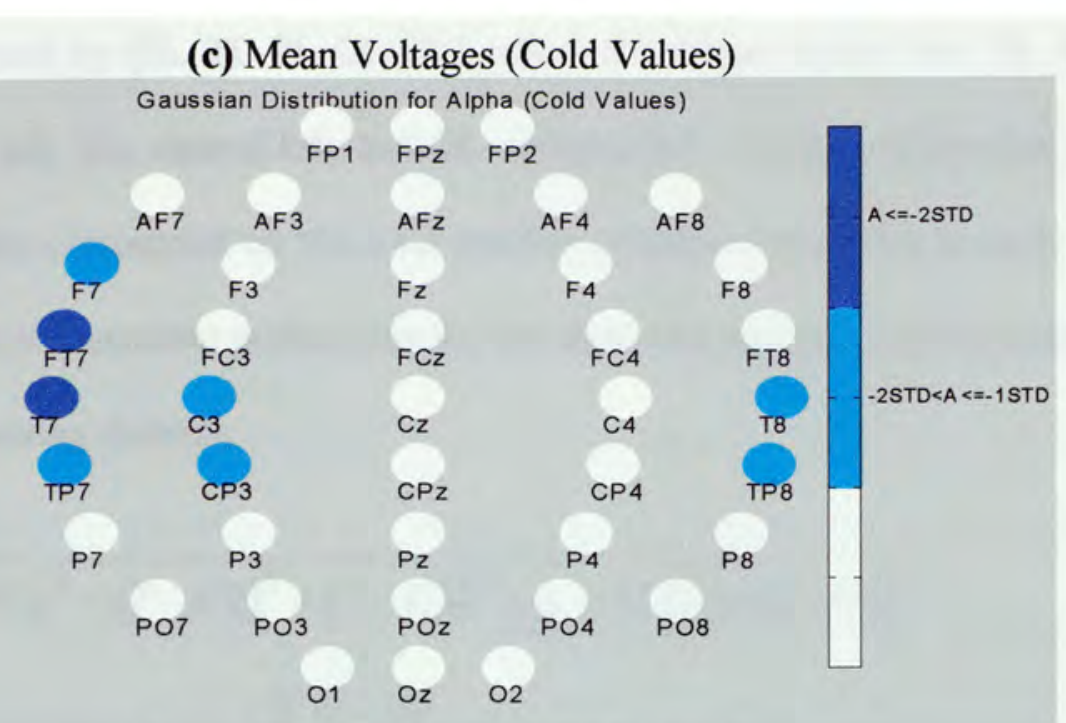

Figure 5.9. Topographical Distributions

\subsubsection{Minimum Energy Criterion and Results}

When the spectral analysis and the displayed of the EEG signals is performed, an automated program is implemented such that any unknown subject entered to the system is analyzed and compared with the database of the other patients and based on the minimum energy criterion between the vectors generated by the unknown subject and the rest of the subjects forming part of the data base, a precise comparison analysis is outputted such that similar/dissimilar behaviors can be represented topographically. When the program is executed, it creates two arrays of activity for the right and left hemispheres. The vectors represent how many electrodes are active, either in the increasing or decreasing order, in each region and for each hemisphere. As a result four vectors are created for each subject (left positive, left negative, right positive, and right negative). For instance, for the left region representing increasing changes, a typical array 
of activity is formed by [FL TL PL CL OL], where FL means frontal left, TL, temporal left, PL, parietal left, CL, central left, and OL occipital left. The five values that form the arrays of activities correspond to the total number of active electrodes in each of these regions in the human cerebral cortex. Finally, the minimum energy criterion is calculated based on the following formula:

$$
\begin{gathered}
E=\sqrt{(F-U 1)^{2}+(T-U 2)^{2}+(P-U 3)^{2}+(C-U 4)^{2}+(O-U 5)^{2}} \\
\sum(D-U)^{2}
\end{gathered}
$$

Where $E$ is the minimum energy value, $U$ is the unknown array, which is equal to the following: $U=$ [UFL UTL UPL UCL UOL]. Each value represents the quantity of active electrodes for each region of unknown patient and $F, T, P, C, O$ define the distinct regions analyzed, which are Frontal, Temporal, Parietal, Central, and Occipital regions respectively.

The minimum distance value is calculated for every activity array of the unknown patient with respect to the ones already in the database. Once the values are obtained and displayed on the screen, the program chooses the minimum distance for each of the four different cases (left positive, left negative, right positive, and right negative). The final results are represented along with a topographical mapping of the unknown patient and the ones that show a similar behavior. This procedure is done with the five different frequency bands. A complete analysis for each band such as alpha, beta 1 , beta 2 , delta, and theta will be provided in order to cope with the changing fluctuations of the different frequency components. 
For each frequency band we provide the same information. In the following example, we have the output corresponding to the alpha band during an auditory/comprehension task. The first part of the output displays the results of the subtraction realized with the 4 different arrays in order to determine the minimum energy value. It can be observed that the activity vector of the unknown subject is compared with the distinct vectors of the subjects in the database. There are four activity arrays; the number of active electrodes, showing increasing activity with respect to the mean, of the left and right hemispheres, which are called POS LEFT and POS RIGHT; in contrast, the vectors called NEG LEFT and NEG RIGHT are composed by the number of active electrodes that their activity decreases with respect to the mean in the left and right hemispheres. To conclude, the minimum energy value is displayed for each group and the subjects that have similar behaviors are shown as well as the topographical representation of the unknown subjects and the best similarity match between the unknown subject and the rest of the subjects. Next we can see an example of the output of the program implemented. Note that the topographically maps show the electrodes that have a mean voltage that is higher than one standard deviation.

The example give below is but an illustration of a typical case. All other cases, which are treated in the same manner, are provided for all subjects taking part of this experimental study in Appendix G.

\section{Auditory/Comprehension}

\%\%RESULTS WHEN RUNNING PATIENT 1 WITH RESPECT TO THE REST (8) 
Energy Minimum Distance (ALPHA POS LEFT) of Subject $1 \mathrm{Vs}$ Unknown $=1.000$ Energy Minimum Distance (ALPHA POS LEFT) of Subject 2 Vs Unknown $=2.000$ Energy Minimum Distance (ALPHA POS LEFT) of Subject 3 Vs Unknown $=2.000$ Energy Minimum Distance (ALPHA POS LEFT) of Subject 4 Vs Unknown $=3.000$ Energy Minimum Distance (ALPHA POS LEFT) of Subject 5 Vs Unknown $=4.000$ Energy Minimum Distance (ALPHA POS LEFT) of Subject 6 Vs Unknown $=2.000$ Energy Minimum Distance (ALPHA POS LEFT) of Subject 7 Vs Unknown $=1.000$ Energy Minimum Distance (ALPHA POS LEFT) of Subject 8 Vs Unknown $=3.000$ $\% * * * * * * * * * * * * * * * * * * * * * * * * * * * * * * * * * * * * * * * * * * * * * * * * * * * * * * * * * * * * * * * * * * * *$

Energy Minimum Distance (ALPHA POS RIGHT) of Subject 1 Vs Unknown $=3.000$ Energy Minimum Distance (ALPHA POS RIGHT) of Subject 2 Vs Unknown $=2.000$ Energy Minimum Distance (ALPHA POS RIGHT) of Subject 3 Vs Unknown $=3.000$ Energy Minimum Distance (ALPHA POS RIGHT) of Subject 4 Vs Unknown $=3.000$ Energy Minimum Distance (ALPHA POS RIGHT) of Subject 5 Vs Unknown $=4.000$ Energy Minimum Distance (ALPHA POS RIGHT) of Subject 6 Vs Unknown $=3.000$ Energy Minimum Distance (ALPHA POS RIGHT) of Subject 7 Vs Unknown $=3.000$ Energy Minimum Distance (ALPHA POS RIGHT) of Subject 8 Vs Unknown $=3.000$ \%

Energy Minimum Distance (ALPHA NEG LEFT) of Subject 1 Vs Unknown $=3.000$ Energy Minimum Distance (ALPHA NEG LEFT) of Subject 2 Vs Unknown $=3.000$ Energy Minimum Distance (ALPHA NEG LEFT) of Subject 3 Vs Unknown $=9.000$ Energy Minimum Distance (ALPHA NEG LEFT) of Subject 4 Vs Unknown $=5.000$ Energy Minimum Distance (ALPHA NEG LEFT) of Subject 5 Vs Unknown $=11.000$ Energy Minimum Distance (ALPHA NEG LEFT) of Subject 6 Vs Unknown $=9.000$ Energy Minimum Distance (ALPHA NEG LEFT) of Subject 7 Vs Unknown $=2.000$ Energy Minimum Distance (ALPHA NEG LEFT) of Subject 8 Vs Unknown $=5.000$

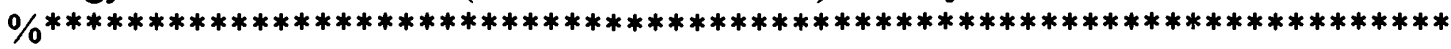

Energy Minimum Distance (ALPHA NEG RIGHT) of Subject 1 Vs Unknown $=1.000$ Energy Minimum Distance (ALPHA NEG RIGHT) of Subject 2 Vs Unknown $=1.000$ Energy Minimum Distance (ALPHA NEG RIGHT) of Subject 3 Vs Unknown $=5.000$ Energy Minimum Distance (ALPHA NEG RIGHT) of Subject 4 Vs Unknown $=7.000$ Energy Minimum Distance (ALPHA NEG RIGHT) of Subject 5 Vs Unknown $=4.000$ Energy Minimum Distance (ALPHA NEG RIGHT) of Subject 6 Vs Unknown $=1.000$ Energy Minimum Distance (ALPHA NEG RIGHT) of Subject 7 Vs Unknown $=3.000$ Energy Minimum Distance (ALPHA NEG RIGHT) of Subject 8 Vs Unknown $=4.000$ $\% * * * * * * * * * * * * * * * * * * * * * * * * * * * * * * * * * * * * * * * * * * * * * * * * * * * * * * * * * * * * * * * * * * * * *)$ $\% * * * * * * * * * * * * * * * * * * * * * * * *$ FINAL RESULTS* 
Energy Minimum Distance (ALPHA POS LEFT) is 1

Minimum Distance (ALPHA POS LEFT) belongs to subjects 28
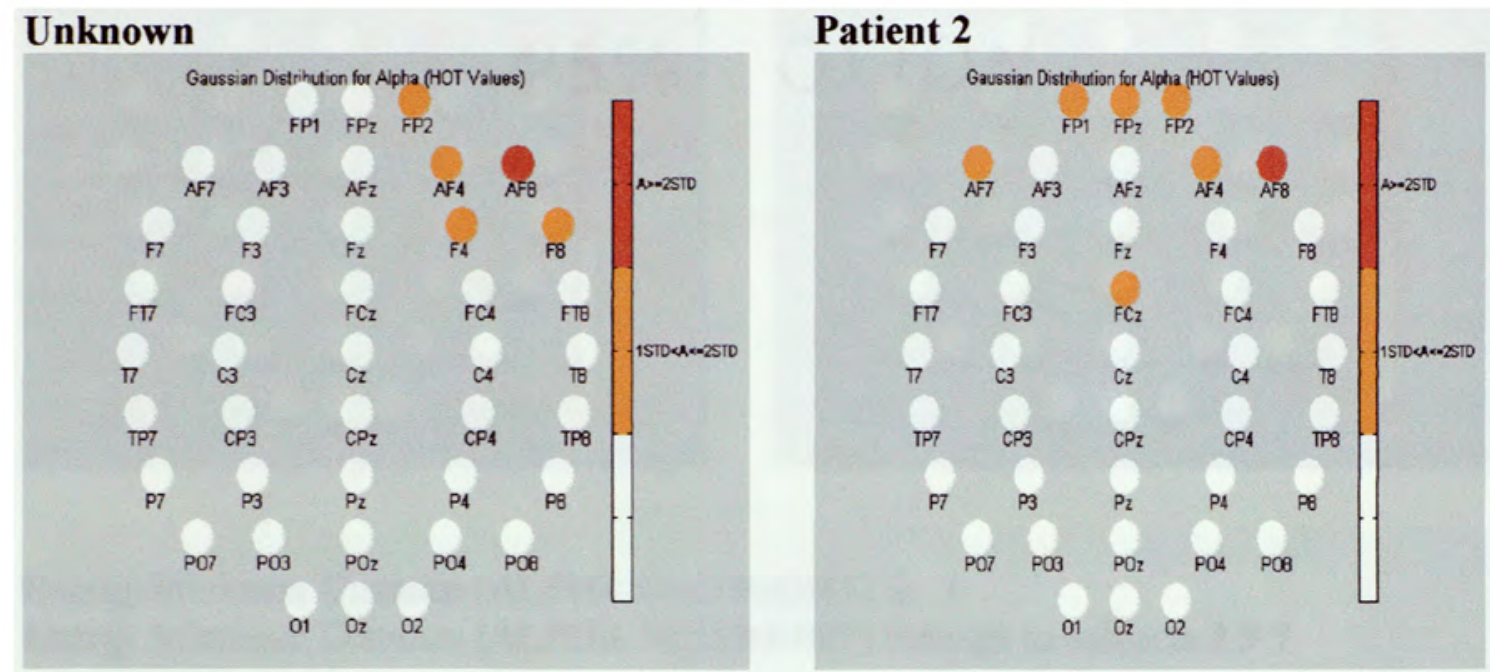

Energy Minimum Distance (ALPHA NEG LEFT) is 2

Energy Minimum Distance (ALPHA NEG LEFT) belongs to subject 8

\section{Unknown}

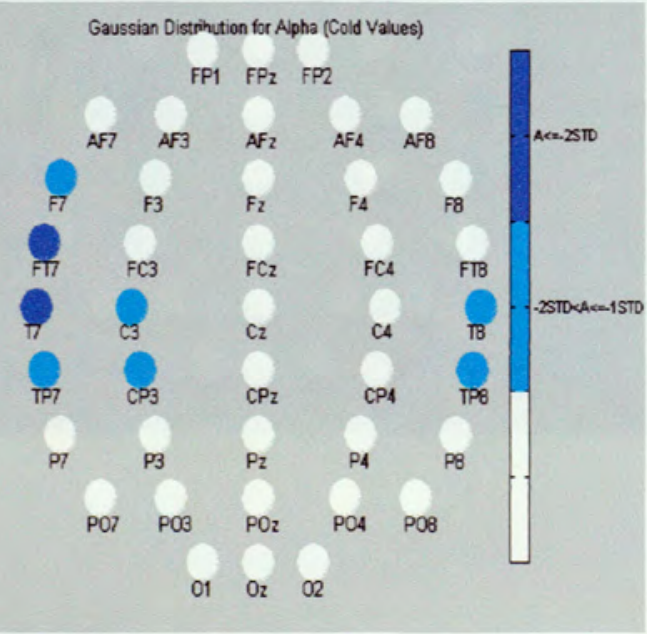

\section{Patient 8}

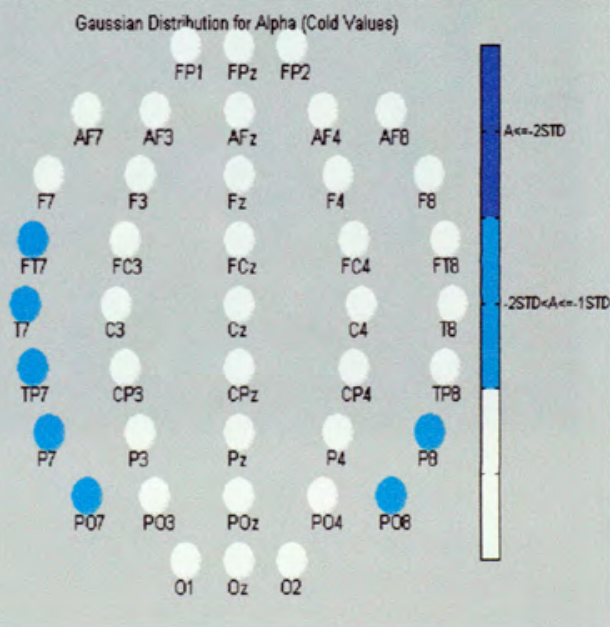

Energy Minimum Distance (ALPHA POS RIGHT) is 2 Energy Minimum Distance (ALPHA POS RIGHT) belongs to subject 3 
The program performs in time domain the RMS ratio for each electrode during auditory/comprehension and answering parts. The program is passed 7 parameters, which are the baseline file and the 6 listening/answering files. It reads the files and creates a matrix, where each column of a given matrix belongs to a specific electrode. We used 41 electrodes positioned evenly around the scalp, so we have a good understanding of what is happening and what part of the brain is responsible for a given task. Prior to process all the EEG signals, the noise and the DC offset is reduced from each electrode by the same way it was already explained in the previous approach. After that, five Butterworth digital filters are created. The band pass filters created had an order 2 and the cut off frequencies were divided for the four main frequencies of the brain, which are alpha, beta, delta, and theta. The beta was further divided in two bands because the range of the beta band was too extensive to analyze. The ranges for all the bands are as follows: Alpha (8-13HZ), Beta1 (13-20HZ), Beta2 (20-30HZ), Delta (1-4HZ), and Theta (4-8HZ). Once the filters are ready, the baseline and the listening/answering files were filtered five times, the results are saved separated from each other. For example, the baseline was filtered five times, so we have the resultant signal after been filtered for the Alpha band filter, the Beta 1-2, Delta, and Theta filters. The same procedure was done to the other 6 listening/answering files. The RMS was calculated for each column of the original files and filtered files. The RMS is calculated using the following formula:

$$
R M S=\sqrt{\frac{\sum_{l=1}^{N} x_{(1)}^{2}}{N}}
$$

Where $x(i)$ is the EEG data of an specific electrode 
An RMS ratio is the relation between the original signal and the output signal. This ratio was calculated as follows:

$$
\text { Ratio }=\frac{R M S(x i n)}{R M S(x o u t)}
$$

Where xout is the filtered EEG signal and xin is the original EEG signal.

As a consequence, for each listening/answering files, five different ratios were calculated. In other words, a ratio for Alpha, Beta1-2, Delta, and Theta bands was obtained from each file. In order to see a significant change, the ratios of each band obtained for the baseline file was subtracted from the ratios of each band for the Listening/ Answering files. After this, an average of the six RMS ratios was taken in order to enhance our results.

When all the values are calculated for each electrode inside the file, an average is made using the six files together. An average is made 41 times, in other words, the variance of each electrode is average together with the same electrode of the other five files. Once we have the 41 values together in one file, the variance from the baseline of each electrode is also subtracted, this way we end up with the actual changes of the listening/answering activity for each electrode. Finally, a display is done in a similar way as the one explained above. The Gaussian Distribution is applied to all these values in order to represent with different colors the values that fall in the range of 1 standard deviation or 2 standard deviation or higher or less than 2 standard deviation. 


\subsection{Skewness Versus Kurtosis Analysis}

The skewness is the measure of the nonsymmetrical distribution of a given histogram, which is the following:

$$
S K=\Sigma(x-\mu)^{3},
$$

Where $S K$ stands for the skewness, $x$ is the value of each point of the histogram and $\mu$ is the mean of the entire histogram.

Kurtosis is based on the data depending if the histogram that forms the data is peaked or flat relative to a normal distribution. Histograms with high kurtosis tend to have a distinct peak near the mean. They decline usually fast, and have heavy tails. On the contrary, histograms with low kurtosis value tend to have a flat top near the mean. The following formula was used to calculate the kurtosis value for each histogram $[24,14]$.

$$
K=\Sigma \frac{(x-\mu)^{4}}{N \sigma^{4}}-3
$$

Where $K$ represents the kurtosis value with $\mu$ and $\sigma$ being the computed mean and standard deviation of the histogram.

Figure 5.11 (a)-(e) represents the skewness versus the kurtosis values for each frequency band. These values were calculated using the histogram composed of mean voltages for each channel. The histogram of each frequency band is represented for each patient. Therefore, 9 values represent each figure. A Kurtosis and skew values are calculated for each patient and for each frequency band. It is noted in the following 
representations that these values cannot be used to draw any conclusions about the activity of the brain during a listening/comprehension task, but to rather illustrate the variability in these activities. The values are distributed in a very wide range. They differ from each other and they do not concentrate in one region for classification. The hope with this analysis was to classify in different regions the kurtosis and skewness values for each band, but the results are scattered. The alpha values seem to vary from -40 to 0 in the $\mathrm{x}$ direction, Beta 1 and Beta 2 from -10 to 160 , and delta and theta frequencies from 20 to 0.

(a) Skeweness Vs. Kurtosis

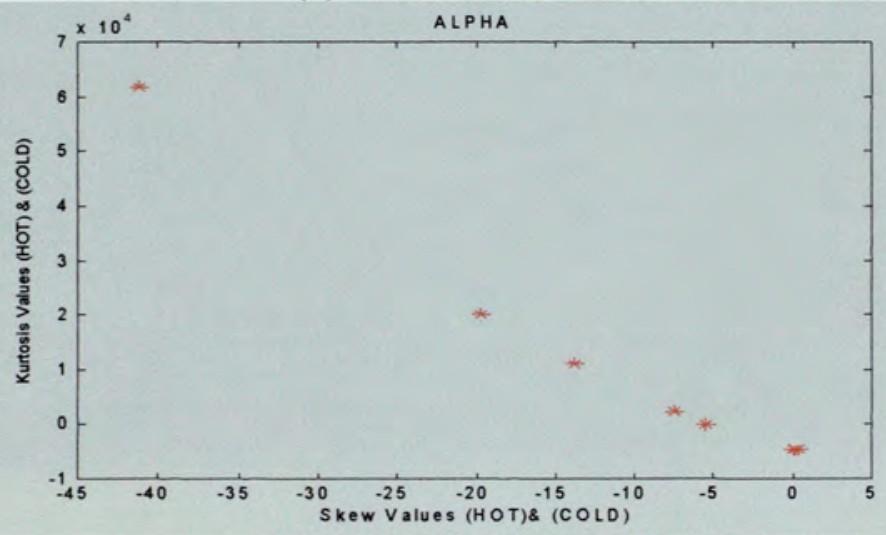

(b) Skeweness Vs. Kurtosis

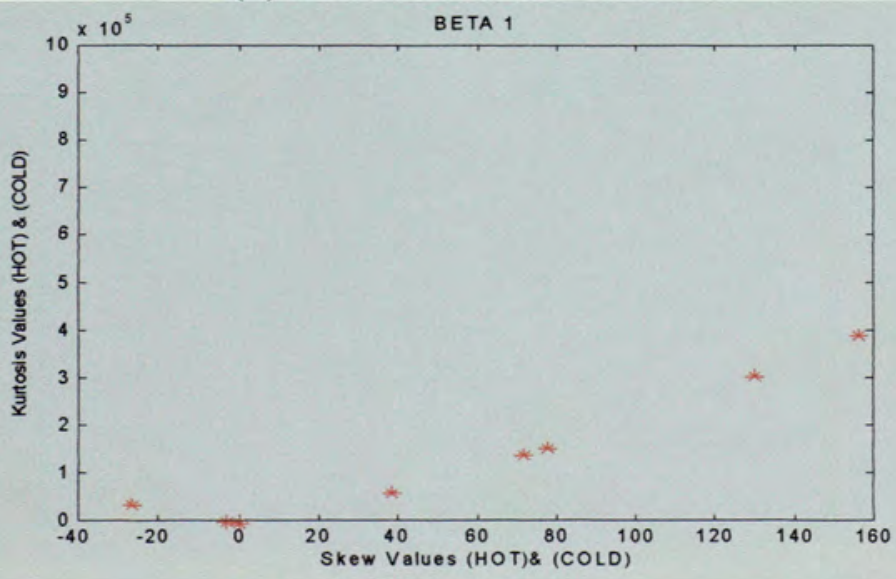


(c) Skeweness Vs Kurtosis

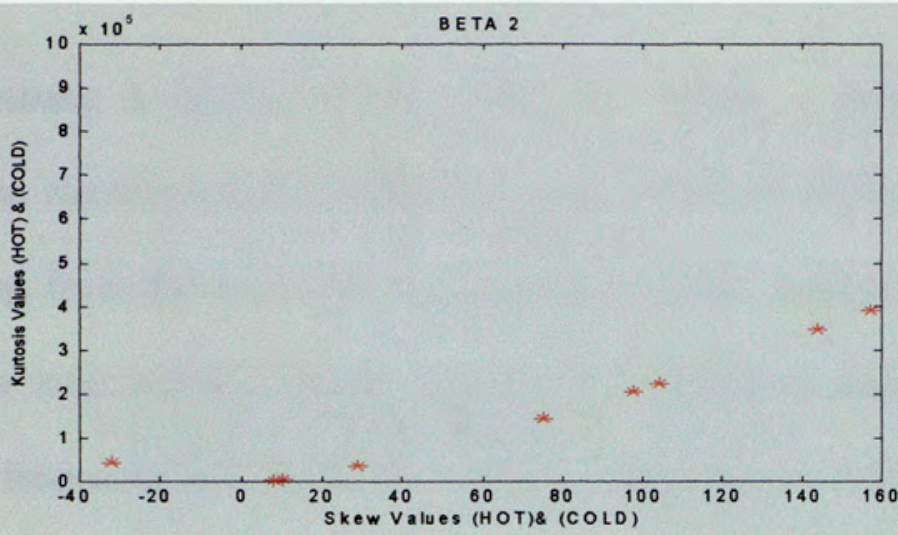

(d) Skeweness Vs Kurtosis

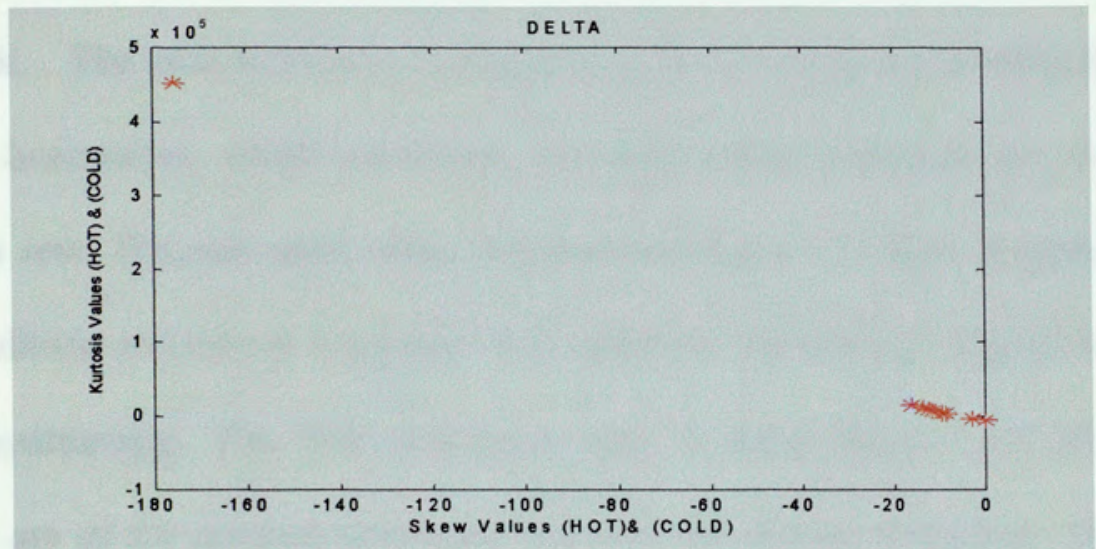

(e) Skeweness Vs Kurtosis

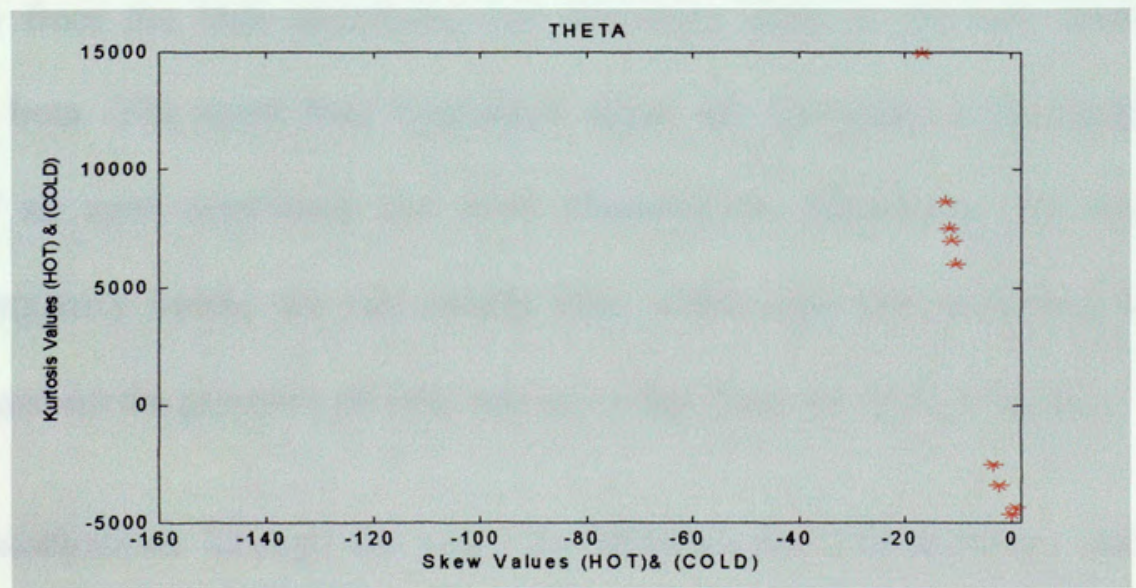

Figure 5.11. Skeweness Vs. Kurtosis (all frequency bands) 


\subsection{Discussion and Analysis of Results}

Before making a conclusion about the final results, a summary and a brief explanation of the significance of the different brain waves are explained. The electrical activity emanating from the brain can be classified into four categories of brainwaves, ranging from the most activity, fastest frequency and minimum amplitude to the least activity, slowest frequency and maximum amplitude. Beta (Figure 5.12 (b)), which is the fastest and has the slowest amplitude, involves mental activities and speech production. For instance, a person making a speech would be in beta when he/she is engaged in his/her work. . The next brainwave category in order of frequency is alpha (Figure 5.12 (a)). Alpha brainwaves, which are slower, and with higher amplitude, are noted when a patient is at rest. The next state, theta brainwaves (Figure 5.12 (d)), is typically of even greater amplitude and slower frequency. It is related to the process of good ideas and the state of daydreaming. The final brainwave state is delta (figure 5.12 (c)). Here the brainwaves are of the greatest amplitude and with the slowest frequency. They typically center on a range of 1 to 4 cycles per second. In summary, there are four brainwave states that range from the high amplitude, low frequency delta to the low amplitude, high frequency beta. The same four brainwave states are common to the human species. People of all ages experience the same characteristic brainwaves. By analyzing the distinct frequency bands, we can usually infer which type task is hardest for a given patient, based on the presence of slow waves, or fast brain waves $[2,7,10,16]$.

Investigations through the years has demonstrated that although one frequency band may predominate at any given time, depending on the activity level of the 
individual, the remaining three frequency bands are present at all times. For instance, if a person is involved in a mental task and exhibiting a beta brainwave pattern, there also exists in that person's brain a component of alpha, theta and delta, even though these may be present only at the trace level $[4,9]$.

(a)

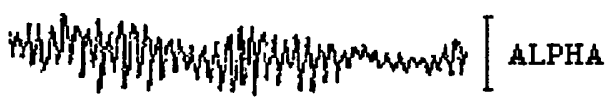

(b)

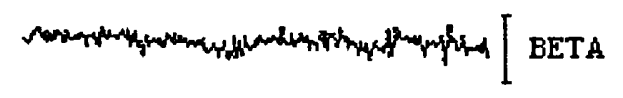

(c)

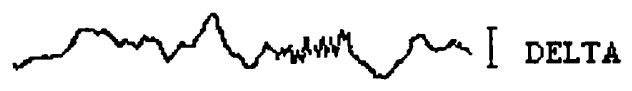

(d)

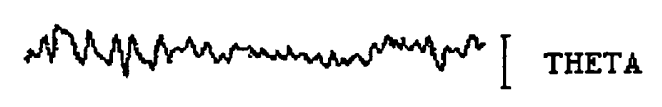

Figure 5.12. Main Frequency Bands

Based in our results obtained after analyzing 9 patients during an auditory/comprehension test, the first impression one gets is that EEG signals are quite unpredictable. Amplitude and frequency do not contain enough information to know exactly what is happening in one patient, but provide sufficient information to gain insight on the functional mapping during a specific task. When analyzing the results by means of an FFT, the EEG power spectrum was calculated across the 41-recorded leads 
in the four different frequency ranges, in the baseline and separately for each block (listening and answering). The EEG epoch for the available realizations (listening and answering) was 5 to 7 seconds; 6 five to seven seconds segments were averaged.

First, we analyzed for brain regions involved in auditory/comprehension task performance. During the listening/comprehension task, changes in the beta frequency less than $20 \mathrm{~Hz}$, which is involved with mental activity, is more predominant in the left hemisphere. This corroborates the premise that the left hemisphere is associated with more logical thoughts patterns, analytical approaches to problem solving and verbal fluency in the articulation of ideas. Nevertheless, changes in delta, the slowest frequency that is associated with less concentration, is predominant in the right hemisphere. The right hemisphere dominance is associated more with relatively less skill in articulations of thoughts $[11,13,16,26,27]$.

During the answering task it looks like bilaterally the frontal region is the more active. Since Broca's area is located in the frontal lobe and it is associated with the production of language, the positive fluctuations of all frequency bands with respect to the mean are concentrated in the frontal cortex. In addition, there are some changes in activity also in the posterior and central regions for beta frequency $[10,31]$.

Summarizing the data of the auditory/comprehension task studied in this thesis, we conclude that the main effect of delta frequency band presents the highest amplitude in all the 9 patients. Theta frequency as an overall in 6 patients out of 9 is the highest amplitude after delta. Finally, delta and alpha show the smallest amplitudes during this 
task. The fluctuations in frequency start in minimum amplitude in alpha and beta and higher amplitudes in delta and theta. During the answering task, delta also shows the highest amplitude followed by theta. Alpha shows the minimum amplitude in general, and beta is in the middle in terms of amplitude.

It was also determined that alpha frequency, during an auditory/comprehension task, exhibits a significant increment in electrical activity in the frontal region; while it shows a decrement in the temporal region. These results are in agreement with earlier studies that affirm that alpha is stronger in the frontal cortex $[2,7,19,25]$.

Theta frequency activity is evidently increased in the frontal region of the brain during the auditory-comprehension task. This concurred with previous researches that claim that theta activity is increased during internal focus. As study by (Inouye, Ishihara, and Shinosaki, $1984 \& 1985)$ reported that a rhythmic frontal theta activity occurs during the performance of a mental task. Also, Mizuki (1987) believes that the appearance of theta in the frontal region closely relates to mechanisms of attention or arousal. In the delta band there was a consistent increment in the frontal cortex. According to literature, delta is generally broad or diffused or may be bilateral $[30,31]$.

Graphical results of the program are shown to illustrate the location in the brain with more activity during the auditory/comprehension and response tasks. The graphs basically show the difference in brain activity between the resting phase of baseline and the listening/answering states. In order to establish a comparison with a typical case of EEG in real time during an auditory task, next we show in Figure 5.13 the behavior of the 
EEG signal during an auditory task. In this case the activity from the baseline has not been subtracted. This represents EEG activity as it is during the performance of an auditory/comprehension task. In the following section cumulative results (inter patients) will be analyzed, and it was found that the localization of active regions in the online data is similar with respect to the active regions found after processing this EEG data. It is noted that delta and theta denote increasing changes in the frontal lobe. Beta 1 and beta 2 present a more diffused activity around the scalp. Alpha in this case is predominant in the frontal, parietal and occipital lobes of the cortex. You have to take into consideration that this picture only represents listening number 20 out of the 34 listening sections of that patient. Our results from the thesis are based in the average of the frequency components of 6 listening sections. Some minor differences may appear, but no too distinct from one another.

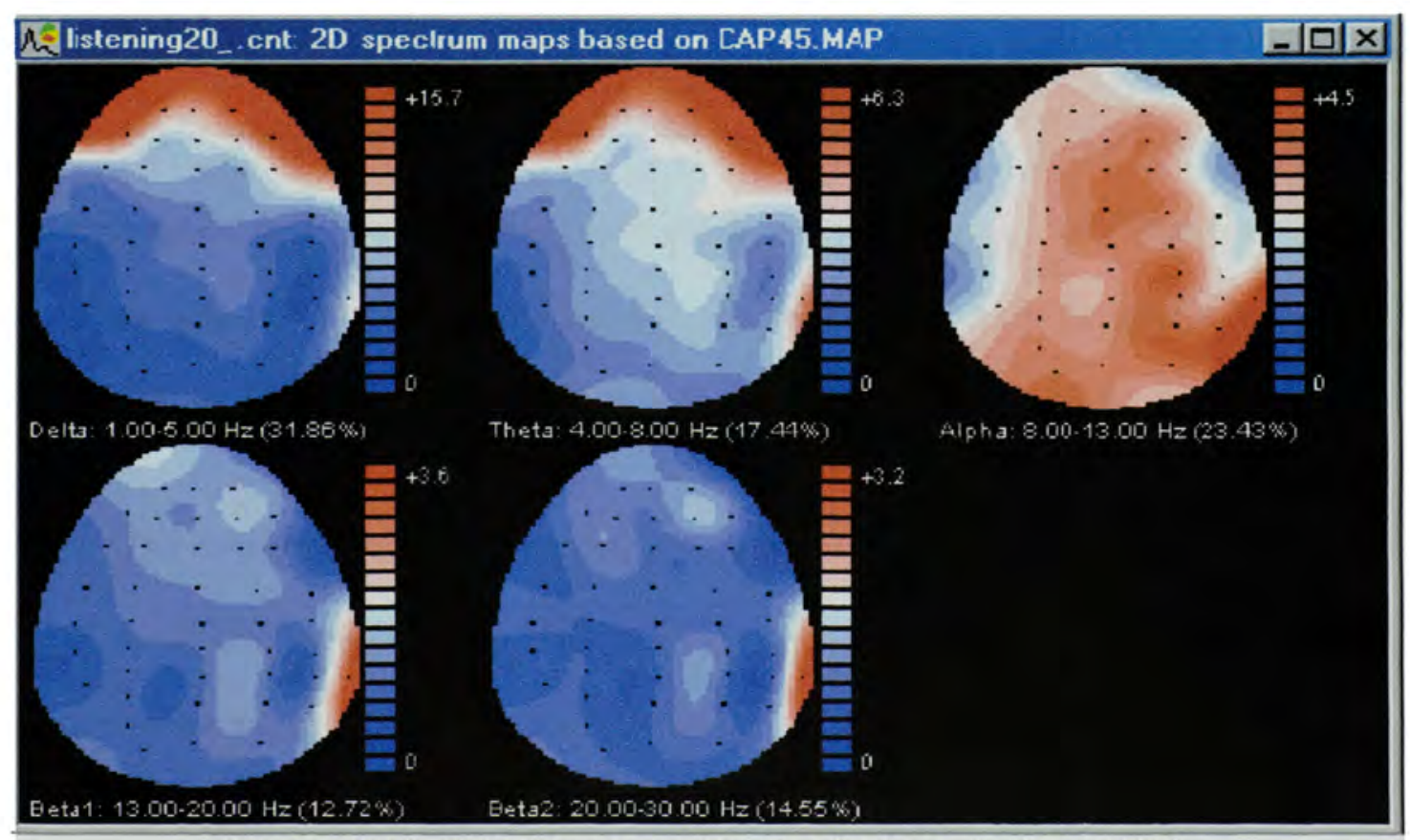

Figure 5.13. EEG Frequency Bands of a Raw Auditory EEG

(Note that the dots reveal the position of the electrodes) 
5.12 Cumulative Results Related to a Positive Change of Activity in the Auditory/Comprehension Task

Alpha waves are those between 8 and $13 \mathrm{~Hz}$. Alpha is a common state for the brain and occurs whenever a person is alert, has closed eyes and is relatively relaxed. This alpha activity on the other hand tends to disappear or decrease when the subject engages in mental concentration or physical movement. It is stronger over the frontal cortex. The increasing alpha activity with respect to the mean is predominant in the frontal region; all of the subjects have an increment of alpha in the frontal region (see Figure 5.14). The alpha activity even though apparent in the frontal left hemisphere, seems to predominate in the right hemisphere since electrodes FP2, AF4 and AF8 are active in more than 4 patients simultaneously. The following Figure represents in red the electrodes that were active in 4 or more patients at the same time, the electrodes in orange were active at the same time in 2 or 3 patients, and the electrodes in light orange were active only in one patient. The figure to the left gives the details of the figure to the right. The histogram (see Figure 5.14 (a)) indicates the number of patients that had a specific electrode active. The $\mathrm{x}$-axis corresponds to the number of electrodes and the $y$-axis corresponds to the number of patients $[19,25]$.

The lowest frequencies are Delta. These are less than $4 \mathrm{~Hz}$. Delta is generally broad or diffused and may be bilateral, and widespread. The increased changes with respect to the mean in delta activity are predominant in the frontal region in 8 subjects out of 9 (See Figure 5.15). The activity seems to predominate in both hemispheres in the frontal lobe. In the right hemisphere, electrodes $\mathrm{FP}_{2}$ and $\mathrm{AF}_{7}$ are active 8 to 7 times out of 
9. Similarly, electrodes $\mathrm{FP}_{1}$ and $\mathrm{AF}_{7}$ in the left hemisphere are active 8 to 9 times out of

9.

(a)

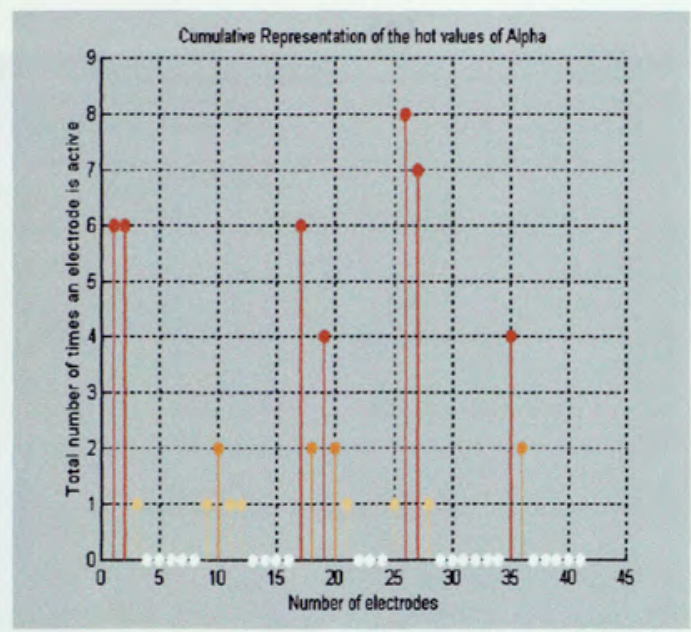

(b)

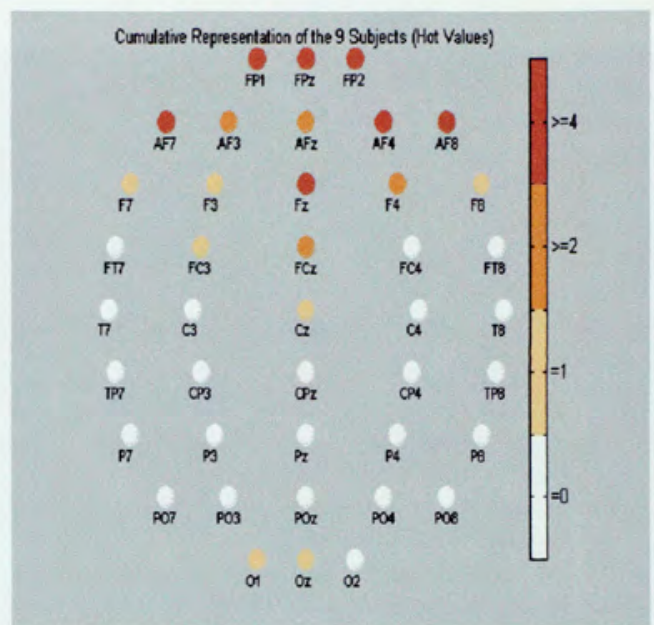

Alpha Frequency (a)

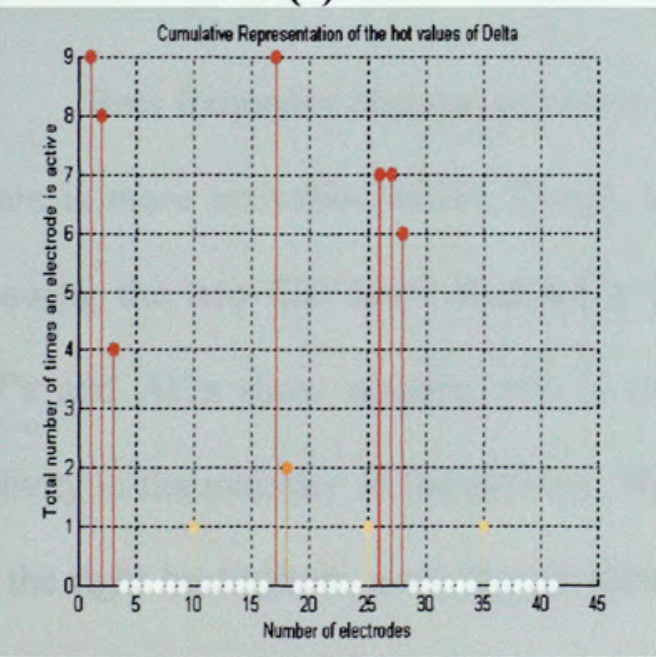

(b)

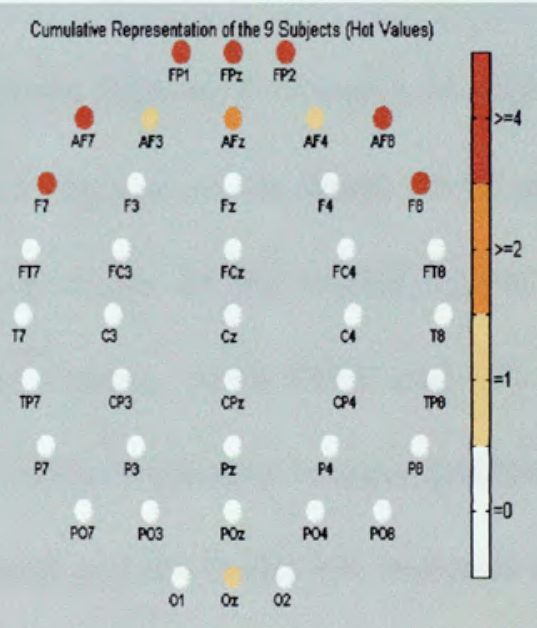

Figure 5.15. Hot Values Delta Frequency

Theta activity has a frequency of 4 to $8 \mathrm{~Hz}$ and is classified as slow activity. Theta waves are strong during internal focus and meditation. It is usually regional, but may 
involve many lobes. Theta activity in this case is predominant in the frontal region (Figure 5.116 (b)) in the 9 subjects. It involves both hemispheres even though there is a more concentrated activity in the left hemisphere [30].

(a)

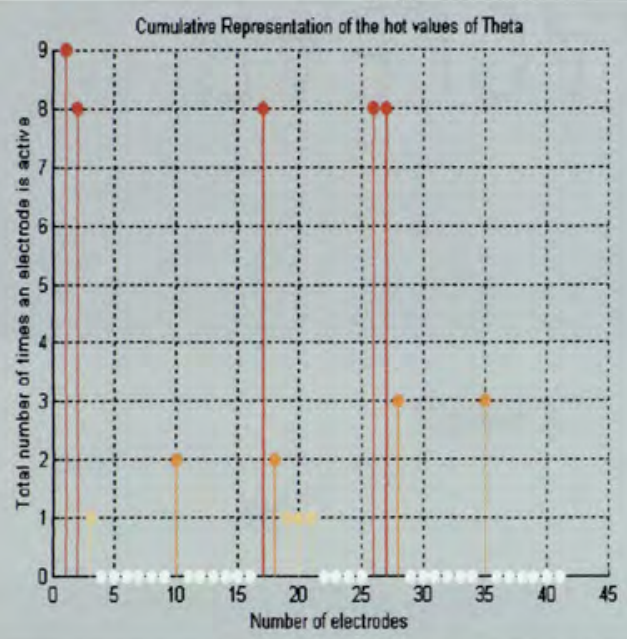

(b)

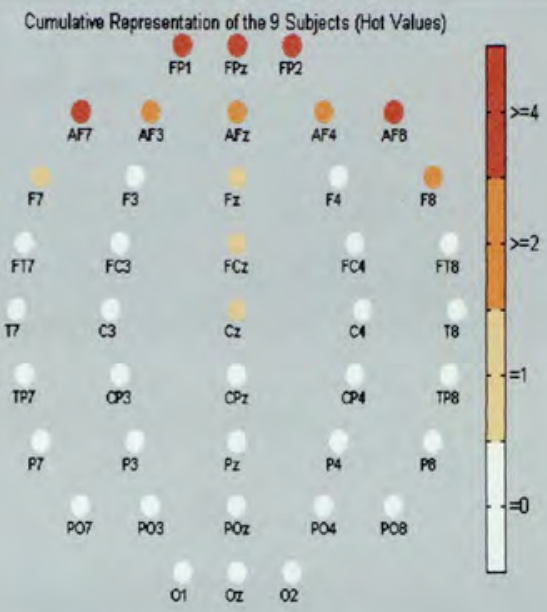

Figure 5.16. Hot Values Theta Frequency

Beta frequency changes as can be observed in the Figures 5.17 and 5.18 show that there is more activation in the frontal and occipital regions of the brain. Both regions showing the two first rows involved in this task are active. In the frontal region, rows FP's and AF's show activity, and in the occipital regions, rows PO's and O's show activity in the majority of the patients. The activity of this frequency is more predominant in the right hemisphere, even though there exist partial activity in the left occipital region involving electrodes $\mathrm{PO}_{3}$ and $\mathrm{O}_{1}$ in beta 2 . It is also noted, that these changes are based mostly in 5 patients out of 9 . So, the regions involve in this activity reflect changes based on more than 50 percent of the total number of patients taken into consideration in this thesis. 
(a)

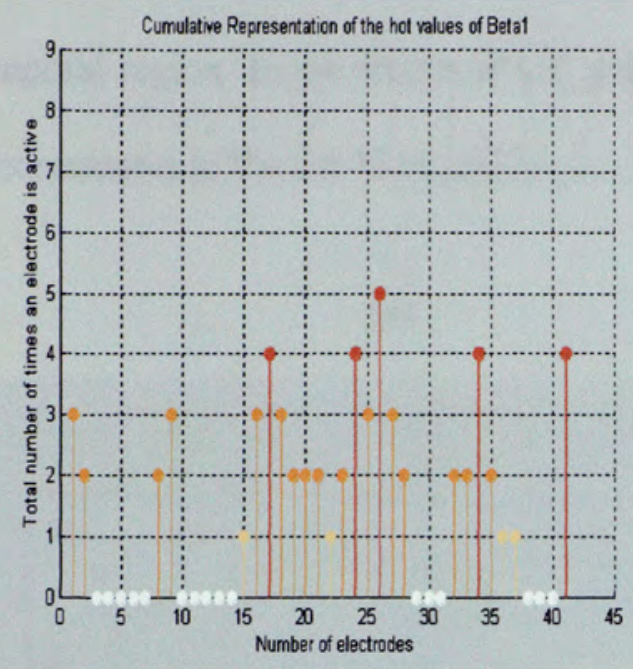

(b)

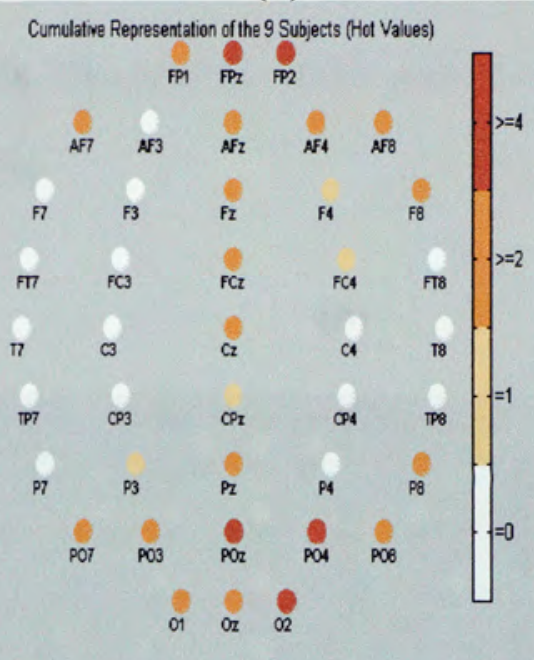

Figure 5.17. Hot Values Beta 1 Frequency

(a)

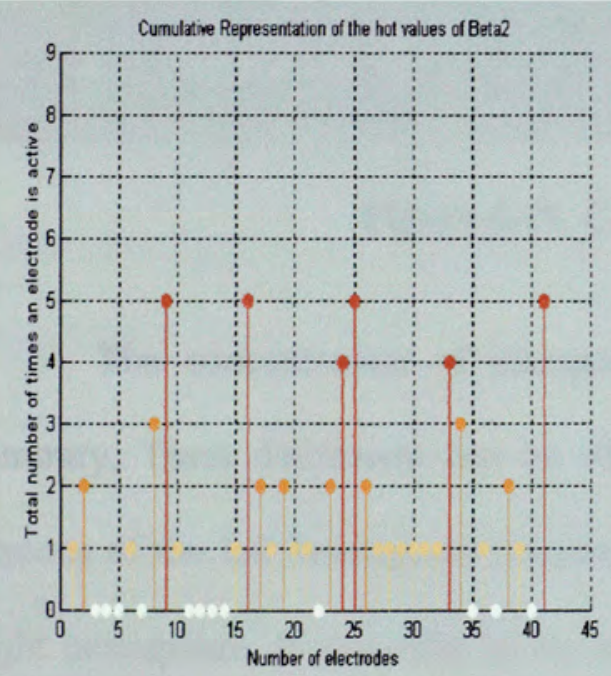

(b)

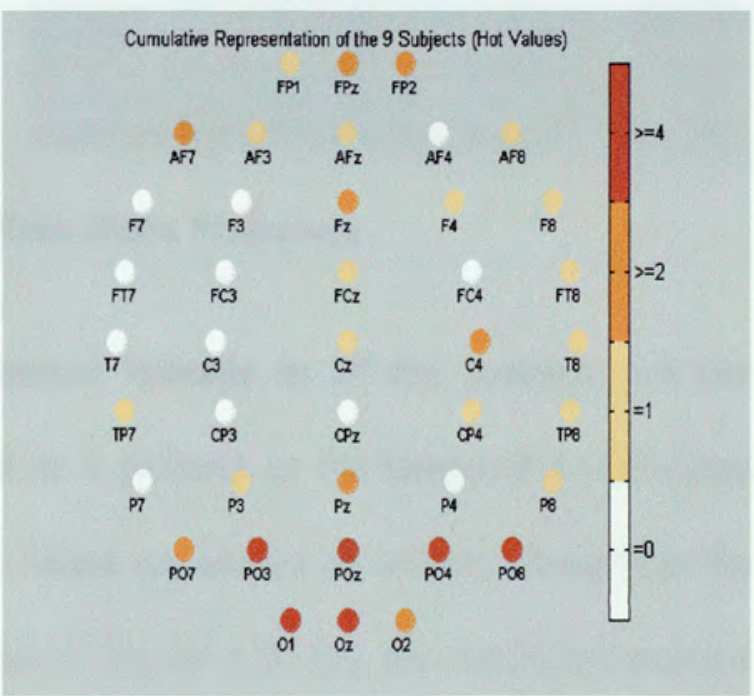

Figure 5.18. Hot Values Beta 2 Frequency

5.13 Cumulative Results Related to a Negative Change of Activity in the Auditory/Comprehension Task

Alpha frequency band has a decrement of activity with respect to the mean in 9 
subjects in the parietal region; 8 subjects have also an evident decrement of activity in the temporal region. In the temporal left and right lobes some activity can be observed, but it predominates in the left hemisphere (see Figure 5.19).

(a)

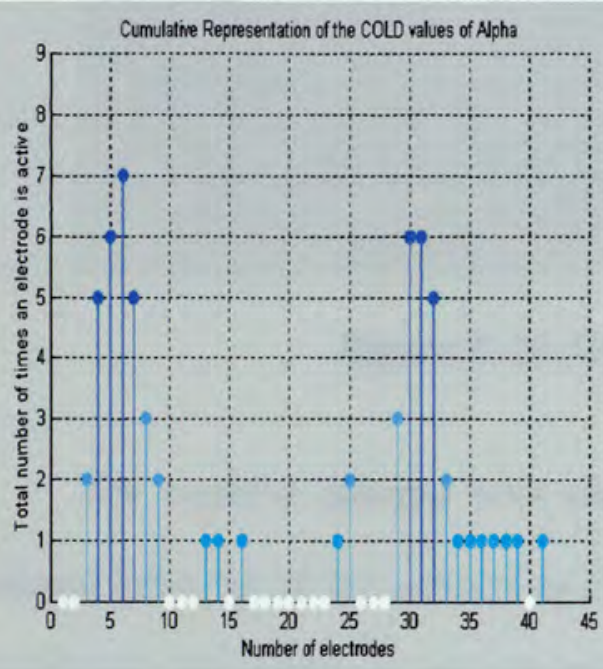

(b)

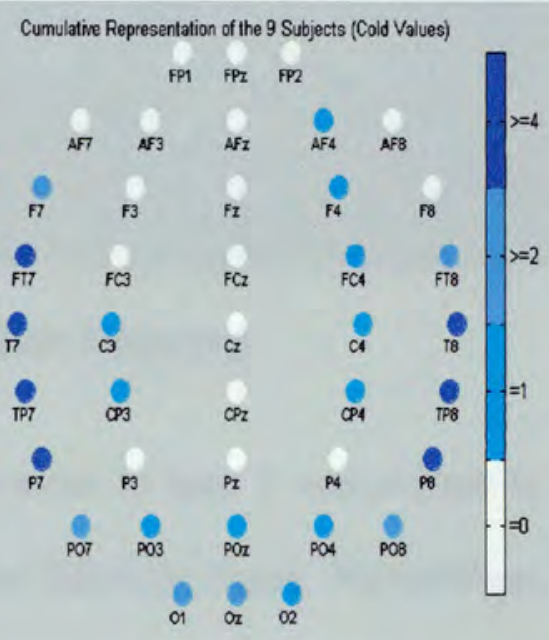

Figure 5.19. Cold Values Alpha Frequency

The concentration of changes is located laterally in all the patients. On the contrary, Theta decrement can be observed in 4 patients in the temporal and parietal regions of the left hemisphere (Figure 5.20). There are almost no activity changes in the right hemisphere. If you refer to the histogram in Figure 5.20 (a), the electrodes marked in light blue in the right hemisphere only refer to the activation of one patient. When weighting and judging the number of total electrodes active in each hemisphere, there are more electrodes marked dark blue in the left side than the right side. 
(a)

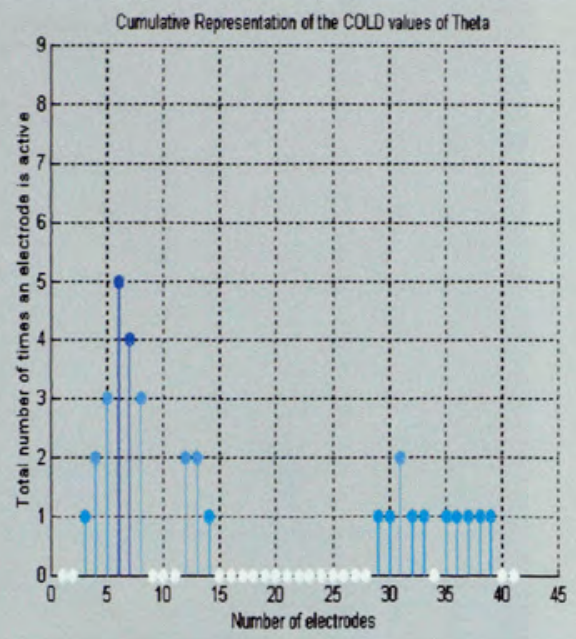

(b)

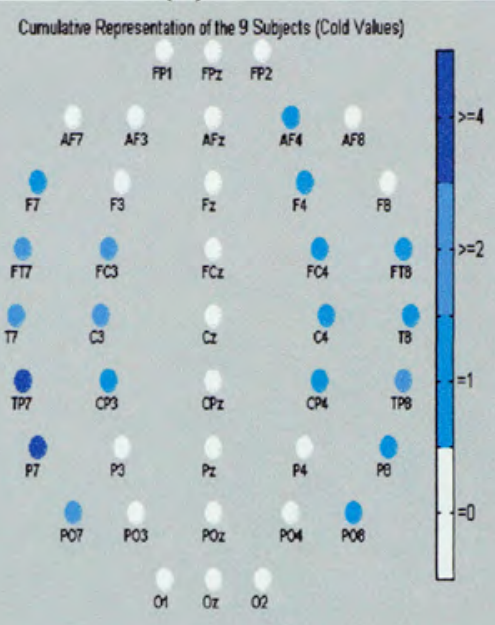

Figure 5. 20. Cold Values Theta Frequency

The negative changes with respect to the mean in beta 1 concentrate in both temporal lobes for all the patients as observed in the following figure. Nevertheless, beta 2 seems to concentrate in the left hemisphere as shown in the Figures 5.21 and 5.22. Electrodes $\mathrm{FT}_{7}, \mathrm{~T}_{7}$, and $\mathrm{TP}_{7}$ are the most active in most of the patients (more than 5 patients at a time).

(a)

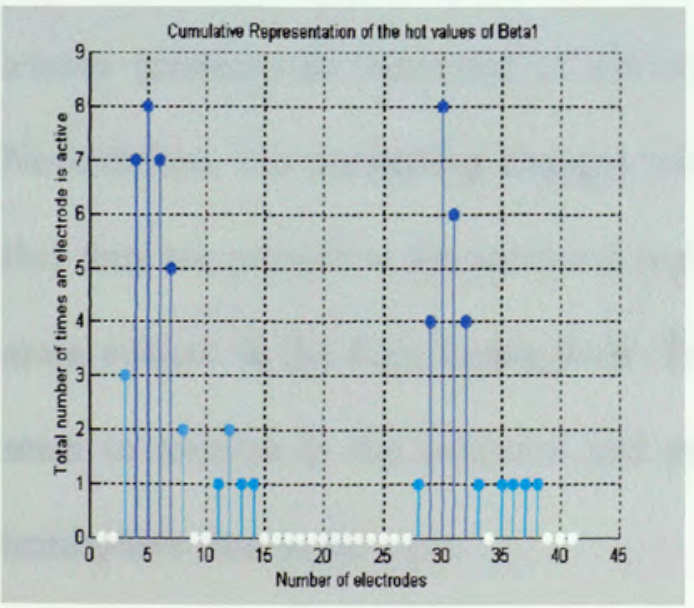

(b)

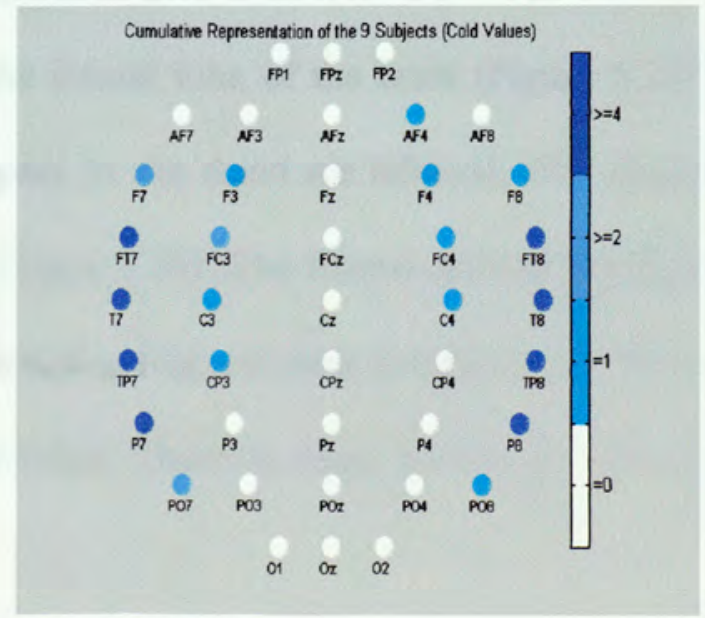

Figure 5. 21. Cold Values Beta 1 Frequency 
(a)

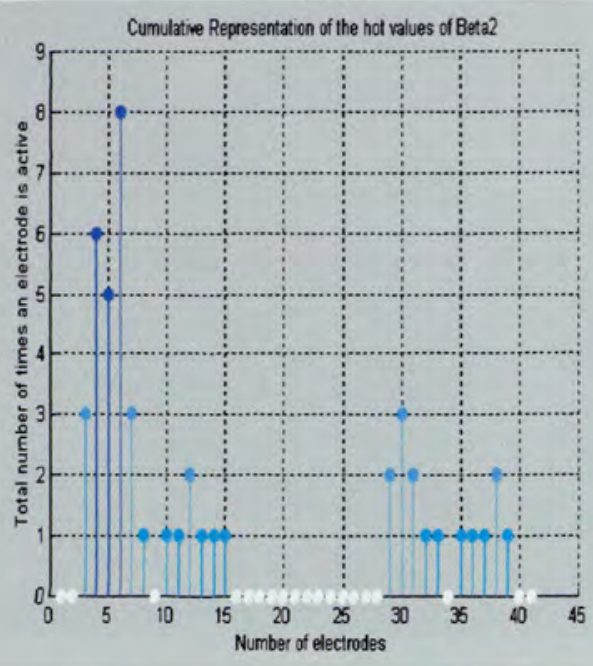

(b)

Cumulative Representation of the 9 Subjects (Cold Values)

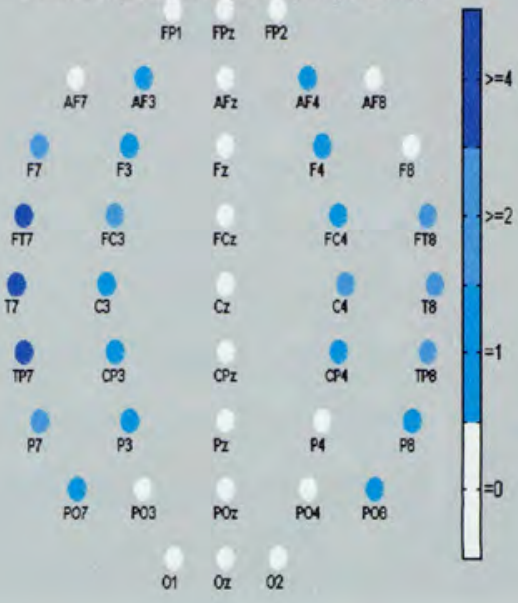

Figure 5. 22. Cold Values Beta 2 Frequency

5.16 Cumulative Results Related to a Positive and Negative Change of Activity in the Answering Task

In the response time the EEG signal is also well analyzed for each frequency band. As a general observation, the activity changes in alpha here are more projected to the frontal region, since the articulation when producing the words that form part of the answer produces an increment of activity in the frontal lobe of the brain (Figure 5.23). Nevertheless, the decreasing changes with respect to the mean are bilateral, that means that they are present in the temporal regions (Figure 5.24). The frontal activity is a little more evident in the right hemisphere. The decreasing changes with respect to the mean seem to localize in the temporal and parietal lobes. There is more activity in the left hemisphere than in the right. 
(a)

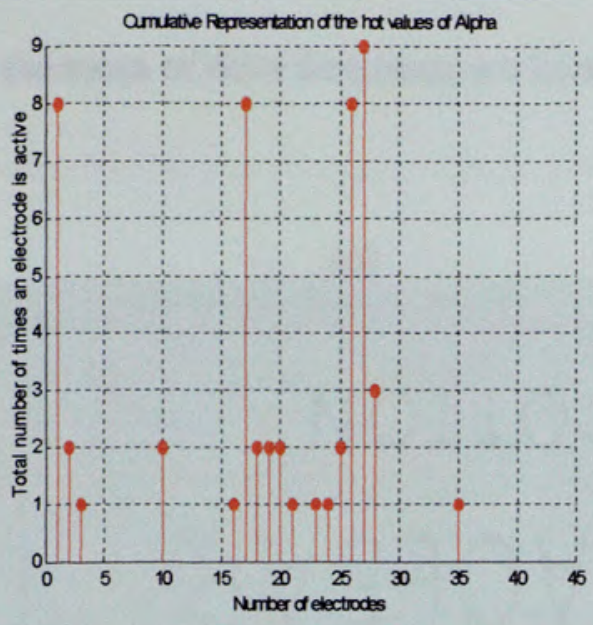

(b)

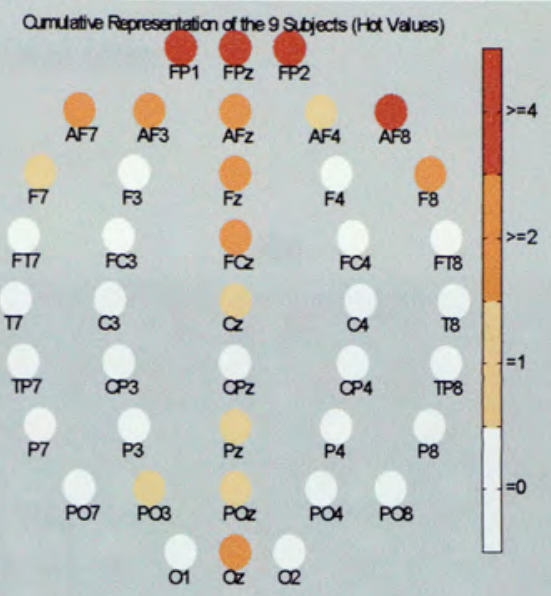

Figure 5. 23. Alpha Increasing Changes

(a)

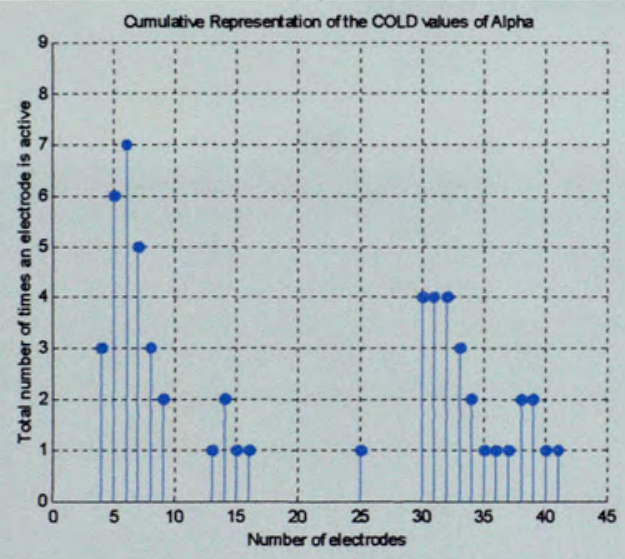

(b)

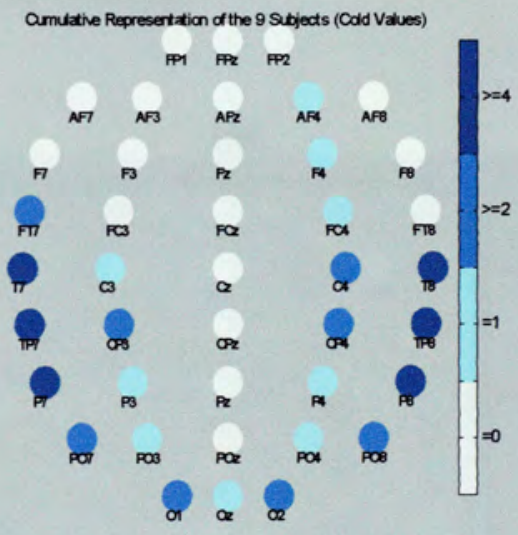

Figure 5. 24. Alpha Decreasing Changes

Delta frequency presents increasing changes localize bilateral in the frontal region. The activity is concentrated in the first two rows of the frontal lobe of the brain as shown in Figure 5.25. There are not too many decreasing changes appearing, but they seem to concentrate in the right hemisphere (Figure 5.26). There are no decreasing changes. Only two patients at the same time have some electrodes active in the central 
right cerebral cortex. In this case the localization of the increasing changes with respect to the mean of delta frequency are located in the frontal lobe.

(a)

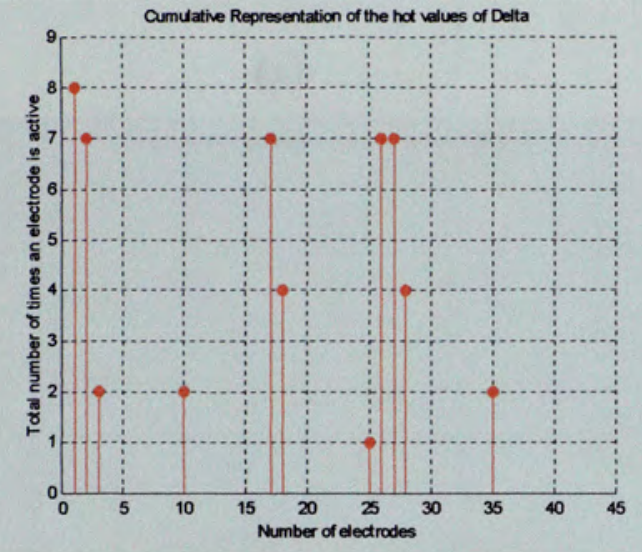

(b)

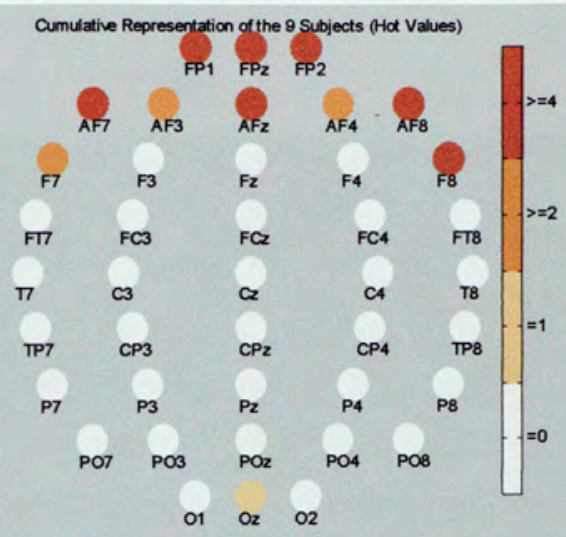

Figure 5. 25. Delta Increasing Changes

(a)

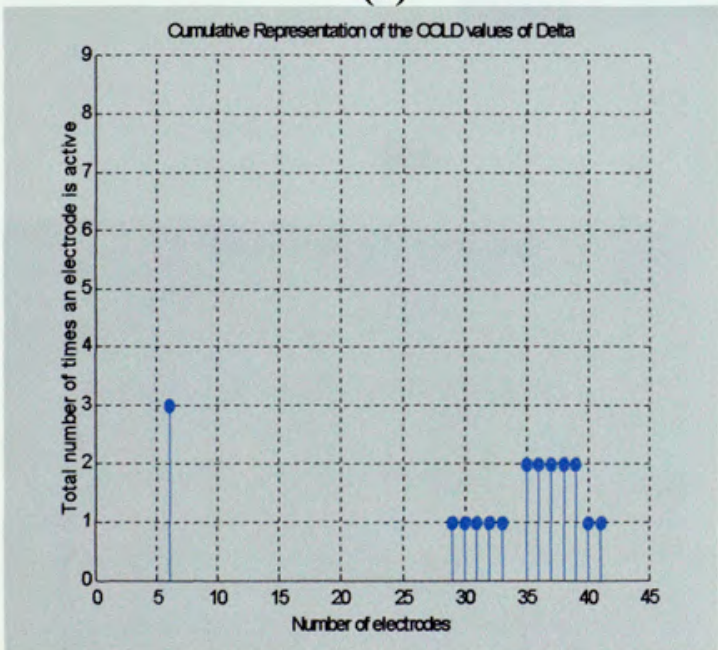

(b)

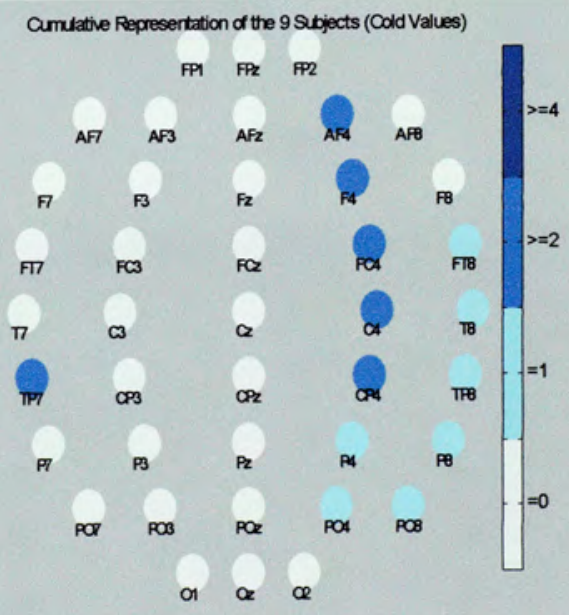

Figure 5.26. Delta Decreasing Changes

In the betal and beta 2 frequency bands, the increasing changes with respect to the mean are concentrated in the right hemisphere. The more concurrent electrodes 
involved are localized in the frontal and posterior lobe, which belong to the occipital region (see Figures 5.27 and 5.29). In figures 5.28 and 5.30, it is evident that the decreasing changes are concentrated in the left hemisphere.

(a)

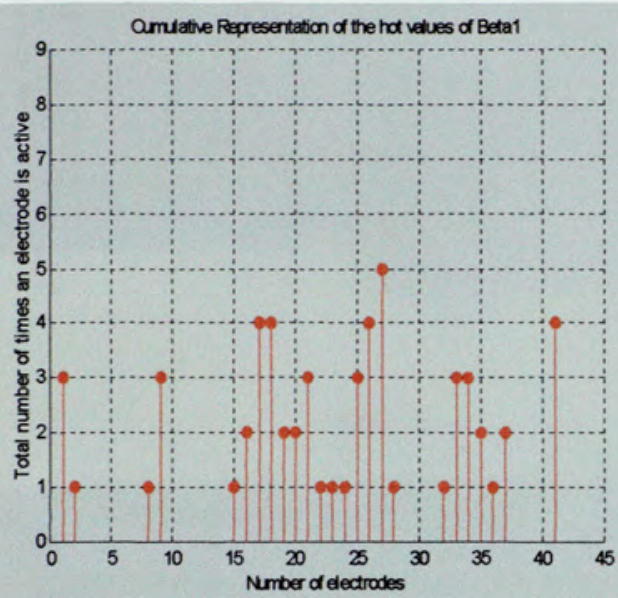

(b)

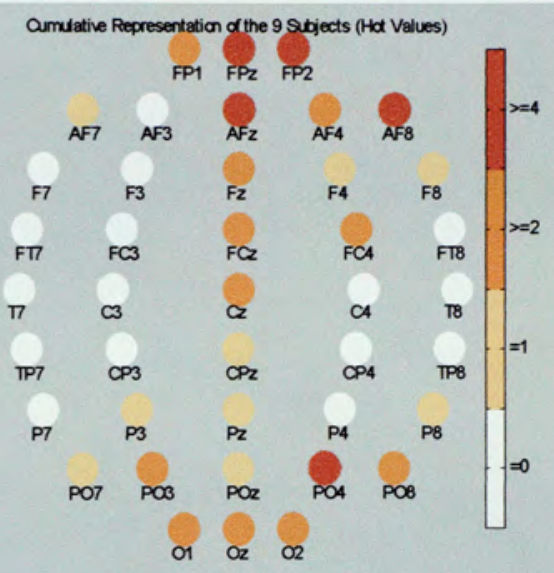

Figure 5.27. Beta 1 Increasing Changes

(a)

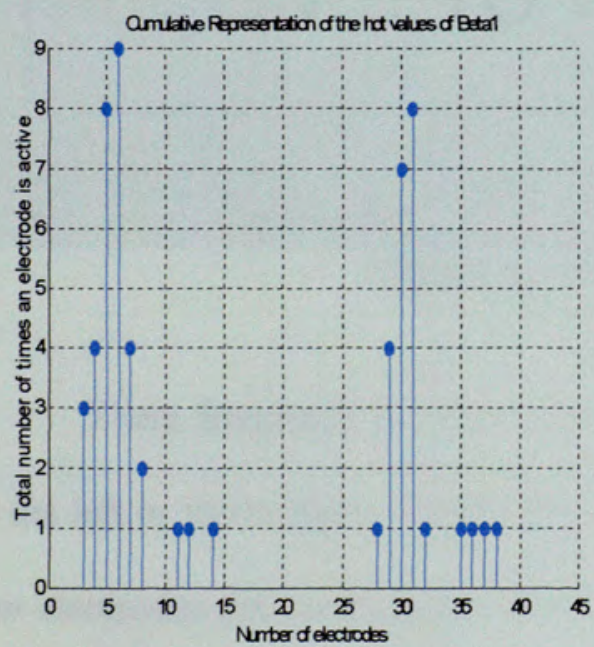

(b)

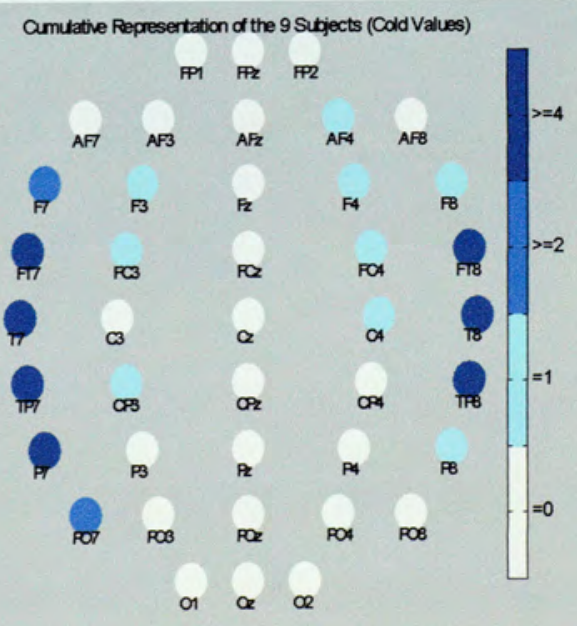

Figure 5. 28. Beta 1 Decreasing Changes 

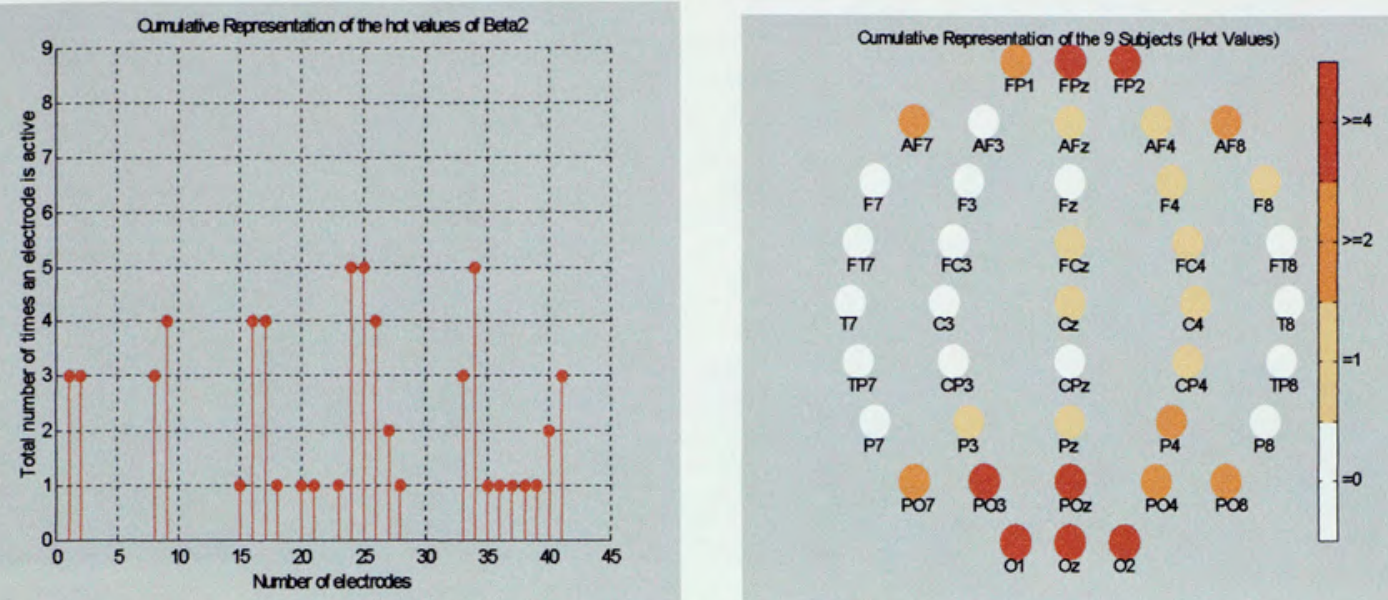

Figure 5.29. Beta 2 Increasing Changes

(a)

(b)
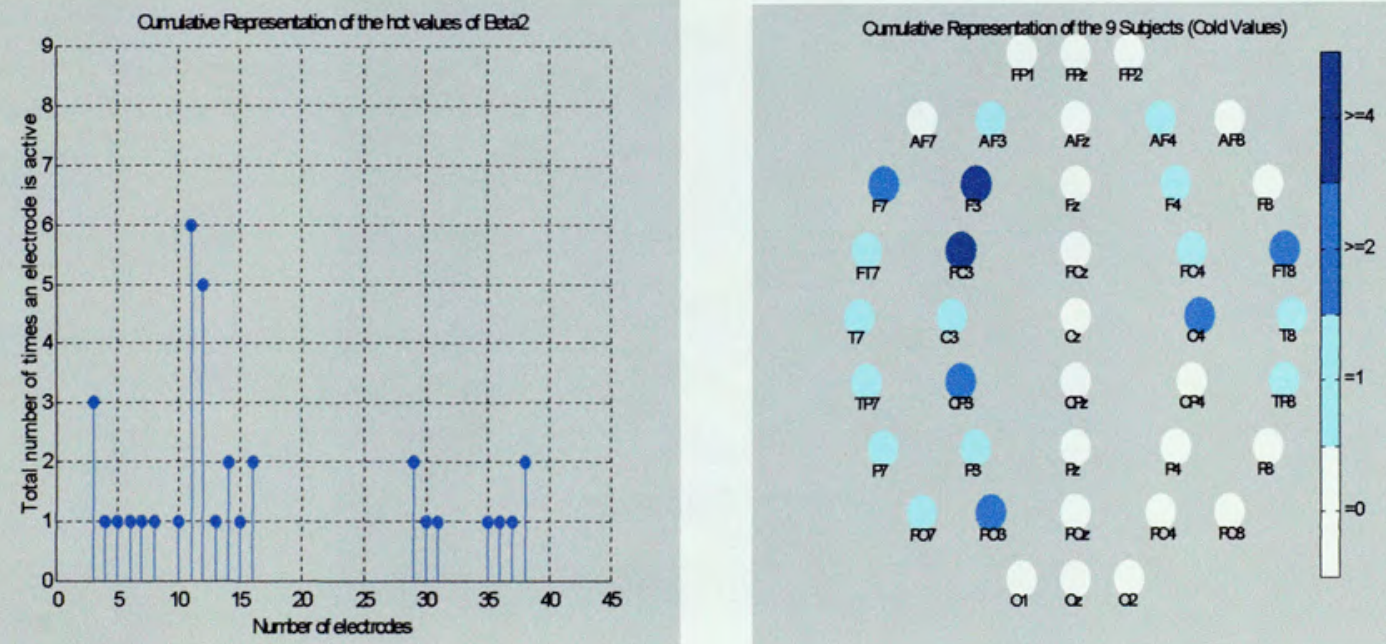

Figure 5.30. Beta 2 Decreasing Changes

Theta frequency band is also present most of the time in the frontal region either to the left or to the right. Nevertheless, there is not much decreasing activity present, only few electrodes are active some of the times, but not in most of the patients at the same time, so their activation is not relevant in statistical terms. 

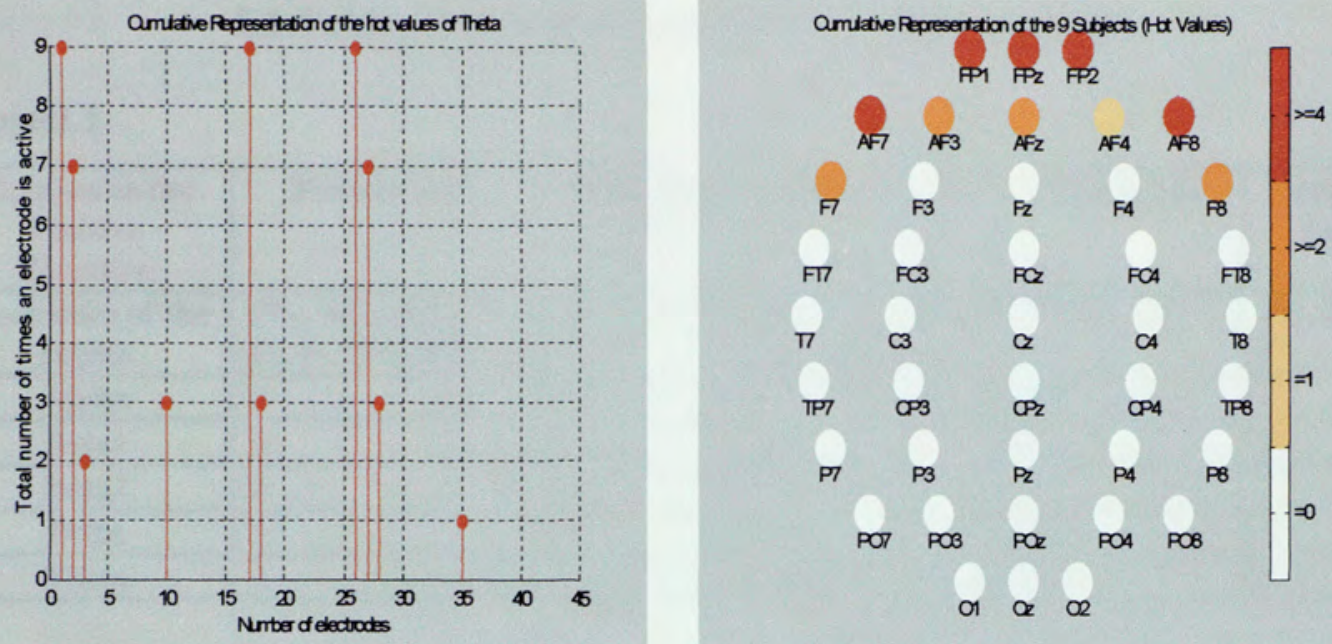

Figure 5.31. Theta Increasing Changes

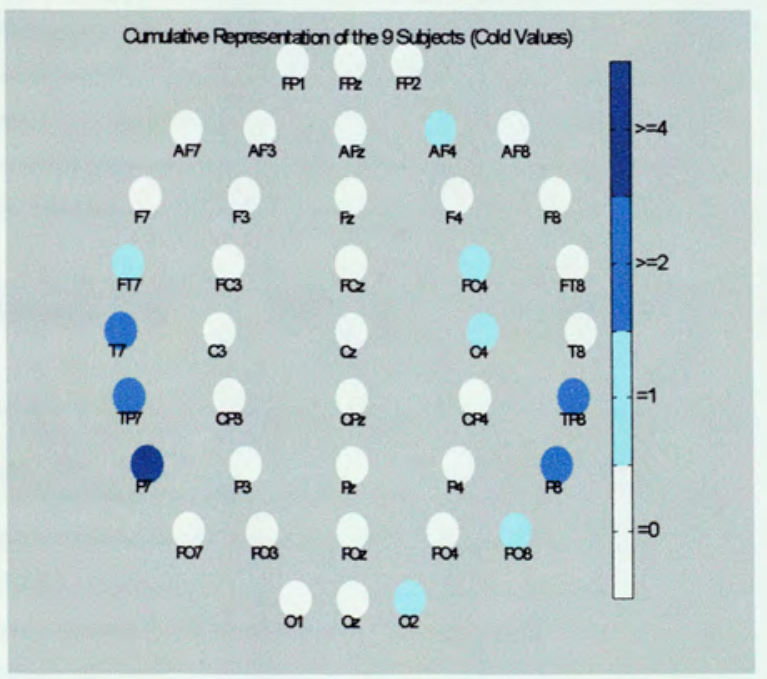

Figure 5.32. Theta Increasing Changes

\subsection{Tabulated Results of the Auditory/Comprehension Task}

The following results are tabulated for comparative analysis for all the 9 subjects for activities in both the positive and negative ranges. 
5.1 Table: Tabulated Positive Results (Auditory Task)

Subject 1

\begin{tabular}{|c|l|l|l|l|l|}
\hline $\begin{array}{c}\text { Changes in the } \\
\text { Positive } \\
\text { Direction }\end{array}$ & Frontal Left & $\begin{array}{c}\text { Temporal } \\
\text { Left }\end{array}$ & Parietal Left & Central Left & $\begin{array}{c}\text { Occipital } \\
\text { Left }\end{array}$ \\
\hline $\begin{array}{c}\text { Electrodes of the } \\
\text { region }\end{array}$ & $\begin{array}{l}\mathrm{FP}_{1}, \mathrm{AF}_{7}, \mathrm{AF}_{3}, \\
\mathrm{~F}_{7}, \mathrm{~F}_{3}, \mathrm{FC}_{3}, \mathrm{FT}_{7}\end{array}$ & $\mathrm{FT}_{7}, \mathrm{~T}_{7}, \mathrm{TP}_{7}$ & $\begin{array}{l}\mathrm{TP}_{7}, \mathrm{CP}_{3}, \mathrm{P}_{7}, \\
\mathrm{P}_{3}, \mathrm{PO}_{7}, \mathrm{PO}_{3}\end{array}$ & $\mathrm{FC}_{3}, \mathrm{C}_{3}, \mathrm{CP}_{3}$ & $\begin{array}{l}\mathrm{PO}_{7}, \mathrm{PO}_{3}, \\
\mathrm{O}_{1}\end{array}$ \\
\hline Alpha & 2 & 0 & 0 & 1 & 0 \\
\hline Beta1 & 0 & 0 & 0 & 0 & 1 \\
\hline Beta2 & 0 & 0 & 2 & 0 & 3 \\
\hline Delta & 3 & 0 & 0 & 0 & 0 \\
\hline Theta & 2 & 0 & 0 & 0 & 0 \\
\hline
\end{tabular}

\begin{tabular}{|c|l|l|l|l|l|}
\hline $\begin{array}{c}\text { Changes in the } \\
\text { Positive } \\
\text { Direction }\end{array}$ & \multicolumn{1}{|c|}{ Frontal Right } & \multicolumn{1}{|c|}{$\begin{array}{c}\text { Temporal } \\
\text { Right }\end{array}$} & \multicolumn{1}{|c|}{$\begin{array}{c}\text { Parietal } \\
\text { Right }\end{array}$} & \multicolumn{1}{c|}{$\begin{array}{c}\text { Central Right } \\
\text { Right }\end{array}$} \\
\hline $\begin{array}{c}\text { Electrodes of the } \\
\text { region }\end{array}$ & $\begin{array}{l}\mathrm{FP}_{2}, \mathrm{AF}_{4}, \mathrm{~F}_{8}, \mathrm{~F}_{4}, \\
\mathrm{~F}_{8}, \mathrm{FC}_{4}, \mathrm{FT}_{8}\end{array}$ & $\mathrm{FT}_{8}, \mathrm{~T}_{8}, \mathrm{TP}_{8}$ & $\begin{array}{l}\mathrm{TP}_{8}, \mathrm{CP}_{4}, \mathrm{P}_{8}, \\
\mathrm{P}_{4}, \mathrm{PO}_{8}, \mathrm{PO}_{4}\end{array}$ & $\mathrm{FC}_{4}, \mathrm{C}_{4}, \mathrm{CP}_{4}$ & $\begin{array}{l}\mathrm{PO}_{8}, \mathrm{PO}_{4}, \\
\mathrm{O}_{2}\end{array}$ \\
\hline Alpha & 2 & 0 & 0 & 0 & 0 \\
\hline Beta1 & 0 & 0 & 3 & 0 & 3 \\
\hline Beta2 & 0 & 0 & 2 & 0 & 3 \\
\hline Delta & 2 & 0 & 0 & 0 & 0 \\
\hline Theta & 2 & 0 & 0 & 0 & 0 \\
\hline
\end{tabular}

Subject 2

\begin{tabular}{|c|l|l|l|l|l|}
\hline $\begin{array}{c}\text { Changes in the } \\
\text { Positive } \\
\text { Direction }\end{array}$ & \multicolumn{1}{|c|}{ Frontal Left } & $\begin{array}{c}\text { Temporal } \\
\text { Left }\end{array}$ & Parietal Left & \multicolumn{1}{|c|}{ Central Left } & $\begin{array}{l}\text { Occipital } \\
\text { Left }\end{array}$ \\
\hline $\begin{array}{c}\text { Electrodes of the } \\
\text { region }\end{array}$ & $\begin{array}{l}\mathrm{FP}_{1}, \mathrm{AF}_{7}, \mathrm{AF}_{3}, \\
\mathrm{~F}_{7}, \mathrm{~F}_{3}, \mathrm{FC}_{3}, \mathrm{FT}_{7}\end{array}$ & $\mathrm{FT}_{7}, \mathrm{~T}_{7}, \mathrm{TP}_{7}$ & $\begin{array}{l}\mathrm{TP}_{7}, \mathrm{CP}_{3}, \mathrm{P}_{7}, \\
\mathrm{P}_{3}, \mathrm{PO}_{7}, \mathrm{PO}_{3}\end{array}$ & $\mathrm{FC}_{3}, \mathrm{C}_{3}, \mathrm{CP}_{3}$ & $\begin{array}{l}\mathrm{PO}_{7}, \mathrm{PO}_{3}, \\
\mathrm{O}_{1}\end{array}$ \\
\hline Alpha & 2 & 0 & 0 & 0 & 0 \\
\hline Beta1 & 0 & 0 & 0 & 0 & 0 \\
\hline Beta2 & 0 & 0 & 2 & 0 & 3 \\
\hline Delta & 2 & 0 & 0 & 0 & 0 \\
\hline Theta & 2 & 0 & 0 & 0 & 0 \\
\hline
\end{tabular}

\begin{tabular}{|c|l|l|l|l|l|}
\hline $\begin{array}{c}\text { Changes in the } \\
\text { Positive } \\
\text { Direction }\end{array}$ & Frontal Right & $\begin{array}{c}\text { Temporal } \\
\text { Right }\end{array}$ & \multicolumn{1}{|c|}{$\begin{array}{c}\text { Parietal } \\
\text { Right }\end{array}$} & Central Right & $\begin{array}{c}\text { Occipital } \\
\text { Right }\end{array}$ \\
\hline $\begin{array}{c}\text { Electrodes of the } \\
\text { region }\end{array}$ & $\begin{array}{l}\mathrm{FP}_{2}, \mathrm{AF}_{4}, \mathrm{~F}_{8}, \mathrm{~F}_{4}, \\
\mathrm{~F}_{8}, \mathrm{FC}_{4}, \mathrm{FT}_{8}\end{array}$ & $\mathrm{FT}_{8}, \mathrm{~T}_{8}, \mathrm{TP}_{8}$ & $\begin{array}{l}\mathrm{TP}_{8}, \mathrm{CP}_{4}, \mathrm{P}_{8}, \\
\mathrm{P}_{4}, \mathrm{PO}_{8}, \mathrm{PO}_{4}\end{array}$ & $\mathrm{FC}_{4}, \mathrm{C}_{4}, \mathrm{CP}_{4}$ & $\begin{array}{l}\mathrm{PO}_{8}, \mathrm{PO}_{4}, \\
\mathrm{O}_{2}\end{array}$ \\
\hline Alpha & 3 & 0 & 0 & 0 & 0 \\
\hline Beta1 & 4 & 0 & 0 & 0 & 0 \\
\hline Beta2 & 0 & 0 & 3 & 1 & 3 \\
\hline Delta & 2 & 0 & 0 & 0 & 0 \\
\hline Theta & 4 & 0 & 0 & 0 & 0 \\
\hline
\end{tabular}


Subject 3

\begin{tabular}{|c|l|l|l|l|l|}
\hline $\begin{array}{c}\text { Changes in the } \\
\text { Positive } \\
\text { Direction }\end{array}$ & \multicolumn{1}{|c|}{ Frontal Left } & $\begin{array}{c}\text { Temporal } \\
\text { Left }\end{array}$ & Parietal Left & Central Left & $\begin{array}{c}\text { Occipital } \\
\text { Left }\end{array}$ \\
\hline $\begin{array}{c}\text { Electrodes of the } \\
\text { region }\end{array}$ & $\begin{array}{l}\mathrm{FP}_{1}, \mathrm{AF}_{7}, \mathrm{AF}_{3}, \\
\mathrm{~F}_{7}, \mathrm{~F}_{3}, \mathrm{FC}_{3}, \mathrm{FT}_{7}\end{array}$ & $\mathrm{FT}_{7}, \mathrm{~T}_{7}, \mathrm{TP}_{7}$ & $\begin{array}{l}\mathrm{TP} \\
\mathrm{P} 3, \mathrm{CP} 3, \mathrm{PO} 7, \mathrm{PO} 3\end{array}$ & $\mathrm{FC} 3, \mathrm{C} 3, \mathrm{CP} 3$ & $\begin{array}{l}\mathrm{PO}_{7}, \mathrm{PO} 3, \\
\mathrm{O}_{1}\end{array}$ \\
\hline Alpha & 0 & 0 & 0 & 0 & 1 \\
\hline Beta1 & 0 & 0 & 0 & 0 & 0 \\
\hline Beta2 & 0 & 0 & 0 & 0 & 0 \\
\hline Delta & 4 & 0 & 0 & 0 & 0 \\
\hline Theta & 2 & 0 & 0 & 0 & 0 \\
\hline
\end{tabular}

\begin{tabular}{|c|c|c|c|c|c|}
\hline $\begin{array}{l}\text { Changes in the } \\
\text { Positive } \\
\text { Direction }\end{array}$ & Frontal Right & $\begin{array}{c}\text { Temporal } \\
\text { Right }\end{array}$ & $\begin{array}{c}\text { Parietal } \\
\text { Right }\end{array}$ & Central Right & $\begin{array}{c}\text { Occipital } \\
\text { Right }\end{array}$ \\
\hline $\begin{array}{l}\text { Electrodes of the } \\
\text { region }\end{array}$ & $\begin{array}{l}\mathrm{FP}_{2}, \mathrm{AF} 4, \mathrm{~F}_{8}, \mathrm{~F}_{4}, \\
\mathrm{~F}_{8}, \mathrm{FC} 4, \mathrm{FT}_{8}\end{array}$ & $\mathrm{FT}_{8}, \mathrm{~T}_{8}, \mathrm{TP}_{8}$ & $\begin{array}{l}\mathrm{TP}_{8}, \mathrm{CP}_{4}, \mathrm{P}_{8}, \\
\mathrm{P}_{4}, \mathrm{PO}_{8}, \mathrm{PO}_{4}\end{array}$ & $\mathrm{FC}_{4}, \mathrm{C}_{4}, \mathrm{CP}_{4}$ & $\begin{array}{l}\mathrm{PO}_{8}, \mathrm{PO}_{4}, \\
\mathrm{O}_{2}\end{array}$ \\
\hline Alpha & 2 & 0 & 0 & 0 & 0 \\
\hline Beta1 & 1 & 0 & 0 & 1 & 0 \\
\hline Beta2 & 1 & 0 & 1 & 0 & 1 \\
\hline Delta & 1 & 0 & 0 & 0 & 0 \\
\hline Theta & 1 & 0 & 0 & 0 & 0 \\
\hline
\end{tabular}

Subject 4

\begin{tabular}{|c|l|l|l|l|l|}
\hline $\begin{array}{c}\text { Changes in the } \\
\text { Positive } \\
\text { Direction }\end{array}$ & \multicolumn{1}{|c|}{ Frontal Left } & $\begin{array}{c}\text { Temporal } \\
\text { Left }\end{array}$ & Parietal Left & \multicolumn{1}{|c|}{ Central Left } & $\begin{array}{c}\text { Occipital } \\
\text { Left }\end{array}$ \\
\hline $\begin{array}{c}\text { Electrodes of the } \\
\text { region }\end{array}$ & $\begin{array}{l}\mathrm{FP}_{1}, \mathrm{AF}_{7}, \mathrm{AF}_{3}, \\
\mathrm{~F}_{7}, \mathrm{~F}_{3}, \mathrm{FC}_{3}, \mathrm{FT}_{7}\end{array}$ & $\mathrm{FT}_{7}, \mathrm{~T}_{7}, \mathrm{TP}_{7}$ & $\begin{array}{l}\mathrm{TP} \\
\mathrm{P} 3, \mathrm{CP} 3, \mathrm{PO} 7, \mathrm{PO} 3\end{array}$ & $\mathrm{FC} 3, \mathrm{C} 3, \mathrm{CP} 3$ & $\begin{array}{l}\mathrm{PO}_{7}, \mathrm{PO} 3, \\
\mathrm{O}_{1}\end{array}$ \\
\hline Alpha & 2 & 0 & 0 & 0 & 0 \\
\hline Beta1 & 2 & 0 & 0 & 0 & 0 \\
\hline Beta2 & 2 & 0 & 0 & 0 & 0 \\
\hline Delta & 2 & 0 & 0 & 0 & 0 \\
\hline Theta & 2 & 0 & 0 & 0 & 0 \\
\hline
\end{tabular}

\begin{tabular}{|c|l|l|l|l|l|}
\hline $\begin{array}{c}\text { Changes in the } \\
\text { Positive } \\
\text { Direction }\end{array}$ & Frontal Right & \multicolumn{1}{|c|}{$\begin{array}{c}\text { Temporal } \\
\text { Right }\end{array}$} & \multicolumn{1}{|c|}{$\begin{array}{c}\text { Parietal } \\
\text { Right }\end{array}$} & \multicolumn{1}{c|}{$\begin{array}{c}\text { Central Right } \\
\text { Right }\end{array}$} \\
\hline $\begin{array}{c}\text { Electrodes of the } \\
\text { region }\end{array}$ & $\begin{array}{l}\mathrm{FP}_{2}, \mathrm{AF}_{4}, \mathrm{~F}_{8}, \mathrm{~F}_{4}, \\
\mathrm{~F}_{8}, \mathrm{FC} 4, \mathrm{FT}_{8}\end{array}$ & $\mathrm{FT}_{8}, \mathrm{~T}_{8}, \mathrm{TP}_{8}$ & $\begin{array}{l}\mathrm{TP}_{8}, \mathrm{CP}_{4}, \mathrm{P}_{8}, \\
\mathrm{P}_{4}, \mathrm{PO}_{8}, \mathrm{PO}_{4}\end{array}$ & $\mathrm{FC}_{4}, \mathrm{C}_{4}, \mathrm{CP}_{4}$ & $\begin{array}{l}\mathrm{PO}_{8}, \mathrm{PO}_{4}, \\
\mathrm{O}_{2}\end{array}$ \\
\hline Alpha & 2 & 0 & 0 & 0 & 0 \\
\hline Beta1 & 3 & 0 & 0 & 0 & 0 \\
\hline Beta2 & 3 & 0 & 0 & 0 & 0 \\
\hline Delta & 3 & 0 & 0 & 0 & 0 \\
\hline Theta & 2 & 0 & 0 & 0 & 0 \\
\hline
\end{tabular}


Subject 5

\begin{tabular}{|c|l|l|l|l|l|}
\hline $\begin{array}{c}\text { Changes in the } \\
\text { Positive } \\
\text { Direction }\end{array}$ & \multicolumn{1}{|c|}{ Frontal Left } & $\begin{array}{c}\text { Temporal } \\
\text { Left }\end{array}$ & Parietal Left & \multicolumn{1}{|c|}{ Central Left } & $\begin{array}{c}\text { Occipital } \\
\text { Left }\end{array}$ \\
\hline $\begin{array}{c}\text { Electrodes of the } \\
\text { region }\end{array}$ & $\begin{array}{l}\mathrm{FP}_{1}, \mathrm{AF}_{7}, \mathrm{AF}_{3}, \\
\mathrm{~F}_{7}, \mathrm{~F}_{3}, \mathrm{FC}_{3}, \mathrm{FT}_{7}\end{array}$ & $\mathrm{FT}_{7}, \mathrm{~T}_{7}, \mathrm{TP}_{7}$ & $\begin{array}{l}\mathrm{TP} \\
\mathrm{P} 3, \mathrm{CP} 3, \mathrm{PO} 7, \mathrm{PO} 3\end{array}$ & $\mathrm{FC} 3, \mathrm{C} 3, \mathrm{CP} 3$ & $\begin{array}{l}\mathrm{PO}_{7}, \mathrm{PO} 3, \\
\mathrm{O}_{1}\end{array}$ \\
\hline Alpha & 0 & 0 & 0 & 0 & 0 \\
\hline Beta1 & 0 & 0 & 2 & 0 & 3 \\
\hline Beta2 & 0 & 0 & 1 & 0 & 2 \\
\hline Delta & 1 & 0 & 0 & 0 & 0 \\
\hline Theta & 1 & 0 & 0 & 0 & 0 \\
\hline
\end{tabular}

\begin{tabular}{|c|l|l|l|l|l|}
\hline $\begin{array}{c}\text { Changes in the } \\
\text { Positive } \\
\text { Direction }\end{array}$ & \multicolumn{1}{|c|}{ Frontal Right } & \multicolumn{1}{|c|}{$\begin{array}{c}\text { Temporal } \\
\text { Right }\end{array}$} & \multicolumn{1}{|c|}{$\begin{array}{c}\text { Parietal } \\
\text { Right }\end{array}$} & \multicolumn{1}{c|}{$\begin{array}{c}\text { Central Right } \\
\text { Right }\end{array}$} \\
\hline $\begin{array}{c}\text { Electrodes of the } \\
\text { region }\end{array}$ & $\begin{array}{l}\mathrm{FP}_{2}, \mathrm{AF}_{4}, \mathrm{~F}_{8}, \mathrm{~F}_{4}, \\
\mathrm{~F}_{8}, \mathrm{FC} 4, \mathrm{FT}_{8}\end{array}$ & $\mathrm{FT}_{8}, \mathrm{~T}_{8}, \mathrm{TP}_{8}$ & $\begin{array}{l}\mathrm{TP}_{8}, \mathrm{CP}_{4}, \mathrm{P}_{8}, \\
\mathrm{P}_{4}, \mathrm{PO}_{8}, \mathrm{PO}_{4}\end{array}$ & $\mathrm{FC}_{4}, \mathrm{C}_{4}, \mathrm{CP}_{4}$ & $\begin{array}{l}\mathrm{PO}_{8}, \mathrm{PO}_{4}, \\
\mathrm{O}_{2}\end{array}$ \\
\hline Alpha & 5 & 0 & 0 & 0 & 0 \\
\hline Beta1 & 1 & 0 & 1 & 0 & 1 \\
\hline Beta2 & 0 & 0 & 1 & 1 & 1 \\
\hline Delta & 4 & 0 & 0 & 0 & 0 \\
\hline Theta & 4 & 0 & 0 & 0 & 0 \\
\hline
\end{tabular}

Subject 6

\begin{tabular}{|c|l|l|l|l|l|}
\hline $\begin{array}{c}\text { Changes in the } \\
\text { Positive } \\
\text { Direction }\end{array}$ & Frontal Left & $\begin{array}{c}\text { Temporal } \\
\text { Left }\end{array}$ & Parietal Left & Central Left & $\begin{array}{l}\text { Occipital } \\
\text { Left }\end{array}$ \\
\hline $\begin{array}{c}\text { Electrodes of the } \\
\text { region }\end{array}$ & $\begin{array}{l}\mathrm{FP}_{1}, \mathrm{AF}_{7}, \mathrm{AF}_{3}, \\
\mathrm{~F}_{7}, \mathrm{~F}_{3}, \mathrm{FC}_{3}, \mathrm{FT}_{7}\end{array}$ & $\mathrm{FT}_{7}, \mathrm{~T}_{7}, \mathrm{TP}_{7}$ & $\begin{array}{l}\mathrm{TP} \\
\mathrm{P} 3, \mathrm{CP} 3, \mathrm{PO} 7, \mathrm{PO} 3\end{array}$ & $\mathrm{FC} 3, \mathrm{C} 3, \mathrm{CP} 3$ & $\begin{array}{l}\mathrm{PO}_{7}, \mathrm{PO} 3, \\
\mathrm{O}_{1}\end{array}$ \\
\hline Alpha & 3 & 0 & 0 & 0 & 0 \\
\hline Beta1 & 1 & 0 & 0 & 0 & 0 \\
\hline Beta2 & 1 & 0 & 0 & 0 & 0 \\
\hline Delta & 3 & 0 & 0 & 0 & 0 \\
\hline Theta & 3 & 0 & 0 & 0 & 0 \\
\hline
\end{tabular}

\begin{tabular}{|c|c|c|c|c|c|}
\hline $\begin{array}{c}\text { Changes in the } \\
\text { Positive } \\
\text { Direction }\end{array}$ & Frontal Right & $\begin{array}{c}\text { Temporal } \\
\text { Right }\end{array}$ & $\begin{array}{l}\text { Parietal } \\
\text { Right }\end{array}$ & Central Right & $\begin{array}{c}\text { Occipital } \\
\text { Right }\end{array}$ \\
\hline $\begin{array}{l}\text { Electrodes of the } \\
\text { region }\end{array}$ & $\begin{array}{l}\mathrm{FP}_{2}, \mathrm{AF} 4, \mathrm{~F}_{8}, \mathrm{~F}_{4}, \\
\mathrm{~F}_{8}, \mathrm{FC} 4, \mathrm{FT}_{8}\end{array}$ & $\mathrm{FT}_{8}, \mathrm{~T}_{8}, \mathrm{TP}_{8}$ & $\begin{array}{l}\mathrm{TP}_{8}, \mathrm{CP}_{4}, \mathrm{P}_{8}, \\
\mathrm{P}_{4}, \mathrm{PO}_{8}, \mathrm{PO}_{4}\end{array}$ & $\mathrm{FC}_{4}, \mathrm{C}_{4}, \mathrm{CP}_{4}$ & $\begin{array}{l}\mathrm{PO}_{8}, \mathrm{PO}_{4} \\
\mathrm{O}_{2}\end{array}$ \\
\hline Alpha & 2 & 0 & 0 & 0 & 0 \\
\hline Beta1 & 1 & 0 & 3 & 0 & 3 \\
\hline Beta2 & 1 & 0 & 0 & 0 & 0 \\
\hline Delta & 3 & 0 & 0 & 0 & 0 \\
\hline Theta & 3 & 0 & 0 & 0 & 0 \\
\hline
\end{tabular}


Subject 7

\begin{tabular}{|c|l|l|l|l|l|}
\hline $\begin{array}{c}\text { Changes in the } \\
\text { Positive } \\
\text { Direction }\end{array}$ & \multicolumn{1}{|c|}{ Frontal Left } & $\begin{array}{c}\text { Temporal } \\
\text { Left }\end{array}$ & Parietal Left & Central Left & $\begin{array}{c}\text { Occipital } \\
\text { Left }\end{array}$ \\
\hline $\begin{array}{c}\text { Electrodes of the } \\
\text { region }\end{array}$ & $\begin{array}{l}\mathrm{FP}_{1}, \mathrm{AF}_{7}, \mathrm{AF}_{3}, \\
\mathrm{~F}_{7}, \mathrm{~F}_{3}, \mathrm{FC}_{3}, \mathrm{FT}_{7}\end{array}$ & $\mathrm{FT}_{7}, \mathrm{~T}_{7}, \mathrm{TP}_{7}$ & $\begin{array}{l}\mathrm{TP} \\
\mathrm{P} 3, \mathrm{CP} 3, \mathrm{PO} 7, \mathrm{PO} 3\end{array}$ & $\mathrm{FC} 3, \mathrm{C} 3, \mathrm{CP} 3$ & $\begin{array}{l}\mathrm{PO}_{7}, \mathrm{PO} 3, \\
\mathrm{O}_{1}\end{array}$ \\
\hline Alpha & 4 & 0 & 0 & 0 & 0 \\
\hline Beta1 & 1 & 0 & 0 & 0 & 0 \\
\hline Beta2 & 1 & 0 & 1 & 0 & 2 \\
\hline Delta & 3 & 0 & 0 & 0 & 0 \\
\hline Theta & 4 & 0 & 0 & 0 & 0 \\
\hline
\end{tabular}

\begin{tabular}{|c|c|c|c|c|c|}
\hline $\begin{array}{c}\text { Changes in the } \\
\text { Positive } \\
\text { Direction }\end{array}$ & Frontal Right & $\begin{array}{c}\text { Temporal } \\
\text { Right }\end{array}$ & $\begin{array}{c}\text { Parietal } \\
\text { Right }\end{array}$ & Central Right & $\begin{array}{c}\text { Occipita } \\
\text { Right }\end{array}$ \\
\hline $\begin{array}{l}\text { Electrodes of the } \\
\text { region }\end{array}$ & $\begin{array}{l}\mathrm{FP}_{2}, \mathrm{AF} 4, \mathrm{~F}_{8}, \mathrm{~F}_{4}, \\
\mathrm{~F}_{8}, \mathrm{FC} 4, \mathrm{FT}_{8}\end{array}$ & $\mathrm{FT}_{8}, \mathrm{~T}_{8}, \mathrm{TP}_{8}$ & $\begin{array}{l}\mathrm{TP}_{8}, \mathrm{CP}_{4}, \mathrm{P}_{8}, \\
\mathrm{P}_{4}, \mathrm{PO}_{8}, \mathrm{PO}_{4}\end{array}$ & $\mathrm{FC}_{4}, \mathrm{C}_{4}, \mathrm{CP}_{4}$ & $\begin{array}{l}\mathrm{PO}_{8}, \mathrm{PO}_{4}, \\
\mathrm{O}_{2}\end{array}$ \\
\hline Alpha & 1 & 0 & 0 & 0 & 0 \\
\hline Beta1 & 3 & 0 & 0 & 0 & 0 \\
\hline Beta2 & 0 & 0 & 3 & 0 & 2 \\
\hline Delta & 3 & 0 & 0 & 0 & 0 \\
\hline Theta & 1 & 0 & 0 & 0 & 0 \\
\hline
\end{tabular}

\section{Subject 8}

\begin{tabular}{|c|l|l|l|l|l|}
\hline $\begin{array}{c}\text { Changes in the } \\
\text { Positive } \\
\text { Direction }\end{array}$ & \multicolumn{1}{|c|}{ Frontal Left } & $\begin{array}{c}\text { Temporal } \\
\text { Left }\end{array}$ & Parietal Left & Central Left & $\begin{array}{l}\text { Occipital } \\
\text { Left }\end{array}$ \\
\hline $\begin{array}{c}\text { Electrodes of the } \\
\text { region }\end{array}$ & $\begin{array}{l}\mathrm{FP}_{1}, \mathrm{AF}_{7}, \mathrm{AF}_{3}, \\
\mathrm{~F}_{7}, \mathrm{~F}_{3}, \mathrm{FC}_{3}, \mathrm{FT}_{7}\end{array}$ & $\mathrm{FT}_{7}, \mathrm{~T}_{7}, \mathrm{TP}_{7}$ & $\begin{array}{l}\mathrm{TP}_{7}, \mathrm{CP} 3, \mathrm{P} 7, \\
\mathrm{P} 3, \mathrm{PO} 7, \mathrm{PO} 3\end{array}$ & $\mathrm{FC} 3, \mathrm{C} 3, \mathrm{CP} 3$ & $\begin{array}{l}\mathrm{PO}_{7}, \mathrm{PO} 3, \\
\mathrm{O}_{7}\end{array}$ \\
\hline Alpha & 2 & 0 & 0 & 0 & 0 \\
\hline Beta1 & 1 & 0 & 1 & 0 & 1 \\
\hline Beta2 & 1 & 0 & 0 & 0 & 0 \\
\hline Delta & 2 & 0 & 0 & 0 & 0 \\
\hline Theta & 2 & 0 & 0 & 0 & 0 \\
\hline
\end{tabular}

\begin{tabular}{|c|l|l|l|l|l|}
\hline $\begin{array}{c}\text { Changes in the } \\
\text { Positive } \\
\text { Direction }\end{array}$ & Frontal Right & $\begin{array}{c}\text { Temporal } \\
\text { Right }\end{array}$ & \multicolumn{1}{|c|}{$\begin{array}{c}\text { Parietal } \\
\text { Right }\end{array}$} & Central Right & $\begin{array}{c}\text { Occipital } \\
\text { Right }\end{array}$ \\
\hline $\begin{array}{c}\text { Electrodes of the } \\
\text { region }\end{array}$ & $\begin{array}{l}\mathrm{FP}_{2}, \mathrm{AF}_{4}, \mathrm{~F}_{8}, \mathrm{~F}_{4}, \\
\mathrm{~F}_{8}, \mathrm{FC} 4, \mathrm{FT}_{8}\end{array}$ & $\mathrm{FT}_{8}, \mathrm{~T}_{8}, \mathrm{TP}_{8}$ & $\begin{array}{l}\mathrm{TP}_{8}, \mathrm{CP}_{4}, \mathrm{P}_{8}, \\
\mathrm{P}_{4}, \mathrm{PO}_{8}, \mathrm{PO}_{4}\end{array}$ & $\mathrm{FC}_{4}, \mathrm{C}_{4}, \mathrm{CP}_{4}$ & $\begin{array}{l}\mathrm{PO}_{8}, \mathrm{PO}_{4}, \\
\mathrm{O}_{2}\end{array}$ \\
\hline Alpha & 2 & 0 & 0 & 0 & 0 \\
\hline Beta1 & 1 & 0 & 0 & 0 & 1 \\
\hline Beta2 & 1 & 0 & 0 & 0 & 0 \\
\hline Delta & 1 & 0 & 0 & 0 & 0 \\
\hline Theta & 2 & 0 & 0 & 0 & 0 \\
\hline
\end{tabular}




\section{Subject 9}

\begin{tabular}{|c|c|c|c|c|c|}
\hline $\begin{array}{c}\text { Changes in the } \\
\text { Positive } \\
\text { Direction }\end{array}$ & Frontal Left & $\begin{array}{c}\text { Temporal } \\
\text { Left }\end{array}$ & Parietal Left & Central Left & $\begin{array}{c}\text { Occipital } \\
\text { Left }\end{array}$ \\
\hline $\begin{array}{l}\text { Electrodes of the } \\
\text { region }\end{array}$ & $\begin{array}{l}\mathrm{FP}_{1}, \mathrm{AF}_{7}, \mathrm{AF}_{3}, \\
\mathrm{~F}_{7}, \mathrm{~F}_{3}, \mathrm{FC}_{3}, \mathrm{FT}_{7}\end{array}$ & $\mathrm{FT}_{7}, \mathrm{~T}_{7}, \mathrm{TP}_{7}$ & $\begin{array}{l}\mathrm{TP}_{7}, \mathrm{CP} 3, \mathrm{P} 7 \\
\mathrm{P} 3, \mathrm{PO} 7, \mathrm{PO} 3\end{array}$ & $\mathrm{FC} 3, \mathrm{C} 3, \mathrm{CP} 3$ & $\begin{array}{l}\mathrm{PO}_{7}, \mathrm{PO} 3, \\
\mathrm{O}_{1}\end{array}$ \\
\hline Alpha & 1 & 0 & 0 & 0 & 0 \\
\hline Beta1 & 0 & 0 & 3 & 0 & 3 \\
\hline Beta2 & 0 & 0 & 3 & 0 & 3 \\
\hline Delta & 2 & 0 & 0 & 0 & 0 \\
\hline Theta & 2 & 0 & 0 & 0 & 0 \\
\hline
\end{tabular}

\begin{tabular}{|c|l|l|l|l|l|}
\hline $\begin{array}{c}\text { Changes in the } \\
\text { Positive } \\
\text { Direction }\end{array}$ & Frontal Right & \multicolumn{1}{|c|}{$\begin{array}{c}\text { Temporal } \\
\text { Right }\end{array}$} & \multicolumn{1}{|c|}{$\begin{array}{c}\text { Parietal } \\
\text { Right }\end{array}$} & \multicolumn{1}{c|}{$\begin{array}{c}\text { Central Right } \\
\text { Right }\end{array}$} \\
\hline $\begin{array}{c}\text { Electrodes of the } \\
\text { region }\end{array}$ & $\begin{array}{l}\mathrm{FP}_{2}, \mathrm{AF} 4, \mathrm{~F}_{8}, \mathrm{~F}_{4}, \\
\mathrm{~F}_{8}, \mathrm{FC} 4, \mathrm{FT}_{8}\end{array}$ & $\mathrm{FT}_{8}, \mathrm{~T}_{8}, \mathrm{TP}_{8}$ & $\begin{array}{l}\mathrm{TP}_{8}, \mathrm{CP}_{4}, \mathrm{P}_{8}, \\
\mathrm{P}_{4}, \mathrm{PO}_{8}, \mathrm{PO}_{4}\end{array}$ & $\mathrm{FC}_{4}, \mathrm{C}_{4}, \mathrm{CP}_{4}$ & $\begin{array}{l}\mathrm{PO}_{8}, \mathrm{PO}_{4}, \\
\mathrm{O}_{2}\end{array}$ \\
\hline Alpha & 2 & 0 & 0 & 0 & 0 \\
\hline Beta1 & 0 & 0 & 1 & 0 & 2 \\
\hline Beta2 & 0 & 0 & 1 & 0 & 2 \\
\hline Delta & 2 & 0 & 0 & 0 & 0 \\
\hline Theta & 2 & 0 & 0 & 0 & 0 \\
\hline
\end{tabular}

5.2 Table: Tabulated Negative Results (Auditory Task)

\section{Subject 1}

\begin{tabular}{|c|l|l|l|l|l|}
\hline $\begin{array}{c}\text { Changes in the } \\
\text { Negative } \\
\text { Direction }\end{array}$ & Frontal Left & $\begin{array}{c}\text { Temporal } \\
\text { Left }\end{array}$ & Parietal Left & Central Left & $\begin{array}{c}\text { Occipital } \\
\text { Left }\end{array}$ \\
\hline $\begin{array}{c}\text { Electrodes of the } \\
\text { region }\end{array}$ & $\begin{array}{l}\mathrm{FP}_{1}, \mathrm{AF}_{7}, \mathrm{AF}_{3}, \\
\mathrm{~F}_{7}, \mathrm{~F}_{3}, \mathrm{FC}_{3}, \mathrm{FT}_{7}\end{array}$ & $\mathrm{FT}_{7}, \mathrm{~T}_{7}, \mathrm{TP}_{7}$ & $\begin{array}{l}\mathrm{TP} \\
\mathrm{P} 3, \mathrm{CP} 3, \mathrm{PO} 7, \mathrm{PO} 3\end{array}$ & $\mathrm{FC} 3, \mathrm{C} 3, \mathrm{CP} 3$ & $\begin{array}{l}\mathrm{PO}_{7}, \mathrm{PO} 3, \\
\mathrm{O}_{1}\end{array}$ \\
\hline Alpha & 1 & 3 & 3 & 0 & 1 \\
\hline Beta1 & 2 & 3 & 2 & 0 & 0 \\
\hline Beta2 & 1 & 3 & 2 & 0 & 0 \\
\hline Delta & 0 & 1 & 2 & 0 & 0 \\
\hline Theta & 1 & 3 & 3 & 0 & 1 \\
\hline
\end{tabular}




\begin{tabular}{|c|l|l|l|l|l|}
\hline $\begin{array}{c}\text { Changes in the } \\
\text { Negative } \\
\text { Direction }\end{array}$ & \multicolumn{1}{|c|}{ Frontal Right } & \multicolumn{1}{|c|}{$\begin{array}{c}\text { Temporal } \\
\text { Right }\end{array}$} & \multicolumn{1}{|c|}{$\begin{array}{c}\text { Parietal } \\
\text { Right }\end{array}$} & $\begin{array}{l}\text { Central Right } \\
\text { Right }\end{array}$ \\
\hline $\begin{array}{c}\text { Electrodes of the } \\
\text { region }\end{array}$ & $\begin{array}{l}\mathrm{FP}_{2}, \mathrm{AF} 4, \mathrm{~F}_{8}, \mathrm{~F}_{4}, \\
\mathrm{~F}_{8}, \mathrm{FC} 4, \mathrm{FT}_{8}\end{array}$ & $\mathrm{FT}_{8}, \mathrm{~T}_{8}, \mathrm{TP}_{8}$ & $\begin{array}{l}\mathrm{TP}_{8}, \mathrm{CP}_{4}, \mathrm{P}_{8}, \\
\mathrm{P}_{4}, \mathrm{PO}_{8}, \mathrm{PO}_{4}\end{array}$ & $\mathrm{FC}_{4}, \mathrm{C}_{4}, \mathrm{CP}_{4}$ & $\begin{array}{l}\mathrm{PO}_{8}, \mathrm{PO}_{4}, \\
\mathrm{O}_{2}\end{array}$ \\
\hline Alpha & 0 & 0 & 2 & 0 & 1 \\
\hline Beta1 & 0 & 1 & 0 & 0 & 0 \\
\hline Beta2 & 0 & 0 & 0 & 0 & 0 \\
\hline Delta & 0 & 0 & 0 & 0 & 0 \\
\hline Theta & 0 & 0 & 2 & 0 & 1 \\
\hline
\end{tabular}

Subject 2

\begin{tabular}{|c|l|l|l|l|l|}
\hline $\begin{array}{c}\text { Changes in the } \\
\text { Negative } \\
\text { Direction }\end{array}$ & Frontal Left & \multicolumn{1}{|c|}{$\begin{array}{c}\text { Temporal } \\
\text { Left }\end{array}$} & Parietal Left & Central Left & $\begin{array}{c}\text { Occipital } \\
\text { Left }\end{array}$ \\
\hline $\begin{array}{c}\text { Electrodes of the } \\
\text { region }\end{array}$ & $\begin{array}{l}\mathrm{FP}_{1}, \mathrm{AF}_{7}, \mathrm{AF}_{3}, \\
\mathrm{~F}_{7}, \mathrm{~F}_{3}, \mathrm{FC}_{3}, \mathrm{FT}_{7}\end{array}$ & $\mathrm{FT}_{7}, \mathrm{~T}_{7}, \mathrm{TP}_{7}$ & $\begin{array}{l}\mathrm{TP} \\
\mathrm{P} 3, \mathrm{CP} 3, \mathrm{P} 7, \mathrm{PO} 3\end{array}$ & $\mathrm{FC} 3, \mathrm{C} 3, \mathrm{CP} 3$ & $\begin{array}{l}\mathrm{PO}_{7}, \mathrm{PO} 3, \\
\mathrm{O}_{7}\end{array}$ \\
\hline Alpha & 1 & 3 & 2 & 0 & 0 \\
\hline Beta1 & 1 & 3 & 2 & 0 & 0 \\
\hline Beta2 & 2 & 3 & 1 & 0 & 0 \\
\hline Delta & 0 & 0 & 0 & 0 & 0 \\
\hline Theta & 0 & 2 & 2 & 0 & 0 \\
\hline
\end{tabular}

\begin{tabular}{|c|c|c|c|c|c|}
\hline $\begin{array}{c}\text { Changes in the } \\
\text { Negative } \\
\text { Direction }\end{array}$ & Frontal Right & $\begin{array}{c}\text { Temporal } \\
\text { Right }\end{array}$ & $\begin{array}{c}\text { Parietal } \\
\text { Right }\end{array}$ & Central Right & $\begin{array}{c}\text { Occipital } \\
\text { Right }\end{array}$ \\
\hline $\begin{array}{l}\text { Electrodes of the } \\
\text { region }\end{array}$ & $\begin{array}{l}\mathrm{FP}_{2}, \mathrm{AF} 4, \mathrm{~F}_{8}, \mathrm{~F}_{4}, \\
\mathrm{~F}_{8}, \mathrm{FC} 4, \mathrm{FT}_{8}\end{array}$ & $\mathrm{FT}_{8}, \mathrm{~T}_{8}, \mathrm{TP}_{8}$ & $\begin{array}{l}\mathrm{TP}_{8}, \mathrm{CP}_{4}, \mathrm{P}_{8}, \\
\mathrm{P}_{4}, \mathrm{PO}_{8}, \mathrm{PO}_{4}\end{array}$ & $\mathrm{FC}_{4}, \mathrm{C}_{4}, \mathrm{CP}_{4}$ & $\begin{array}{l}\mathrm{PO}_{8}, \mathrm{PO}_{4}, \\
\mathrm{O}_{2}\end{array}$ \\
\hline Alpha & 0 & 2 & 2 & 0 & 0 \\
\hline Beta1 & 0 & 2 & 2 & 0 & 0 \\
\hline Beta2 & 0 & 1 & 0 & 0 & 0 \\
\hline Delta & 0 & 1 & 1 & 0 & 0 \\
\hline Theta & 0 & 0 & 0 & 0 & 0 \\
\hline
\end{tabular}

\section{Subject 3}

\begin{tabular}{|c|l|l|l|l|l|}
\hline $\begin{array}{c}\text { Changes in the } \\
\text { Negative } \\
\text { Direction }\end{array}$ & \multicolumn{1}{|c|}{ Frontal Left } & $\begin{array}{c}\text { Temporal } \\
\text { Left }\end{array}$ & Parietal Left & Central Left & $\begin{array}{c}\text { Occipital } \\
\text { Left }\end{array}$ \\
\hline $\begin{array}{c}\text { Electrodes of the } \\
\text { region }\end{array}$ & $\begin{array}{l}\mathrm{FP}_{1}, \mathrm{AF}_{7}, \mathrm{AF}_{3}, \\
\mathrm{~F}_{7}, \mathrm{~F}_{3}, \mathrm{FC}_{3}, \mathrm{FT}_{7}\end{array}$ & $\mathrm{FT}_{7}, \mathrm{~T}_{7}, \mathrm{TP}_{7}$ & $\begin{array}{l}\mathrm{TP} \\
\mathrm{P} 3, \mathrm{CP} 3, \mathrm{PO} 7,\end{array}$ & $\mathrm{FC}, \mathrm{C} 3, \mathrm{CP} 3$ & $\begin{array}{l}\mathrm{PO}_{7}, \mathrm{PO} 3, \\
\mathrm{O}_{1}\end{array}$ \\
\hline Alpha & 1 & 3 & 2 & 0 & 0 \\
\hline Beta1 & 1 & 3 & 3 & 0 & 1 \\
\hline Beta2 & 1 & 3 & 5 & 1 & 1 \\
\hline Delta & 0 & 0 & 0 & 0 & 0 \\
\hline Theta & 1 & 2 & 4 & 3 & 1 \\
\hline
\end{tabular}




\begin{tabular}{|c|l|l|l|l|l|}
\hline $\begin{array}{c}\text { Changes in the } \\
\text { Negative } \\
\text { Direction }\end{array}$ & \multicolumn{1}{|c|}{ Frontal Right } & \multicolumn{1}{|c|}{$\begin{array}{c}\text { Temporal } \\
\text { Right }\end{array}$} & \multicolumn{1}{|c|}{$\begin{array}{c}\text { Parietal } \\
\text { Right }\end{array}$} & Central Right & $\begin{array}{l}\text { Occipital } \\
\text { Right }\end{array}$ \\
\hline $\begin{array}{c}\text { Electrodes of the } \\
\text { region }\end{array}$ & $\begin{array}{l}\mathrm{FP}_{2}, \mathrm{AF} 4, \mathrm{~F}_{8}, \mathrm{~F}_{4}, \\
\mathrm{~F}_{8}, \mathrm{FC} 4, \mathrm{FT}_{8}\end{array}$ & $\mathrm{FT}_{8}, \mathrm{~T}_{8}, \mathrm{TP}_{8}$ & $\begin{array}{l}\mathrm{TP}_{8}, \mathrm{CP}_{4}, \mathrm{P}_{8}, \\
\mathrm{P}_{4}, \mathrm{PO}_{8}, \mathrm{PO}_{4}\end{array}$ & $\mathrm{FC}_{4}, \mathrm{C}_{4}, \mathrm{CP}_{4}$ & $\begin{array}{l}\mathrm{PO}_{8}, \mathrm{PO}_{4}, \\
\mathrm{O}_{2}\end{array}$ \\
\hline Alpha & 0 & 1 & 1 & 0 & 0 \\
\hline Beta1 & 0 & 2 & 2 & 0 & 0 \\
\hline Beta2 & 0 & 0 & 0 & 0 & 0 \\
\hline Delta & 0 & 0 & 0 & 0 & 0 \\
\hline Theta & 0 & 0 & 0 & 0 & 0 \\
\hline
\end{tabular}

\section{Subject 4}

\begin{tabular}{|c|l|l|l|l|l|}
\hline $\begin{array}{c}\text { Changes in the } \\
\text { Negative } \\
\text { Direction }\end{array}$ & Frontal Left & $\begin{array}{c}\text { Temporal } \\
\text { Left }\end{array}$ & Parietal Left & Central Left & $\begin{array}{c}\text { Occipital } \\
\text { Left }\end{array}$ \\
\hline $\begin{array}{c}\text { Electrodes of the } \\
\text { region }\end{array}$ & $\begin{array}{l}\mathrm{FP}_{1}, \mathrm{AF}_{7}, \mathrm{AF}_{3}, \\
\mathrm{~F}_{7}, \mathrm{~F}_{3}, \mathrm{FC}_{3}, \mathrm{FT}_{7}\end{array}$ & $\mathrm{FT}_{7}, \mathrm{~T}_{7}, \mathrm{TP}_{7}$ & $\begin{array}{l}\mathrm{TP}_{7}, \mathrm{CP} 3, \mathrm{P} 7, \\
\mathrm{P3}, \mathrm{PO} 7, \mathrm{PO} 3\end{array}$ & $\mathrm{FC} 3, \mathrm{C} 3, \mathrm{CP} 3$ & $\begin{array}{l}\mathrm{PO}_{7}, \mathrm{PO} 3, \\
\mathrm{O}_{1}\end{array}$ \\
\hline Alpha & 0 & 1 & 3 & 0 & 2 \\
\hline Beta1 & 0 & 1 & 3 & 0 & 1 \\
\hline Beta2 & 0 & 1 & 1 & 0 & 0 \\
\hline Delta & 0 & 0 & 0 & 0 & 0 \\
\hline Theta & 0 & 0 & 0 & 0 & 0 \\
\hline
\end{tabular}

\begin{tabular}{|c|c|c|c|c|c|}
\hline $\begin{array}{l}\text { Changes in the } \\
\text { Negative } \\
\text { Direction }\end{array}$ & Frontal Right & $\begin{array}{c}\text { Temporal } \\
\text { Right }\end{array}$ & $\begin{array}{l}\text { Parietal } \\
\text { Right }\end{array}$ & Central Right & $\begin{array}{c}\text { Occipital } \\
\text { Right }\end{array}$ \\
\hline $\begin{array}{l}\text { Electrodes of the } \\
\text { region }\end{array}$ & $\begin{array}{l}\mathrm{FP}_{2}, \mathrm{AF} 4, \mathrm{~F}_{8}, \mathrm{~F}_{4}, \\
\mathrm{~F}_{8}, \mathrm{FC} 4, \mathrm{FT}_{8}\end{array}$ & $\mathrm{FT}_{8}, \mathrm{~T}_{8}, \mathrm{TP}_{8}$ & $\begin{array}{l}\mathrm{TP}_{8}, \mathrm{CP}_{4}, \mathrm{P}_{8}, \\
\mathrm{P}_{4}, \mathrm{PO}_{8}, \mathrm{PO}_{4}\end{array}$ & $\mathrm{FC}_{4}, \mathrm{C}_{4}, \mathrm{CP}_{4}$ & $\begin{array}{l}\mathrm{PO}_{8}, \mathrm{PO}_{4}, \\
\mathrm{O}_{2}\end{array}$ \\
\hline Alpha & 1 & 3 & 3 & 0 & 1 \\
\hline Beta1 & 1 & 3 & 3 & 0 & 1 \\
\hline Beta2 & 0 & 1 & 3 & 0 & 1 \\
\hline Delta & 0 & 0 & 0 & 0 & 0 \\
\hline Theta & 0 & 0 & 0 & 0 & 0 \\
\hline
\end{tabular}

\section{Subject 5}

\begin{tabular}{|c|l|l|l|l|l|}
\hline $\begin{array}{c}\text { Changes in the } \\
\text { Negative } \\
\text { Direction }\end{array}$ & \multicolumn{1}{|c|}{ Frontal Left } & $\begin{array}{c}\text { Temporal } \\
\text { Left }\end{array}$ & Parietal Left & Central Left & $\begin{array}{l}\text { Occipital } \\
\text { Left }\end{array}$ \\
\hline $\begin{array}{c}\text { Electrodes of the } \\
\text { region }\end{array}$ & $\begin{array}{l}\mathrm{FP}_{1}, \mathrm{AF}_{7}, \mathrm{AF}_{3}, \\
\mathrm{~F}_{7}, \mathrm{~F}_{3}, \mathrm{FC}_{3}, \mathrm{FT}_{7}\end{array}$ & $\mathrm{FT}_{7}, \mathrm{~T}_{7}, \mathrm{TP}_{7}$ & $\begin{array}{l}\mathrm{TP} \\
\mathrm{P} 3, \mathrm{CP} 3, \mathrm{PO} 7, \mathrm{PO} 3\end{array}$ & $\mathrm{FC} 3, \mathrm{C} 3, \mathrm{CP} 3$ & $\begin{array}{l}\mathrm{PO}_{7}, \mathrm{PO} 3, \\
\mathrm{O}_{1}\end{array}$ \\
\hline Alpha & 2 & 3 & 2 & 2 & 0 \\
\hline Beta1 & 4 & 2 & 0 & 1 & 0 \\
\hline Beta2 & 5 & 2 & 0 & 1 & 0 \\
\hline Delta & 0 & 0 & 0 & 0 & 0 \\
\hline Theta & 3 & 2 & 0 & 2 & 0 \\
\hline
\end{tabular}




\begin{tabular}{|c|l|l|l|l|l|}
\hline $\begin{array}{c}\text { Changes in the } \\
\text { Negative } \\
\text { Direction }\end{array}$ & Frontal Right & $\begin{array}{c}\text { Temporal } \\
\text { Right }\end{array}$ & \multicolumn{1}{|c|}{$\begin{array}{c}\text { Parietal } \\
\text { Right }\end{array}$} & Central Right & $\begin{array}{c}\text { Occipital } \\
\text { Right }\end{array}$ \\
\hline $\begin{array}{c}\text { Electrodes of the } \\
\text { region }\end{array}$ & $\begin{array}{l}\mathrm{FP}_{2}, \mathrm{AF}_{4}, \mathrm{~F}_{8}, \mathrm{~F}_{4}, \\
\mathrm{~F}_{8}, \mathrm{FC} 4, \mathrm{FT}_{8}\end{array}$ & $\mathrm{FT}_{8}, \mathrm{~T}_{8}, \mathrm{TP}_{8}$ & $\begin{array}{l}\mathrm{TP}_{8}, \mathrm{CP}_{4}, \mathrm{P}_{8}, \\
\mathrm{P}_{4}, \mathrm{PO}_{8}, \mathrm{PO}_{4}\end{array}$ & $\mathrm{FC}_{4}, \mathrm{C}_{4}, \mathrm{CP}_{4}$ & $\begin{array}{l}\mathrm{PO}_{8}, \mathrm{PO}_{4}, \\
\mathrm{O}_{2}\end{array}$ \\
\hline Alpha & 0 & 2 & 1 & 0 & 0 \\
\hline Beta1 & 0 & 2 & 1 & 0 & 0 \\
\hline Beta2 & 0 & 0 & 0 & 0 & 0 \\
\hline Delta & 0 & 0 & 0 & 0 & 0 \\
\hline Theta & 0 & 1 & 1 & 0 & 0 \\
\hline
\end{tabular}

\section{Subject 6}

\begin{tabular}{|c|l|l|l|l|l|}
\hline $\begin{array}{c}\text { Changes in the } \\
\text { Negative } \\
\text { Direction }\end{array}$ & Frontal Left & $\begin{array}{c}\text { Temporal } \\
\text { Left }\end{array}$ & Parietal Left & \multicolumn{1}{|c|}{ Central Left } & $\begin{array}{c}\text { Occipital } \\
\text { Left }\end{array}$ \\
\hline $\begin{array}{c}\text { Electrodes of the } \\
\text { region }\end{array}$ & $\begin{array}{l}\mathrm{FP}_{1}, \mathrm{AF}_{7}, \mathrm{AF}_{3}, \\
\mathrm{~F}_{7}, \mathrm{~F}_{3}, \mathrm{FC}_{3}, \mathrm{FT}_{7}\end{array}$ & $\mathrm{FT}_{7}, \mathrm{~T}_{7}, \mathrm{TP}_{7}$ & $\begin{array}{l}\mathrm{TP} \\
\mathrm{P} 3, \mathrm{CP} 3, \mathrm{PO} 7, \mathrm{PO} 3\end{array}$ & $\mathrm{FC} 3, \mathrm{C} 3, \mathrm{CP} 3$ & $\begin{array}{l}\mathrm{PO}_{7}, \mathrm{PO} 3, \\
\mathrm{O}_{1}\end{array}$ \\
\hline Alpha & 0 & 2 & 2 & 0 & 0 \\
\hline Beta1 & 0 & 2 & 1 & 0 & 0 \\
\hline Beta2 & 0 & 1 & 1 & 0 & 0 \\
\hline Delta & 0 & 0 & 0 & 0 & 0 \\
\hline Theta & 0 & 0 & 0 & 0 & 0 \\
\hline
\end{tabular}

\begin{tabular}{|c|l|l|l|l|l|}
\hline $\begin{array}{c}\text { Changes in the } \\
\text { Negative } \\
\text { Direction }\end{array}$ & \multicolumn{1}{|c|}{ Frontal Right } & $\begin{array}{c}\text { Temporal } \\
\text { Right }\end{array}$ & \multicolumn{1}{|c|}{$\begin{array}{c}\text { Parietal } \\
\text { Right }\end{array}$} & Central Right & $\begin{array}{l}\text { Occipital } \\
\text { Right }\end{array}$ \\
\hline $\begin{array}{c}\text { Electrodes of the } \\
\text { region }\end{array}$ & $\begin{array}{l}\mathrm{FP}_{2}, \mathrm{AF} 4, \mathrm{~F}_{8}, \mathrm{~F}_{4}, \\
\mathrm{~F}_{8}, \mathrm{FC} 4, \mathrm{FT}_{8}\end{array}$ & $\mathrm{FT}_{8}, \mathrm{~T}_{8}, \mathrm{TP}_{8}$ & $\begin{array}{l}\mathrm{TP}_{8}, \mathrm{CP}_{4}, \mathrm{P}_{8}, \\
\mathrm{P}_{4}, \mathrm{PO}_{8}, \mathrm{PO}_{4}\end{array}$ & $\mathrm{FC}_{4}, \mathrm{C}_{4}, \mathrm{CP}_{4}$ & $\begin{array}{l}\mathrm{PO}_{8}, \mathrm{PO}_{4}, \\
\mathrm{O}_{2}\end{array}$ \\
\hline Alpha & 4 & 2 & 1 & 3 & 0 \\
\hline Beta1 & 4 & 2 & 0 & 2 & 0 \\
\hline Beta2 & 4 & 2 & 1 & 3 & 0 \\
\hline Delta & 3 & 0 & 0 & 2 & 0 \\
\hline Theta & 4 & 3 & 2 & 3 & 0 \\
\hline
\end{tabular}

\section{Subject 7}

\begin{tabular}{|c|l|l|l|l|l|}
\hline $\begin{array}{c}\text { Changes in the } \\
\text { Negative } \\
\text { Direction }\end{array}$ & Frontal Left & \multicolumn{1}{|c|}{$\begin{array}{c}\text { Temporal } \\
\text { Left }\end{array}$} & Parietal Left & Central Left & $\begin{array}{c}\text { Occipital } \\
\text { Left }\end{array}$ \\
\hline $\begin{array}{c}\text { Electrodes of the } \\
\text { region }\end{array}$ & $\begin{array}{l}\mathrm{FP}_{1}, \mathrm{AF}_{7}, \mathrm{AF}_{3}, \\
\mathrm{~F}_{7}, \mathrm{~F}_{3}, \mathrm{FC}_{3}, \mathrm{FT}_{7}\end{array}$ & $\mathrm{FT}_{7}, \mathrm{~T}_{7}, \mathrm{TP}_{7}$ & $\begin{array}{l}\mathrm{TP} \\
\mathrm{P}, \mathrm{CP} 3, \mathrm{PO} 7, \mathrm{PO} 3\end{array}$ & $\mathrm{FC} 3, \mathrm{C} 3, \mathrm{CP} 3$ & $\begin{array}{l}\mathrm{PO}_{7}, \mathrm{PO} 3, \\
\mathrm{O}_{1}\end{array}$ \\
\hline Alpha & 0 & 0 & 3 & 0 & 3 \\
\hline Beta1 & 2 & 3 & 3 & 3 & 0 \\
\hline Beta2 & 2 & 3 & 2 & 2 & 0 \\
\hline Delta & 0 & 0 & 0 & 0 & 0 \\
\hline Theta & 0 & 1 & 3 & 0 & 1 \\
\hline
\end{tabular}




\begin{tabular}{|c|l|l|l|l|l|}
\hline $\begin{array}{c}\text { Changes in the } \\
\text { Negative } \\
\text { Direction }\end{array}$ & \multicolumn{1}{|c|}{ Frontal Right } & $\begin{array}{c}\text { Temporal } \\
\text { Right }\end{array}$ & \multicolumn{1}{|c|}{$\begin{array}{c}\text { Parietal } \\
\text { Right }\end{array}$} & \multicolumn{1}{c|}{$\begin{array}{c}\text { Central Right } \\
\text { Right }\end{array}$} \\
\hline $\begin{array}{c}\text { Electrodes of the } \\
\text { region }\end{array}$ & $\begin{array}{l}\mathrm{FP}_{2}, \mathrm{AF}_{4}, \mathrm{~F}_{8}, \mathrm{~F}_{4}, \\
\mathrm{~F}_{8}, \mathrm{FC}, \mathrm{FT}_{8}\end{array}$ & $\mathrm{FT}_{8}, \mathrm{~T}_{8}, \mathrm{TP}_{8}$ & $\begin{array}{l}\mathrm{TP}_{8}, \mathrm{CP}_{4}, \mathrm{P}_{8}, \\
\mathrm{P}_{4}, \mathrm{PO}_{8}, \mathrm{PO}_{4}\end{array}$ & $\mathrm{FC}_{4}, \mathrm{C}_{4}, \mathrm{CP}_{4}$ & $\begin{array}{l}\mathrm{PO}_{8}, \mathrm{PO}_{4}, \\
\mathrm{O}_{2}\end{array}$ \\
\hline Alpha & 0 & 0 & 1 & 0 & 2 \\
\hline Beta1 & 0 & 0 & 0 & 0 & 0 \\
\hline Beta2 & 0 & 0 & 0 & 0 & 0 \\
\hline Delta & 0 & 0 & 0 & 0 & 0 \\
\hline Theta & 0 & 0 & 0 & 0 & 0 \\
\hline
\end{tabular}

\section{Subject 8}

\begin{tabular}{|c|l|l|l|l|l|}
\hline $\begin{array}{c}\text { Changes in the } \\
\text { Negative } \\
\text { Direction }\end{array}$ & \multicolumn{1}{|c|}{ Frontal Left } & $\begin{array}{c}\text { Temporal } \\
\text { Left }\end{array}$ & Parietal Left & Central Left & $\begin{array}{c}\text { Occipital } \\
\text { Left }\end{array}$ \\
\hline $\begin{array}{c}\text { Electrodes of the } \\
\text { region }\end{array}$ & $\begin{array}{l}\mathrm{FP}_{1}, \mathrm{AF}_{7}, \mathrm{AF}_{3}, \\
\mathrm{~F}_{7}, \mathrm{~F}_{3}, \mathrm{FC}_{3}, \mathrm{FT}_{7}\end{array}$ & $\mathrm{FT}_{7}, \mathrm{~T}_{7}, \mathrm{TP}_{7}$ & $\begin{array}{l}\mathrm{TP}_{7}, \mathrm{CP} 3, \mathrm{P} 7, \\
\mathrm{P} 3, \mathrm{PO} 7, \mathrm{PO} 3\end{array}$ & $\mathrm{FC}, \mathrm{C} 3, \mathrm{CP} 3$ & $\begin{array}{l}\mathrm{PO}_{7}, \mathrm{PO} 3, \\
\mathrm{O}_{1}\end{array}$ \\
\hline Alpha & 0 & 0 & 0 & 0 & 0 \\
\hline Beta1 & 1 & 3 & 1 & 0 & 0 \\
\hline Beta2 & 0 & 1 & 1 & 0 & 0 \\
\hline Delta & 0 & 0 & 0 & 0 & 0 \\
\hline Theta & 0 & 0 & 0 & 0 & 0 \\
\hline
\end{tabular}

\begin{tabular}{|c|l|l|l|l|l|}
\hline $\begin{array}{c}\text { Changes in the } \\
\text { Negative } \\
\text { Direction }\end{array}$ & \multicolumn{1}{|c|}{ Frontal Right } & $\begin{array}{c}\text { Temporal } \\
\text { Right }\end{array}$ & \multicolumn{1}{|c|}{$\begin{array}{c}\text { Parietal } \\
\text { Right }\end{array}$} & Central Right & $\begin{array}{c}\text { Occipital } \\
\text { Right }\end{array}$ \\
\hline $\begin{array}{c}\text { Electrodes of the } \\
\text { region }\end{array}$ & $\begin{array}{l}\mathrm{FP}_{2}, \mathrm{AF}_{4}, \mathrm{~F}_{8}, \mathrm{~F}_{4}, \\
\mathrm{~F}_{8}, \mathrm{FC}, \mathrm{FT}_{8}\end{array}$ & $\mathrm{FT}_{8}, \mathrm{~T}_{8}, \mathrm{TP}_{8}$ & $\begin{array}{l}\mathrm{TP}_{8}, \mathrm{CP}_{4}, \mathrm{P}_{8}, \\
\mathrm{P}_{4}, \mathrm{PO}_{8}, \mathrm{PO}_{4}\end{array}$ & $\mathrm{FC}_{4}, \mathrm{C}_{4}, \mathrm{CP}_{4}$ & $\begin{array}{l}\mathrm{PO}_{8}, \mathrm{PO}_{4}, \\
\mathrm{O}_{2}\end{array}$ \\
\hline Alpha & 0 & 2 & 2 & 0 & 0 \\
\hline Beta1 & 1 & 3 & 2 & 0 & 0 \\
\hline Beta2 & 1 & 3 & 1 & 1 & 0 \\
\hline Delta & 4 & 3 & 6 & 3 & 2 \\
\hline Theta & 0 & 0 & 0 & 0 & 0 \\
\hline
\end{tabular}

\section{Subject 9}

\begin{tabular}{|c|l|l|l|l|l|}
\hline $\begin{array}{c}\text { Changes in the } \\
\text { Negative } \\
\text { Direction }\end{array}$ & Frontal Left & $\begin{array}{c}\text { Temporal } \\
\text { Left }\end{array}$ & Parietal Left & Central Left & $\begin{array}{c}\text { Occipital } \\
\text { Left }\end{array}$ \\
\hline $\begin{array}{c}\text { Electrod } \\
\text { es of the } \\
\text { region }\end{array}$ & $\begin{array}{l}\mathrm{FP}_{1}, \mathrm{AF}_{7}, \mathrm{AF}_{3}, \\
\mathrm{~F}_{3}, \mathrm{FC}_{3}, \mathrm{FT}_{7}\end{array}$ & $\mathrm{FT}_{7}, \mathrm{~T}_{7}, \mathrm{TP}_{7}$ & $\begin{array}{l}\mathrm{TP}_{7}, \mathrm{CP} 3, \mathrm{P} 7, \\
\mathrm{P} 3, \mathrm{PO} 7, \mathrm{PO} 3\end{array}$ & $\mathrm{FC}, \mathrm{C} 3, \mathrm{CP} 3$ & $\begin{array}{l}\mathrm{PO}_{7}, \mathrm{PO}_{3}, \\
\mathrm{O}_{1}\end{array}$ \\
\hline Alpha & 2 & 3 & 2 & 0 & 0 \\
\hline Beta1 & 2 & 3 & 1 & 0 & 0 \\
\hline Beta2 & 2 & 2 & 1 & 0 & 0 \\
\hline Delta & 0 & 0 & 0 & 0 & 0 \\
\hline Theta & 0 & 1 & 1 & 0 & 0 \\
\hline
\end{tabular}




\begin{tabular}{|c|l|l|l|l|l|}
\hline $\begin{array}{c}\text { Changes in the } \\
\text { Negative } \\
\text { Direction }\end{array}$ & Frontal Right & $\begin{array}{c}\text { Temporal } \\
\text { Right }\end{array}$ & \multicolumn{1}{|c|}{$\begin{array}{c}\text { Parietal } \\
\text { Right }\end{array}$} & Central Right & $\begin{array}{c}\text { Occipital } \\
\text { Right }\end{array}$ \\
\hline $\begin{array}{c}\text { Electrodes of the } \\
\text { region }\end{array}$ & $\begin{array}{l}\mathrm{FP}_{2}, \mathrm{AF}_{4}, \mathrm{~F}_{8}, \mathrm{~F}_{4}, \\
\mathrm{~F}_{8}, \mathrm{FC} 4, \mathrm{FT}_{8}\end{array}$ & $\mathrm{FT}_{8}, \mathrm{~T}_{8}, \mathrm{TP}_{8}$ & $\begin{array}{l}\mathrm{TP}_{8}, \mathrm{CP}_{4}, \mathrm{P}_{8}, \\
\mathrm{P}_{4}, \mathrm{PO}_{8}, \mathrm{PO}_{4}\end{array}$ & $\mathrm{FC}_{4}, \mathrm{C}_{4}, \mathrm{CP}_{4}$ & $\begin{array}{l}\mathrm{PO}_{8}, \mathrm{PO}_{4}, \\
\mathrm{O}_{2}\end{array}$ \\
\hline Alpha & 1 & 3 & 2 & 0 & 0 \\
\hline Beta1 & 2 & 3 & 1 & 0 & 0 \\
\hline Beta2 & 0 & 0 & 0 & 0 & 0 \\
\hline Delta & 0 & 0 & 0 & 0 & 0 \\
\hline Theta & 0 & 0 & 0 & 0 & 0 \\
\hline
\end{tabular}

The detailed tables show the regions in the brain divided in sub-regions. This way a more comprehensive analysis could be accomplished. In the frontal lobe of the brain, Alpha frequency shows consistently an increment of activity for all subjects in the two first rows of electrodes (FP's and AF's). On the other hand, a decrement of brain activity is observed in most of the subjects in the frontal central and frontal temporal regions. Delta frequency shows a significant change in the positive direction in the 3 first rows of electrodes (FP's, F's, AF's) in almost all patients. A negative change is not presented for this specific frequency band. Theta band also shows a positive change in the first three rows of the frontal region (FP's, F's, AF's) and no negative changes.

Alpha band has less activity in the temporal left and temporal right regions of the brain. Since most of the subjects were right-handed, there is more change of activity in the left side than the right side. A positive change of activity is not visible in the right side of the brain. For theta band there is a slight change of negative activity in the left temporal lobe.

So far, the results obtained from the research indicate that the frontal and temporal lobes are more implicated with these activities involving auditory comprehension tasks. 


\section{15 Tabulated Results of the Answering Task}

The active electrodes that represent an increment with respect to the mean in the response time seem to concentrate in the frontal region. Since the articulation of the mouth at the time of responding will affect the EEG recordings, the activity is evidently concentrated in the frontal left and frontal right regions of the brain. Almost all the frequency bands reveal some kind of activity in the frontal lobe. Next, all the tables for the response time are provided for all the subjects and again for both positive and negative changes.

The decreasing changes with respect to the mean seem to localize in the temporal lobes of the brain. Alpha frequency activity is distributed to both sides, specifically in the right and left temporal lobes. Beta 1 and Beta 2 are more concentrated in the left temporal region. These results coincide with each other; there is similar response in all the patients analyzed in this research.

5.3 Table: Tabulated Positive Results (Answering Task)

\section{Subject 1}

\begin{tabular}{|c|l|l|l|l|l|}
\hline $\begin{array}{c}\text { Changes in the } \\
\text { Positive } \\
\text { Direction }\end{array}$ & Frontal Left & $\begin{array}{c}\text { Temporal } \\
\text { Left }\end{array}$ & Parietal Left & Central Left & $\begin{array}{l}\text { Occipital } \\
\text { Left }\end{array}$ \\
\hline $\begin{array}{c}\text { Electrodes of the } \\
\text { region }\end{array}$ & $\begin{array}{l}\mathrm{FP}_{1}, \mathrm{AF}_{7}, \mathrm{AF}_{3}, \\
\mathrm{~F}_{7}, \mathrm{~F}_{3}, \mathrm{FC}_{3}, \mathrm{FT}_{7}\end{array}$ & $\mathrm{FT}_{7}, \mathrm{~T}_{7}, \mathrm{TP}_{7}$ & $\begin{array}{l}\mathrm{TP}_{7}, \mathrm{CP}_{3}, \mathrm{P}_{7}, \\
\mathrm{P}_{3}, \mathrm{PO}_{7}, \mathrm{PO}_{3}\end{array}$ & $\mathrm{FC}_{3}, \mathrm{C}_{3}, \mathrm{CP}_{3}$ & $\begin{array}{l}\mathrm{PO}_{7}, \mathrm{PO}_{3}, \\
\mathrm{O}_{1}\end{array}$ \\
\hline Alpha & 3 & 0 & 0 & 0 & 0 \\
\hline Beta1 & 0 & 0 & 0 & 0 & 1 \\
\hline Beta2 & 0 & 0 & 2 & 0 & 3 \\
\hline Delta & 3 & 0 & 0 & 0 & 0 \\
\hline Theta & 2 & 0 & 0 & 0 & 0 \\
\hline
\end{tabular}




\begin{tabular}{|c|c|c|c|c|c|}
\hline $\begin{array}{c}\text { Changes in the } \\
\text { Positive } \\
\text { Direction }\end{array}$ & Frontal Right & $\begin{array}{l}\text { Temporal } \\
\text { Right }\end{array}$ & $\begin{array}{c}\text { Parietal } \\
\text { Right }\end{array}$ & Central Right & $\begin{array}{c}\text { Occipital } \\
\text { Right }\end{array}$ \\
\hline $\begin{array}{l}\text { Electrodes of the } \\
\text { region }\end{array}$ & $\begin{array}{l}\mathrm{FP}_{2}, \mathrm{AF}_{4}, \mathrm{~F}_{8}, \mathrm{~F}_{4}, \\
\mathrm{~F}_{8}, \mathrm{FC}_{4}, \mathrm{FT}_{8}\end{array}$ & $\mathrm{FT}_{8}, \mathrm{~T}_{8}, \mathrm{TP}_{8}$ & $\begin{array}{l}\mathrm{TP}_{8}, \mathrm{CP}_{4}, \mathrm{P}_{8} \\
\mathrm{P}_{4}, \mathrm{PO}_{8}, \mathrm{PO}_{4}\end{array}$ & $\mathrm{FC}_{4}, \mathrm{C}_{4}, \mathrm{CP}_{4}$ & $\begin{array}{l}\mathrm{PO}_{8}, \mathrm{PO}_{4}, \\
\mathrm{O}_{2}\end{array}$ \\
\hline Alpha & 1 & 0 & 0 & 0 & 0 \\
\hline Beta1 & 0 & 0 & 2 & 0 & 2 \\
\hline Beta2 & 0 & 0 & 0 & 0 & 1 \\
\hline Delta & 1 & 0 & 0 & 0 & 0 \\
\hline Theta & 1 & 0 & 0 & 0 & 0 \\
\hline
\end{tabular}

\section{Subject 2}

\begin{tabular}{|c|l|l|l|l|l|}
\hline $\begin{array}{c}\text { Changes in the } \\
\text { Positive } \\
\text { Direction }\end{array}$ & \multicolumn{1}{|c|}{ Frontal Left } & $\begin{array}{c}\text { Temporal } \\
\text { Left }\end{array}$ & Parietal Left & Central Left & $\begin{array}{c}\text { Occipital } \\
\text { Left }\end{array}$ \\
\hline $\begin{array}{c}\text { Electrodes of the } \\
\text { region }\end{array}$ & $\begin{array}{l}\mathrm{FP}_{1}, \mathrm{AF}_{7}, \mathrm{AF}_{3}, \\
\mathrm{~F}_{7}, \mathrm{~F}_{3}, \mathrm{FC}_{3}, \mathrm{FT}_{7}\end{array}$ & $\mathrm{FT}_{7}, \mathrm{~T}_{7}, \mathrm{TP}_{7}$ & $\begin{array}{l}\mathrm{TP}_{7}, \mathrm{CP}_{3}, \mathrm{P}_{7}, \\
\mathrm{P}_{3}, \mathrm{PO}_{7}, \mathrm{PO}_{3}\end{array}$ & $\mathrm{FC}_{3}, \mathrm{C}_{3}, \mathrm{CP}_{3}$ & $\begin{array}{l}\mathrm{PO}_{7}, \mathrm{PO}_{3}, \\
\mathrm{O}_{1}\end{array}$ \\
\hline Alpha & 2 & 0 & 0 & 0 & 0 \\
\hline Beta1 & 0 & 0 & 0 & 0 & 0 \\
\hline Beta2 & 0 & 0 & 2 & 0 & 3 \\
\hline Delta & 2 & 0 & 0 & 0 & 0 \\
\hline Theta & 2 & 0 & 0 & 0 & 0 \\
\hline
\end{tabular}

\begin{tabular}{|c|l|l|l|l|l|}
\hline $\begin{array}{c}\text { Changes in the } \\
\text { Positive } \\
\text { Direction }\end{array}$ & \multicolumn{1}{|c|}{ Frontal Right } & $\begin{array}{c}\text { Temporal } \\
\text { Right }\end{array}$ & \multicolumn{1}{|c|}{$\begin{array}{c}\text { Parietal } \\
\text { Right }\end{array}$} & Central Right & $\begin{array}{c}\text { Occipital } \\
\text { Right }\end{array}$ \\
\hline $\begin{array}{c}\text { Electrodes of the } \\
\text { region }\end{array}$ & $\begin{array}{l}\mathrm{FP}_{2}, \mathrm{AF} 4, \mathrm{~F}_{8}, \mathrm{~F}_{4}, \\
\mathrm{~F}_{8}, \mathrm{FC} 4, \mathrm{FT}_{8}\end{array}$ & $\mathrm{FT}_{8}, \mathrm{~T}_{8}, \mathrm{TP}_{8}$ & $\begin{array}{l}\mathrm{TP}_{8}, \mathrm{CP}_{4}, \mathrm{P}_{8}, \\
\mathrm{P}_{4}, \mathrm{PO}_{8}, \mathrm{PO}_{4}\end{array}$ & $\mathrm{FC}_{4}, \mathrm{C}_{4}, \mathrm{CP}_{4}$ & $\begin{array}{l}\mathrm{PO}_{8}, \mathrm{PO}_{4}, \\
\mathrm{O}_{2}\end{array}$ \\
\hline Alpha & 2 & 0 & 0 & 0 & 0 \\
\hline Beta1 & 2 & 0 & 0 & 0 & 0 \\
\hline Beta2 & 0 & 0 & 3 & 0 & 3 \\
\hline Delta & 4 & 0 & 0 & 0 & 0 \\
\hline Theta & 2 & 0 & 0 & 0 & 0 \\
\hline
\end{tabular}

\section{Subject 3}

\begin{tabular}{|c|l|l|l|l|l|}
\hline $\begin{array}{c}\text { Changes in the } \\
\text { Positive } \\
\text { Direction }\end{array}$ & \multicolumn{1}{|c|}{ Frontal Left } & $\begin{array}{c}\text { Temporal } \\
\text { Left }\end{array}$ & Parietal Left & Central Left & $\begin{array}{c}\text { Occipital } \\
\text { Left }\end{array}$ \\
\hline $\begin{array}{c}\text { Electrodes of the } \\
\text { region }\end{array}$ & $\begin{array}{l}\mathrm{FP}_{1}, \mathrm{AF}_{7}, \mathrm{AF}_{3}, \\
\mathrm{~F}_{7}, \mathrm{~F}_{3}, \mathrm{FC}_{3}, \mathrm{FT}_{7}\end{array}$ & $\mathrm{FT}_{7}, \mathrm{~T}_{7}, \mathrm{TP}_{7}$ & $\begin{array}{l}\mathrm{TP} \\
\mathrm{P} 3, \mathrm{CP} 3, \mathrm{P} 7, \mathrm{PO} 3\end{array}$ & $\mathrm{FC}, \mathrm{C} 3, \mathrm{CP} 3$ & $\begin{array}{l}\mathrm{PO}_{7}, \mathrm{PO} 3, \\
\mathrm{O}_{1}\end{array}$ \\
\hline Alpha & 2 & 0 & 0 & 0 & 0 \\
\hline Beta1 & 0 & 0 & 0 & 0 & 0 \\
\hline Beta2 & 0 & 0 & 0 & 0 & 0 \\
\hline Delta & 3 & 0 & 0 & 0 & 0 \\
\hline Theta & 3 & 0 & 0 & 0 & 0 \\
\hline
\end{tabular}




\begin{tabular}{|c|c|c|c|c|c|}
\hline $\begin{array}{l}\text { Changes in the } \\
\text { Positive } \\
\text { Direction }\end{array}$ & Frontal Right & $\begin{array}{c}\text { Temporal } \\
\text { Right }\end{array}$ & $\begin{array}{c}\text { Parietal } \\
\text { Right }\end{array}$ & Central Right & $\begin{array}{c}\text { Occipital } \\
\text { Right }\end{array}$ \\
\hline $\begin{array}{l}\text { Electrodes of the } \\
\text { region }\end{array}$ & $\begin{array}{l}\mathrm{FP}_{2}, \mathrm{AF} 4, \mathrm{~F}_{8}, \mathrm{~F}_{4}, \\
\mathrm{~F}_{8}, \mathrm{FC} 4, \mathrm{FT}_{8}\end{array}$ & $\mathrm{FT}_{8}, \mathrm{~T}_{8}, \mathrm{TP}_{8}$ & $\begin{array}{l}\mathrm{TP}_{8}, \mathrm{CP}_{4}, \mathrm{P}_{8} \\
\mathrm{P}_{4}, \mathrm{PO}_{8}, \mathrm{PO}_{4}\end{array}$ & $\mathrm{FC}_{4}, \mathrm{C}_{4}, \mathrm{CP}_{4}$ & $\begin{array}{l}\mathrm{PO}_{8}, \mathrm{PO}_{4}, \\
\mathrm{O}_{2}\end{array}$ \\
\hline Alpha & 2 & 0 & 0 & 0 & 0 \\
\hline Beta1 & 2 & 0 & 0 & 1 & 0 \\
\hline Beta2 & 3 & 0 & 1 & 1 & 1 \\
\hline Delta & 1 & 0 & 0 & 0 & 0 \\
\hline Theta & 1 & 0 & 0 & 0 & 0 \\
\hline
\end{tabular}

\section{Subject 4}

\begin{tabular}{|c|l|l|l|l|l|}
\hline $\begin{array}{c}\text { Changes in the } \\
\text { Positive } \\
\text { Direction }\end{array}$ & \multicolumn{1}{|c|}{ Frontal Left } & $\begin{array}{c}\text { Temporal } \\
\text { Left }\end{array}$ & Parietal Left & \multicolumn{1}{|c|}{ Central Left } & $\begin{array}{c}\text { Occipital } \\
\text { Left }\end{array}$ \\
\hline $\begin{array}{c}\text { Electrodes of the } \\
\text { region }\end{array}$ & $\begin{array}{l}\mathrm{FP}_{1}, \mathrm{AF}_{7}, \mathrm{AF}_{3}, \\
\mathrm{~F}_{7}, \mathrm{~F}_{3}, \mathrm{FC}_{3}, \mathrm{FT}_{7}\end{array}$ & $\mathrm{FT}_{7}, \mathrm{~T}_{7}, \mathrm{TP}_{7}$ & $\begin{array}{l}\mathrm{TP}_{7}, \mathrm{CP} 3, \mathrm{P} 7, \\
\mathrm{P} 3, \mathrm{PO} 7, \mathrm{PO} 3\end{array}$ & $\mathrm{FC} 3, \mathrm{C} 3, \mathrm{CP} 3$ & $\begin{array}{l}\mathrm{PO}_{7}, \mathrm{PO} 3, \\
\mathrm{O}_{1}\end{array}$ \\
\hline Alpha & 2 & 0 & 0 & 0 & 0 \\
\hline Beta1 & 2 & 0 & 0 & 0 & 0 \\
\hline Beta2 & 2 & 0 & 0 & 0 & 0 \\
\hline Delta & 2 & 0 & 0 & 0 & 0 \\
\hline Theta & 2 & 0 & 0 & 0 & 0 \\
\hline
\end{tabular}

\begin{tabular}{|c|l|l|l|l|l|}
\hline $\begin{array}{c}\text { Changes in the } \\
\text { Positive } \\
\text { Direction }\end{array}$ & \multicolumn{1}{|c|}{ Frontal Right } & $\begin{array}{c}\text { Temporal } \\
\text { Right }\end{array}$ & \multicolumn{1}{|c|}{$\begin{array}{c}\text { Parietal } \\
\text { Right }\end{array}$} & Central Right & $\begin{array}{c}\text { Occipital } \\
\text { Right }\end{array}$ \\
\hline $\begin{array}{c}\text { Electrodes of the } \\
\text { region }\end{array}$ & $\begin{array}{l}\mathrm{FP}_{2}, \mathrm{AF} 4, \mathrm{~F}_{8}, \mathrm{~F}_{4}, \\
\mathrm{~F}_{8}, \mathrm{FC} 4, \mathrm{FT}_{8}\end{array}$ & $\mathrm{FT}_{8}, \mathrm{~T}_{8}, \mathrm{TP}_{8}$ & $\begin{array}{l}\mathrm{TP}_{8}, \mathrm{CP}_{4}, \mathrm{P}_{8}, \\
\mathrm{P}_{4}, \mathrm{PO}_{8}, \mathrm{PO}_{4}\end{array}$ & $\mathrm{FC}_{4}, \mathrm{C}_{4}, \mathrm{CP}_{4}$ & $\begin{array}{l}\mathrm{PO}_{8}, \mathrm{PO}_{4}, \\
\mathrm{O}_{2}\end{array}$ \\
\hline Alpha & 2 & 0 & 0 & 0 & 0 \\
\hline Beta1 & 3 & 0 & 0 & 0 & 0 \\
\hline Beta2 & 3 & 0 & 0 & 0 & 0 \\
\hline Delta & 2 & 0 & 0 & 0 & 0 \\
\hline Theta & 2 & 0 & 0 & 0 & 0 \\
\hline
\end{tabular}

\section{Subject 5}

\begin{tabular}{|c|l|l|l|l|l|}
\hline $\begin{array}{c}\text { Changes in the } \\
\text { Positive } \\
\text { Direction }\end{array}$ & Frontal Left & $\begin{array}{c}\text { Temporal } \\
\text { Left }\end{array}$ & Parietal Left & Central Left & $\begin{array}{c}\text { Occipital } \\
\text { Left }\end{array}$ \\
\hline $\begin{array}{c}\text { Electrodes of the } \\
\text { region }\end{array}$ & $\begin{array}{l}\mathrm{FP}_{1}, \mathrm{AF}_{7}, \mathrm{AF}_{3}, \\
\mathrm{~F}_{7}, \mathrm{~F}_{3}, \mathrm{FC}_{3}, \mathrm{FT}_{7}\end{array}$ & $\mathrm{FT}_{7}, \mathrm{~T}_{7}, \mathrm{TP}_{7}$ & $\begin{array}{l}\mathrm{TP} \\
\mathrm{P}, \mathrm{CP} 3, \mathrm{PO} 7, \mathrm{FC}, \mathrm{C} 3, \mathrm{CP} 3\end{array}$ & $\begin{array}{l}\mathrm{PO}_{7}, \mathrm{PO} 3, \\
\mathrm{O}_{1}\end{array}$ \\
\hline Alpha & 1 & 0 & 0 & 0 & 0 \\
\hline Beta1 & 0 & 0 & 1 & 0 & 2 \\
\hline Beta2 & 0 & 0 & 1 & 0 & 2 \\
\hline Delta & 1 & 0 & 0 & 0 & 0 \\
\hline Theta & 1 & 0 & 0 & 0 & 0 \\
\hline
\end{tabular}




\begin{tabular}{|c|c|c|c|c|c|}
\hline $\begin{array}{c}\text { Changes in the } \\
\text { Positive } \\
\text { Direction }\end{array}$ & Frontal Right & $\begin{array}{c}\text { Temporal } \\
\text { Right }\end{array}$ & $\begin{array}{c}\text { Parietal } \\
\text { Right }\end{array}$ & Central Right & $\begin{array}{c}\text { Occipital } \\
\text { Right }\end{array}$ \\
\hline $\begin{array}{c}\text { Electrodes of the } \\
\text { region }\end{array}$ & $\begin{array}{l}\mathrm{FP}_{2}, \mathrm{AF} 4, \mathrm{~F}_{8}, \mathrm{~F}_{4}, \\
\mathrm{~F}_{8}, \mathrm{FC} 4, \mathrm{FT}_{8}\end{array}$ & $\mathrm{FT}_{8}, \mathrm{~T}_{8}, \mathrm{TP}_{8}$ & $\begin{array}{l}\mathrm{TP}_{8}, \mathrm{CP}_{4}, \mathrm{P}_{8} \\
\mathrm{P}_{4}, \mathrm{PO}_{8}, \mathrm{PO}_{4}\end{array}$ & $\mathrm{FC}_{4}, \mathrm{C}_{4}, \mathrm{CP}_{4}$ & $\begin{array}{l}\mathrm{PO}_{8}, \mathrm{PO}_{4}, \\
\mathrm{O}_{2}\end{array}$ \\
\hline Alpha & 4 & 0 & 0 & 0 & 0 \\
\hline Beta1 & 4 & 0 & 1 & 1 & 1 \\
\hline Beta2 & 1 & 0 & 3 & 2 & 1 \\
\hline Delta & 4 & 0 & 0 & 0 & 0 \\
\hline Theta & 4 & 0 & 0 & 0 & 0 \\
\hline
\end{tabular}

\section{Subject 6}

\begin{tabular}{|c|l|l|l|l|l|}
\hline $\begin{array}{c}\text { Changes in the } \\
\text { Positive } \\
\text { Direction }\end{array}$ & \multicolumn{1}{|c|}{ Frontal Left } & $\begin{array}{c}\text { Temporal } \\
\text { Left }\end{array}$ & Parietal Left & Central Left & $\begin{array}{c}\text { Occipital } \\
\text { Left }\end{array}$ \\
\hline $\begin{array}{c}\text { Electrodes of the } \\
\text { region }\end{array}$ & $\begin{array}{l}\mathrm{FP}_{1}, \mathrm{AF}_{7}, \mathrm{AF}_{3}, \\
\mathrm{~F}_{7}, \mathrm{~F}_{3}, \mathrm{FC}_{3}, \mathrm{FT}_{7}\end{array}$ & $\mathrm{FT}_{7}, \mathrm{~T}_{7}, \mathrm{TP}_{7}$ & $\begin{array}{l}\mathrm{TP} \\
\mathrm{P} 3, \mathrm{CP} 3, \mathrm{PO} 7,\end{array}$ & $\mathrm{FC} 3, \mathrm{C} 3, \mathrm{CP} 3$ & $\begin{array}{l}\mathrm{PO}_{7}, \mathrm{PO} 3, \\
\mathrm{O}_{1}\end{array}$ \\
\hline Alpha & 0 & 0 & 0 & 0 & 0 \\
\hline Beta1 & 0 & 0 & 0 & 0 & 0 \\
\hline Beta2 & 0 & 0 & 0 & 0 & 0 \\
\hline Delta & 3 & 0 & 0 & 0 & 0 \\
\hline Theta & 4 & 0 & 0 & 0 & 0 \\
\hline
\end{tabular}

\begin{tabular}{|c|l|l|l|l|l|}
\hline $\begin{array}{c}\text { Changes in the } \\
\text { Positive } \\
\text { Direction }\end{array}$ & Frontal Right & $\begin{array}{c}\text { Temporal } \\
\text { Right }\end{array}$ & \multicolumn{1}{|c|}{$\begin{array}{c}\text { Parietal } \\
\text { Right }\end{array}$} & Central Right & $\begin{array}{c}\text { Occipital } \\
\text { Right }\end{array}$ \\
\hline $\begin{array}{c}\text { Electrodes of the } \\
\text { region }\end{array}$ & $\begin{array}{l}\mathrm{FP}_{2}, \mathrm{AF}_{4}, \mathrm{~F}_{8}, \mathrm{~F}_{4}, \\
\mathrm{~F}_{8}, \mathrm{FC}, \mathrm{FT}_{8}\end{array}$ & $\mathrm{FT}_{8}, \mathrm{~T}_{8}, \mathrm{TP}_{8}$ & $\begin{array}{l}\mathrm{TP}_{8}, \mathrm{CP}_{4}, \mathrm{P}_{8}, \\
\mathrm{P}_{4}, \mathrm{PO}_{8}, \mathrm{PO}_{4}\end{array}$ & $\mathrm{FC}_{4}, \mathrm{C}_{4}, \mathrm{CP}_{4}$ & $\mathrm{PO}_{8}, \mathrm{PO}_{4}$, \\
\hline Alpha & 3 & 0 & 0 & 0 & 0 \\
\hline Beta1 & 1 & 0 & 2 & 0 & 3 \\
\hline Beta2 & 1 & 0 & 1 & 0 & 2 \\
\hline Delta & 3 & 0 & 0 & 0 & 0 \\
\hline Theta & 2 & 0 & 0 & 0 & 0 \\
\hline
\end{tabular}

\section{Subject 7}

\begin{tabular}{|c|l|l|l|l|l|}
\hline $\begin{array}{c}\text { Changes in the } \\
\text { Positive } \\
\text { Direction }\end{array}$ & \multicolumn{1}{|c|}{ Frontal Left } & $\begin{array}{c}\text { Temporal } \\
\text { Left }\end{array}$ & Parietal Left & Central Left & $\begin{array}{c}\text { Occipital } \\
\text { Left }\end{array}$ \\
\hline $\begin{array}{c}\text { Electrodes of the } \\
\text { region }\end{array}$ & $\begin{array}{l}\mathrm{FP}_{1}, \mathrm{AF}_{7}, \mathrm{AF}_{3}, \\
\mathrm{~F}_{7}, \mathrm{~F}_{3}, \mathrm{FC}_{3}, \mathrm{FT}_{7}\end{array}$ & $\mathrm{FT}_{7}, \mathrm{~T}_{7}, \mathrm{TP}_{7}$ & $\begin{array}{l}\mathrm{TP} \\
\mathrm{P} 3, \mathrm{CP} 3, \mathrm{PO} 7,\end{array}$ & $\mathrm{FC} 3, \mathrm{C} 3, \mathrm{CP} 3$ & $\begin{array}{l}\mathrm{PO}_{7}, \mathrm{PO} 3, \\
\mathrm{O}_{1}\end{array}$ \\
\hline Alpha & 4 & 0 & 0 & 0 & 0 \\
\hline Beta1 & 2 & 0 & 0 & 0 & 0 \\
\hline Beta2 & 2 & 0 & 0 & 0 & 0 \\
\hline Delta & 3 & 0 & 0 & 0 & 0 \\
\hline Theta & 4 & 0 & 0 & 0 & 0 \\
\hline
\end{tabular}




\begin{tabular}{|c|c|c|c|c|c|}
\hline $\begin{array}{c}\text { Changes in the } \\
\text { Positive } \\
\text { Direction }\end{array}$ & Frontal Right & $\begin{array}{c}\text { Temporal } \\
\text { Right }\end{array}$ & $\begin{array}{c}\text { Parietal } \\
\text { Right }\end{array}$ & Central Right & $\begin{array}{c}\text { Occipital } \\
\text { Right }\end{array}$ \\
\hline $\begin{array}{c}\text { Electrodes of the } \\
\text { region }\end{array}$ & $\begin{array}{l}\mathrm{FP}_{2}, \mathrm{AF} 4, \mathrm{~F}_{8}, \mathrm{~F}_{4}, \\
\mathrm{~F}_{8}, \mathrm{FC} 4, \mathrm{FT}_{8}\end{array}$ & $\mathrm{FT}_{8}, \mathrm{~T}_{8}, \mathrm{TP}_{8}$ & $\begin{array}{l}\mathrm{TP}_{8}, \mathrm{CP}_{4}, \mathrm{P}_{8} \\
\mathrm{P}_{4}, \mathrm{PO}_{8}, \mathrm{PO}_{4}\end{array}$ & $\mathrm{FC}_{4}, \mathrm{C}_{4}, \mathrm{CP}_{4}$ & $\begin{array}{l}\mathrm{PO}_{8}, \mathrm{PO}_{4} \\
\mathrm{O}_{2}\end{array}$ \\
\hline Alpha & 1 & 0 & 0 & 0 & 0 \\
\hline Beta1 & 2 & 0 & 0 & 0 & 0 \\
\hline Beta2 & 1 & 0 & 0 & 0 & 0 \\
\hline Delta & 2 & 0 & 0 & 0 & 0 \\
\hline Theta & 2 & 0 & 0 & 0 & 0 \\
\hline
\end{tabular}

\section{Subject 8}

\begin{tabular}{|c|l|l|l|l|l|}
\hline $\begin{array}{c}\text { Changes in the } \\
\text { Positive } \\
\text { Direction }\end{array}$ & Frontal Left & $\begin{array}{c}\text { Temporal } \\
\text { Left }\end{array}$ & Parietal Left & Central Left & $\begin{array}{c}\text { Occipital } \\
\text { Left }\end{array}$ \\
\hline $\begin{array}{c}\text { Electrodes of the } \\
\text { region }\end{array}$ & $\begin{array}{l}\mathrm{FP}_{1}, \mathrm{AF}_{7}, \mathrm{AF}_{3}, \\
\mathrm{~F}_{7}, \mathrm{~F}_{3}, \mathrm{FC}_{3}, \mathrm{FT}_{7}\end{array}$ & $\mathrm{FT}_{7}, \mathrm{~T}_{7}, \mathrm{TP}_{7}$ & $\begin{array}{l}\mathrm{TP}_{7}, \mathrm{CP} 3, \mathrm{P} 7, \\
\mathrm{P} 3, \mathrm{PO} 7, \mathrm{PO} 3\end{array}$ & $\mathrm{FC} 3, \mathrm{C} 3, \mathrm{CP} 3$ & $\begin{array}{l}\mathrm{PO}_{7}, \mathrm{PO} 3, \\
\mathrm{O}_{1}\end{array}$ \\
\hline Alpha & 1 & 0 & 0 & 0 & 0 \\
\hline Beta1 & 1 & 0 & 0 & 0 & 0 \\
\hline Beta2 & 2 & 0 & 0 & 0 & 0 \\
\hline Delta & 0 & 0 & 0 & 0 & 0 \\
\hline Theta & 2 & 0 & 0 & 0 & 0 \\
\hline
\end{tabular}

\begin{tabular}{|c|c|c|c|c|c|}
\hline $\begin{array}{c}\text { Changes in the } \\
\text { Positive } \\
\text { Direction }\end{array}$ & Frontal Right & $\begin{array}{l}\text { Temporal } \\
\text { Right }\end{array}$ & $\begin{array}{c}\text { Parietal } \\
\text { Right }\end{array}$ & Central Right & $\begin{array}{c}\text { Occipital } \\
\text { Right }\end{array}$ \\
\hline $\begin{array}{c}\text { Electrodes of the } \\
\text { region }\end{array}$ & $\begin{array}{l}\mathrm{FP}_{2}, \mathrm{AF} 4, \mathrm{~F}_{8}, \mathrm{~F}_{4}, \\
\mathrm{~F}_{8}, \mathrm{FC} 4, \mathrm{FT}_{8}\end{array}$ & $\mathrm{FT}_{8}, \mathrm{~T}_{8}, \mathrm{TP}_{8}$ & $\begin{array}{l}\mathrm{TP}_{8}, \mathrm{CP}_{4}, \mathrm{P}_{8} \\
\mathrm{P}_{4}, \mathrm{PO}_{8}, \mathrm{PO}_{4}\end{array}$ & $\mathrm{FC}_{4}, \mathrm{C}_{4}, \mathrm{CP}_{4}$ & $\begin{array}{l}\mathrm{PO}_{8}, \mathrm{PO}_{4}, \\
\mathrm{O}_{2}\end{array}$ \\
\hline Alpha & 3 & 0 & 0 & 0 & 0 \\
\hline Beta1 & 2 & 0 & 2 & 0 & 3 \\
\hline Beta2 & 1 & 0 & 0 & 0 & 1 \\
\hline Delta & 0 & 0 & 0 & 0 & 0 \\
\hline Theta & 3 & 0 & 0 & 0 & 0 \\
\hline
\end{tabular}

\section{Subject 9}

\begin{tabular}{|c|l|l|l|l|l|}
\hline $\begin{array}{c}\text { Changes in the } \\
\text { Positive } \\
\text { Direction }\end{array}$ & Frontal Left & $\begin{array}{c}\text { Temporal } \\
\text { Left }\end{array}$ & Parietal Left & \multicolumn{1}{|c|}{ Central Left } & $\begin{array}{c}\text { Occipital } \\
\text { Left }\end{array}$ \\
\hline $\begin{array}{c}\text { Electrodes of the } \\
\text { region }\end{array}$ & $\begin{array}{l}\mathrm{FP}_{1}, \mathrm{AF}_{7}, \mathrm{AF}_{3}, \\
\mathrm{~F}_{7}, \mathrm{~F}_{3}, \mathrm{FC}_{3}, \mathrm{FT}_{7}\end{array}$ & $\mathrm{FT}_{7}, \mathrm{~T}_{7}, \mathrm{TP}_{7}$ & $\begin{array}{l}\mathrm{TP} \\
\mathrm{P} 3, \mathrm{CP} 3, \mathrm{PO} 7, \mathrm{PO} 3\end{array}$ & $\mathrm{FC} 3, \mathrm{C} 3, \mathrm{CP} 3$ & $\begin{array}{l}\mathrm{PO}_{7}, \mathrm{PO} 3, \\
\mathrm{O}_{1}\end{array}$ \\
\hline Alpha & 2 & 0 & 1 & 0 & 1 \\
\hline Beta1 & 0 & 0 & 3 & 0 & 3 \\
\hline Beta2 & 0 & 0 & 3 & 0 & 3 \\
\hline Delta & 2 & 0 & 0 & 0 & 0 \\
\hline Theta & 1 & 0 & 0 & 0 & 0 \\
\hline
\end{tabular}




\begin{tabular}{|c|l|l|l|l|l|}
\hline $\begin{array}{c}\text { Changes in the } \\
\text { Positive } \\
\text { Direction }\end{array}$ & \multicolumn{1}{|c|}{ Frontal Right } & \multicolumn{1}{|c|}{$\begin{array}{c}\text { Temporal } \\
\text { Right }\end{array}$} & \multicolumn{1}{|c|}{$\begin{array}{c}\text { Parietal } \\
\text { Right }\end{array}$} & \multicolumn{1}{c|}{ Central Right } & $\begin{array}{c}\text { Occipital } \\
\text { Right }\end{array}$ \\
\hline $\begin{array}{c}\text { Electrodes of the } \\
\text { region }\end{array}$ & $\begin{array}{l}\mathrm{FP}_{2}, \mathrm{AF}_{4}, \mathrm{~F}_{8}, \mathrm{~F}_{4}, \\
\mathrm{~F}_{8}, \mathrm{FC} 4, \mathrm{FT}_{8}\end{array}$ & $\mathrm{FT}_{8}, \mathrm{~T}_{8}, \mathrm{TP}_{8}$ & $\begin{array}{l}\mathrm{TP}_{8}, \mathrm{CP}_{4}, \mathrm{P}_{8}, \\
\mathrm{P}_{4}, \mathrm{PO}_{8}, \mathrm{PO}_{4}\end{array}$ & $\mathrm{FC}_{4}, \mathrm{C}_{4}, \mathrm{CP}_{4}$ & $\begin{array}{l}\mathrm{PO}_{8}, \mathrm{PO}_{4}, \\
\mathrm{O}_{2}\end{array}$ \\
\hline Alpha & 2 & 0 & 0 & 0 & 0 \\
\hline Beta1 & 0 & 0 & 1 & 0 & 1 \\
\hline Beta2 & 0 & 0 & 1 & 0 & 2 \\
\hline Delta & 2 & 0 & 0 & 0 & 0 \\
\hline Theta & 2 & 0 & 0 & 0 & 0 \\
\hline
\end{tabular}

5.4 Table: Tabulated Negative Results (Answering Task)

\section{Subject 1}

\begin{tabular}{|c|l|l|l|l|l|}
\hline $\begin{array}{c}\text { Changes in the } \\
\text { Negative } \\
\text { Direction }\end{array}$ & Frontal Left & $\begin{array}{c}\text { Temporal } \\
\text { Left }\end{array}$ & Parietal Left & Central Left & $\begin{array}{l}\text { Occipital } \\
\text { Left }\end{array}$ \\
\hline $\begin{array}{c}\text { Electrodes of the } \\
\text { region }\end{array}$ & $\begin{array}{l}\mathrm{FP}_{1}, \mathrm{AF}_{7}, \mathrm{AF}_{3}, \\
\mathrm{~F}_{7}, \mathrm{~F}_{3}, \mathrm{FC}_{3}, \mathrm{FT}_{7}\end{array}$ & $\mathrm{FT}_{7}, \mathrm{~T}_{7}, \mathrm{TP}_{7}$ & $\begin{array}{l}\mathrm{TP}, \mathrm{CP} 3, \mathrm{P} 7, \\
\mathrm{P} 3, \mathrm{PO} 7, \mathrm{PO} 3\end{array}$ & $\mathrm{FC}, \mathrm{C} 3, \mathrm{CP} 3$ & $\begin{array}{l}\mathrm{PO}_{7}, \mathrm{PO} 3 \\
\mathrm{O}_{1}\end{array}$ \\
\hline Alpha & 0 & 2 & 3 & 0 & 2 \\
\hline Beta1 & 1 & 3 & 2 & 0 & 0 \\
\hline Beta2 & 1 & 3 & 2 & 1 & 0 \\
\hline Delta & 0 & 0 & 1 & 0 & 0 \\
\hline Theta & 0 & 0 & 1 & 0 & 0 \\
\hline
\end{tabular}

\begin{tabular}{|c|l|l|l|l|l|}
\hline $\begin{array}{c}\text { Changes in the } \\
\text { Negative } \\
\text { Direction }\end{array}$ & Frontal Right & $\begin{array}{c}\text { Temporal } \\
\text { Right }\end{array}$ & \multicolumn{1}{|c|}{$\begin{array}{c}\text { Parietal } \\
\text { Right }\end{array}$} & Central Right & $\begin{array}{c}\text { Occipital } \\
\text { Right }\end{array}$ \\
\hline $\begin{array}{c}\text { Electrodes of the } \\
\text { region }\end{array}$ & $\begin{array}{l}\mathrm{FP}_{2}, \mathrm{AF}_{4}, \mathrm{~F}_{8}, \mathrm{~F}_{4}, \\
\mathrm{~F}_{8}, \mathrm{FC}_{4}, \mathrm{FT}_{8}\end{array}$ & $\mathrm{FT}_{8}, \mathrm{~T}_{8}, \mathrm{TP}_{8}$ & $\begin{array}{l}\mathrm{TP}_{8}, \mathrm{CP}_{4}, \mathrm{P}_{8}, \\
\mathrm{P}_{4}, \mathrm{PO}_{8}, \mathrm{PO}_{4}\end{array}$ & $\mathrm{FC}_{4}, \mathrm{C}_{4}, \mathrm{CP}_{4}$ & $\begin{array}{l}\mathrm{PO}_{8}, \mathrm{PO}_{4} \\
\mathrm{O}_{2}\end{array}$ \\
\hline Alpha & 0 & 1 & 3 & 0 & 2 \\
\hline Beta1 & 1 & 2 & 1 & 0 & 0 \\
\hline Beta2 & 0 & 1 & 1 & 0 & 0 \\
\hline Delta & 0 & 0 & 0 & 0 & 0 \\
\hline Theta & 0 & 0 & 0 & 0 & 0 \\
\hline
\end{tabular}


Subject 2

\begin{tabular}{|c|l|l|l|l|l|}
\hline $\begin{array}{c}\text { Changes in the } \\
\text { Negative } \\
\text { Direction }\end{array}$ & \multicolumn{1}{|c|}{ Frontal Left } & $\begin{array}{c}\text { Temporal } \\
\text { Left }\end{array}$ & Parietal Left & Central Left & $\begin{array}{l}\text { Occipital } \\
\text { Left }\end{array}$ \\
\hline $\begin{array}{c}\text { Electrodes of the } \\
\text { region }\end{array}$ & $\begin{array}{l}\mathrm{FP}_{1}, \mathrm{AF}_{7}, \mathrm{AF}_{3}, \\
\mathrm{~F}_{7}, \mathrm{~F}_{3}, \mathrm{FC}_{3}, \mathrm{FT}_{7}\end{array}$ & $\mathrm{FT}_{7}, \mathrm{~T}_{7}, \mathrm{TP}_{7}$ & $\begin{array}{l}\mathrm{TP} \\
\mathrm{P} 3, \mathrm{CP} 3, \mathrm{PO} 7, \mathrm{PO} 3\end{array}$ & $\mathrm{FC} 3, \mathrm{C} 3, \mathrm{CP} 3$ & $\begin{array}{l}\mathrm{PO}_{7}, \mathrm{PO} 3, \\
\mathrm{O}_{1}\end{array}$ \\
\hline Alpha & 1 & 3 & 2 & 0 & 0 \\
\hline Beta1 & 2 & 3 & 2 & 0 & 0 \\
\hline Beta2 & 2 & 3 & 1 & 0 & 0 \\
\hline Delta & 0 & 1 & 1 & 0 & 0 \\
\hline Theta & 0 & 0 & 0 & 0 & 0 \\
\hline
\end{tabular}

\begin{tabular}{|c|c|c|c|c|c|}
\hline $\begin{array}{l}\text { Changes in the } \\
\text { Negative } \\
\text { Direction }\end{array}$ & Frontal Right & $\begin{array}{c}\text { Temporal } \\
\text { Right }\end{array}$ & $\begin{array}{c}\text { Parietal } \\
\text { Right }\end{array}$ & Central Right & $\begin{array}{c}\text { Occipital } \\
\text { Right }\end{array}$ \\
\hline $\begin{array}{c}\text { Electrodes of the } \\
\text { region }\end{array}$ & $\begin{array}{l}\mathrm{FP}_{2}, \mathrm{AF} 4, \mathrm{~F}_{8}, \mathrm{~F}_{4}, \\
\mathrm{~F}_{8}, \mathrm{FC} 4, \mathrm{FT}_{8}\end{array}$ & $\mathrm{FT}_{8}, \mathrm{~T}_{8}, \mathrm{TP}_{8}$ & $\begin{array}{l}\mathrm{TP}_{8}, \mathrm{CP}_{4}, \mathrm{P}_{8} \\
\mathrm{P}_{4}, \mathrm{PO}_{8}, \mathrm{PO}_{4}\end{array}$ & $\mathrm{FC}_{4}, \mathrm{C}_{4}, \mathrm{CP}_{4}$ & $\begin{array}{l}\mathrm{PO}_{8}, \mathrm{PO}_{4}, \\
\mathrm{O}_{2}\end{array}$ \\
\hline Alpha & 0 & 0 & 0 & 0 & 0 \\
\hline Beta1 & 0 & 2 & 2 & 0 & 0 \\
\hline Beta2 & 0 & 0 & 0 & 0 & 0 \\
\hline Delta & 0 & 0 & 0 & 0 & 0 \\
\hline Theta & 0 & 0 & 0 & 0 & 0 \\
\hline
\end{tabular}

\section{Subject 3}

\begin{tabular}{|c|l|l|l|l|l|}
\hline $\begin{array}{c}\text { Changes in the } \\
\text { Negative } \\
\text { Direction }\end{array}$ & \multicolumn{1}{|c|}{ Frontal Left } & $\begin{array}{c}\text { Temporal } \\
\text { Left }\end{array}$ & Parietal Left & \multicolumn{1}{|c|}{ Central Left } & $\begin{array}{l}\text { Occipital } \\
\text { Left }\end{array}$ \\
\hline $\begin{array}{c}\text { Electrodes of the } \\
\text { region }\end{array}$ & $\begin{array}{l}\mathrm{FP}_{1}, \mathrm{AF}_{7}, \mathrm{AF}_{3}, \\
\mathrm{~F}_{7}, \mathrm{~F}_{3}, \mathrm{FC}_{3}, \mathrm{FT}_{7}\end{array}$ & $\mathrm{FT}_{7}, \mathrm{~T}_{7}, \mathrm{TP}_{7}$ & $\begin{array}{l}\mathrm{TP} \\
\mathrm{P} 3, \mathrm{CP} 3, \mathrm{PO} 7, \mathrm{PO} 3\end{array}$ & $\mathrm{FC} 3, \mathrm{C} 3, \mathrm{CP} 3$ & $\begin{array}{l}\mathrm{PO}_{7}, \mathrm{PO} 3, \\
\mathrm{O}_{1}\end{array}$ \\
\hline Alpha & 0 & 2 & 3 & 1 & 0 \\
\hline Beta1 & 0 & 2 & 3 & 0 & 1 \\
\hline Beta2 & 1 & 3 & 5 & 0 & 2 \\
\hline Delta & 0 & 1 & 1 & 0 & 0 \\
\hline Theta & 0 & 2 & 2 & 0 & 0 \\
\hline
\end{tabular}

\begin{tabular}{|c|l|l|l|l|l|}
\hline $\begin{array}{c}\text { Changes in the } \\
\text { Negative } \\
\text { Direction }\end{array}$ & \multicolumn{1}{|c|}{ Frontal Right } & $\begin{array}{c}\text { Temporal } \\
\text { Right }\end{array}$ & \multicolumn{1}{|c|}{$\begin{array}{c}\text { Parietal } \\
\text { Right }\end{array}$} & Central Right & $\begin{array}{c}\text { Occipital } \\
\text { Right }\end{array}$ \\
\hline $\begin{array}{c}\text { Electrodes of the } \\
\text { region }\end{array}$ & $\begin{array}{l}\mathrm{FP}_{2}, \mathrm{AF} 4, \mathrm{~F}_{8}, \mathrm{~F}_{4}, \\
\mathrm{~F}_{8}, \mathrm{FC} 4, \mathrm{FT}_{8}\end{array}$ & $\mathrm{FT}_{8}, \mathrm{~T}_{8}, \mathrm{TP}_{8}$ & $\begin{array}{l}\mathrm{TP}_{8}, \mathrm{CP}_{4}, \mathrm{P}_{8}, \\
\mathrm{P}_{4}, \mathrm{PO}_{8}, \mathrm{PO}_{4}\end{array}$ & $\mathrm{FC}_{4}, \mathrm{C}_{4}, \mathrm{CP}_{4}$ & $\begin{array}{l}\mathrm{PO}_{8}, \mathrm{PO}_{4}, \\
\mathrm{O}_{2}\end{array}$ \\
\hline Alpha & 0 & 0 & 1 & 0 & 0 \\
\hline Beta1 & 0 & 1 & 1 & 0 & 0 \\
\hline Beta2 & 0 & 0 & 0 & 0 & 0 \\
\hline Delta & 0 & 0 & 0 & 0 & 0 \\
\hline Theta & 0 & 0 & 0 & 0 & 0 \\
\hline
\end{tabular}




\section{Subject 4}

\begin{tabular}{|c|l|l|l|l|l|}
\hline $\begin{array}{c}\text { Changes in the } \\
\text { Negative } \\
\text { Direction }\end{array}$ & \multicolumn{1}{|c|}{ Frontal Left } & $\begin{array}{c}\text { Temporal } \\
\text { Left }\end{array}$ & Parietal Left & \multicolumn{1}{|c|}{ Central Left } & $\begin{array}{c}\text { Occipital } \\
\text { Left }\end{array}$ \\
\hline $\begin{array}{c}\text { Electrodes of the } \\
\text { region }\end{array}$ & $\begin{array}{l}\mathrm{FP}_{1}, \mathrm{AF}_{7}, \mathrm{AF}_{3}, \\
\mathrm{~F}_{7}, \mathrm{~F}_{3}, \mathrm{FC}_{3}, \mathrm{FT}_{7}\end{array}$ & $\mathrm{FT}_{7}, \mathrm{~T}_{7}, \mathrm{TP}_{7}$ & $\begin{array}{l}\mathrm{TP} \\
\mathrm{P} 3, \mathrm{CP} 3, \mathrm{PO} 7, \mathrm{PO} 3\end{array}$ & $\mathrm{FC} 3, \mathrm{C} 3, \mathrm{CP} 3$ & $\begin{array}{l}\mathrm{PO}_{7}, \mathrm{PO} 3, \\
\mathrm{O}_{1}\end{array}$ \\
\hline Alpha & 0 & 1 & 3 & 0 & 1 \\
\hline Beta1 & 0 & 1 & 1 & 0 & 0 \\
\hline Beta2 & 0 & 1 & 1 & 0 & 0 \\
\hline Delta & 0 & 0 & 0 & 0 & 0 \\
\hline Theta & 0 & 0 & 0 & 0 & 0 \\
\hline
\end{tabular}

\begin{tabular}{|c|l|l|l|l|l|}
\hline $\begin{array}{c}\text { Changes in the } \\
\text { Negative } \\
\text { Direction }\end{array}$ & \multicolumn{1}{|c|}{ Frontal Right } & \multicolumn{1}{|c|}{$\begin{array}{c}\text { Temporal } \\
\text { Right }\end{array}$} & \multicolumn{1}{|c|}{$\begin{array}{c}\text { Parietal } \\
\text { Right }\end{array}$} & \multicolumn{1}{c|}{$\begin{array}{c}\text { Central Right } \\
\text { Right }\end{array}$} \\
\hline $\begin{array}{c}\text { Electrodes of the } \\
\text { region }\end{array}$ & $\begin{array}{l}\mathrm{FP}_{2}, \mathrm{AF} 4, \mathrm{~F}_{8}, \mathrm{~F}_{4}, \\
\mathrm{~F}_{8}, \mathrm{FC} 4, \mathrm{FT}_{8}\end{array}$ & $\mathrm{FT}_{8}, \mathrm{~T}_{8}, \mathrm{TP}_{8}$ & $\begin{array}{l}\mathrm{TP}_{8}, \mathrm{CP}_{4}, \mathrm{P}_{8}, \\
\mathrm{P}_{4}, \mathrm{PO}_{8}, \mathrm{PO}_{4}\end{array}$ & $\mathrm{FC}_{4}, \mathrm{C}_{4}, \mathrm{CP}_{4}$ & $\begin{array}{l}\mathrm{PO}_{8}, \mathrm{PO}_{4}, \\
\mathrm{O}_{2}\end{array}$ \\
\hline Alpha & 0 & 2 & 2 & 0 & 0 \\
\hline Beta1 & 1 & 3 & 1 & 0 & 0 \\
\hline Beta2 & 0 & 1 & 5 & 0 & 2 \\
\hline Delta & 0 & 0 & 0 & 0 & 0 \\
\hline Theta & 0 & 0 & 0 & 0 & 0 \\
\hline
\end{tabular}

\section{Subject 5}

\begin{tabular}{|c|l|l|l|l|l|}
\hline $\begin{array}{c}\text { Changes in the } \\
\text { Negative } \\
\text { Direction }\end{array}$ & Frontal Left & \multicolumn{1}{|c|}{$\begin{array}{c}\text { Temporal } \\
\text { Left }\end{array}$} & Parietal Left & \multicolumn{1}{|c|}{ Central Left } & $\begin{array}{c}\text { Occipital } \\
\text { Left }\end{array}$ \\
\hline $\begin{array}{c}\text { Electrodes of the } \\
\text { region }\end{array}$ & $\begin{array}{l}\mathrm{FP}_{1}, \mathrm{AF}_{7}, \mathrm{AF}_{3}, \\
\mathrm{~F}_{7}, \mathrm{~F}_{3}, \mathrm{FC}_{3}, \mathrm{FT}_{7}\end{array}$ & $\mathrm{FT}_{7}, \mathrm{~T}_{7}, \mathrm{TP}_{7}$ & $\begin{array}{l}\mathrm{TP}, \mathrm{CP} 3, \mathrm{P} 7, \\
\mathrm{P} 3, \mathrm{PO} 7, \mathrm{PO} 3\end{array}$ & $\mathrm{FC} 3, \mathrm{C} 3, \mathrm{CP} 3$ & $\begin{array}{l}\mathrm{PO}_{7}, \mathrm{PO} 3, \\
\mathrm{O}_{1}\end{array}$ \\
\hline Alpha & 1 & 2 & 1 & 2 & 0 \\
\hline Beta1 & 4 & 3 & 1 & 1 & 0 \\
\hline Beta2 & 5 & 3 & 1 & 2 & 0 \\
\hline Delta & 0 & 0 & 0 & 0 & 0 \\
\hline Theta & 1 & 2 & 0 & 0 & 0 \\
\hline
\end{tabular}

\begin{tabular}{|c|l|l|l|l|l|}
\hline $\begin{array}{c}\text { Changes in the } \\
\text { Negative } \\
\text { Direction }\end{array}$ & Frontal Right & $\begin{array}{c}\text { Temporal } \\
\text { Right }\end{array}$ & $\begin{array}{c}\text { Parietal } \\
\text { Right }\end{array}$ & Central Right & $\begin{array}{c}\text { Occipital } \\
\text { Right }\end{array}$ \\
\hline $\begin{array}{c}\text { Electrodes of the } \\
\text { region }\end{array}$ & $\begin{array}{l}\mathrm{FP}_{2}, \mathrm{AF}_{4}, \mathrm{~F}_{8}, \mathrm{~F}_{4}, \\
\mathrm{~F}_{8}, \mathrm{FC}_{4}, \mathrm{FT}_{8}\end{array}$ & $\mathrm{FT}_{8}, \mathrm{~T}_{8}, \mathrm{TP}_{8}$ & $\begin{array}{l}\mathrm{TP}_{8}, \mathrm{CP}_{4}, \mathrm{P}_{8}, \\
\mathrm{P}_{4}, \mathrm{PO}_{8}, \mathrm{PO}_{4}\end{array}$ & $\mathrm{FC}_{4}, \mathrm{C}_{4}, \mathrm{CP}_{4}$ & $\begin{array}{l}\mathrm{PO}_{8}, \mathrm{PO}_{4}, \\
\mathrm{O}_{2}\end{array}$ \\
\hline Alpha & 0 & 0 & 0 & 0 & 0 \\
\hline Beta1 & 0 & 2 & 1 & 0 & 0 \\
\hline Beta2 & 0 & 0 & 0 & 0 & 0 \\
\hline Delta & 0 & 0 & 0 & 0 & 0 \\
\hline Theta & 0 & 0 & 0 & 0 & 0 \\
\hline
\end{tabular}


Subject 6

\begin{tabular}{|c|l|l|l|l|l|}
\hline $\begin{array}{c}\text { Changes in the } \\
\text { Negative } \\
\text { Direction }\end{array}$ & Frontal Left & $\begin{array}{c}\text { Temporal } \\
\text { Left }\end{array}$ & Parietal Left & Central Left & $\begin{array}{l}\text { Occipital } \\
\text { Left }\end{array}$ \\
\hline $\begin{array}{c}\text { Electrodes of the } \\
\text { region }\end{array}$ & $\begin{array}{l}\mathrm{FP}_{1}, \mathrm{AF}_{7}, \mathrm{AF}_{3}, \\
\mathrm{~F}_{7}, \mathrm{~F}_{3}, \mathrm{FC}_{3}, \mathrm{FT}_{7}\end{array}$ & $\mathrm{FT}_{7}, \mathrm{~T}_{7}, \mathrm{TP}_{7}$ & $\begin{array}{l}\mathrm{TP}_{7}, \mathrm{CP}_{3}, \mathrm{P}_{7}, \\
\mathrm{P}_{3}, \mathrm{PO}_{7}, \mathrm{PO}_{3}\end{array}$ & $\mathrm{FC}_{3}, \mathrm{C}_{3}, \mathrm{CP}_{3}$ & $\begin{array}{l}\mathrm{PO}_{7}, \mathrm{PO}_{3}, \\
\mathrm{O}_{1}\end{array}$ \\
\hline Alpha & 1 & 3 & 1 & 0 & 0 \\
\hline Beta1 & 0 & 2 & 1 & 0 & 0 \\
\hline Beta2 & 0 & 2 & 1 & 0 & 0 \\
\hline Delta & 0 & 1 & 1 & 0 & 0 \\
\hline Theta & 0 & 1 & 0 & 0 & 0 \\
\hline
\end{tabular}

\begin{tabular}{|c|l|l|l|l|l|}
\hline $\begin{array}{c}\text { Changes in the } \\
\text { Negative } \\
\text { Direction }\end{array}$ & Frontal Right & $\begin{array}{c}\text { Temporal } \\
\text { Right }\end{array}$ & $\begin{array}{c}\text { Parietal } \\
\text { Right }\end{array}$ & Central Right & $\begin{array}{c}\text { Occipital } \\
\text { Right }\end{array}$ \\
\hline $\begin{array}{c}\text { Electrodes of the } \\
\text { region }\end{array}$ & $\begin{array}{l}\mathrm{FP}_{2}, \mathrm{AF}_{4}, \mathrm{~F}_{8}, \mathrm{~F}_{4}, \\
\mathrm{~F}_{8}, \mathrm{FC}_{4}, \mathrm{FT}_{8}\end{array}$ & $\mathrm{FT}_{8}, \mathrm{~T}_{8}, \mathrm{TP}_{8}$ & $\begin{array}{l}\mathrm{TP}_{8}, \mathrm{CP}_{4}, \mathrm{P}_{8}, \\
\mathrm{P}_{4}, \mathrm{PO}_{8}, \mathrm{PO}_{4}\end{array}$ & $\mathrm{FC}_{4}, \mathrm{C}_{4}, \mathrm{CP}_{4}$ & $\begin{array}{l}\mathrm{PO}_{8}, \mathrm{PO}_{4}, \\
\mathrm{O}_{2}\end{array}$ \\
\hline Alpha & 3 & 1 & 1 & 3 & 0 \\
\hline Beta1 & 4 & 2 & 0 & 2 & 0 \\
\hline Beta2 & 4 & 2 & 0 & 2 & 0 \\
\hline Delta & 3 & 0 & 1 & 3 & 0 \\
\hline Theta & 2 & 0 & 2 & 2 & 20 \\
\hline
\end{tabular}

\section{Subject 7}

\begin{tabular}{|c|l|l|l|l|l|}
\hline $\begin{array}{c}\text { Changes in the } \\
\text { Negative } \\
\text { Direction }\end{array}$ & Frontal Left & $\begin{array}{c}\text { Temporal } \\
\text { Left }\end{array}$ & Parietal Left & Central Left & $\begin{array}{c}\text { Occipital } \\
\text { Left }\end{array}$ \\
\hline $\begin{array}{c}\text { Electrodes of the } \\
\text { region }\end{array}$ & $\begin{array}{l}\mathrm{FP}_{1}, \mathrm{AF}_{7}, \mathrm{AF}_{3}, \\
\mathrm{~F}_{7}, \mathrm{~F}_{3}, \mathrm{FC}_{3}, \mathrm{FT}_{7}\end{array}$ & $\mathrm{FT}, \mathrm{T}_{7}, \mathrm{TP}_{7}$ & $\begin{array}{l}\mathrm{TP}_{7}, \mathrm{CP}_{3}, \mathrm{P} 7, \\
\mathrm{P}_{3}, \mathrm{PO}_{7}, \mathrm{PO}_{3}\end{array}$ & $\mathrm{FC}_{3}, \mathrm{C}_{3}, \mathrm{CP}_{3}$ & $\begin{array}{l}\mathrm{PO}_{7}, \mathrm{PO}_{3}, \\
\mathrm{O}_{1}\end{array}$ \\
\hline Alpha & 0 & 1 & 5 & 0 & 3 \\
\hline Beta1 & 0 & 2 & 4 & 1 & 1 \\
\hline Beta2 & 1 & 3 & 3 & 2 & 0 \\
\hline Delta & 0 & 0 & 0 & 0 & 0 \\
\hline Theta & 0 & 0 & 0 & 0 & 0 \\
\hline
\end{tabular}

\begin{tabular}{|c|l|l|l|l|l|}
\hline $\begin{array}{c}\text { Changes in the } \\
\text { Negative } \\
\text { Direction }\end{array}$ & Frontal Right & $\begin{array}{c}\text { Temporal } \\
\text { Right }\end{array}$ & $\begin{array}{c}\text { Parietal } \\
\text { Right }\end{array}$ & Central Right & $\begin{array}{l}\text { Occipital } \\
\text { Right }\end{array}$ \\
\hline $\begin{array}{c}\text { Electrodes of the } \\
\text { region }\end{array}$ & $\begin{array}{l}\mathrm{FP}_{2}, \mathrm{AF}_{4}, \mathrm{~F}_{8}, \mathrm{~F}_{4}, \\
\mathrm{~F}_{8}, \mathrm{FC}_{4}, \mathrm{FT}_{8}\end{array}$ & $\mathrm{FT}_{8}, \mathrm{~T}_{8}, \mathrm{TP}_{8}$ & $\begin{array}{l}\mathrm{TP}_{8}, \mathrm{CP}_{4}, \mathrm{P}_{8}, \\
\mathrm{P}_{4}, \mathrm{PO}_{8}, \mathrm{PO}_{4}\end{array}$ & $\mathrm{FC}_{4}, \mathrm{C}_{4}, \mathrm{CP}_{4}$ & $\begin{array}{l}\mathrm{PO}_{8}, \mathrm{PO}_{4} \\
\mathrm{O}_{2}\end{array}$ \\
\hline Alpha & 0 & 0 & 2 & 0 & 3 \\
\hline Beta1 & 0 & 1 & 1 & 0 & 0 \\
\hline Beta2 & 0 & 2 & 1 & 0 & 0 \\
\hline Delta & 0 & 0 & 0 & 0 & 0 \\
\hline Theta & 0 & 1 & 2 & 0 & 0 \\
\hline
\end{tabular}




\section{Subject 8}

\begin{tabular}{|c|l|l|l|l|l|}
\hline $\begin{array}{c}\text { Changes in the } \\
\text { Negative } \\
\text { Direction }\end{array}$ & \multicolumn{1}{|c|}{ Frontal Left } & $\begin{array}{c}\text { Temporal } \\
\text { Left }\end{array}$ & Parietal Left & \multicolumn{1}{|c|}{ Central Left } & $\begin{array}{c}\text { Occipital } \\
\text { Left }\end{array}$ \\
\hline $\begin{array}{c}\text { Electrodes of the } \\
\text { region }\end{array}$ & $\begin{array}{l}\mathrm{FP}_{1}, \mathrm{AF}_{7}, \mathrm{AF}_{3}, \\
\mathrm{~F}_{7}, \mathrm{~F}_{3}, \mathrm{FC}_{3}, \mathrm{FT}_{7}\end{array}$ & $\mathrm{FT}_{7}, \mathrm{~T}_{7}, \mathrm{TP}_{7}$ & $\begin{array}{l}\mathrm{TP}_{7}, \mathrm{CP}_{3}, \mathrm{P}_{7}, \\
\mathrm{P}_{3}, \mathrm{PO} 7, \mathrm{PO}_{3}\end{array}$ & $\mathrm{FC}_{3}, \mathrm{C}_{3}, \mathrm{CP}_{3}$ & $\begin{array}{l}\mathrm{PO}_{7}, \mathrm{PO}_{3}, \\
\mathrm{O}_{1}\end{array}$ \\
\hline Alpha & 0 & 0 & 0 & 0 & 0 \\
\hline Beta1 & 0 & 2 & 1 & 0 & 0 \\
\hline Beta2 & 0 & 0 & 0 & 0 & 0 \\
\hline Delta & 0 & 0 & 0 & 0 & 0 \\
\hline Theta & 0 & 0 & 0 & 0 & 0 \\
\hline
\end{tabular}

\begin{tabular}{|c|c|c|c|c|c|}
\hline $\begin{array}{c}\text { Changes in the } \\
\text { Negative } \\
\text { Direction }\end{array}$ & Frontal Right & $\begin{array}{c}\text { Temporal } \\
\text { Right }\end{array}$ & $\begin{array}{c}\text { Parietal } \\
\text { Right }\end{array}$ & Central Right & $\begin{array}{c}\text { Occipital } \\
\text { Right }\end{array}$ \\
\hline $\begin{array}{l}\text { Electrodes of the } \\
\text { region }\end{array}$ & $\begin{array}{l}\mathrm{FP}_{2}, \mathrm{AF} 4, \mathrm{~F}_{8}, \mathrm{~F}_{4}, \\
\mathrm{~F}_{8}, \mathrm{FC} 4, \mathrm{FT}_{8}\end{array}$ & $\mathrm{FT}_{8}, \mathrm{~T}_{8}, \mathrm{TP}_{8}$ & $\begin{array}{l}\mathrm{TP}_{8}, \mathrm{CP}_{4}, \mathrm{P}_{8} \\
\mathrm{P}_{4}, \mathrm{PO}_{8}, \mathrm{PO}_{4}\end{array}$ & $\mathrm{FC}_{4}, \mathrm{C}_{4}, \mathrm{CP}_{4}$ & $\begin{array}{l}\mathrm{PO}_{8}, \mathrm{PO}_{4}, \\
\mathrm{O}_{2}\end{array}$ \\
\hline Alpha & 0 & 2 & 3 & 0 & 1 \\
\hline Beta1 & 1 & 3 & 1 & 0 & 0 \\
\hline Beta2 & 1 & 3 & 2 & 1 & 0 \\
\hline Delta & 4 & 3 & 6 & 3 & 2 \\
\hline Theta & 0 & 1 & 1 & 0 & 0 \\
\hline
\end{tabular}

\section{Subject 9}

\begin{tabular}{|c|l|l|l|l|l|}
\hline $\begin{array}{c}\text { Changes in the } \\
\text { Negative } \\
\text { Direction }\end{array}$ & \multicolumn{1}{|c|}{ Frontal Left } & $\begin{array}{c}\text { Temporal } \\
\text { Left }\end{array}$ & Parietal Left & \multicolumn{1}{c|}{ Central Left } & $\begin{array}{l}\text { Occipital } \\
\text { Left }\end{array}$ \\
\hline $\begin{array}{c}\text { Electrodes of the } \\
\text { region }\end{array}$ & $\begin{array}{l}\mathrm{FP}_{1}, \mathrm{AF}_{7}, \mathrm{AF}_{3}, \\
\mathrm{~F}_{7}, \mathrm{~F}_{3}, \mathrm{FC}_{3}, \mathrm{FT}_{7}\end{array}$ & $\mathrm{FT}_{7}, \mathrm{~T}_{7}, \mathrm{TP}_{7}$ & $\begin{array}{l}\mathrm{TP}_{7}, \mathrm{CP}_{3}, \mathrm{P}_{7}, \\
\mathrm{P}_{3}, \mathrm{PO}_{7}, \mathrm{PO}_{3}\end{array}$ & $\mathrm{FC}_{3}, \mathrm{C}_{3}, \mathrm{CP}_{3}$ & $\begin{array}{l}\mathrm{PO}_{7}, \mathrm{PO}_{3}, \\
\mathrm{O}_{1}\end{array}$ \\
\hline Alpha & 0 & 2 & 1 & 0 & 0 \\
\hline Beta1 & 2 & 3 & 1 & 0 & 0 \\
\hline Beta2 & 2 & 3 & 1 & 0 & 0 \\
\hline Delta & 0 & 0 & 0 & 0 & 0 \\
\hline Theta & 0 & 1 & 1 & 0 & 0 \\
\hline
\end{tabular}

\begin{tabular}{|c|c|c|c|c|c|}
\hline $\begin{array}{c}\text { Changes in the } \\
\text { Negative } \\
\text { Direction }\end{array}$ & Frontal Right & $\begin{array}{c}\text { Temporal } \\
\text { Right }\end{array}$ & $\begin{array}{l}\text { Parietal } \\
\text { Right }\end{array}$ & Central Right & $\begin{array}{c}\text { Occipital } \\
\text { Right }\end{array}$ \\
\hline $\begin{array}{l}\text { Electrodes of the } \\
\text { region }\end{array}$ & $\begin{array}{l}\mathrm{FP}_{2}, \mathrm{AF} 4, \mathrm{~F}_{8}, \mathrm{~F}_{4}, \\
\mathrm{~F}_{8}, \mathrm{FC} 4, \mathrm{FT}_{8}\end{array}$ & $\mathrm{FT}_{8}, \mathrm{~T}_{8}, \mathrm{TP}_{8}$ & $\begin{array}{l}\mathrm{TP}_{8}, \mathrm{CP}_{4}, \mathrm{P}_{8} \\
\mathrm{P}_{4}, \mathrm{PO}_{8}, \mathrm{PO}_{4}\end{array}$ & $\mathrm{FC}_{4}, \mathrm{C}_{4}, \mathrm{CP}_{4}$ & $\begin{array}{l}\mathrm{PO}_{8}, \mathrm{PO}_{4}, \\
\mathrm{O}_{2}\end{array}$ \\
\hline Alpha & 0 & 2 & 3 & 2 & 0 \\
\hline Beta1 & 2 & 3 & 1 & 0 & 0 \\
\hline Beta2 & 1 & 0 & 0 & 0 & 0 \\
\hline Delta & 0 & 0 & 0 & 0 & 0 \\
\hline Theta & 0 & 1 & 1 & 0 & 0 \\
\hline
\end{tabular}




\subsection{Asymmetry Ratio Analysis}

Another way to analyze the results from the table is by means of the asymmetry ratio, which relates the left hemisphere to the right hemisphere. Each hemisphere appears to be specialized for some behaviors. For example, it appears that the right hemisphere is dominant for spatial abilities, visual imagery and music. On the contrary, the left hemisphere may be more dominant for language, math and logical abilities. Evidently, these are generalizations because in normal people, the two hemispheres work together and are connected, and share information through the corpus callosum, which is a thick band of 200-250 million nerve fibers [26].

In the following formula $\mathrm{K}$ is the ratio; $\mathrm{R}$ is the number of electrodes active in the right hemisphere and $\mathrm{L}$ is the number of electrodes active in the left hemisphere. If the ratio is negative, that means that the left hemisphere was more active than the right and vice versa if the ratio is positive, then the right hemisphere is more active.

$$
K=\frac{(R-L)}{(R+L)}
$$

This ratio is calculated for each region of the cerebral cortex. It is calculated five times for each of the regions in study such as, frontal, temporal, parietal, central and occipital. A comparison is established for the left and right hemispheres.

For instance, when analyzing the ratio for increasing changes with respect to the mean in alpha frequency for auditory task (see table below), it is found that in the frontal region $\mathrm{K}=0.14$. This means that since the ratio is positive, the distribution of active 
electrodes is more predominant in the right hemisphere. For the temporal and parietal regions $\mathrm{K}=0$, which emphasis that there was no alpha activity at all in any of the hemispheres. In the central and occipital regions $\mathrm{K}=-1$, which denotes that alpha activity is now shifted to the left hemisphere.

5.5 Table: Asymmetry Ratio (Listening Task Positive Values)

\begin{tabular}{|l|c|c|c|c|c|}
\hline BANDS & ALPHA & BETA 1 & BETA 2 & DELTA & THETA \\
\hline Frontal & 0.14 & 0.47 & 0.09 & -0.023 & 0.16 \\
\hline Temporal & 0 & 0 & 0 & 0 & 0 \\
\hline Parietal & 0 & 0.14 & 0.1 & 0 & 0 \\
\hline Central & -1 & 1 & 1 & 0 & 0 \\
\hline Occipital & -1 & 0.11 & 0 & 0 & 0 \\
\hline
\end{tabular}

The next two tables reflect the asymmetry values for each frequency band in general. The results are obtained from the number of electrodes active in each hemisphere at each frequency band. The results show the distribution of activity depending of the frequency under analysis. For instance, alpha-increasing changes with respect to the mean during the auditory/comprehension process seems to have slightly more activity in the right hemisphere, even though there is also evident activity in the left hemisphere. Nevertheless, for the decreasing changes with respect to the mean, even though the activity is bilateral, there exist a little more activity in the left hemisphere. Beta 1 and Beta 2 have more increasing changes in activity in the right hemisphere, but with respect 
to the decreasing changes, there is almost no activity in either hemisphere. Delta and theta frequency bands have a bilateral distribution of increasing changes of activity.

5.6 Table: Asymmetry Ratio (Auditory/Comprehension Task Cumulative Values)

\begin{tabular}{|c|c|c|c|c|c|}
\hline BANDS & ALPHA & BETA 1 & BETA 2 & DELTA & THETA \\
\hline Hot & 0.17 & 0.25 & 0.238 & 0 & 0 \\
\hline Cold & -0.09 & -0.273 & -0.091 & 0.71 & -0.053 \\
& & & & & \\
\hline
\end{tabular}

5.7 Table: Asymmetry Ratio (Answer Task Cumulative Values)

\begin{tabular}{|c|c|c|c|c|c|}
\hline BANDS & ALPHA & BETA 1 & BETA 2 & DELTA & THETA \\
\hline Hot & 0.11 & 0.25 & 0.33 & 0 & -0.143 \\
\hline Cold & -0.09 & -0.14 & -0.23 & 0.846 & -0.27 \\
& & & & & \\
\hline
\end{tabular}

Based on this asymmetry ratio, we can conclude that the increasing and decreasing changes with respect to the mean during the auditory/comprehension and response times are located as follows: 
5.8 Table: Auditory/Comprehension Task (Activity Localization)

\begin{tabular}{|c|c|c|}
\hline Auditory & Positive & Negative \\
\hline Alpha & $\begin{array}{l}\text { Bilateral frontal activity } \\
\text { (more to the Right frontal) }\end{array}$ & $\begin{array}{c}\text { Temporal and parietal Left } \\
\text { and Right (more to the } \\
\text { Left) }\end{array}$ \\
\hline Beta 1 & $\begin{array}{l}\text { Activity in the Right frontal } \\
\text { and occipital lobes (more in } \\
\text { the Right occipital lobe) }\end{array}$ & $\begin{array}{l}\text { Temporal and parietal } \\
\text { activity in the Right and } \\
\text { Left hemispheres }\end{array}$ \\
\hline Beta 2 & $\begin{array}{l}\text { Occipital and partially } \\
\text { parietal Left and Right }\end{array}$ & Temporal and parietal Left \\
\hline Delta & $\begin{array}{l}\text { Bilateral frontal activity } \\
\text { (Left and Right hemisphere) }\end{array}$ & $\begin{array}{l}\text { Not much activity. Some } \\
\text { rare activity in the } \\
\text { temporal and central Right } \\
\text { lobes }\end{array}$ \\
\hline Theta & $\begin{array}{c}\text { Bilateral frontal activity } \\
\text { (Left and Right hemisphere) }\end{array}$ & Temporal and parietal Left \\
\hline
\end{tabular}


5.9 Table: Answering Task (Activity Localization)

\begin{tabular}{|c|c|c|}
\hline Answering & Positive & Negative \\
\hline Alpha & $\begin{array}{l}\text { Frontal activity (More to the } \\
\text { Right hemispheres) }\end{array}$ & $\begin{array}{c}\text { Temporal and parietal Left } \\
\text { and Right (more to the } \\
\text { Left) }\end{array}$ \\
\hline Beta 1 & $\begin{array}{l}\text { Right frontal and occipital } \\
\text { activity) }\end{array}$ & $\begin{array}{l}\text { Temporal and parietal in } \\
\text { both hemispheres (more to } \\
\text { the Left) }\end{array}$ \\
\hline Beta 2 & $\begin{array}{l}\text { Occipital and parietal Left, } \\
\text { and some activity in both } \\
\text { hemispheres in the frontal } \\
\text { row) }\end{array}$ & $\begin{array}{l}\text { Some rare activity in the } \\
\text { central Left region }\end{array}$ \\
\hline Delta & $\begin{array}{l}\text { Bilateral frontal activity } \\
\text { Left and Right } \\
\text { hemispheres) }\end{array}$ & $\begin{array}{c}\text { Not much activity. Some } \\
\text { rare activity in the central } \\
\text { Right lobe }\end{array}$ \\
\hline Theta & $\begin{array}{l}\text { Bilateral frontal activity } \\
\text { (more to the Right) }\end{array}$ & $\begin{array}{l}\text { Almost no activity (some } \\
\text { rare activity to the } \\
\text { temporal Left) }\end{array}$ \\
\hline
\end{tabular}

In the table 5.4 shown above, it is noted referring to the negative changes of most of the frequency bands that the left hemisphere is more involved. This agrees with previous studies that affirm that the left hemisphere is more implicated with the language since Broca's and Wernicke's areas lie on this hemisphere. Broca said that language 
resides in the frontal lobe and most of all the positive changes in the table 5.4 reside in the frontal region of the brain. Also, in table 5.5, referring to the negative changes, even though there is no much activity in any of the hemispheres, there exits some activity showing in the left side. So, this confirms the importance of the left hemisphere in producing the speech. 


\section{CHAPTER VI}

\subsection{Conclusion}

This thesis serves as groundwork on the use of the ESI-256 machine to study the changes of the frequency components in brain activity during an auditory/comprehension process. An important goal was to understand all the features of the ESI-256 machine in order to analyze EEG signals in the context of brain activities related to well designed auditory and listening comprehension tests.

Chapter 1 introduces the requirements and design framework necessary for developing the automated algorithm that sought to characterize dynamic brain patterns during the monitoring of the auditory and listening tests.

Chapter 2 provided a description of the ESI-256 machine and the practical design aspects involved in carrying out the experiments. A thorough explanation of all the features used from the ESI machine was provided in details. In the design setup, it was critical to have been part of a team that shared experience in both the engineering design aspect and the clinical know how. The infrastructure made available through the Neuroscience Center at Miami Children's Hospital facilitated this research work and helped not only in the implementation part, but also in carrying out the feasibility studies needed to confirm the soundness of the algorithm.

Chapter 3 establishes the main characteristics of EEG data related to the auditory/listening comprehension process are assessed in the context of the ESI-256 
machine. Issues pertaining to frequency content, relevance of the different frequency bands towards enhanced EEG analysis, dilemmas imposed by the ubiquitous, recording particularities, montage, and support software with related computer interface displays are all addressed in order to facilitate replication for other related research work.

Chapter 4 addressed both the auditory and listening comprehension process with their characterizing features in EEG recordings. In this Chapter, the focus was on determining which areas of the brain cause a particular function such listening and language comprehension. The main aim is to display these brain activities through statistically verified EEG results that will facilitate impending interpretations. Pertinent issues relate in this case to determining the precise time-course of cortical activity as questions are being processed. Time course information is crucial to the investigation of language comprehension, involving the integration of phonology, syntax, and semantics among other things.

Chapter 5 explained the complete procedure followed in order to interpret the EEG signals during an auditory/comprehension task. Through the development of an automated algorithm, a detailed topographical study was performed and visualized in order to learn which cortical lobes of the brain are active during an auditory/comprehension process. Also, a detailed comparison with the purpose of showing similarities/dissimilarities of the behavior of the distinct frequency bands between all the 9 patients evaluated is provided. Topographical representations are also provided for visual appreciation of the resulting multitude of brain patterns. The algorithm developed in this thesis concentrated on the frequency components of these 
EEG signals, and what they all consequently meant in the whole scheme of the auditory/comprehension process. The results obtained provide distinguishable behaviors that made sense within the common knowledge of brain functional mapping.

The aim of this study was thus to identify those frequencies and associated regions in the brain that best characterize brain activity associated with an auditory/comprehension test. The objectives attained included:

- An analysis of the differences that exist between auditory/comprehension tasks vs. the answering phase.

- A visualization scheme through color-coding maps showing the different activities of the cerebral hemispheres (right vs. left).

- A pattern classification process that contrasted the EEG signals of any new subject included in the experimental study in order to evaluate similar/dissimilar behaviors with those patients already in the database.

All of these objectives were addressed through the analysis of the changes in activity introduced for the different frequency bands.

The statistical analysis of the results obtained reveals the following outcomes:

(1) There were differences of regions activation in all the frequency bands between the left and right hemispheres;

(2) There were differences in the activation of brain regions (frontal, temporal, parietal, central, and occipital); 
(3) There were no relevant differences in the alpha, delta, and theta bands between the two tasks;

(4) The left hemisphere was more involved with the auditor/comprehension task;

(5) The frontal and temporal lobes were more involved in the auditory and answering tasks since Wernicke's area, which processes the language, is located where the parietal lobe meets the temporal lobe and Broca's area, which produces the speech, is located in the frontal lobe.

During this study we were able to confirm that there exist observed patterns of the activities in the brain in different regions, which relate the different behaviors of all the frequency bands in a similar way for all the subjects.

An extension to this research endeavor is one that would address the problem more specifically; taking into consideration groups of subjects with similar cultural backgrounds or shares a same first language. It would be also relevant to have another group that is bilingual for example. In this way, the analysis and conclusion about a certain brain pattern activity could be put into context within the different groups associated with the study. For instance, subjects that have English as the first language, subjects, whose first language is not English, subjects with attention disorders, among others could constitute a first such study. This thesis on the other hand considered the 9 subjects without regard to such cultural or spoken language requirements.

If we separate those groups, more accurate conclusions could be performed for future investigations about this important cognitive process. 
The contribution of this thesis is in the development of a specific non-invasive technique based on EEG data that can be easily implemented in a clinical environment. Mapping the brain with non-invasive techniques produces results that are effective and may be applied to patients, without any health risks. It is this last assertion that this thesis has tried to attain while focusing on auditory and listening comprehension. 


\section{LIST OF REFERENCES}

[1] A. Gevins, Smith, "Neurophysiological measures of working memory and individual differences in cognitive ability and cognitive style", Cerebral Cortex, 10, 829-839, 2000.

[2] B. Greenstein and A. Greenstein: Color Atlas of Neuroscience, Neuroanatomy and Neurophysiology, Thieme Stuttgart New York, 2000.

[3] Carrie, J. R., "A Technique for Analyzing Transient EEG abnormalities," Electroencephalography and Clinical Neurophysiology, 32: 199 - 201, 1972.

[4] Chellaramani, R., McEvoy, L., Chung, S., Smith, \& Gevins, A."Impact of Benzodiazepines on Behavior and Neurophysiology Measures of Working Memory."Cognitive Neuroscience Society Eighth Annual Meeting. March, New York, 2001.

[5] Chellaramani, R., Pellouchoud, E., Smith, M. E., Gevins, A. "Effect of Stimulant medication on attention and working memory in children with ADHD." Cognitive Neuroscience Society Ninth Annual Meeting. April, San Francisco, 2002.

[6] Dorffner G.: Neural Networks for EEG Classification: An Introduction (abstract), Journal of Clinical Monitoring, 2(9)138, 1993.

[7] F. H. Martini, Fundamentals of Anatomy \& Physiology, Fifth Edition, Prentice Hall, New Jersey 07458, 2001.

[8] Frisby, J. P., Seeing: Illusion, Brain, and Mind, Oxford University Press, 1978.

[9] Gevins, A., Leong, H., Smith, M.E., Le, J., \& Du, R., "Mapping Cognitive Brain Function with Modern High-Resolution Electroencephalography," Trends in Neurosciences, 18(10), 429-436, 1995.

[10] Gevins, A., Remonds, A., Handbook Of Electroencephalography And Clinical Neurophysiology, 1, 1987.

[11] Gevins, A., \& Smith, M. E. "Detecting transient cognitive impairment with EEG pattern recognition." Aviat Space, and Environmental Medicine, 70, 1018-1024, 1999.

[12] Gevins, A., Smith, M.E., Leong, H., McEvoy, L., Whitfield, S., Du, R., \& Rush, G., "Monitoring Working Memory Load during Computer-Based Tasks with EEG Pattern Recognition Methods," Human Factors, 40(1), 1-13, 1998.

[13] G.J.C. Lokhorst. "The first theory about hemispheric specialization: Fresh light on an old codex", Journal of the History of Medicine and Allied Sciences, 51 (3): 293-312, 1996. 
[14] Gonzalez, R. C., Woods, R. E., "Image Transforms," Digital Image Processing, Addison-Wesley Publishing Company, 81 - 159, 1993.

[15] Ilan, A. B., \& Gevins, A. "Prolonged neurophysiological effects of cumulative wine drinking." Alcohol, 25, 137-152, 2002.

[16] Inouye, Ishihara, and Shinosaki, "Mathematically Derived Frequency Correlates in Cerebral Function: Theoretical and Clinical Implications for Neurofeedback Training", Journal of Neurotherapy, 1995.

[17] Jasper, H. H., Soloman, P., \& Bradley, C. "Electroencephalographic analysis of behavior problems in children". American Journal of Psychiatry, 95, 641 - 658., 1938.

[18] Lubar, J. F., \& Shouse, M. N. "EEG and behavioral changes in a hyperactive child concurrent with training of the sensorimotor rhythm (SMR)." A preliminary report.

[19] Makeig, S. and Inlow, M., "Lapses in alertness: coherence of fluctuations in performance and the EEG spectrum" Electroencephalography and Clinical Neurophysiology, 86:23-35 (1993).

[20] McEvoy, L. K., Nichols, E. A., Page, B., Smith, M. E., Gevins, A. "Working and Reognition Memory in older Subjects: Effects of an Antihistamine." Cognitive Neuroscience Society Ninth Annual Meeting, April, San Francsico, 2002.

[21] Misiti, M., Misiti Y., Oppenhein, G., Poggi, J. Wavelet Toolbox User's Guide, MathWorks, Inc, 1996.

[22] Neurosoft, Inc., Scan 4.1 Manual, Document Number 2203, Revision A, 1999.

[23] Nichols, E. A., Ilan, A. B., Smith, M.E. \& Gevins, A. "Effects of Marijuana on Neurophysiological Correlates of Working and Intermediate-Term Memory." Annual Meeting of Society for Neuroscience Conference. Nov, San Diego, 2001.

[24] Proakis, J. G., Dimitris, G. M., Digital Signal Processing, Principles, Algorithms and Applications, Prentice Hall, Third Edition, 1996.

[25] Shaw, J. C., "The Ubiquitous Alpha Rhytm - a Selective Review," Journal of Electrophysiological Technology, 18: 5-27, 1992.

[26] Sperry, R., "Some Effects of Disconnecting the Cerebral Hemispheres," Science, 217: $1223-1226,1982$.

[27] Springer, S.P., \& Deutsch, G., Left Brain, Right Brain. San Francisco, CA: W. H. Freeman, 1985. 
[28] Vetterli, M., Kovacevic, J., Wavelets and Subband Coding, Prentice Hall, NJ, 1995.

[29] Wong, P. K. H., Introduction to Brain Topography, Plenum Press, NY, 1991.

[30] Inouye, T.; lshihara, T.; Shinosaki, K. "Generating mechanism for frontal midline theta activity. "Rinsho Noha/Clin. Electroenceph. 26: 796-798 (1984).

[31] Mizuki, Y. "Frontal Lobe: Mental Function and EEG. Am. J. EEG Technol." 27:91$101,1987$. 


\section{APPENDICES}

\section{Appendix A}

\section{Manual for ESI-256 Machine Scan 4.0 Acquire}

1. Turn on amplifiers:

a. One at a time, starting with 1 , then 2 , then 3 , and so on until 8

b. Wait until SN1 is displayed in amplifier 1 before turning on amplifier 2. Do the same for the rest of the amplifiers

2. Re-start the computer

3. Login to the computer

a. User name: Administrator

b. Password: NeuroScan

4. Open Scan 4.0 Acquire

a. Start $->$ Programs $->$ Scan $4.0->$ Acquire

5. Select corresponding setup (for 41 electrodes or for up to 256)
a. Setup $->$ Select

i. For 41 electrodes using MCN system: "cap45.asm"

ii. For 256 electrodes: "cap256.asm"

6. Check impedances
a. Acquisition $->$ Impedance
b. Verify that the electrode impedances are not pink
c. Close impedance window

7. Begin acquisition
a. Acquisition $->$ Start acquisition

8. Record the acquisition
a. Save icon
b. System Disk E -> "Miami Children Hospital" folder $->$ create new folder named with date (example: if today's date is June $5^{\text {th }}, 2003$, name folder: “06-05-03")
c. File name: subject_name (example: if patient's name is Mercedes_Cabrerizo, save as "Mercedes_Cabrerizo")
d. Save button

9. Stop recording 
10. Save subject information

a. Subject $->$ input the information

b. Save as subject_name (example: if patient's name is Mercedes Cabrerizo, save as "Mercedes_Cabrerizo_Info")

11. After all recording is done, to shut down amplifiers:
a. Turn off amplifiers, one at a time, starting with 1 , then 2 , then 3 , and so on until 8
b. Close all programs
c. Log out of the computer
i. Start $\rightarrow$ shut down $\rightarrow$ log out 
Appendix B

\section{Markers for EEG Recordings}

F2 - Stop Listening

F7 - Start Listening

F10-Answer

F11 - No Response 


\section{Manual for ESI-256 Machine Scan 4.1 Edit \\ For Selection of Auditory/Answer Tasks}

1. Open continuous EEG recorded file:
a. C: / Auditory
b. Open folder for a specific date
c. Open original .cnt file (example: patient_name.cnt)

2. Select the "Mark a block" icon in the toolbar

3. Place the mouse on desired points to select start and ending points, one at a time

4. Save as:

patient_name_Listening\#.cnt, or

patient_name_Answering\#.cnt 


\section{Results of the Auditory/Comprehension Task}

For all Frequency Bands

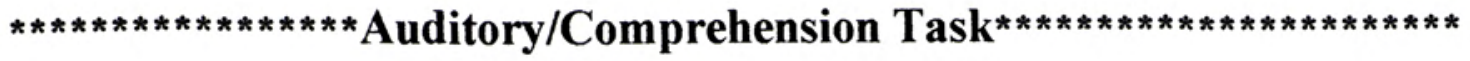

\section{1) SUBJECT D.R.}
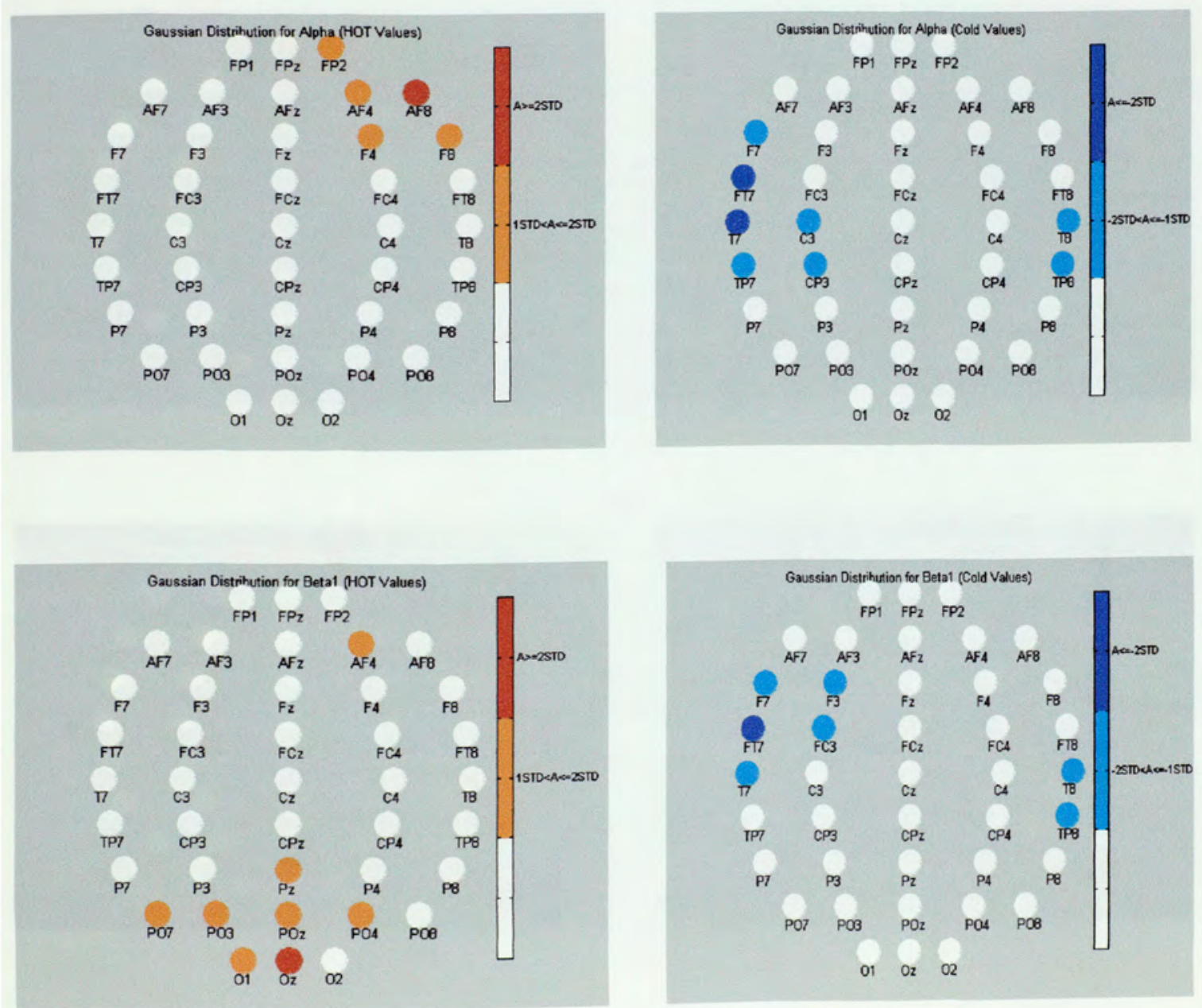

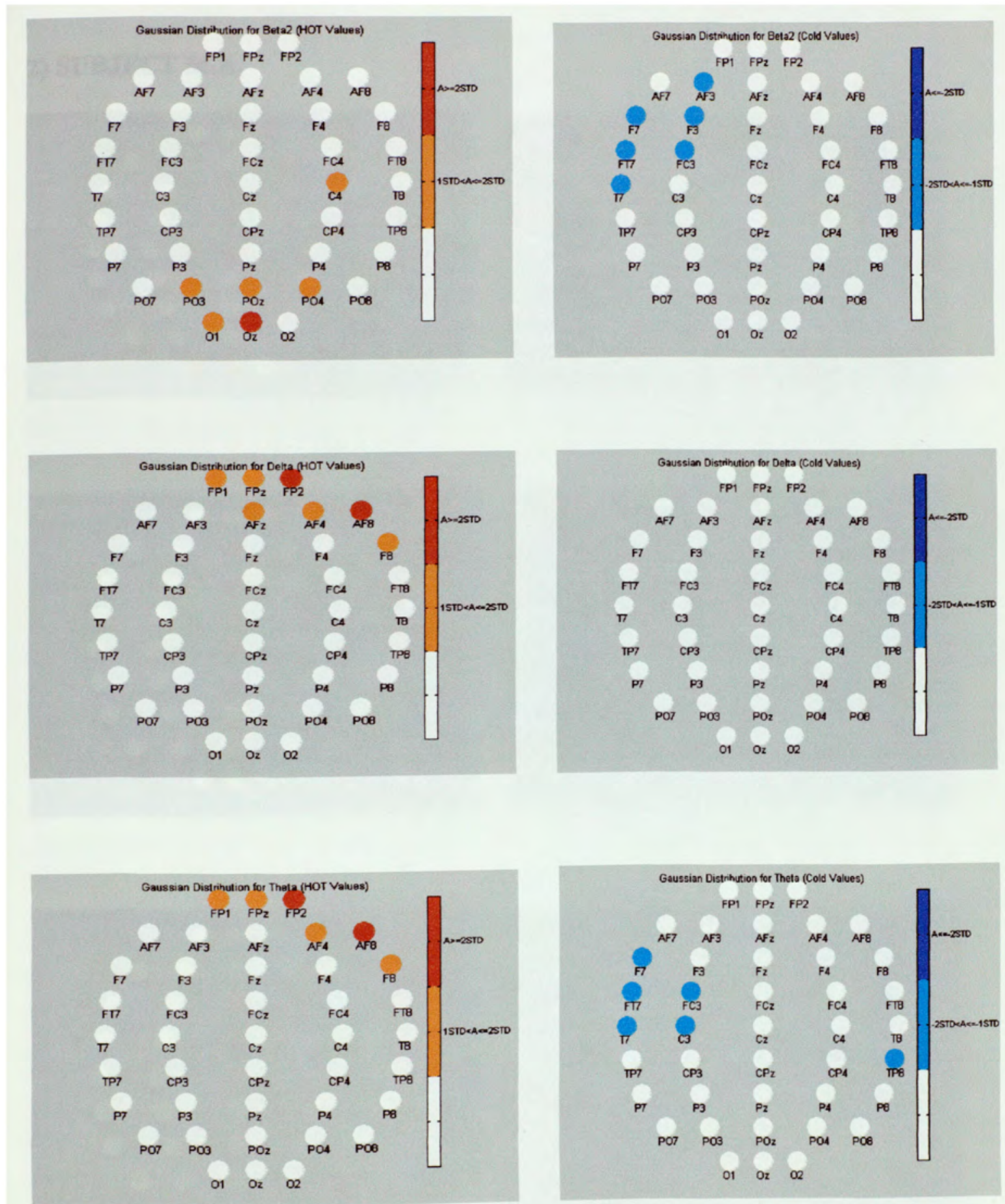


\section{2) SUBJECT M.A.}
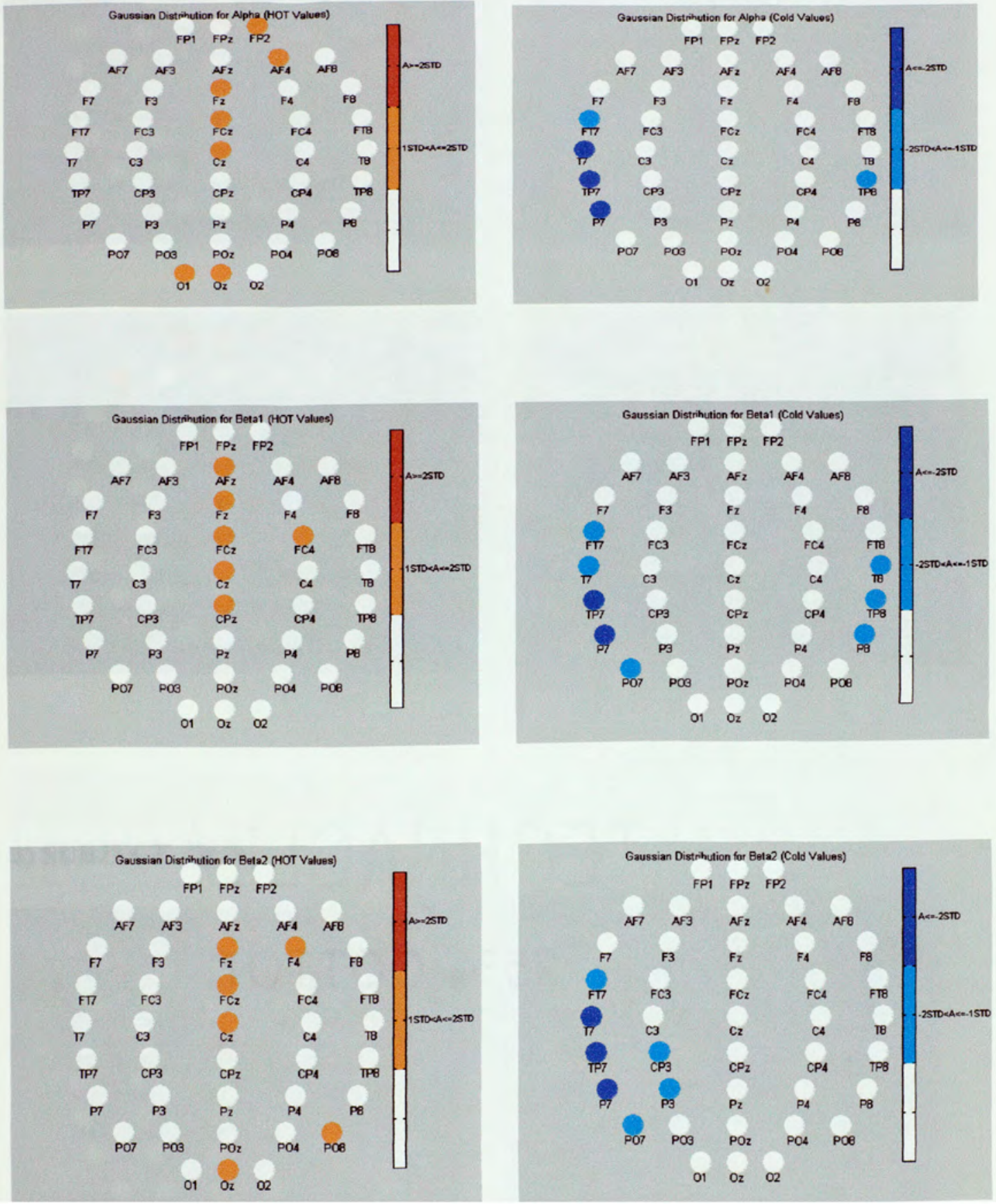

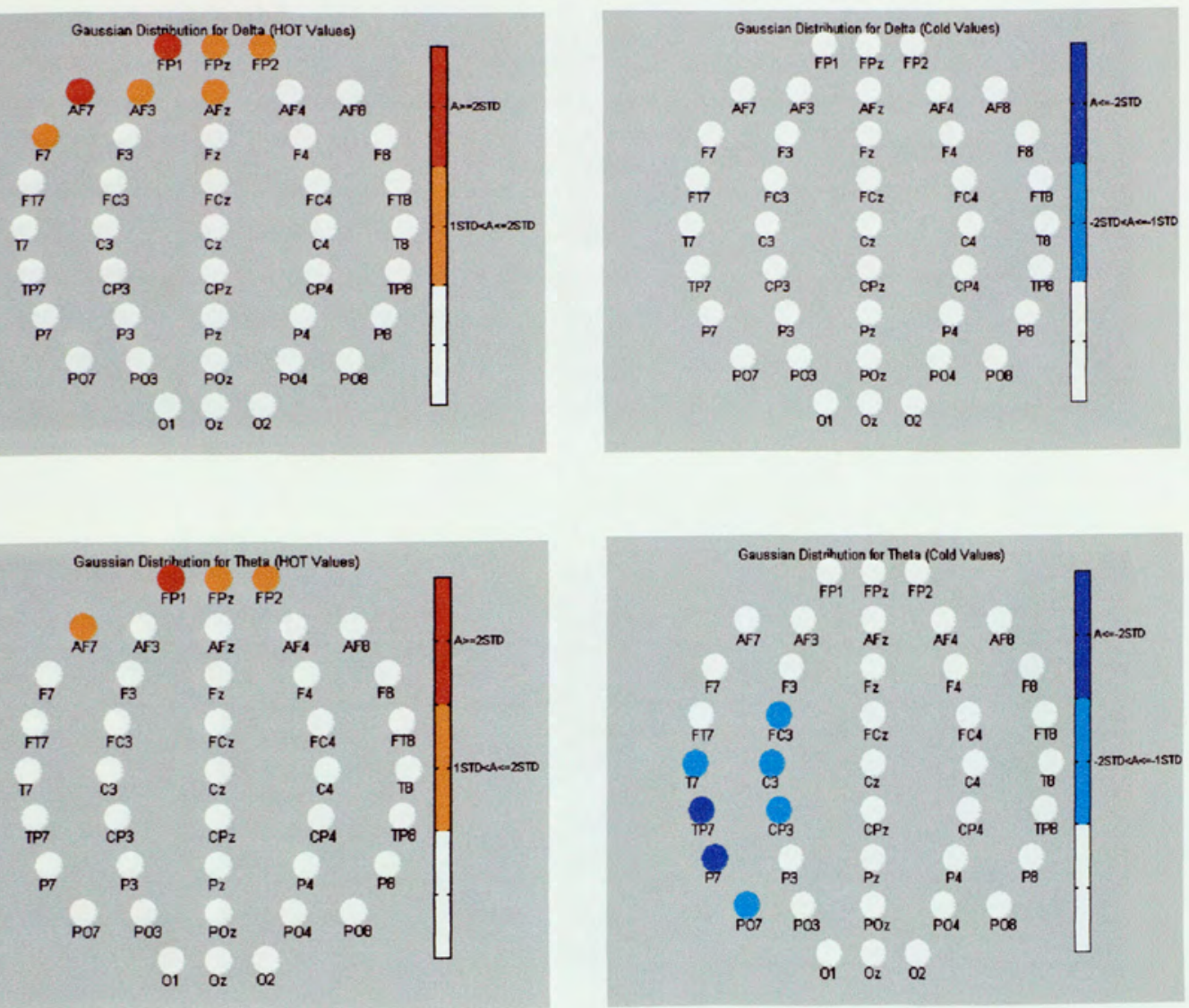

3) SUBJECT M.R.
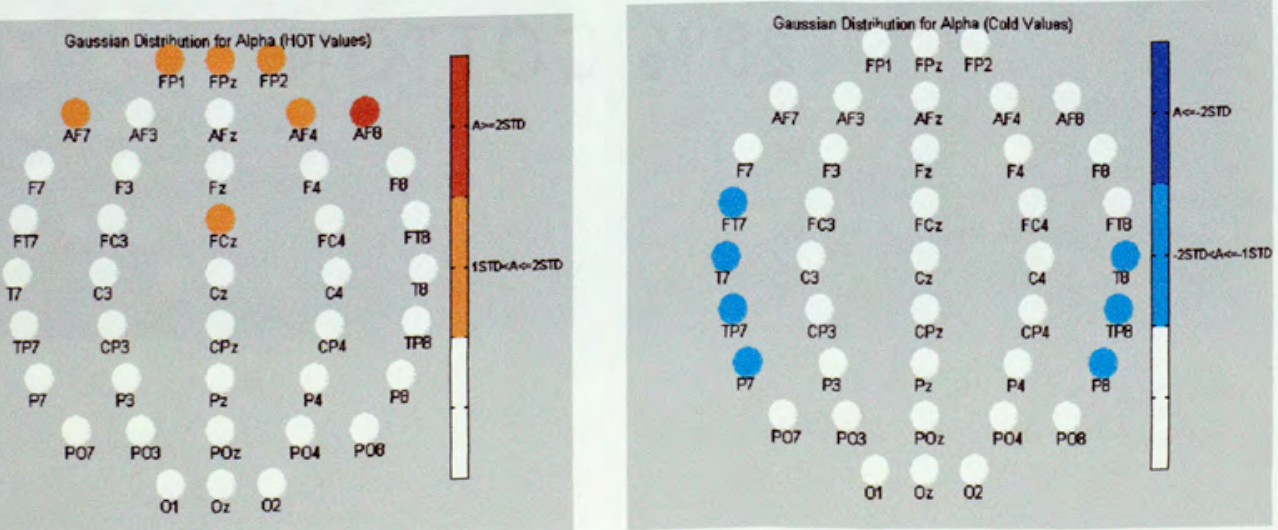

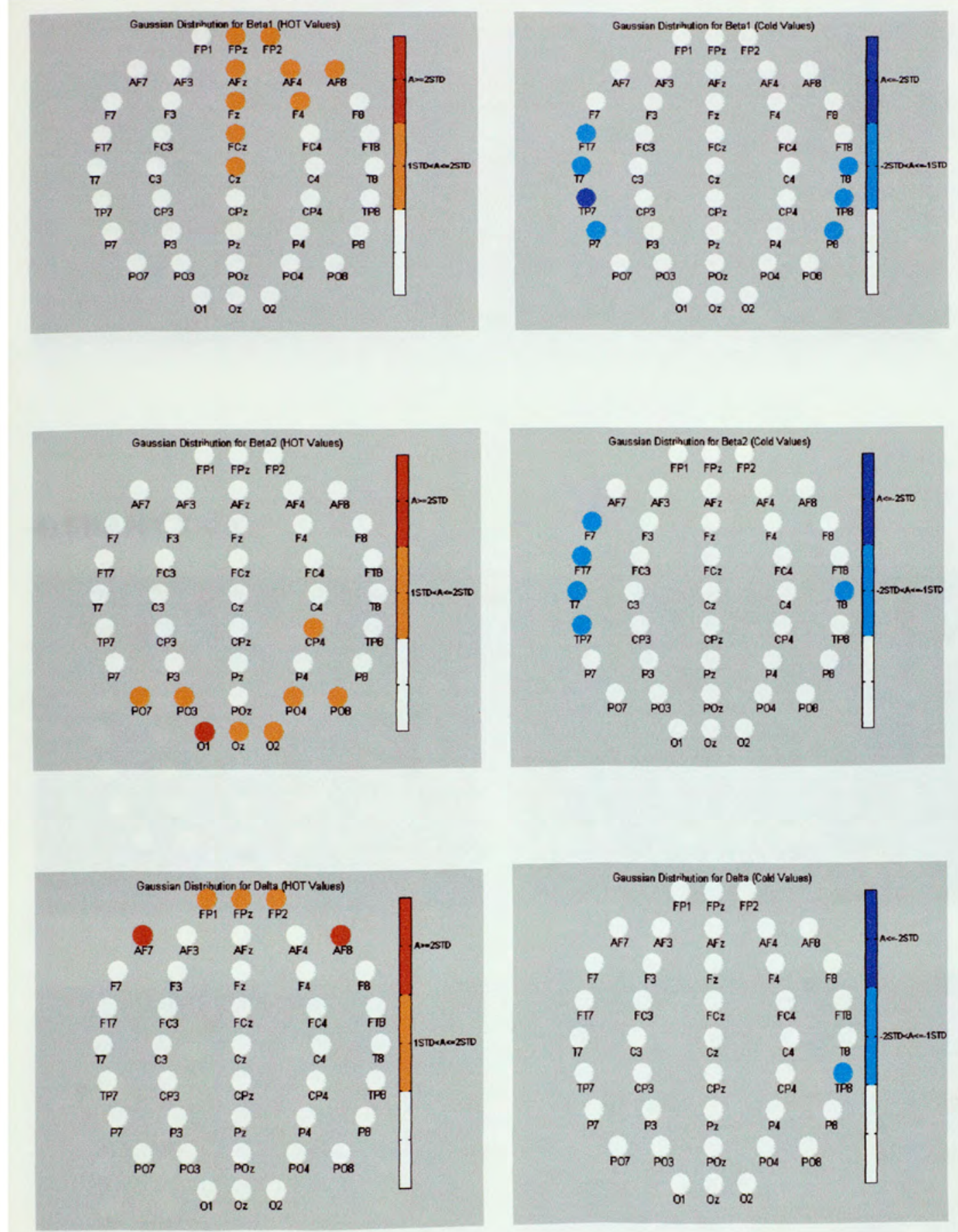

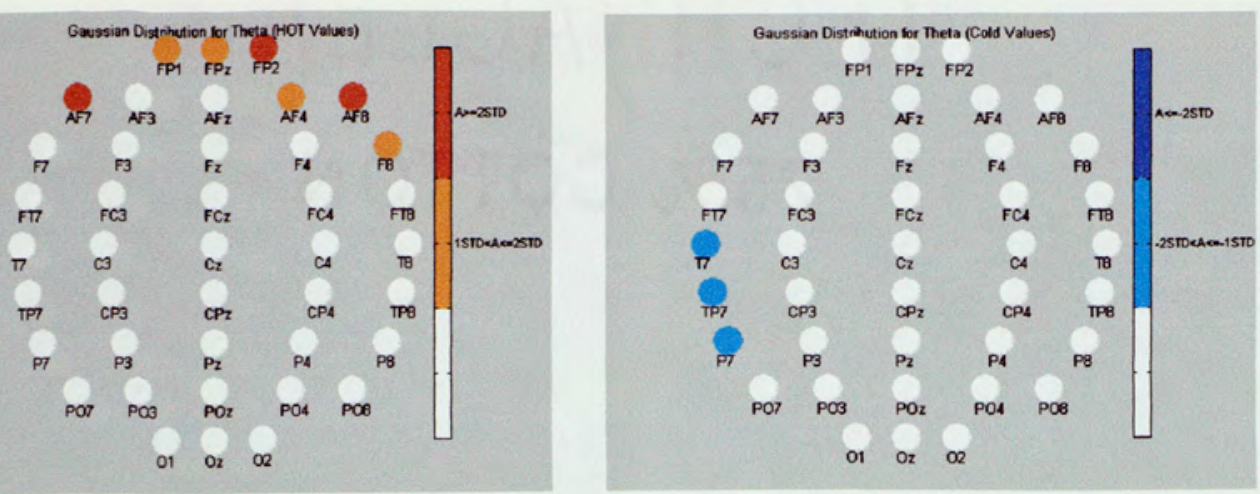

\section{4) SUBJECT C.C.}
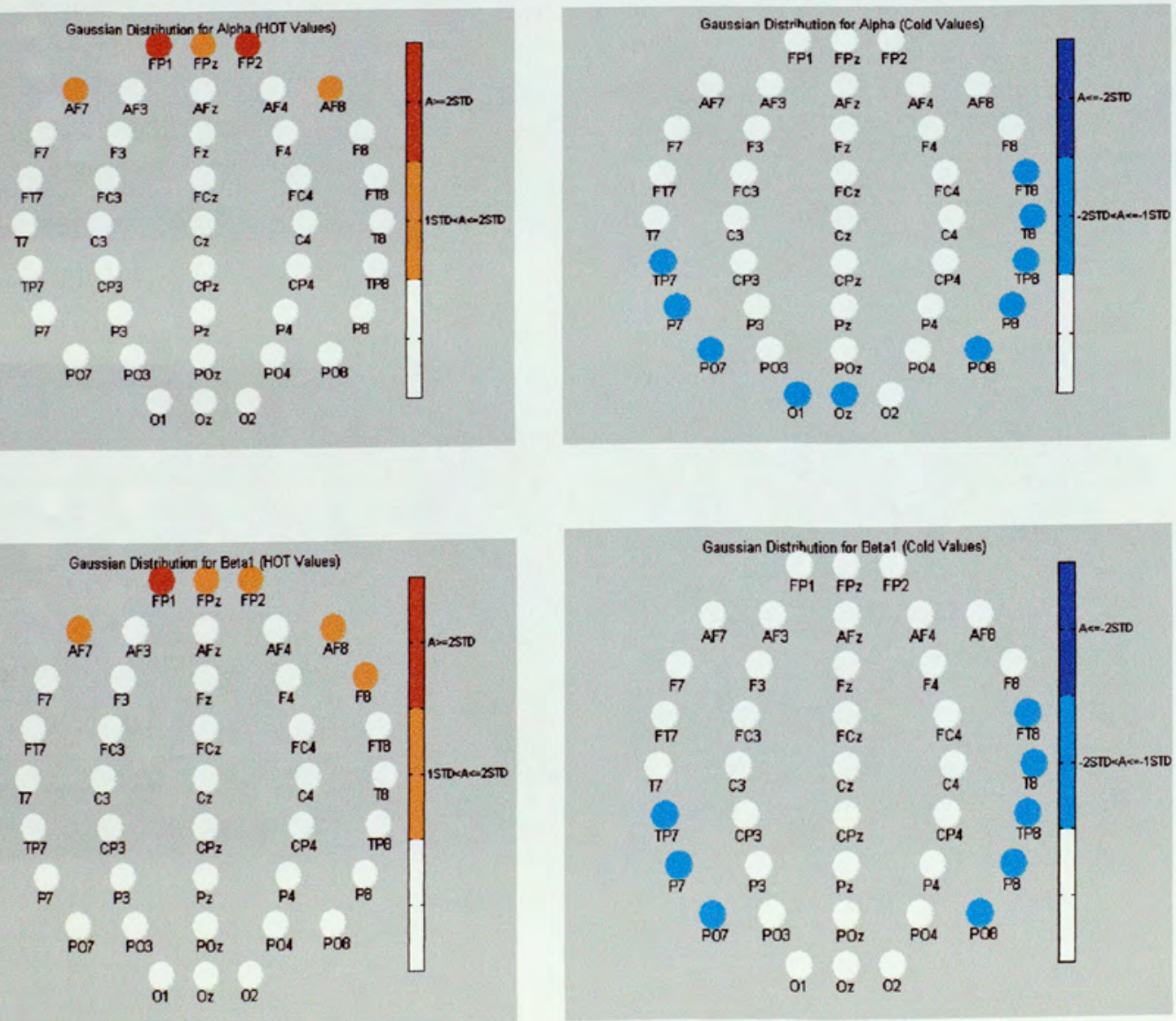

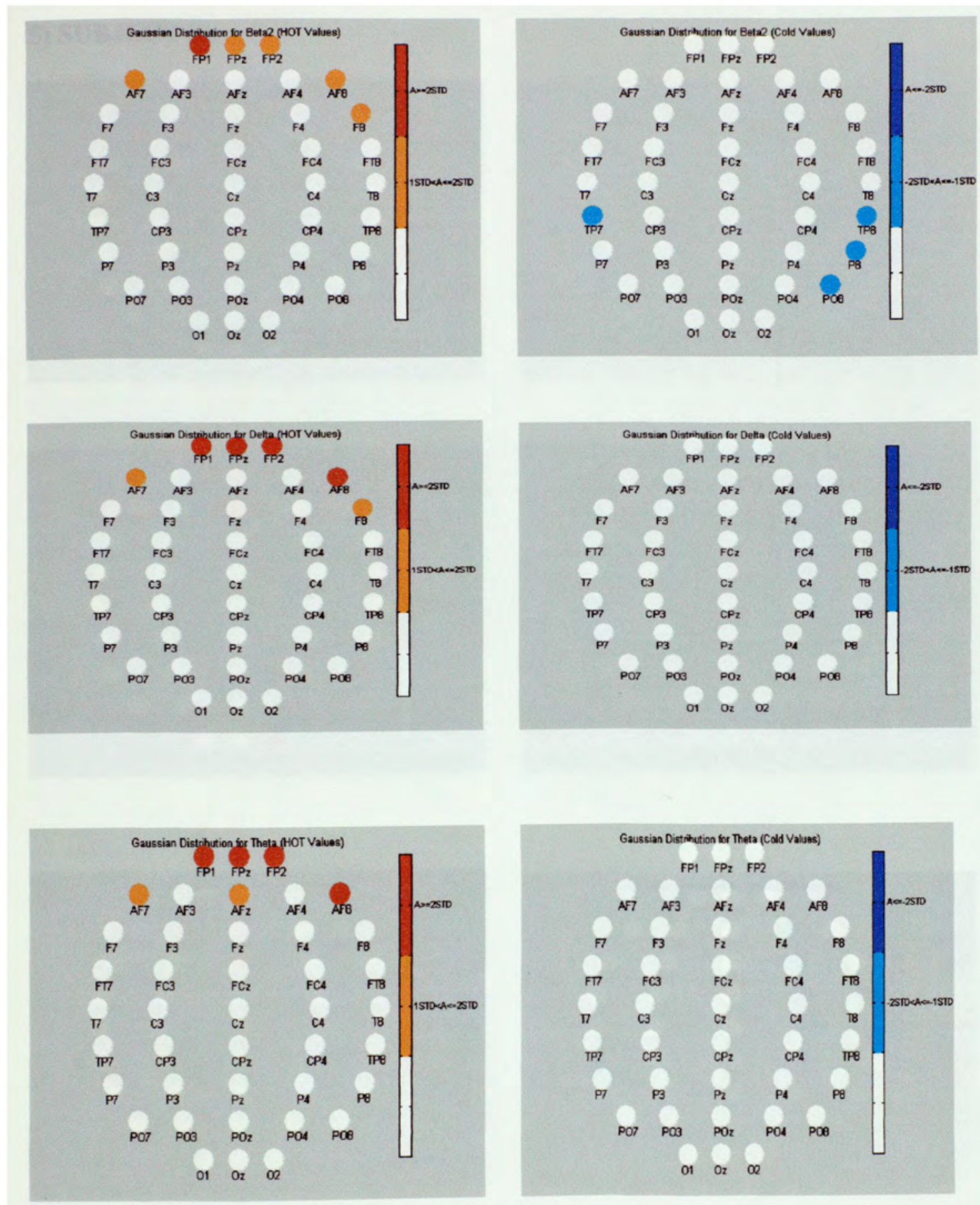


\section{5) SUBJECT G.}
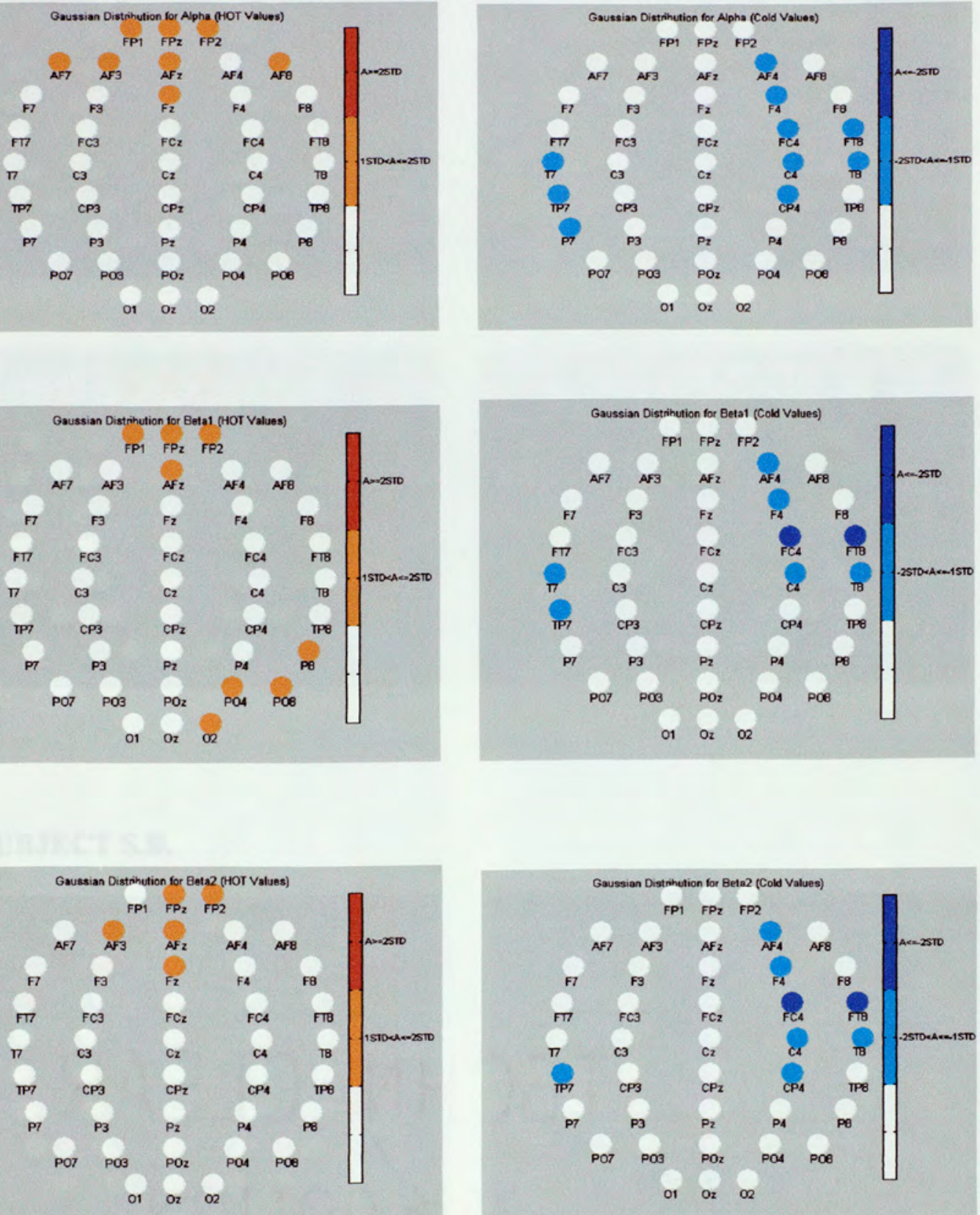

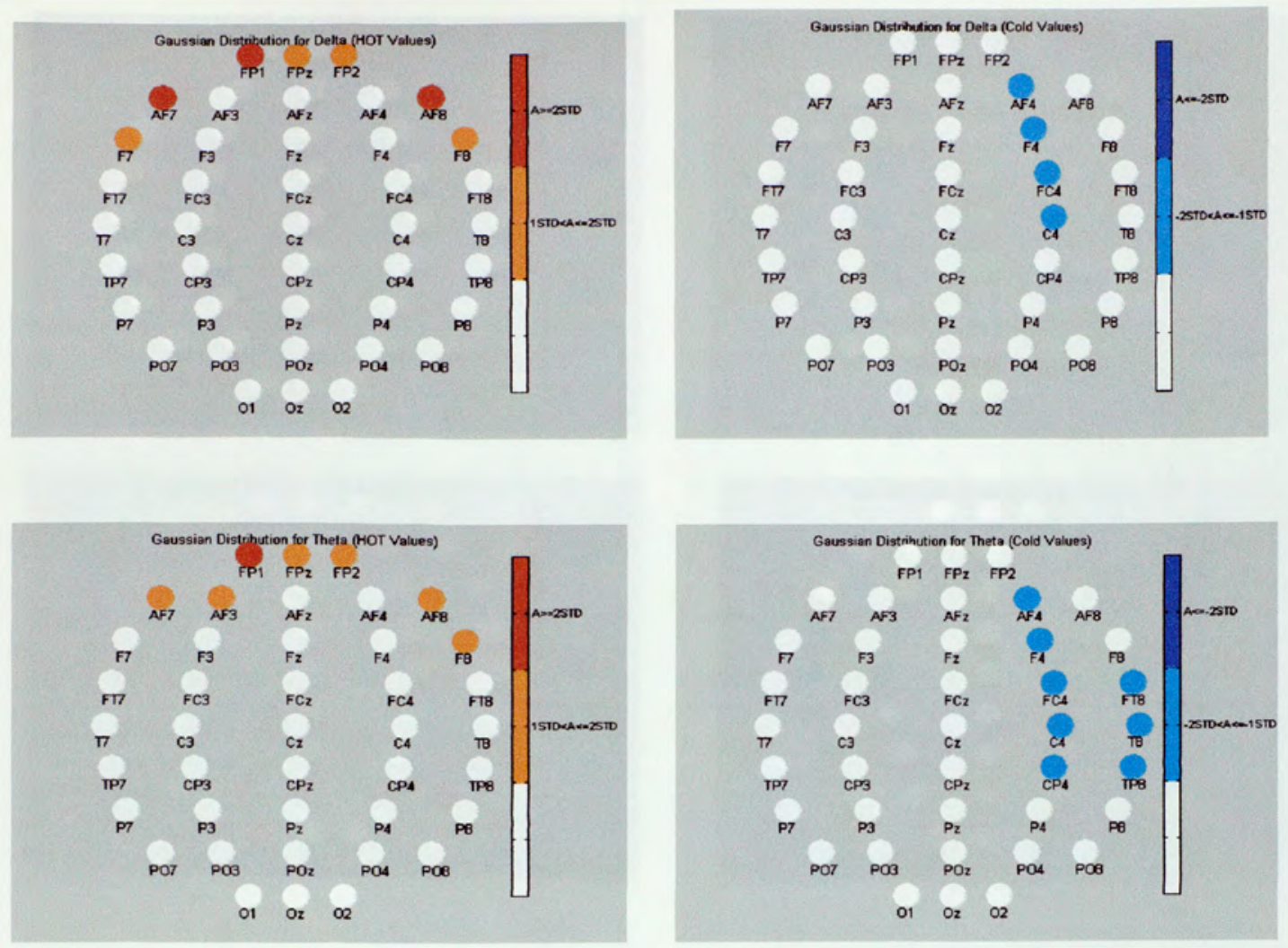

\section{6) SUBJECT S.B.}
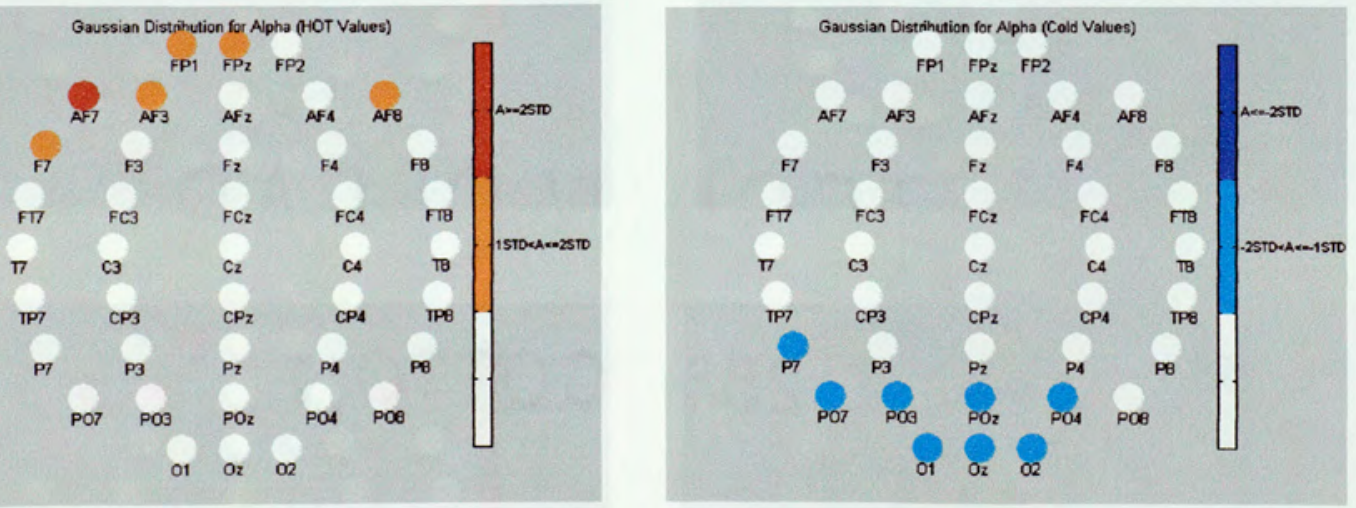

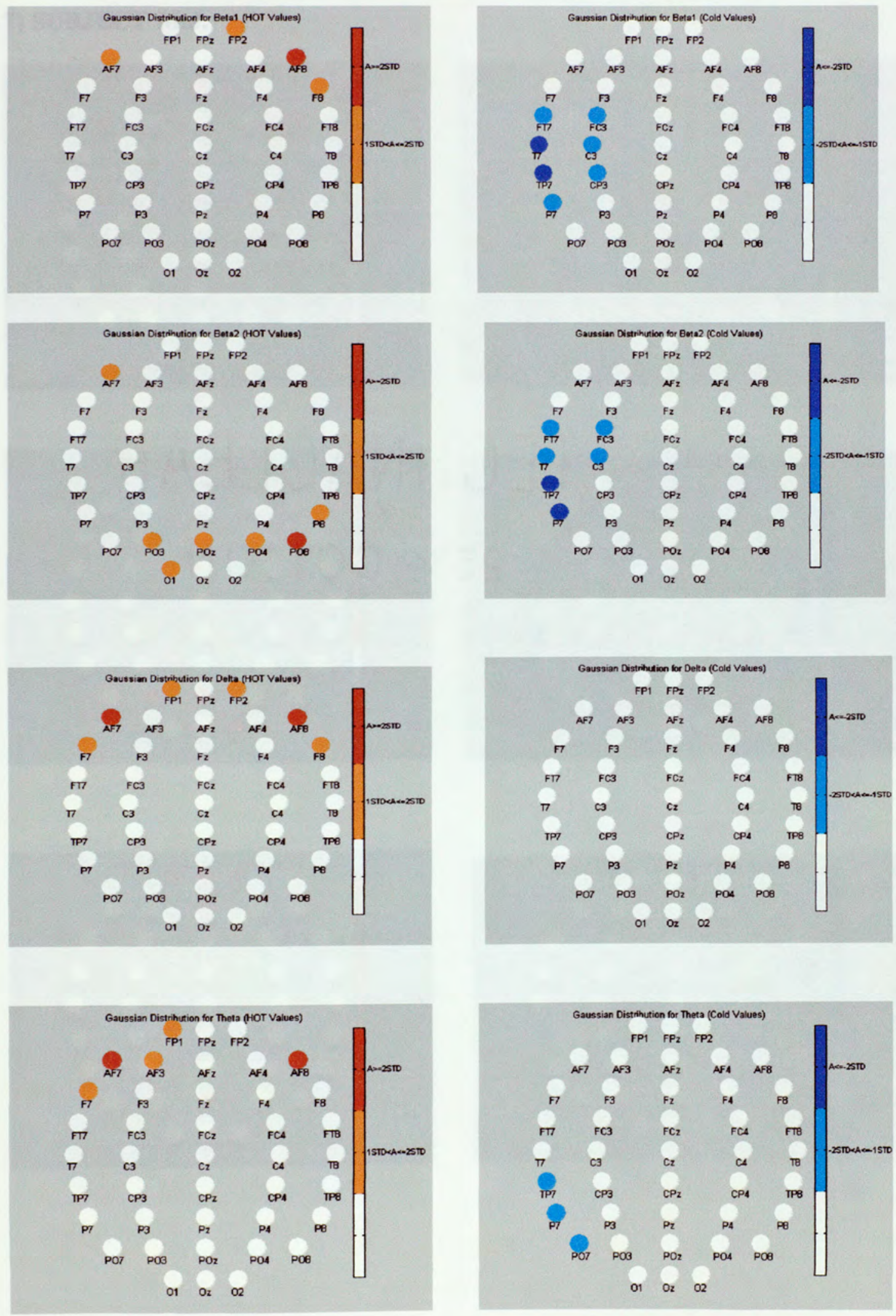


\section{7) SUBJECT M.J.}
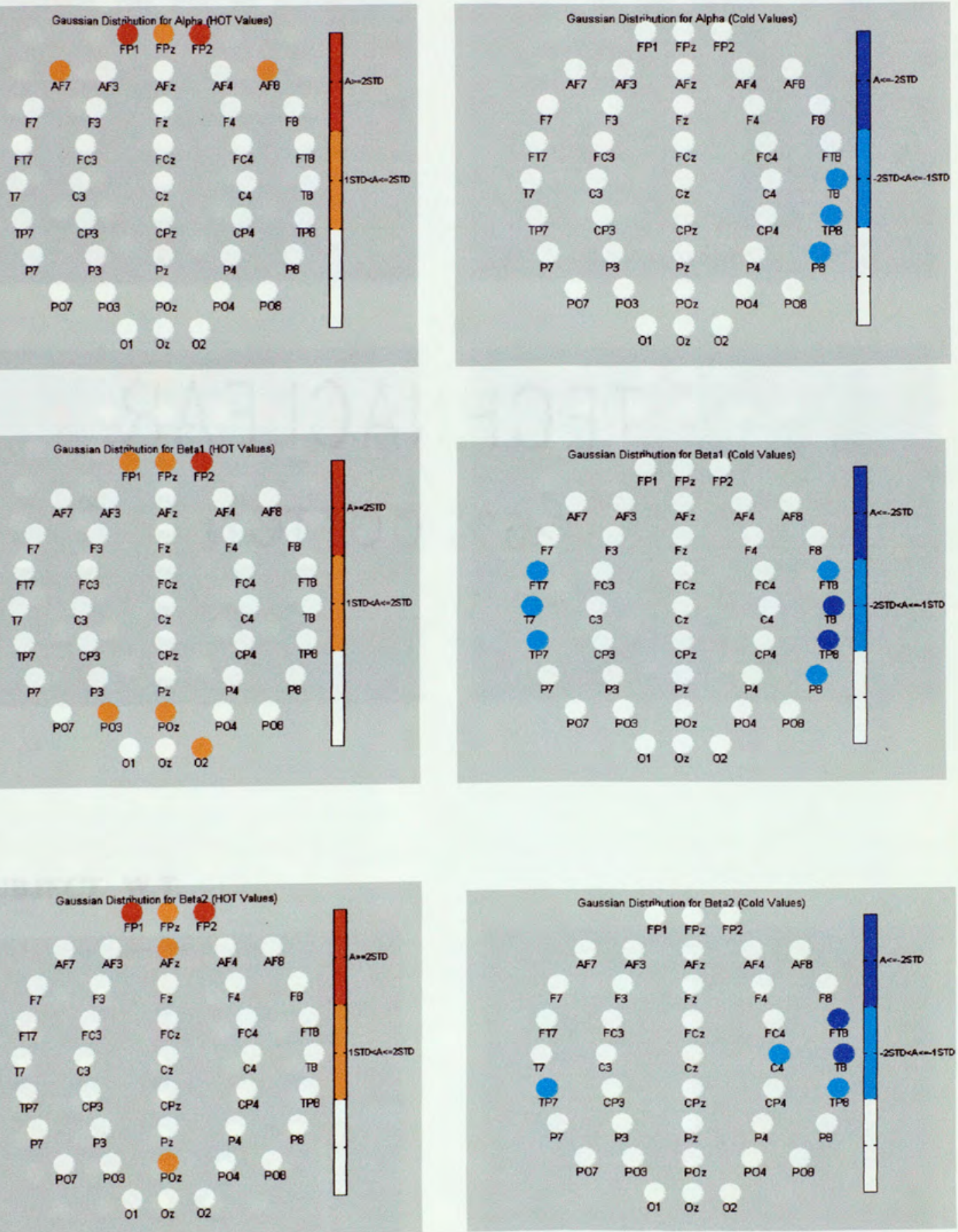

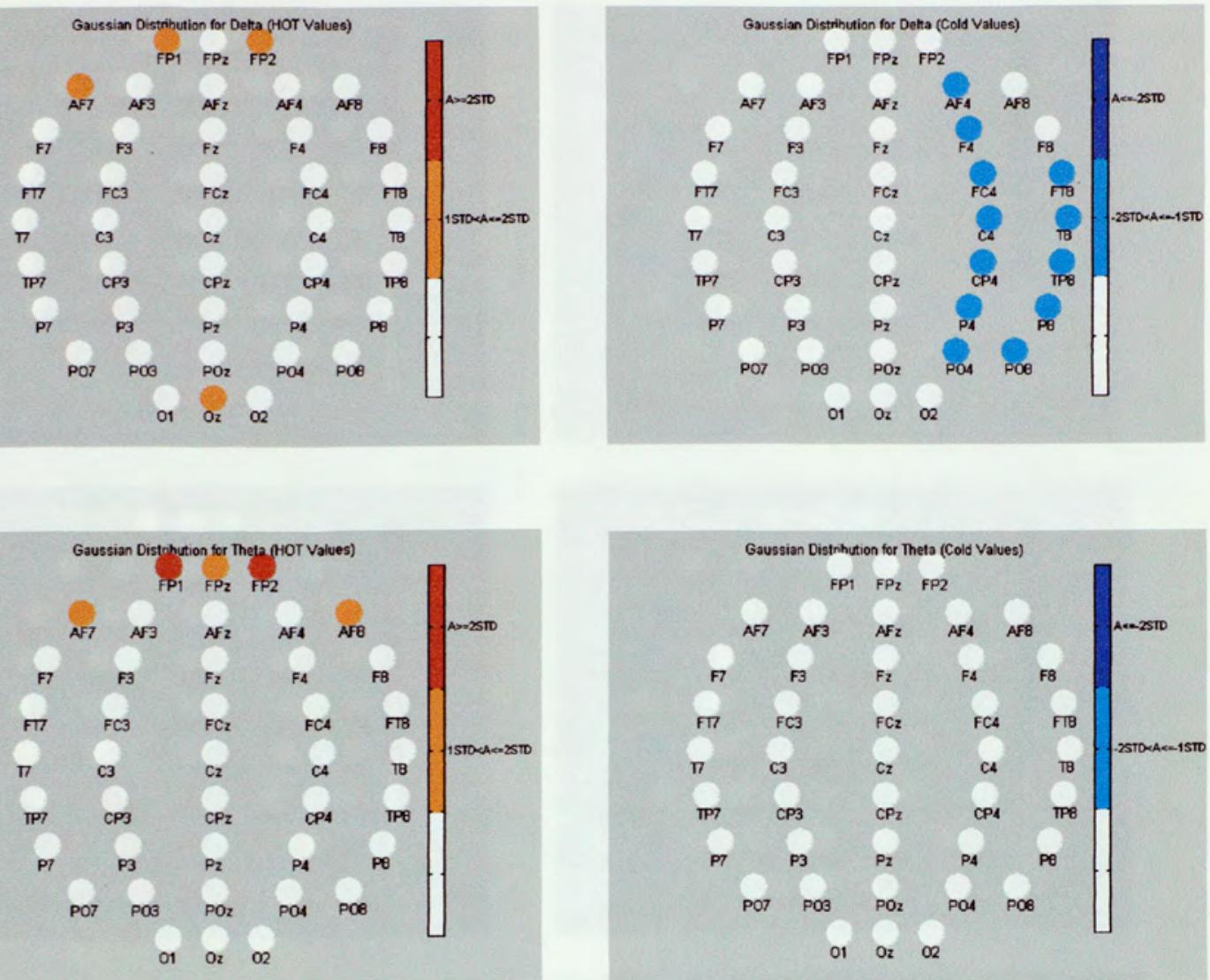

\section{8)SUBJECT W.T.}
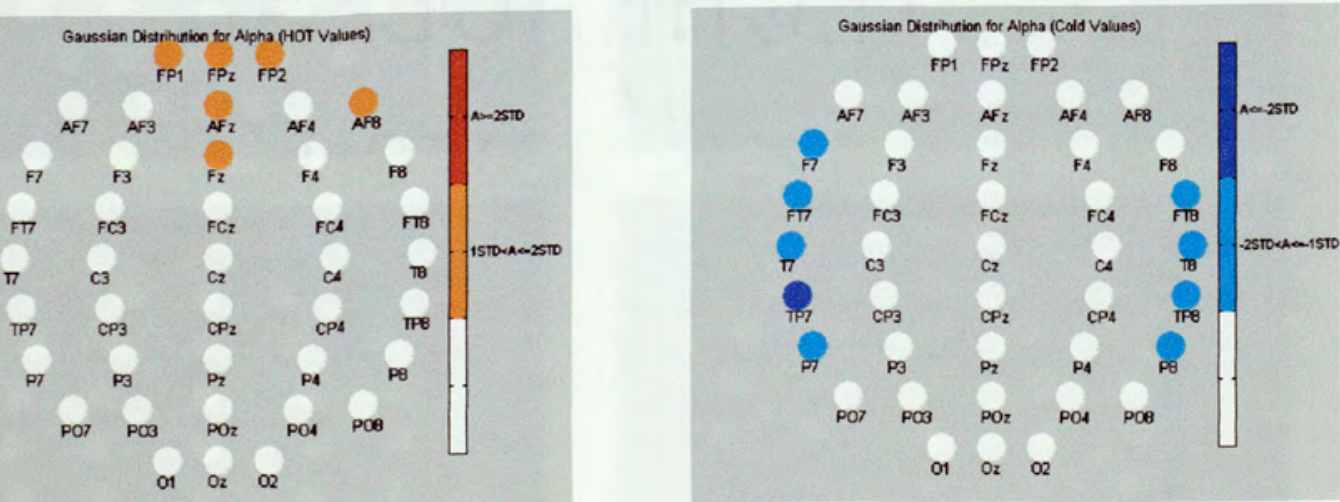

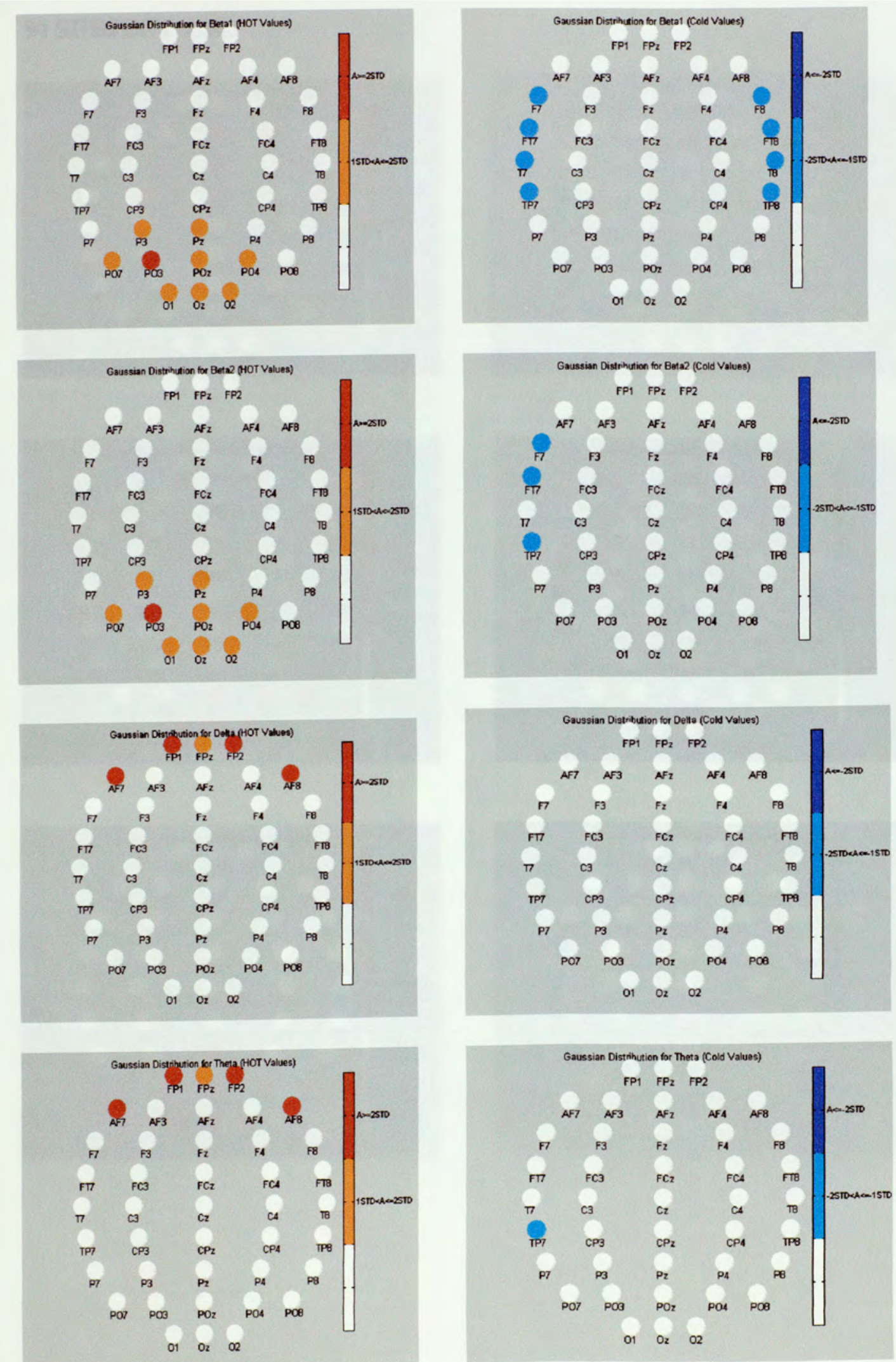
9) SUBJECT L.A.
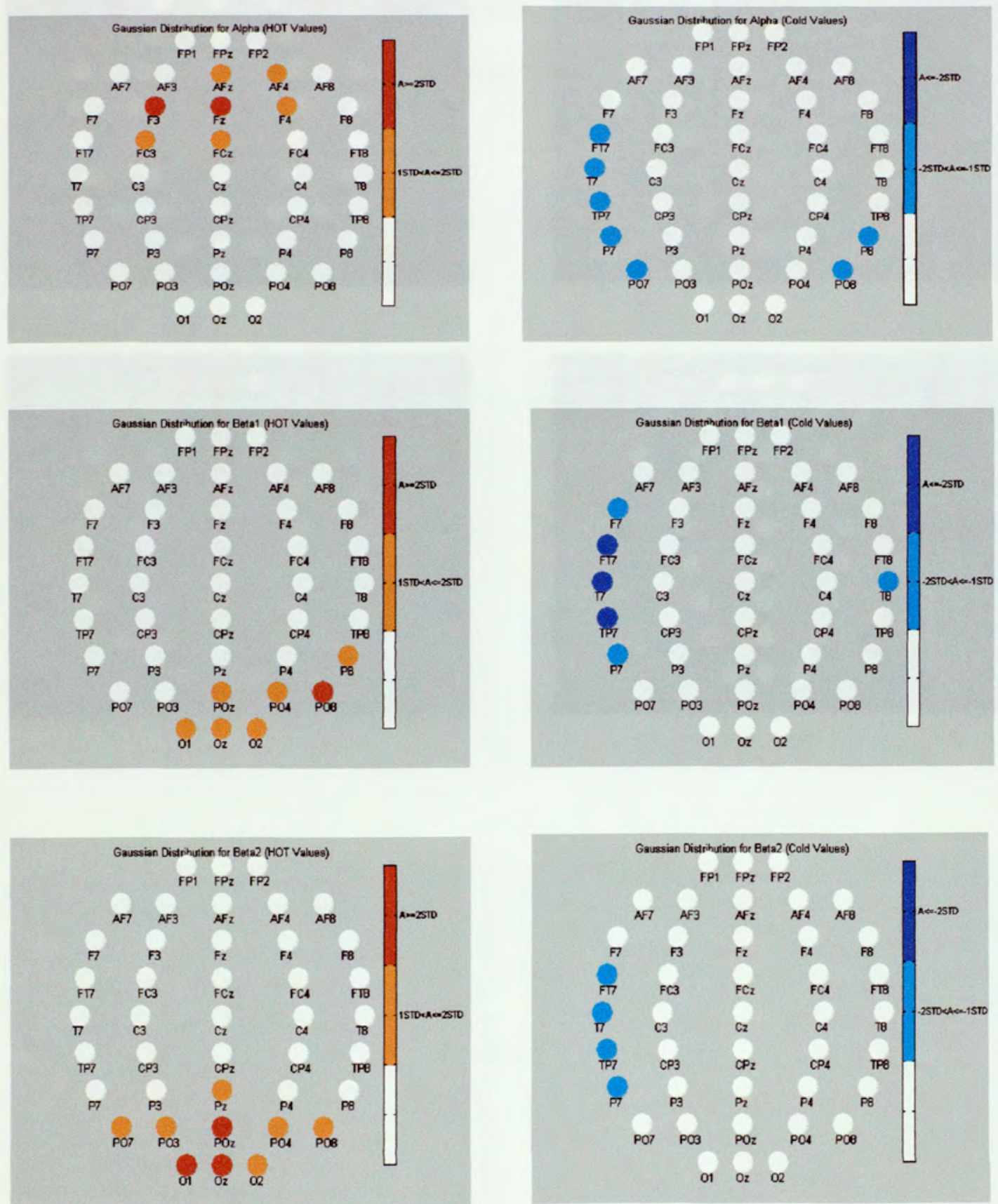

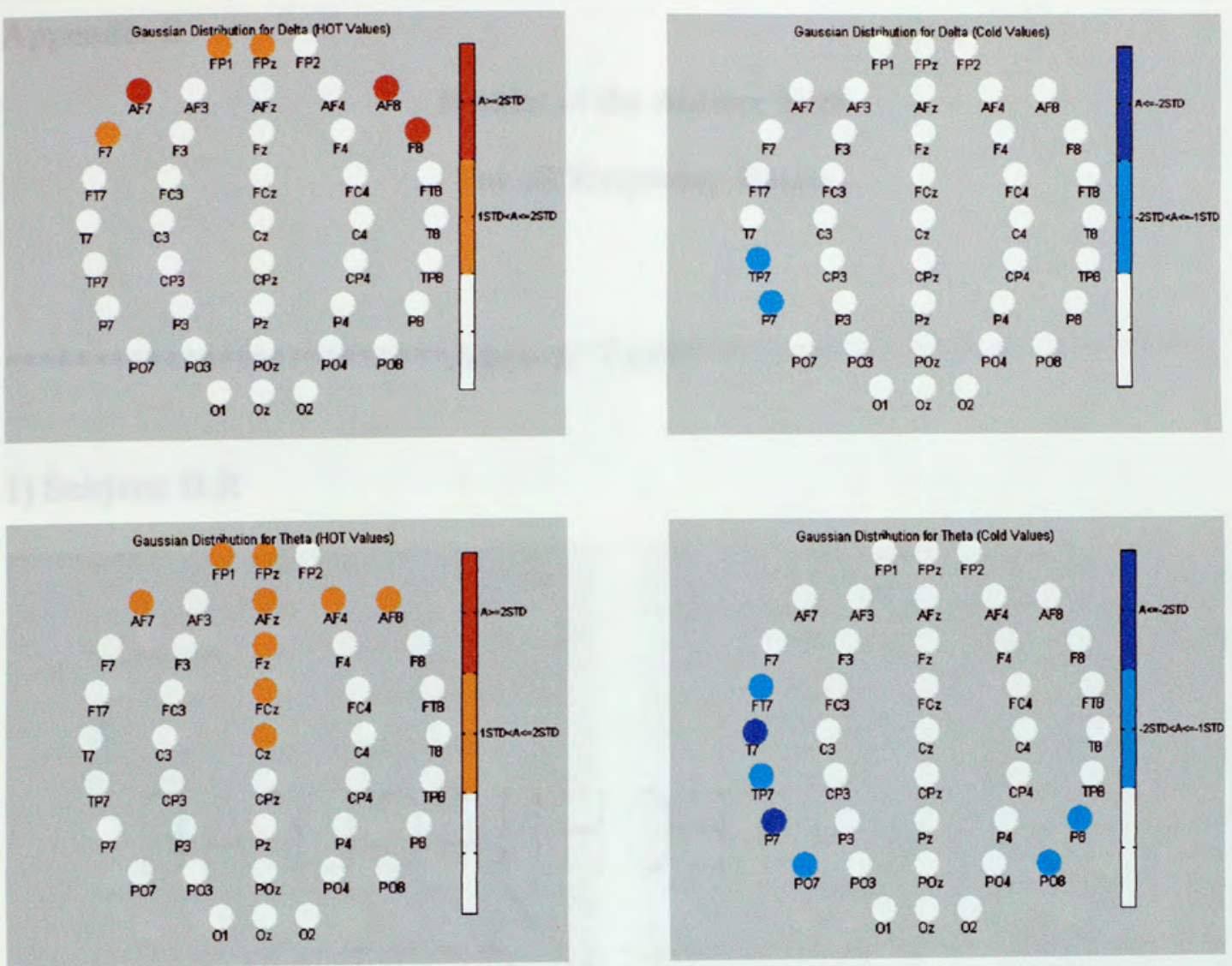
Appendix E

Results of the Answer Task

For all Frequency Bands

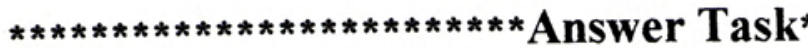

\section{1) Subject: D.R}
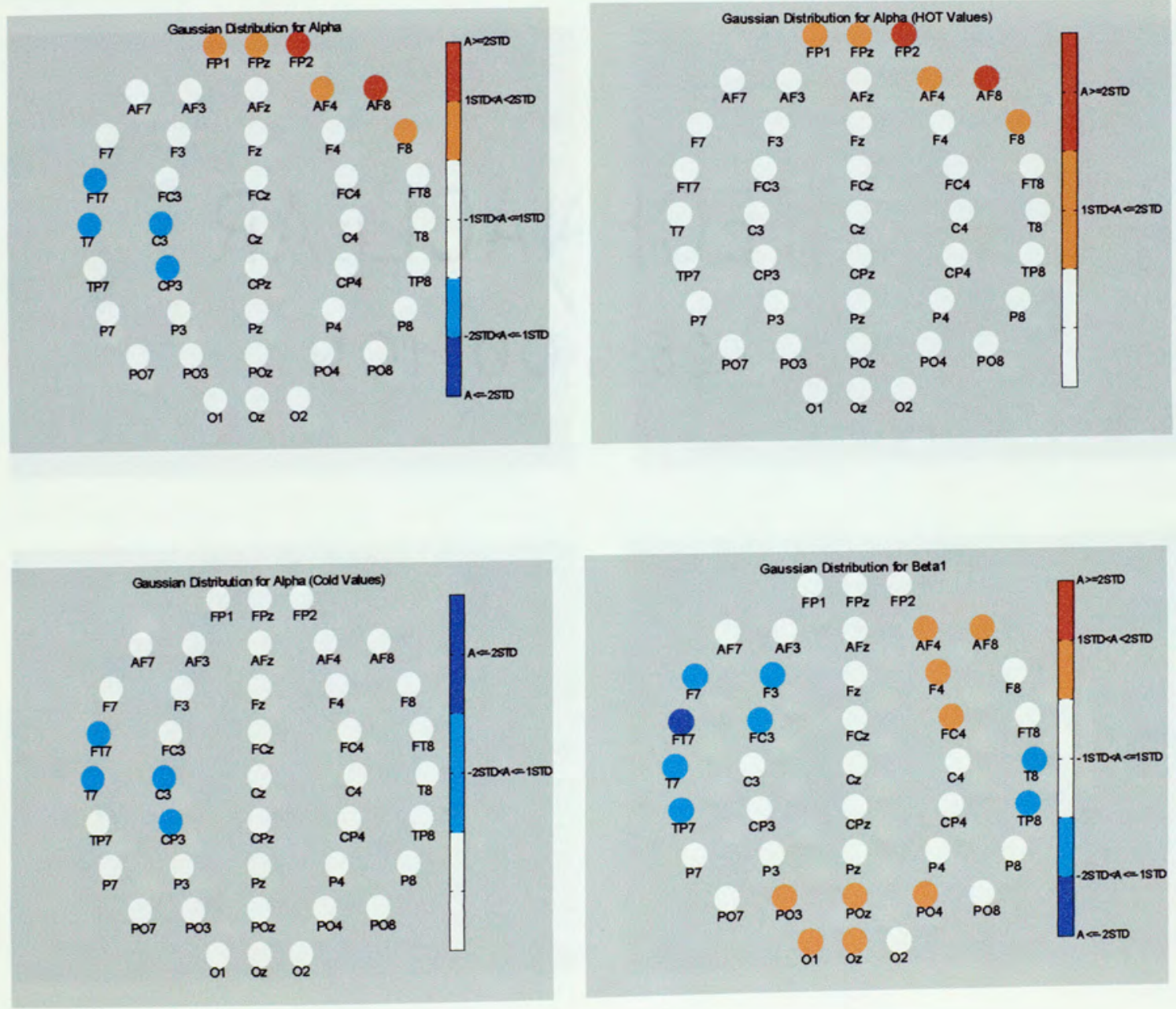

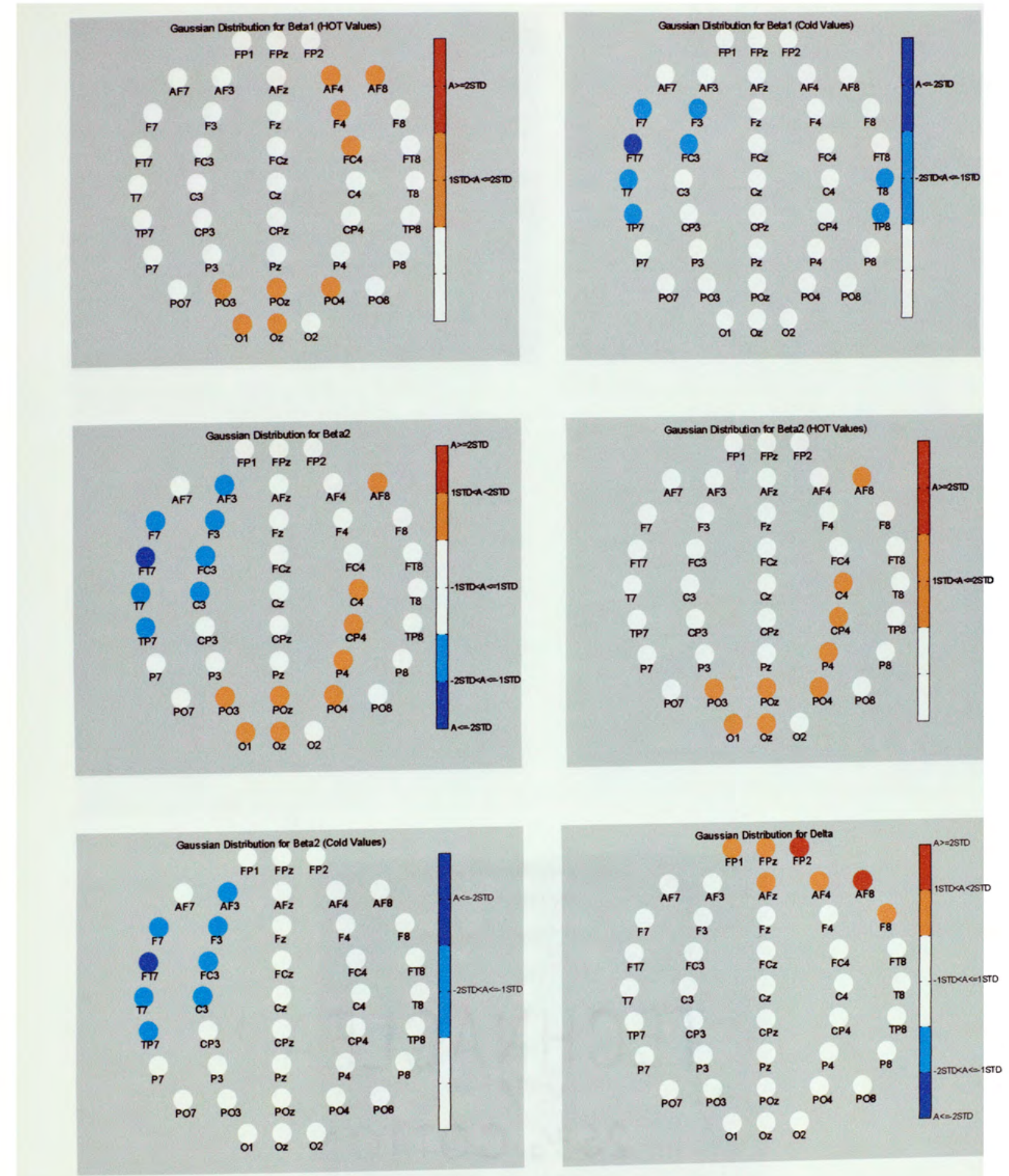

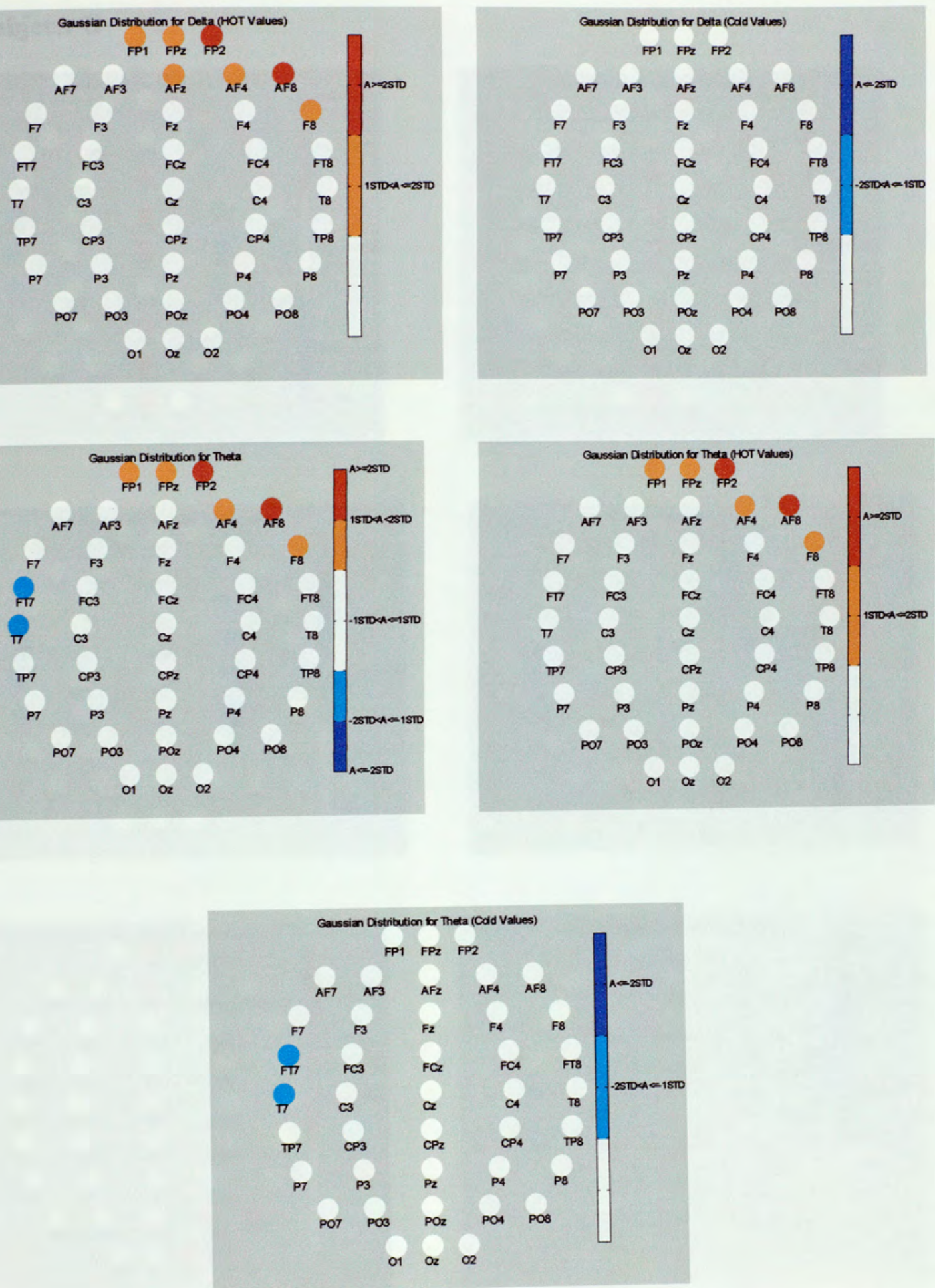
2) Subject: G
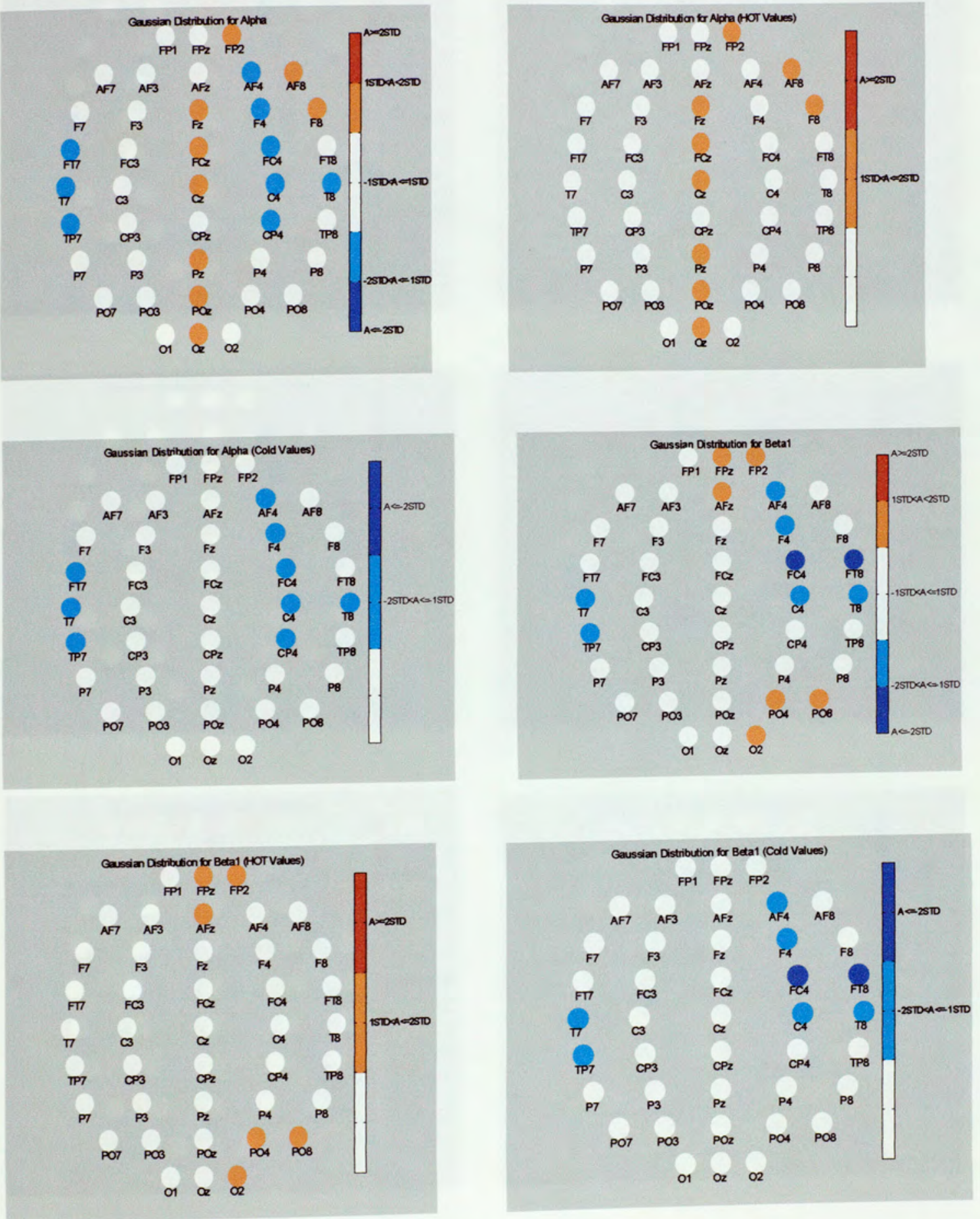

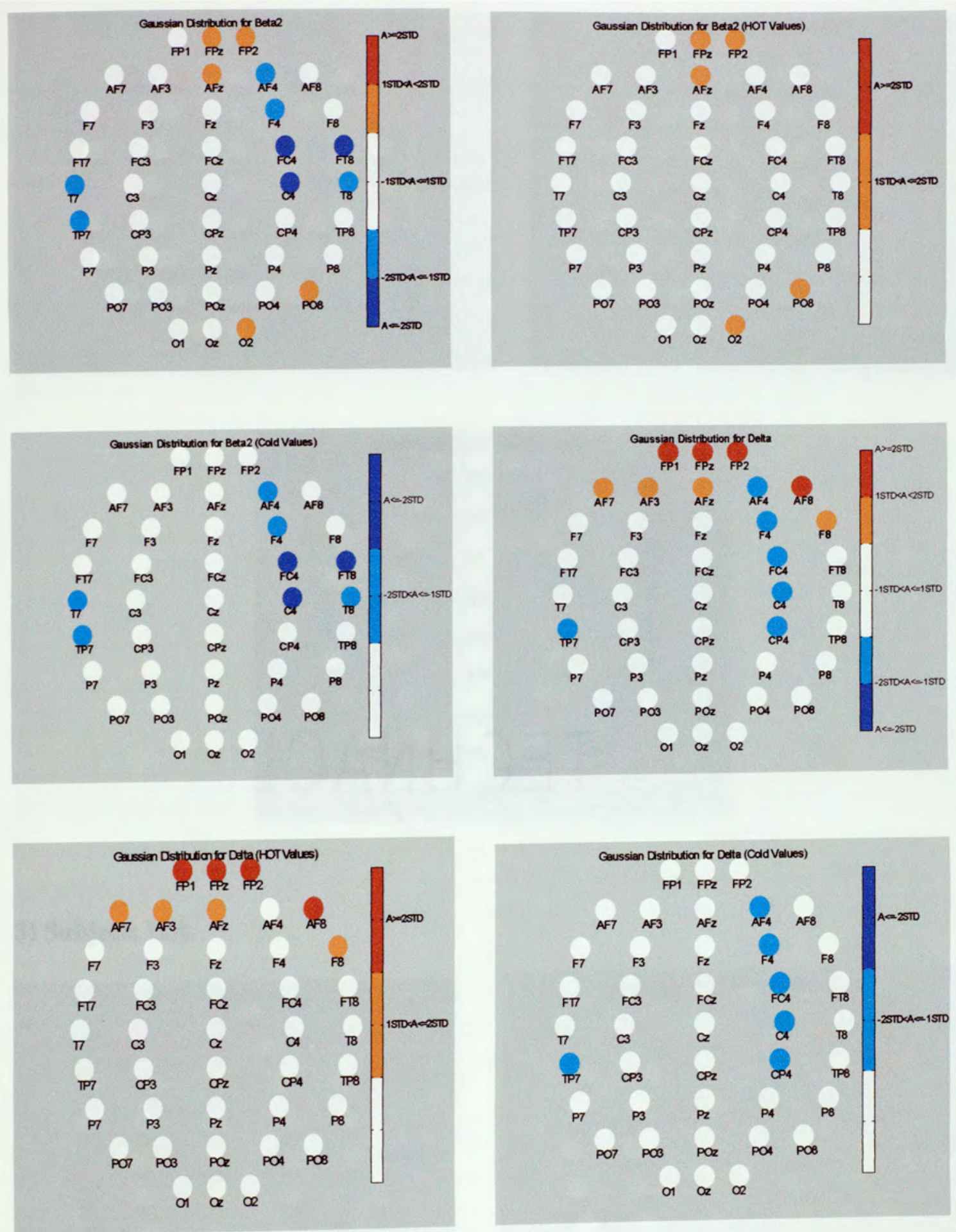

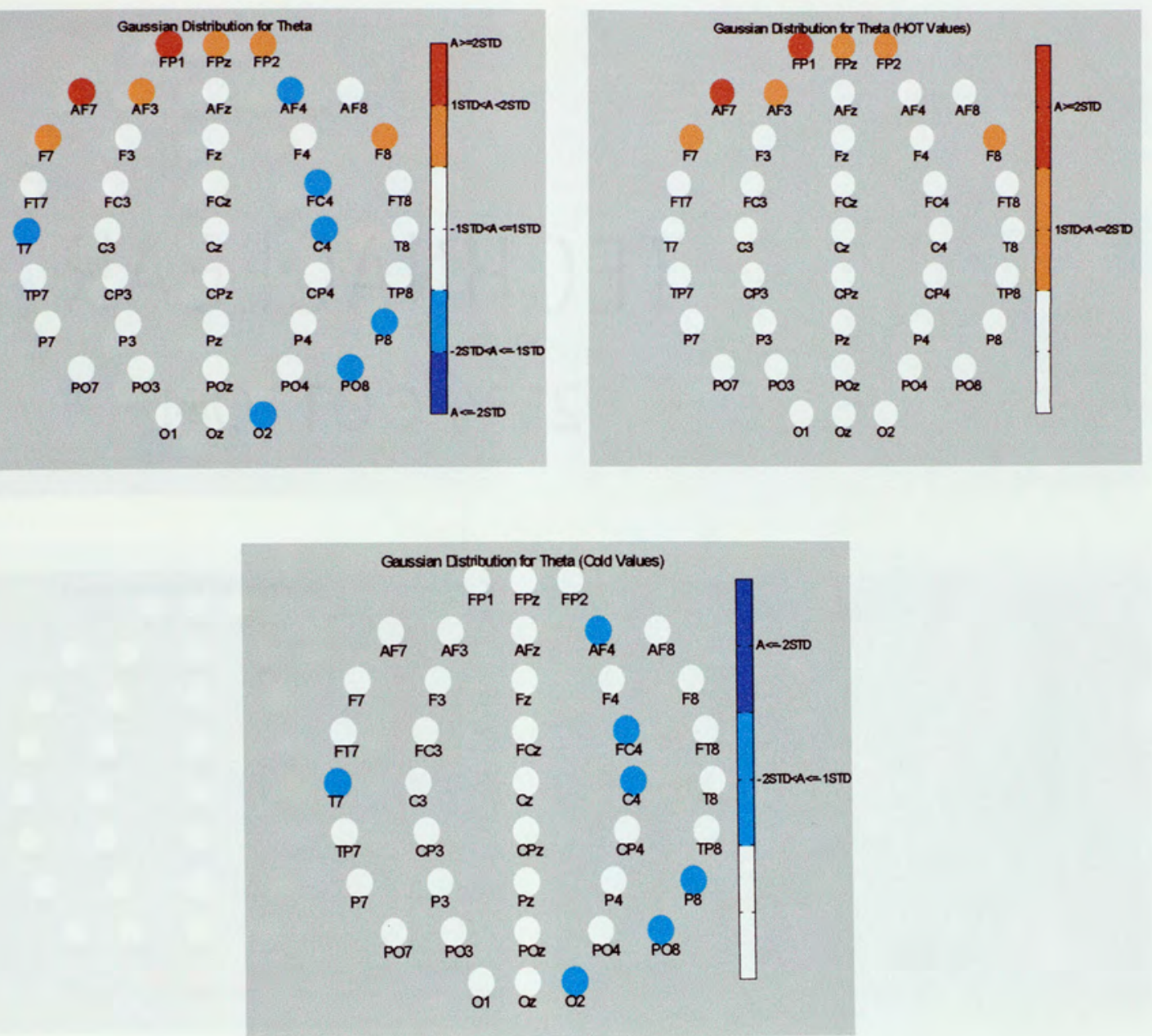

3) Subject: L.A.
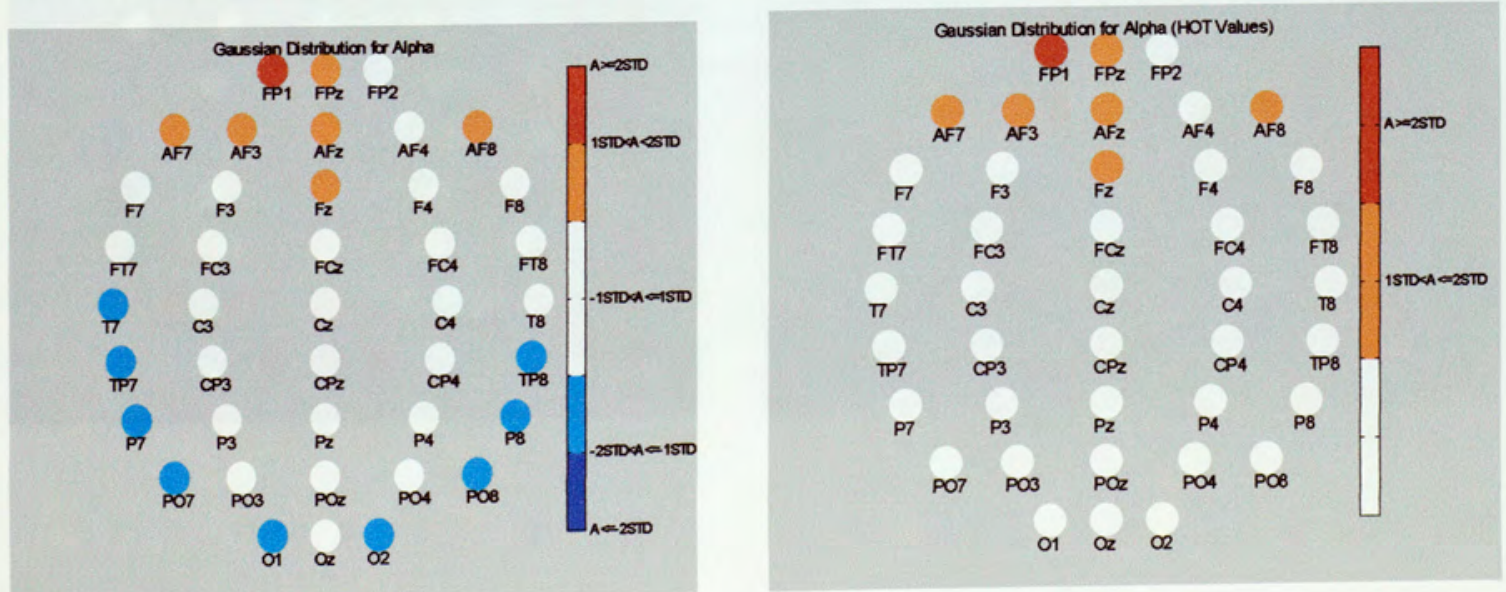

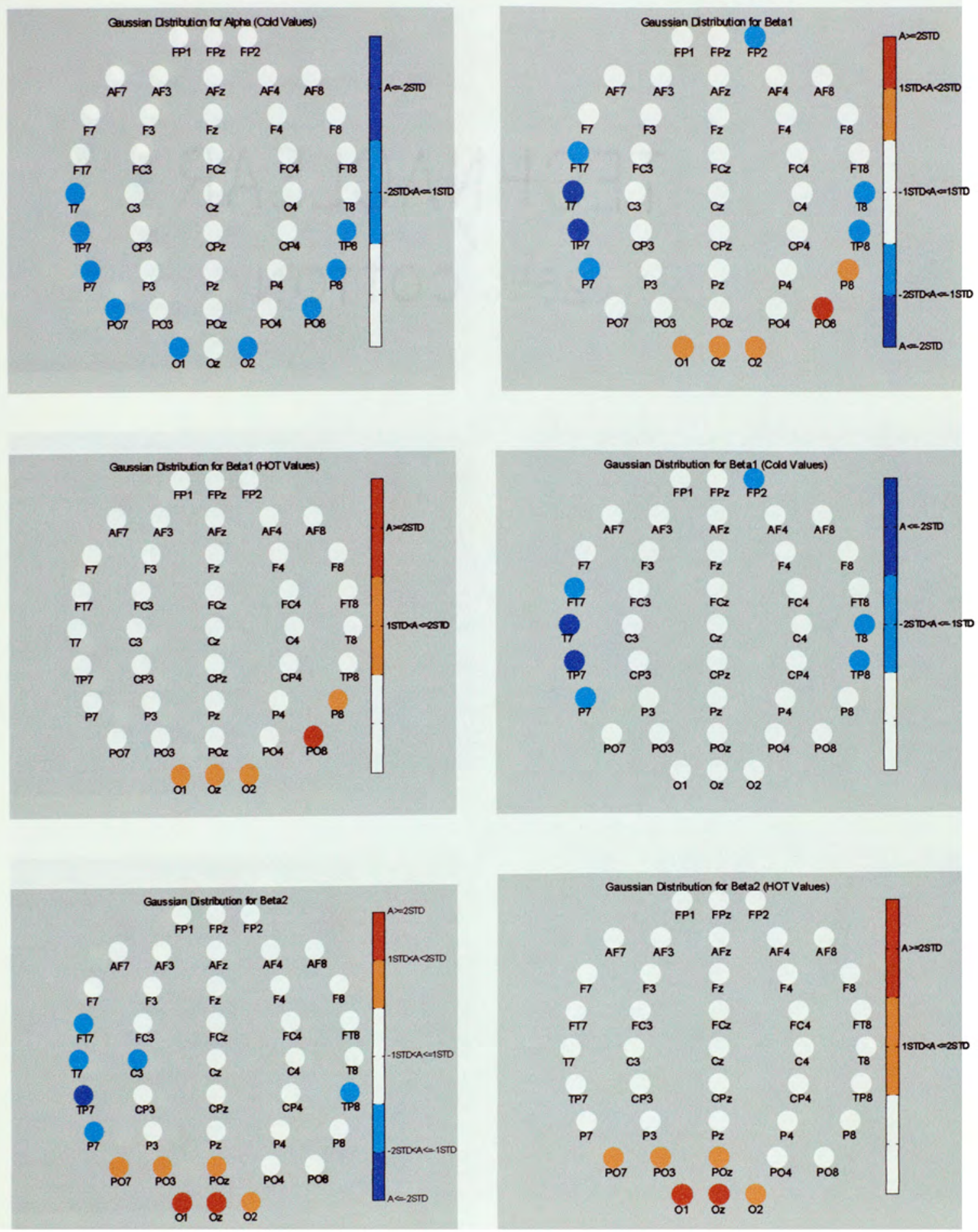

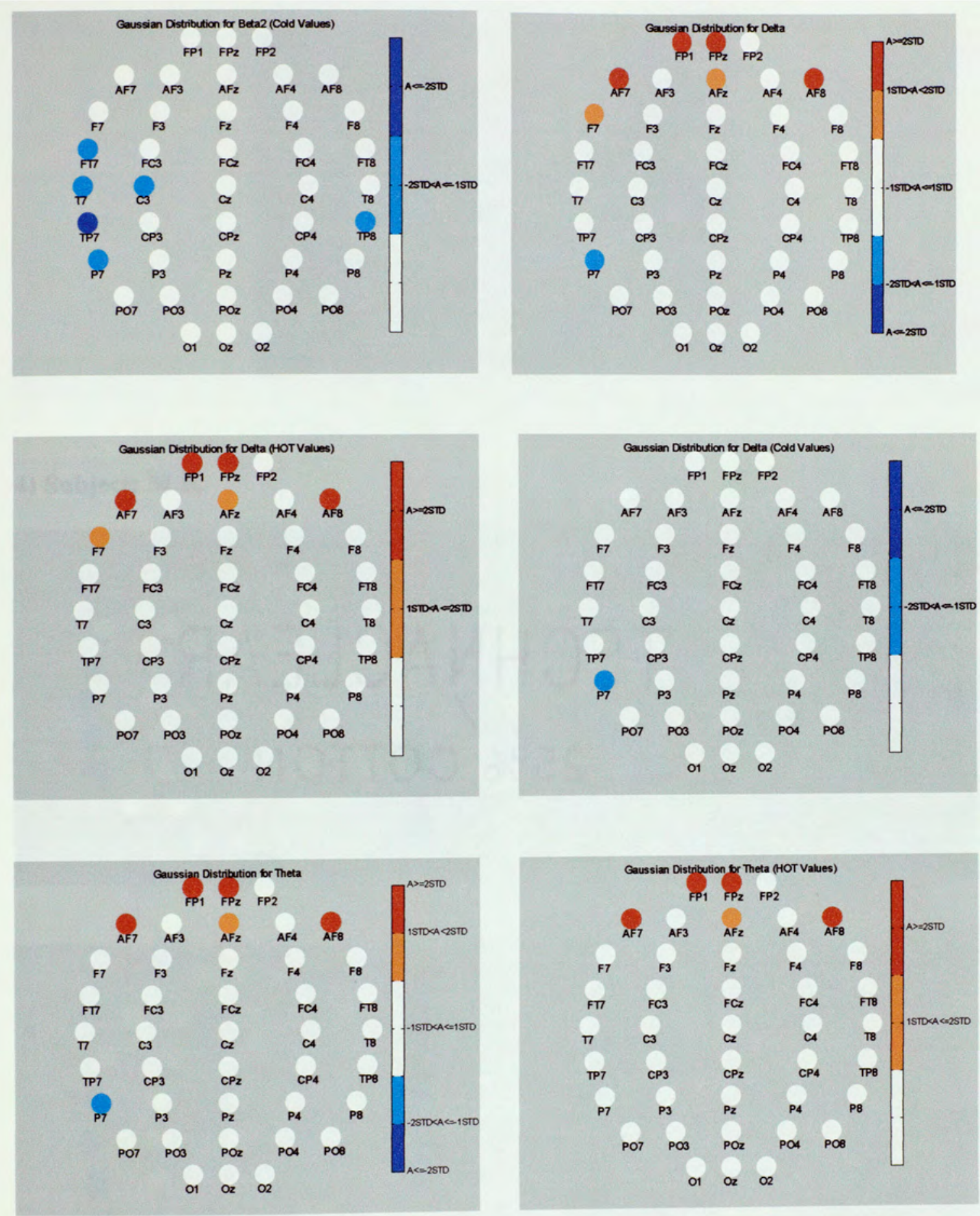


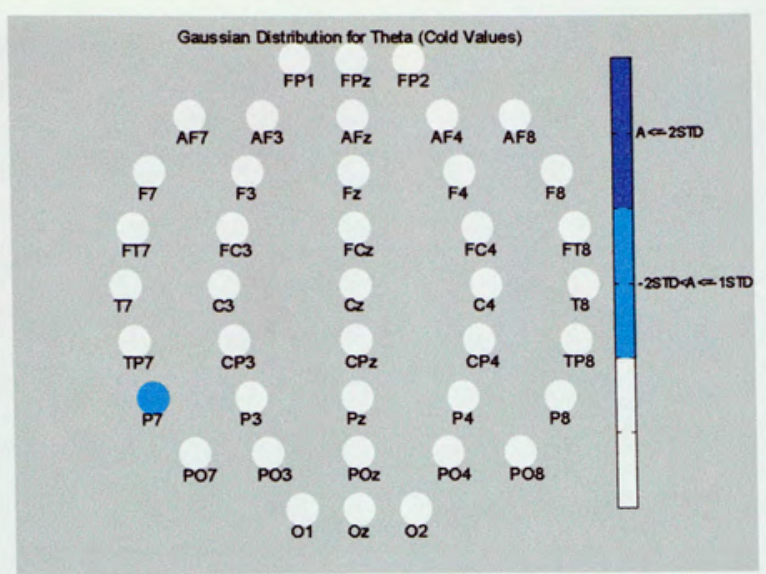

4) Subject: M.R.
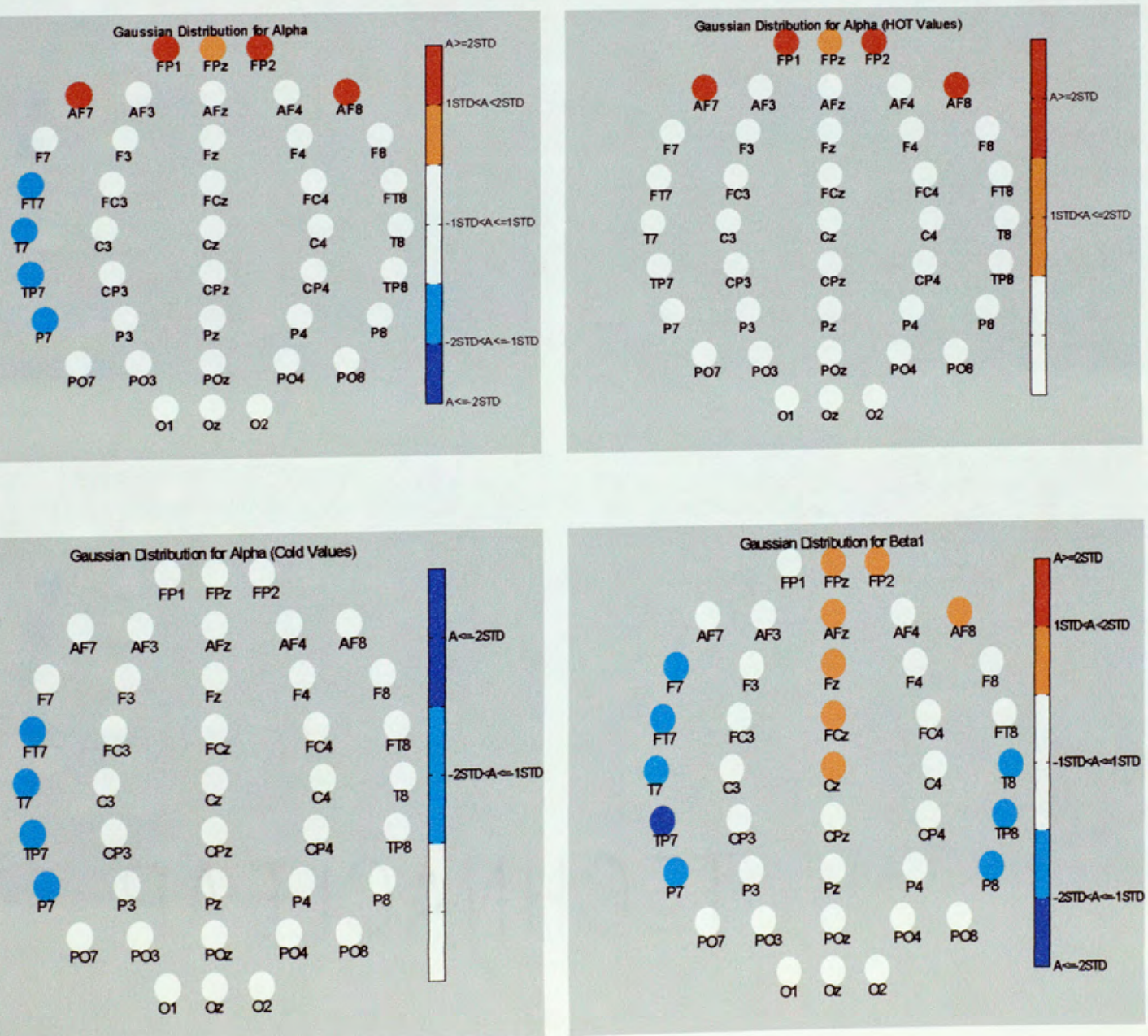

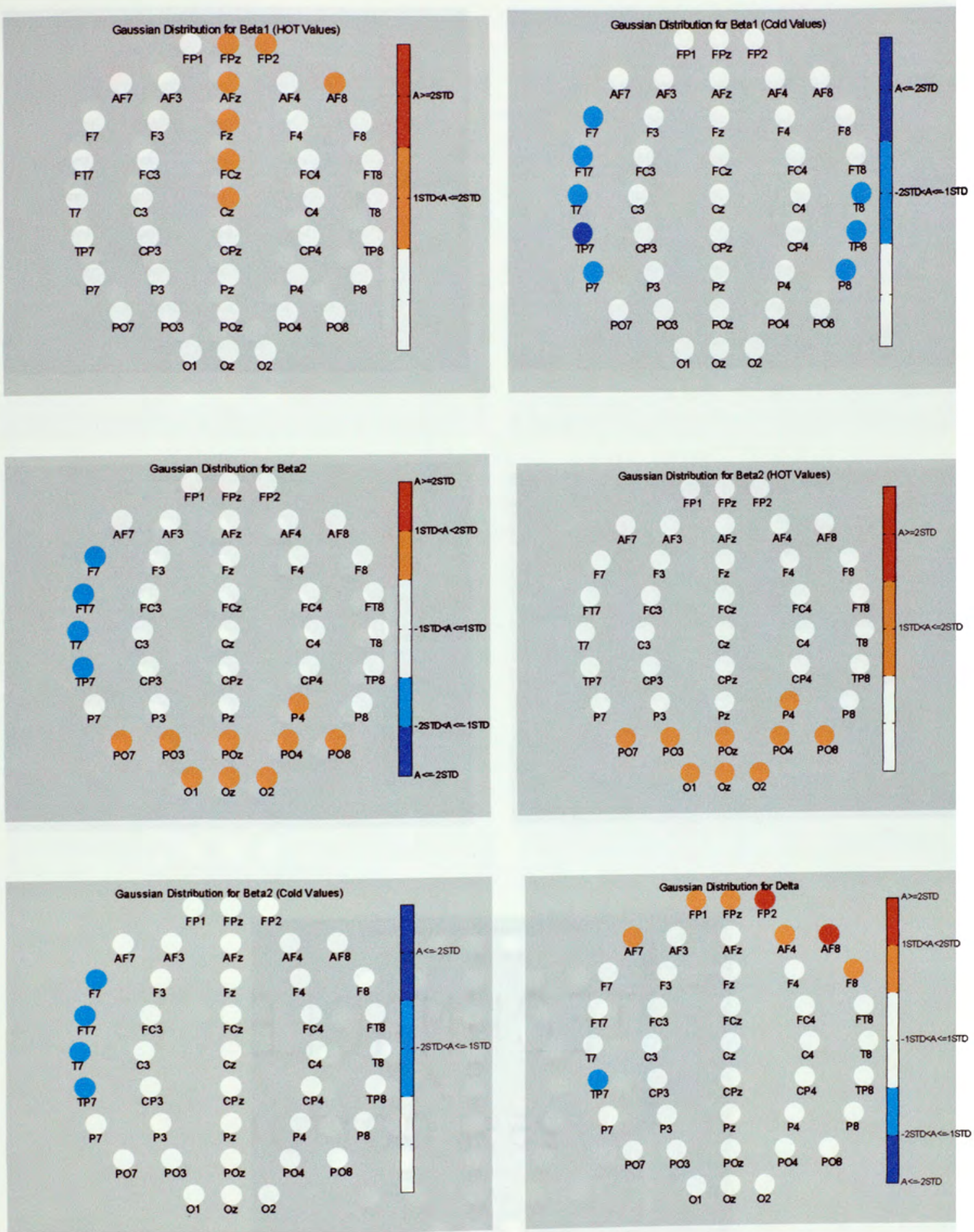

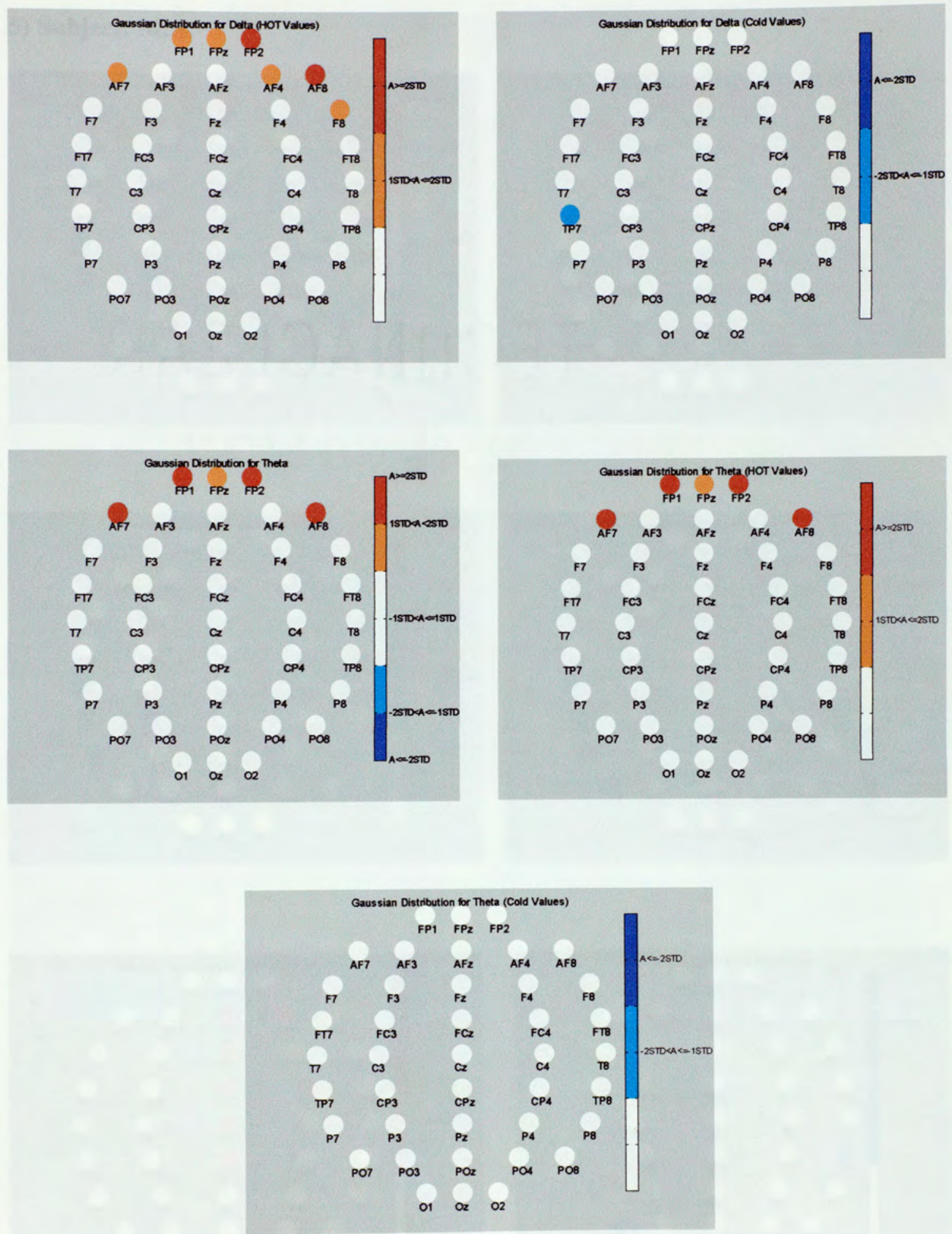


\section{5) Subject: M.A.}
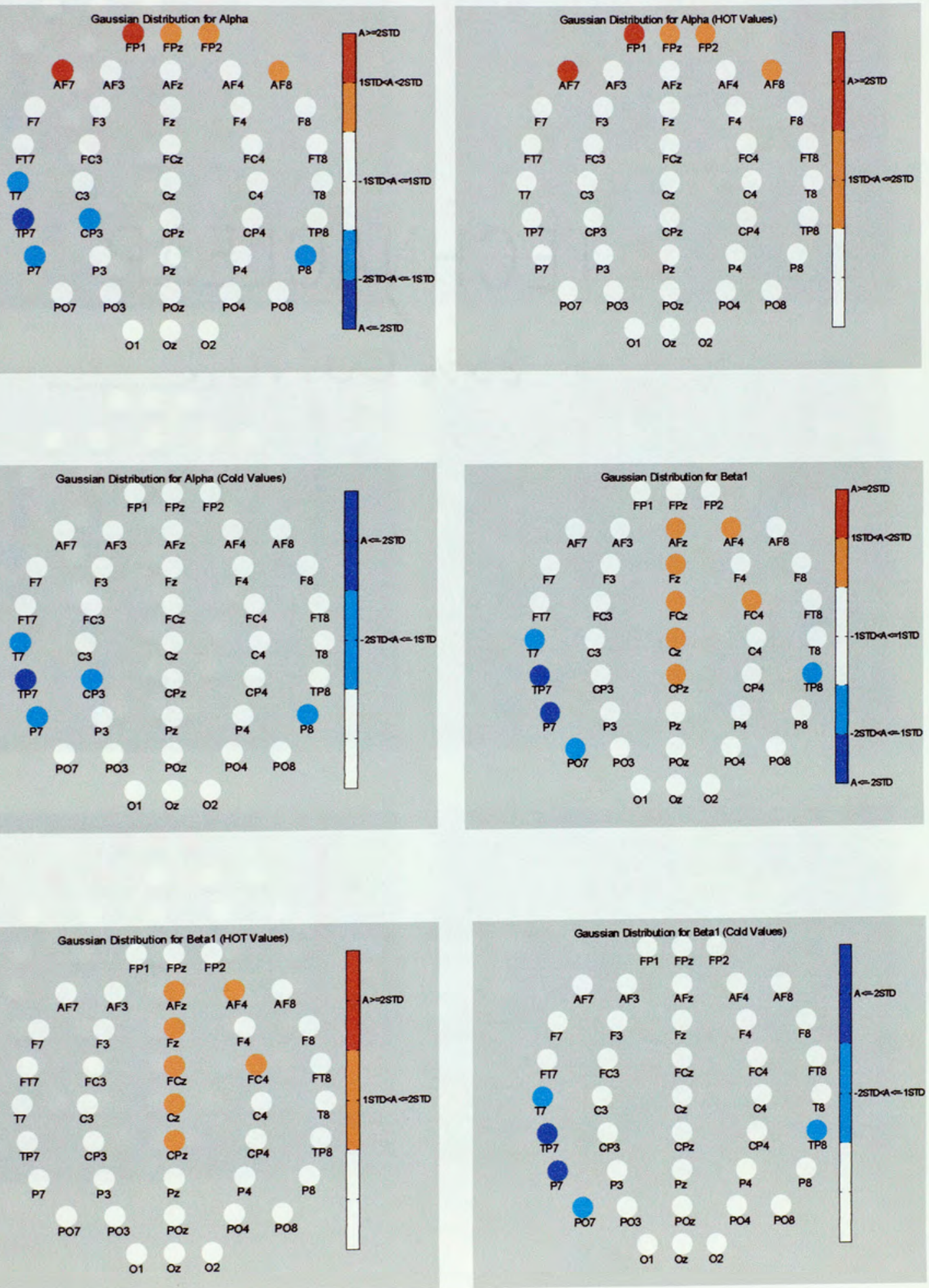

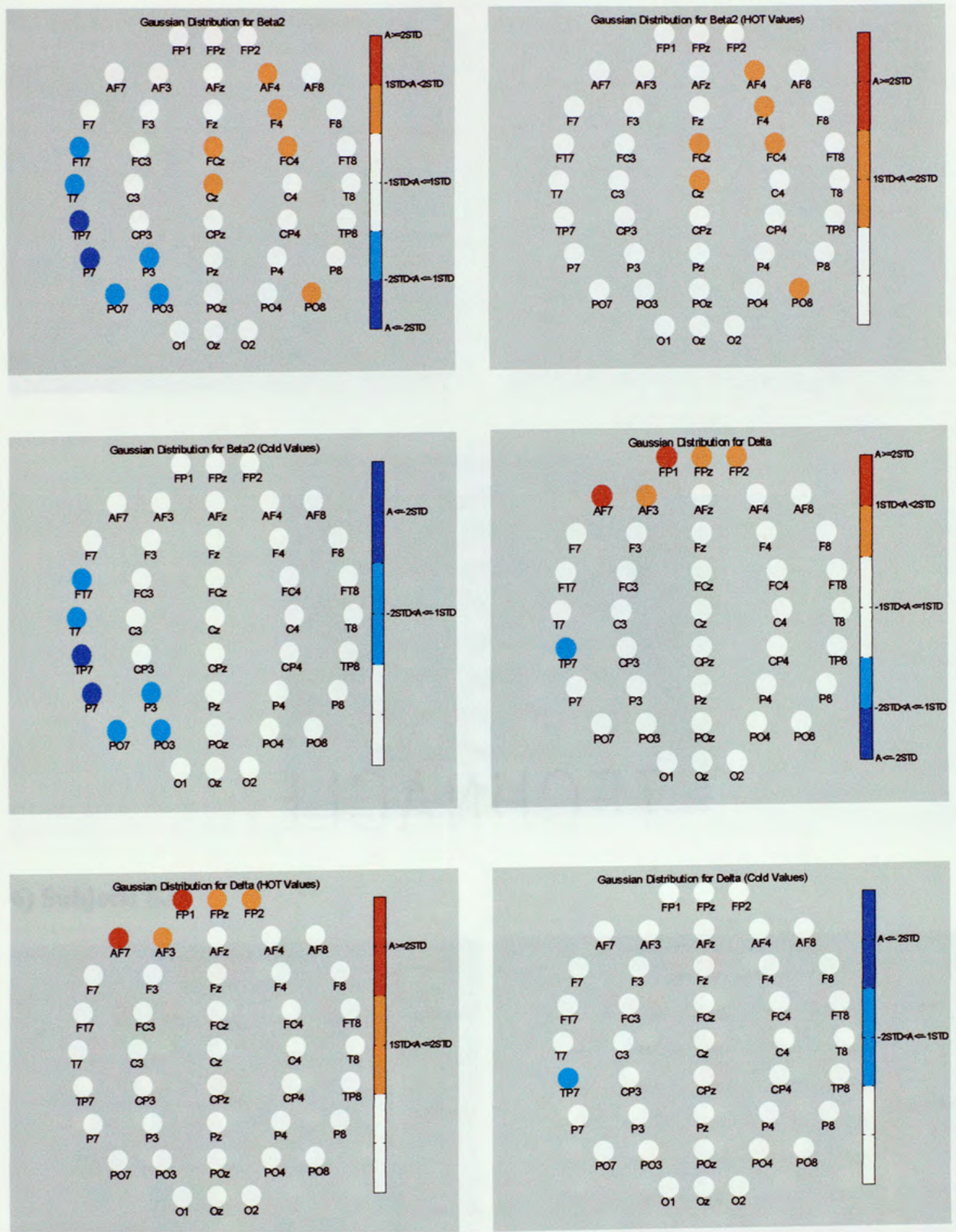

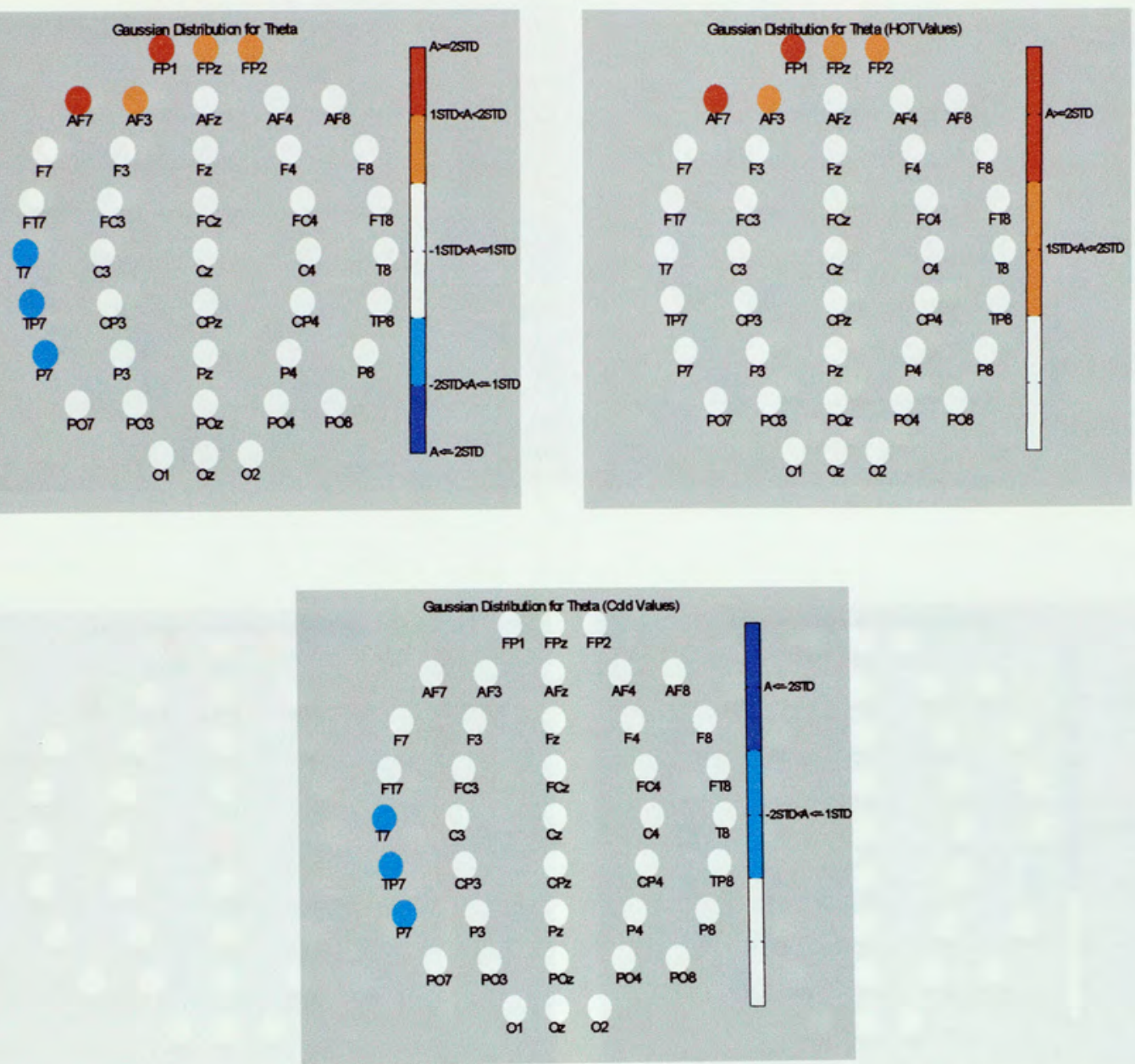

\section{6) Subject: S.B.}
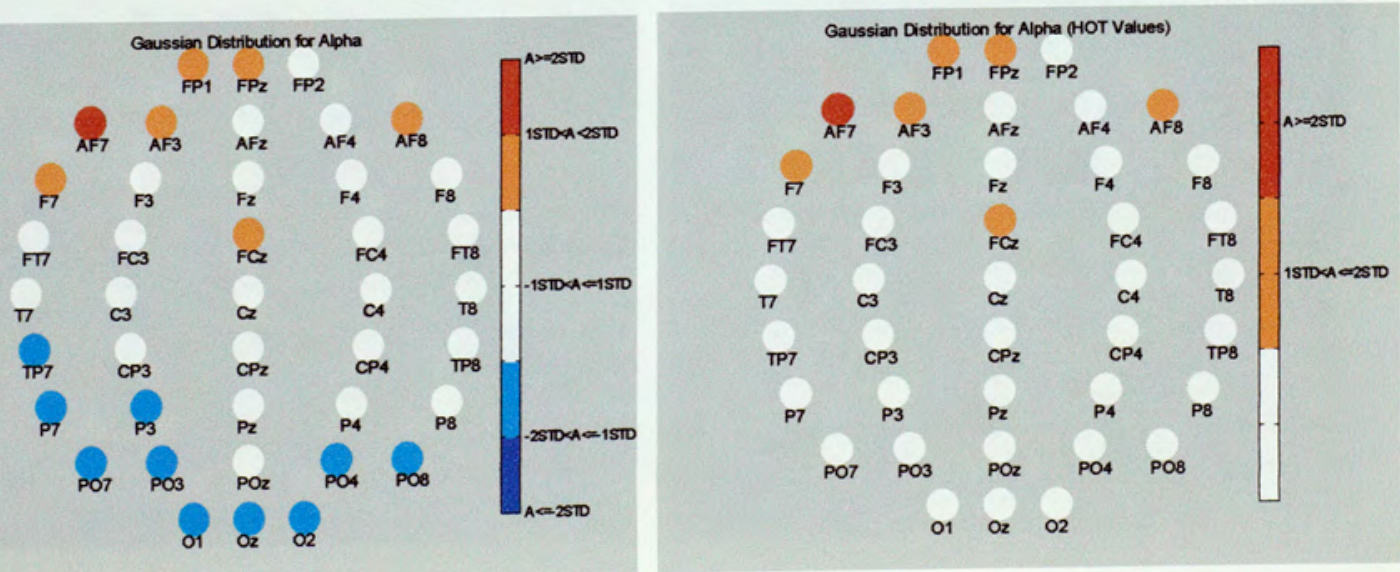

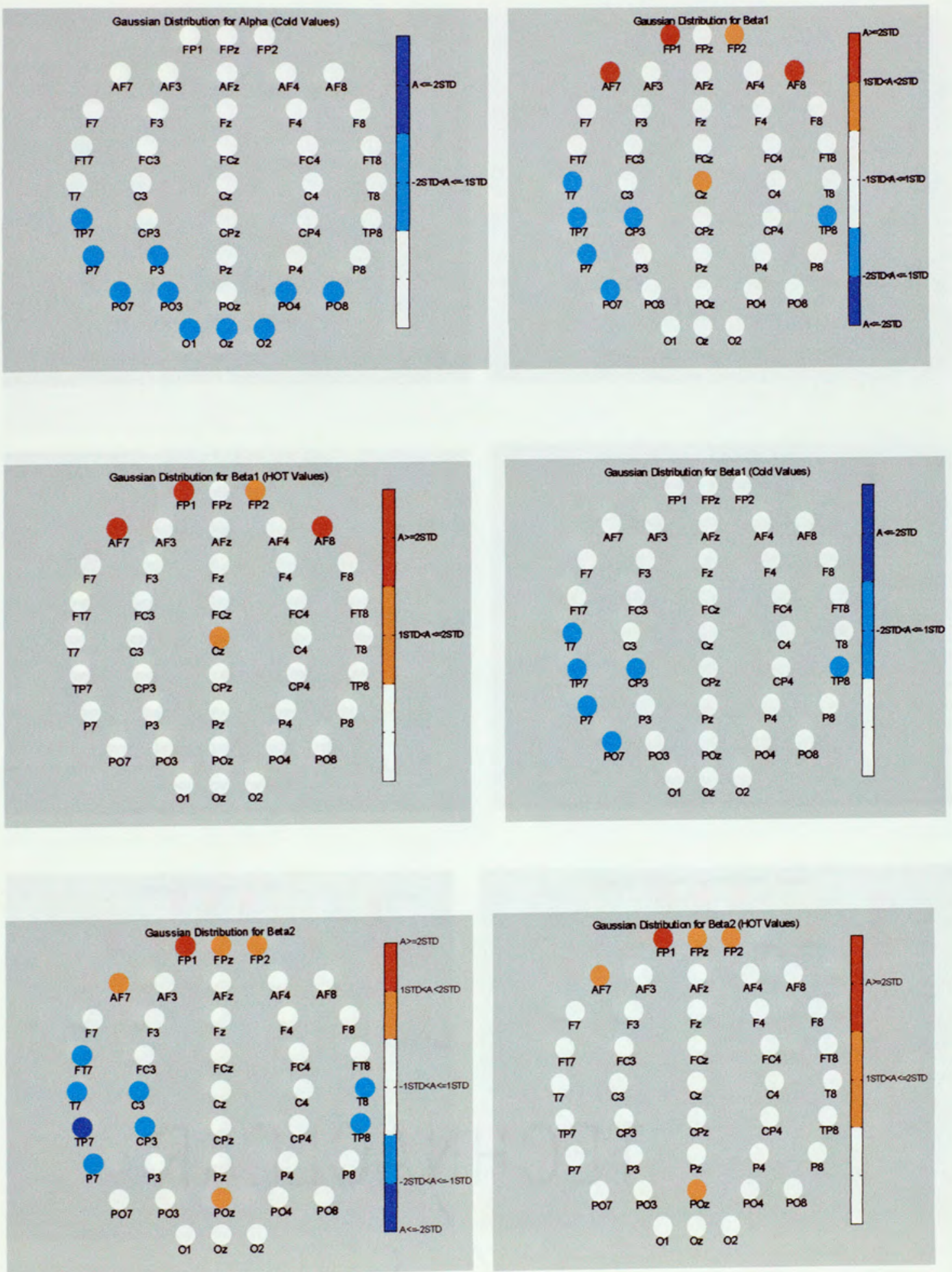

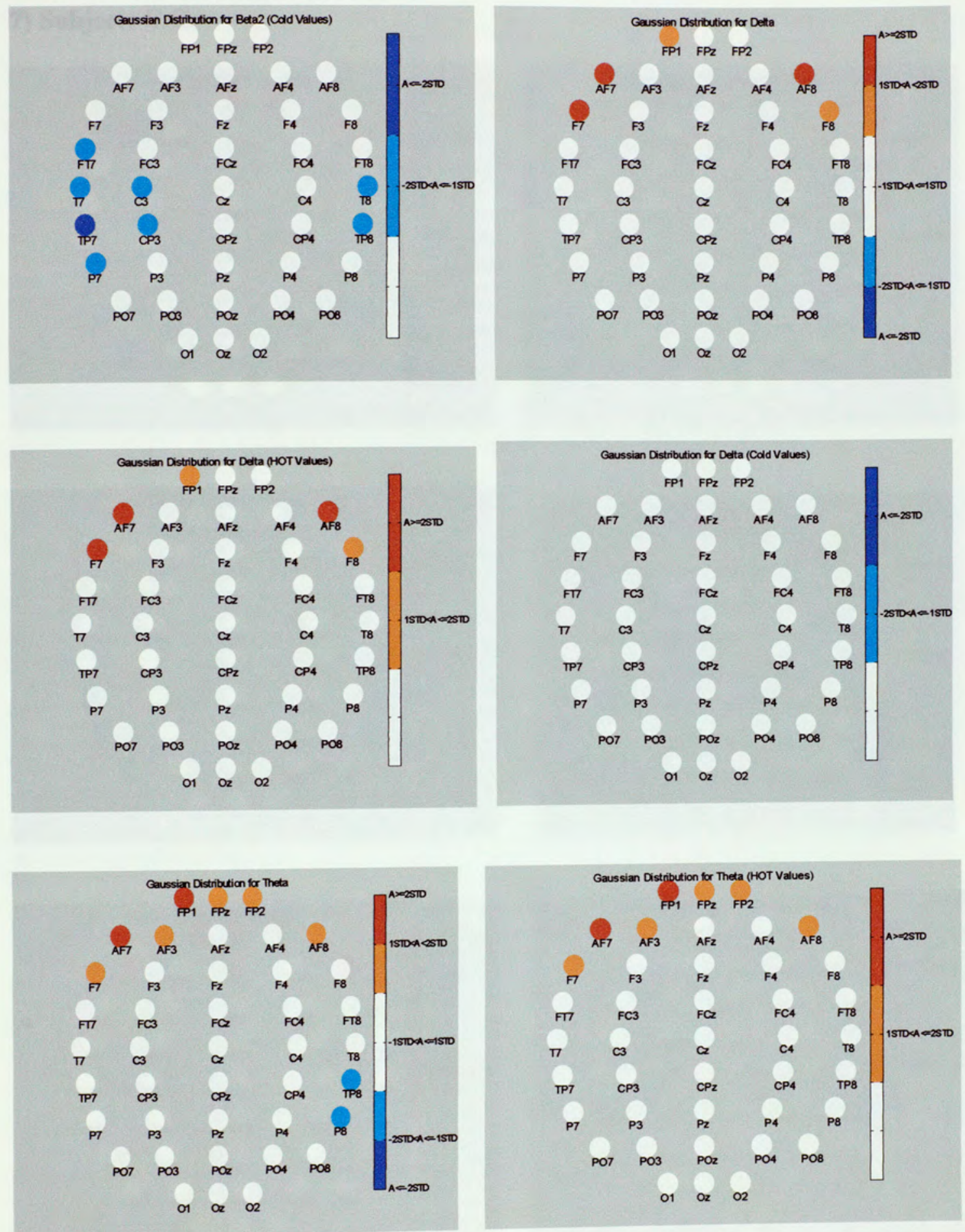
7) Subject: C.C.
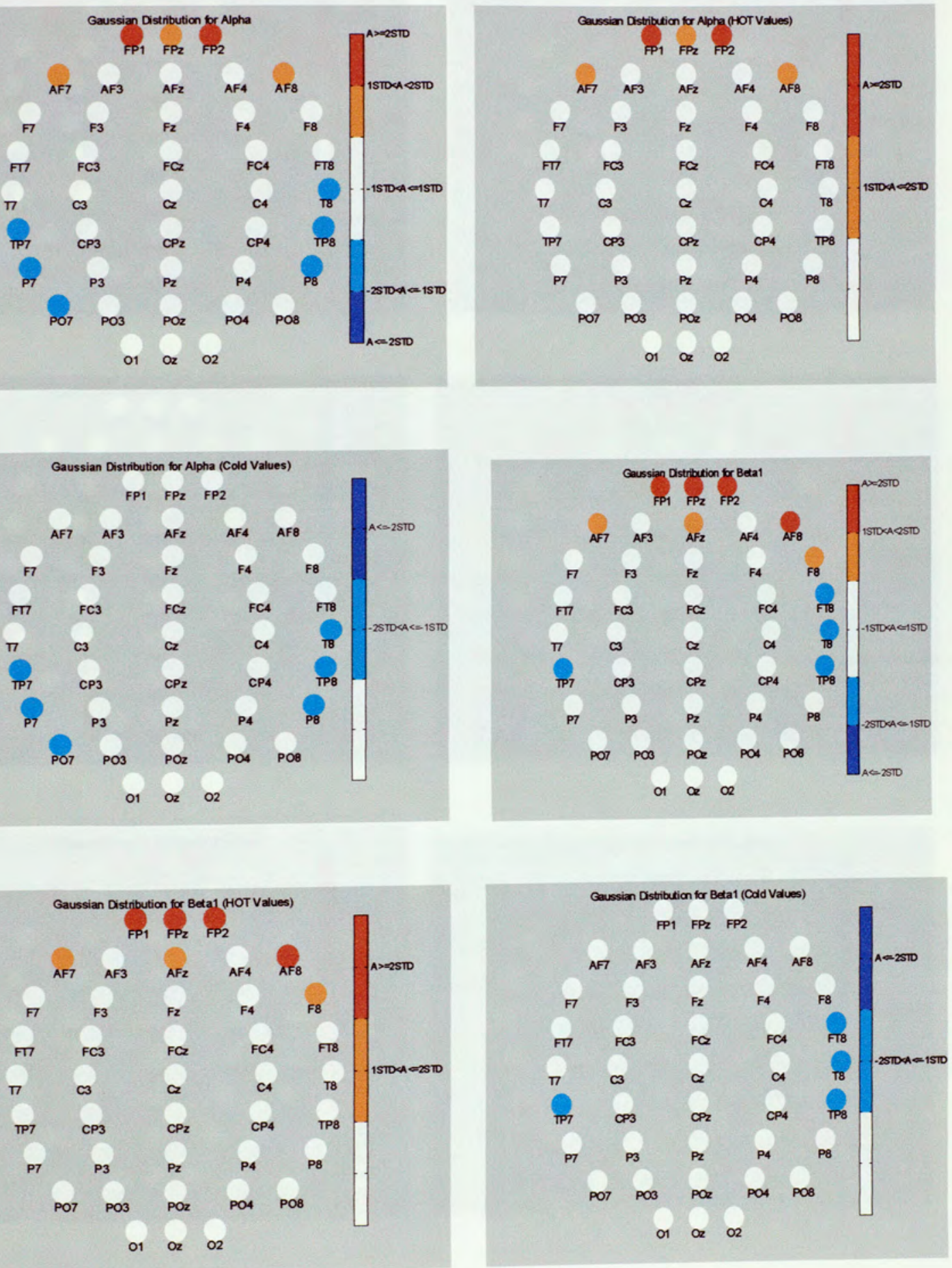

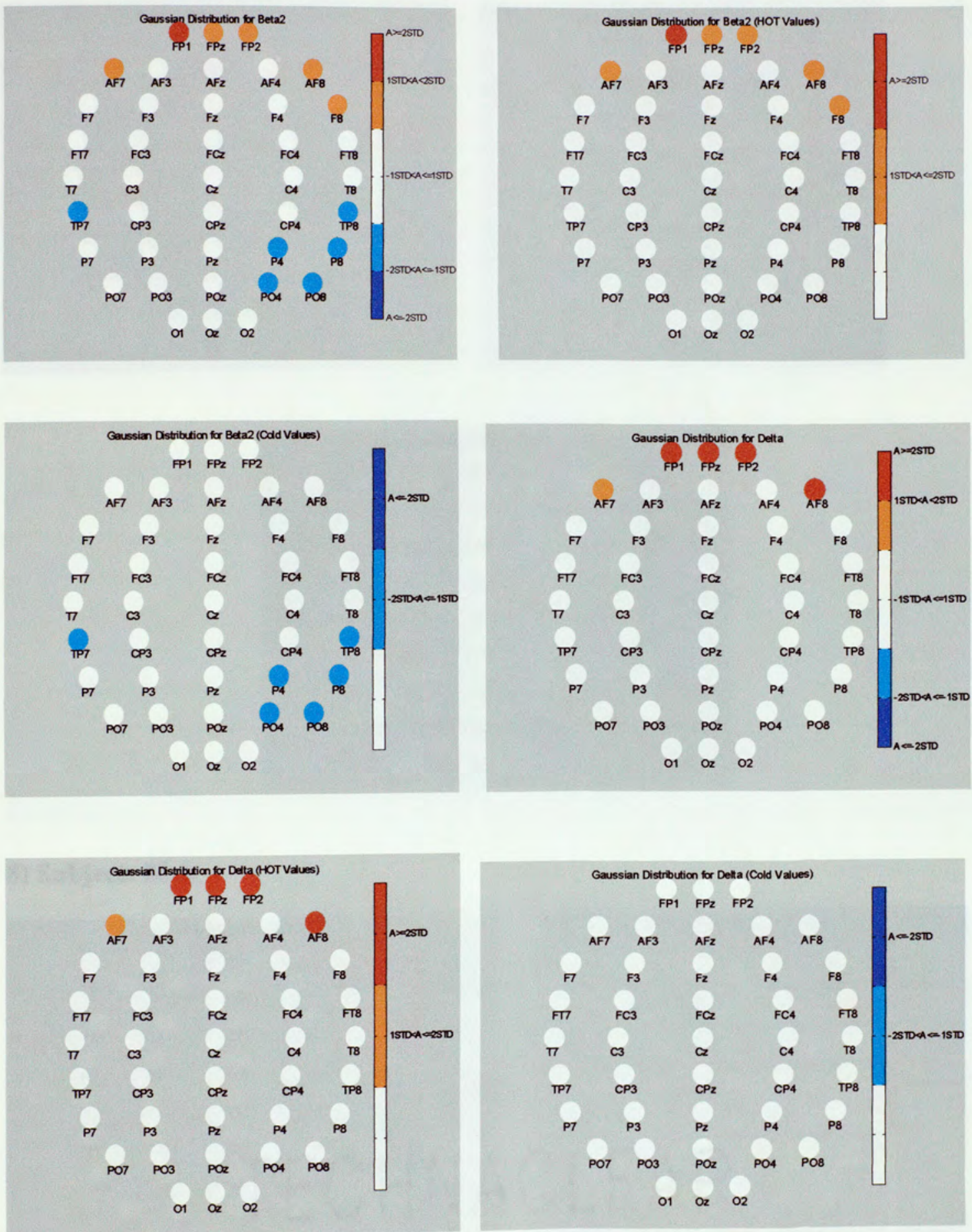

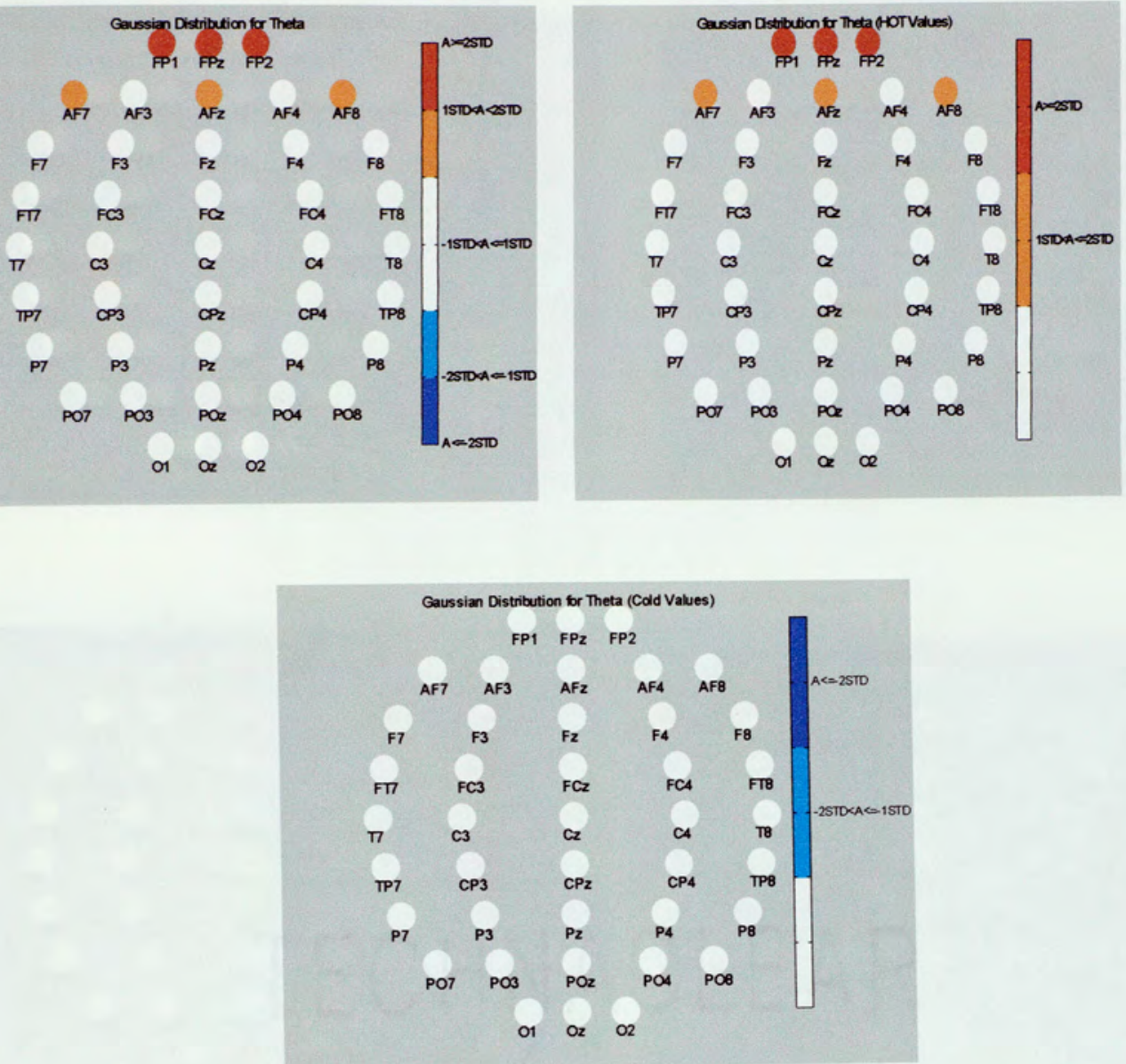

8) Subject: M.J.
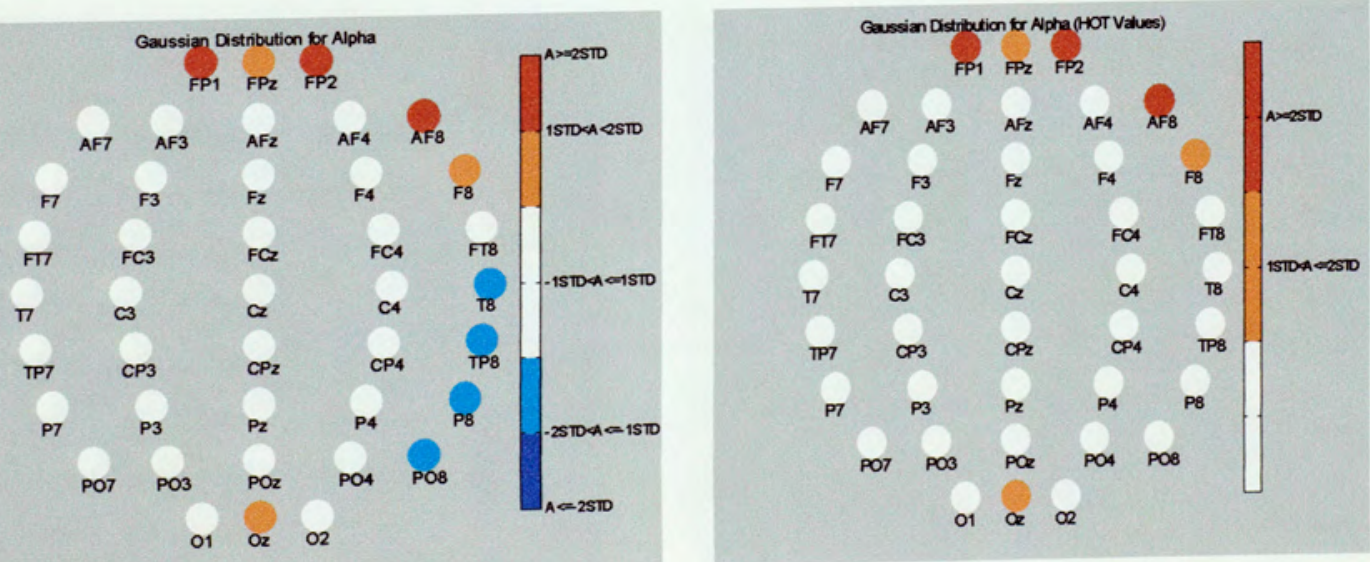

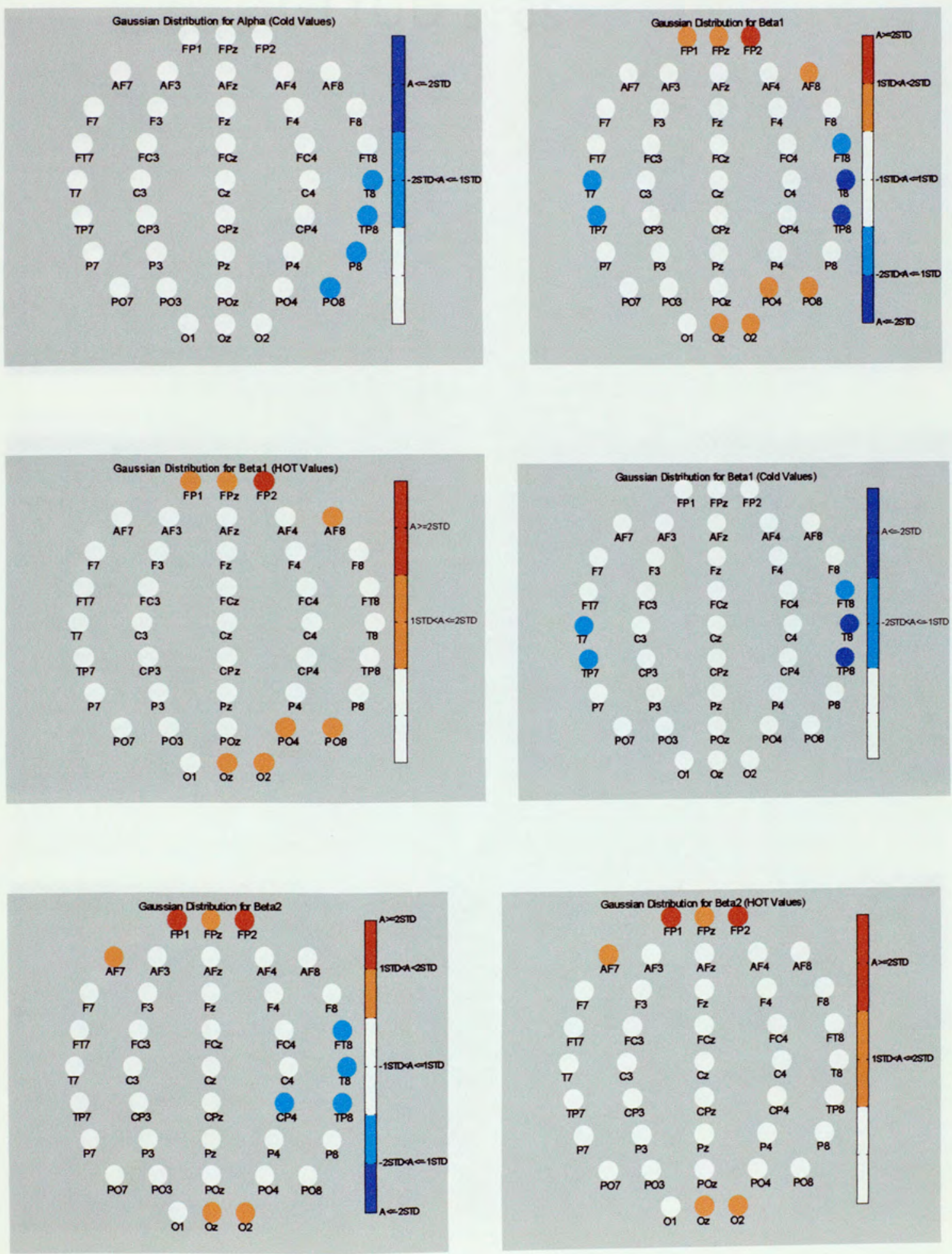

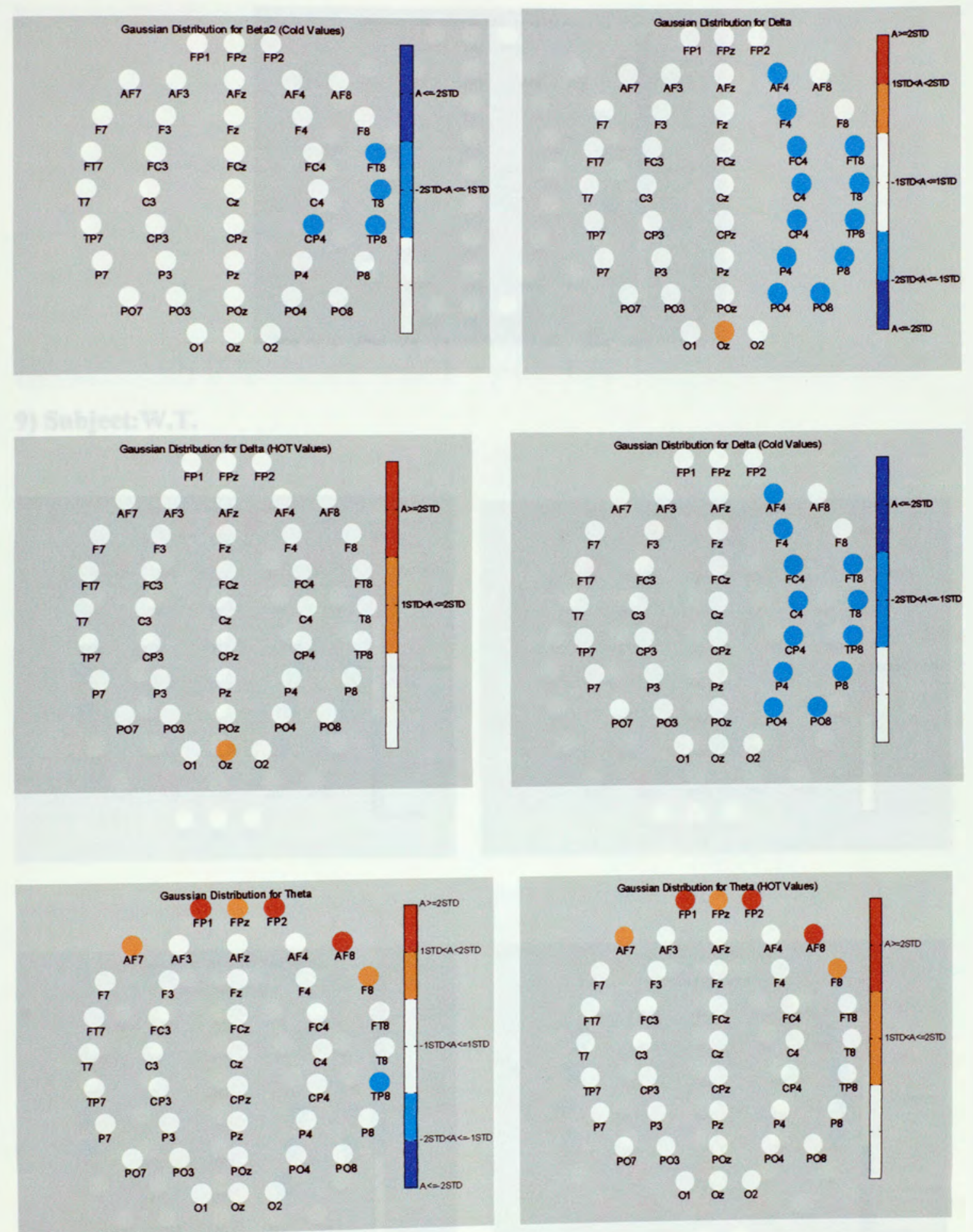


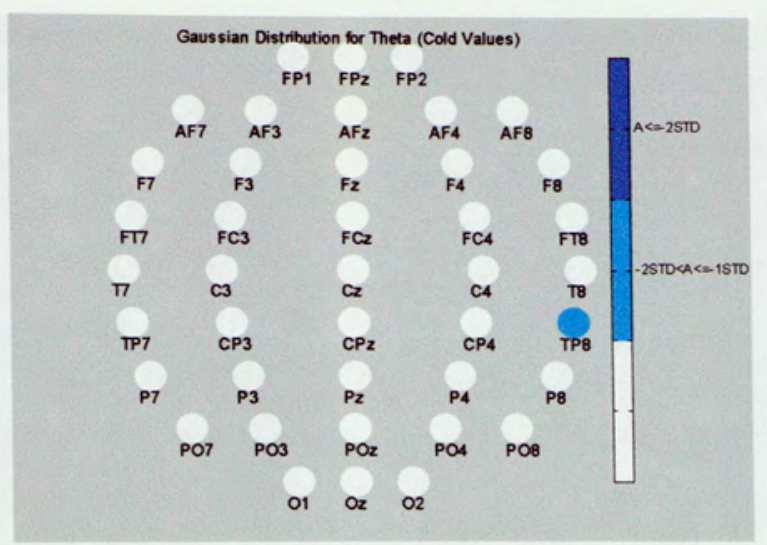

9) Subject:W.T.
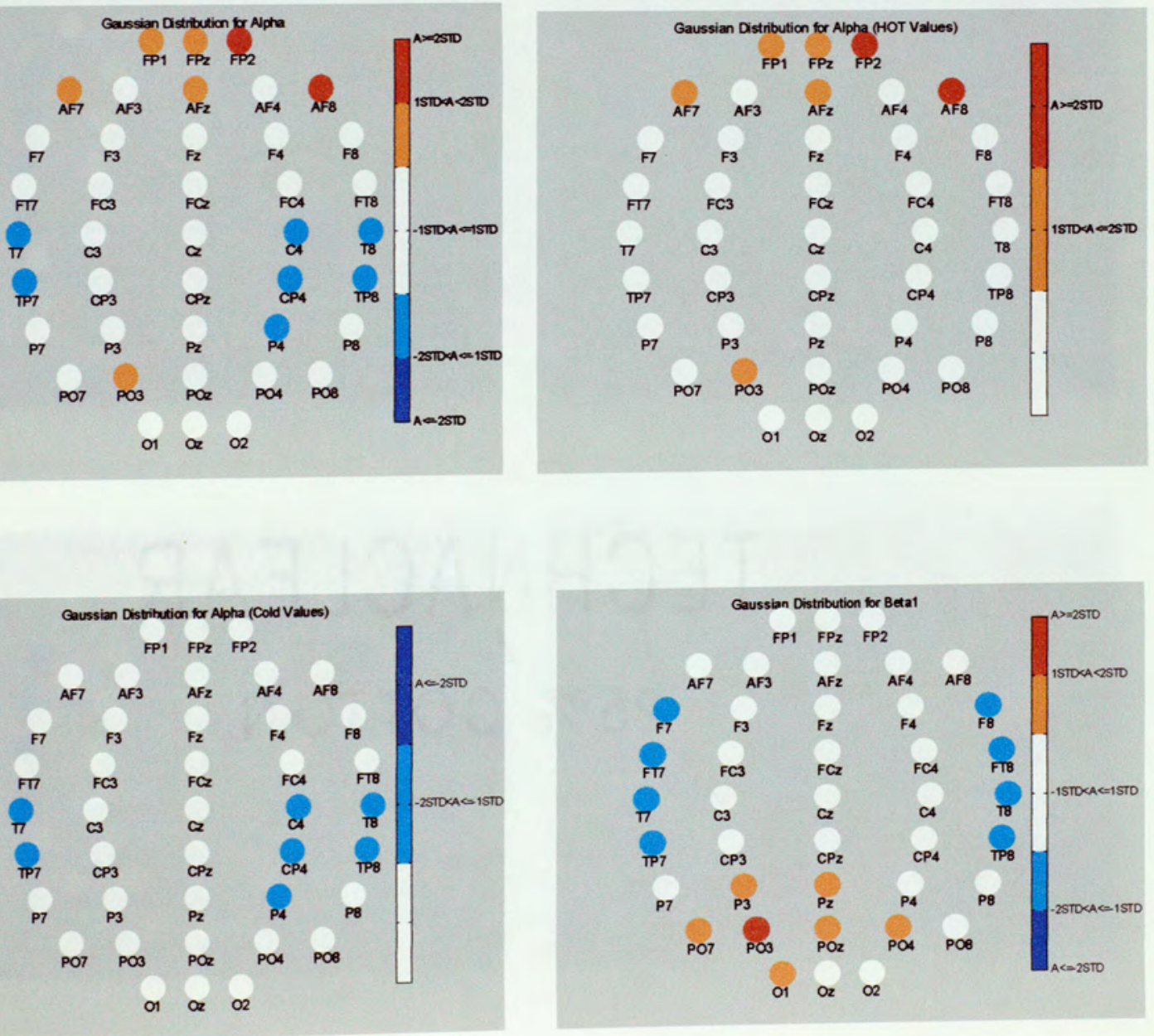

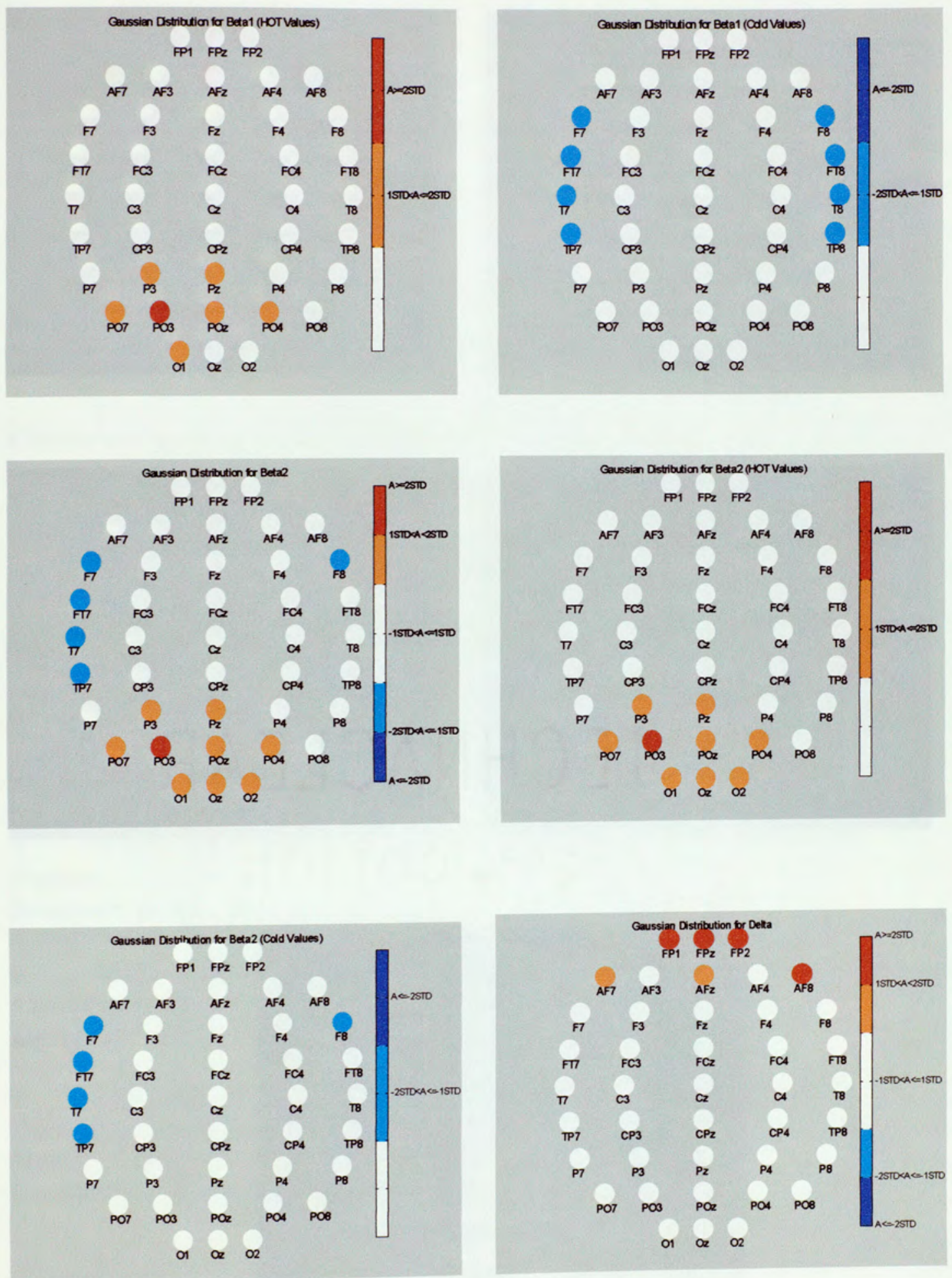

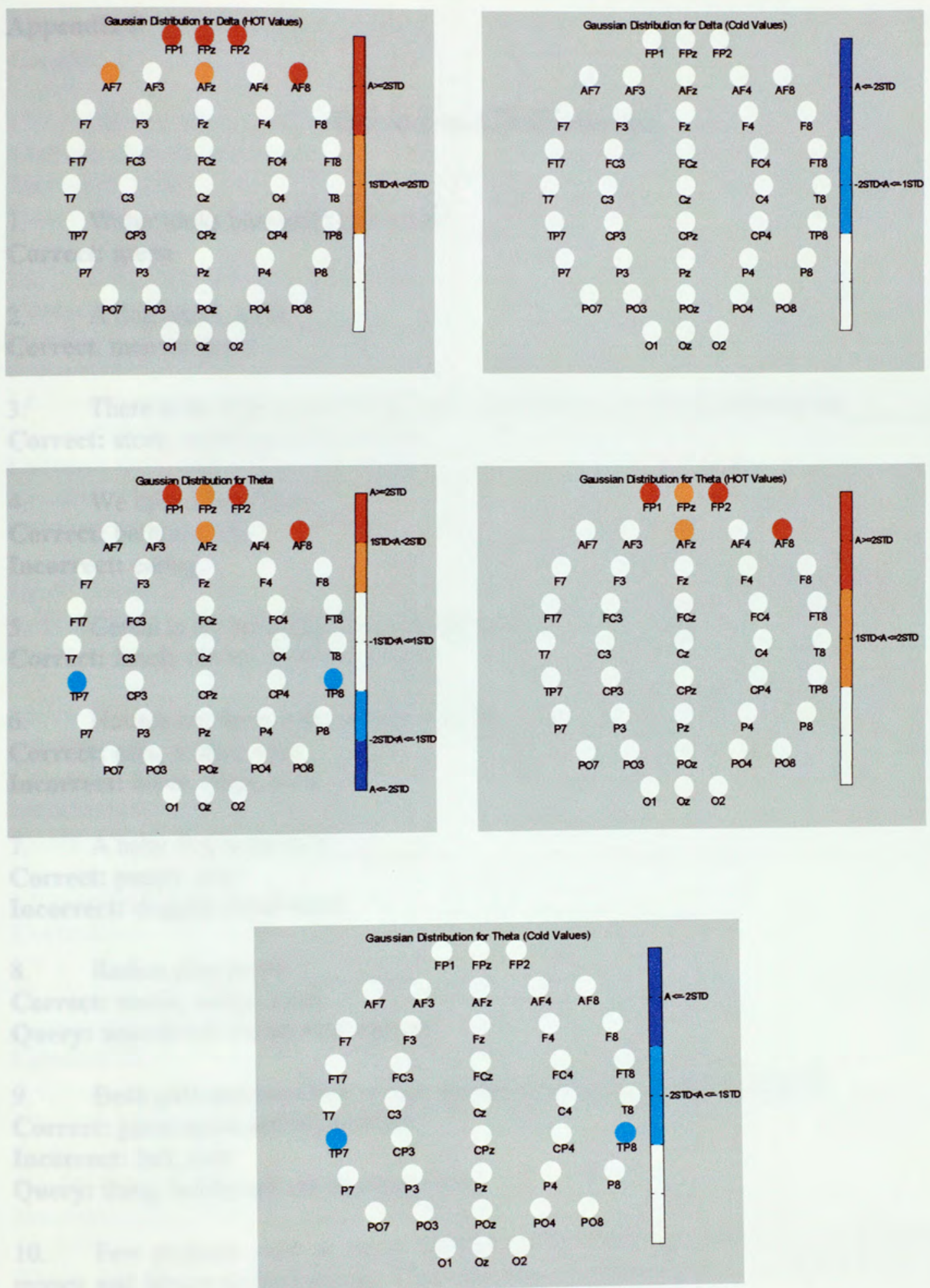


\section{Test 15 Oral Comprehension}

1. Water looks blue and grass looks

Correct: green

2. A dog barks, a cat

Correct: meows, purrs

3. There is no milk in the refrigerator. We need to go and get some at the

Correct: store, supermarket, grocery

4. We take a bath in a

Correct: bathtub, tub

Incorrect: eating

5. Cereal is for breakfast, a sandwich is for

Correct: lunch, dinner, a snack, supper

6. Houses are for people, garages are for

Correct: cars, trucks, vans

Incorrect: bikes, dogs, stuff

7. A baby dog is called a

Correct: puppy, pup

Incorrect: doggie, woof-woof

8. Radios play pretty

Correct: music, songs, loud

Query: sounds-tell me another answer.

9. Both girls and boys like to play softball. For many, it is their favorite

Correct: game,sport,activity,pastime

Incorrect: ball, paly

Query: thing, hobby-tell me another word.

10. Few projects yield so much satisfaction in return for such a small investment in money and labors as beekeeping. Once the bees are established, a single hive can easily produce thirty pounds or more of delicious

Correct: honey

Query: food-Tell me another word. 
11. When a baby is hungry, it may

Correct: cry

12. My car is not as large as yours. For our family, it is the right

Correct: size, choice, model

Incorrect: color

Query: car, one, kind, thing-Tell me another word.

13. Dogs are pets, and dolls are

Correct: toys

Incorrect: babies, girls, to play with

14. If a mother shunk thinks that there is danger to her young, she protects them. She can produce a very unpleasant

Correct: smell, odor, stink, aroma, scent, spary,stench

Incorrect: baby, fight, time

Query: surprise, thing-Tell me another word.

15. Blueberriesa are small and round and sweet. They got this name because their color appears

Correct: blue

16. She might have been the first teenager to win had she not tripped. She was heartbroken, but she would have another

Correct: chance, game, opportunity, race, try, turn

Incorrect: one, friend, heart, leg, trip

Query: time-Tell me another word

17. Carrots can be eaten cooked. They also can be eaten

Correct: raw, uncooked

18. Lacrosse has become one of the fastest-growing team sports. Every year more and more people decide they want to learn how to

Correct: play

19. Days are not always sunny in Hawaii. Some of the wettest places on earth are on these

Correct: islands

Incorrect: planes, land, beaches, countries, ocean, places, planets, shores, states

20. She always enjoys that magazine. It does not matter what else she brings along to

$\overline{\text { Correct: read }}$ 
21. In the unlikely event of an emergency, remember that the parachute is attached to you. It will go where you go. Do not pull the cord until you are clear of the

Correct: plane, airplane, aircraft, tail, wings

Incorrect: ground, air, sky, clouds, area danger, landing, parachute, trees, water

22. During the late 1950s, drive-in theaters were popular in the United States. They combined two things Americans love-cars and

Correct: meal, food, nourishment, nutrition

23. People who eat breakfast daily tend to perform better. They are less tired and irritable that those who go without that

Correct: meal, food, nourishment, nutrition

24. Federal regulations require all carry-on baggage to be stowed during takeoff and landing. These items must be placed under the seat in front of you, unless you are in an aircraft with enclosed overhead

Correct: compartments, storage, bins, cabinets, containers, racks, shelves

Incorrect: place, door, seats, baggage, ceilings, closets, cupboard, roof

Query: space-Tell me another word.

25. Romania is a mountainous country in southeastern Europe. It is nearly as large as Oregon, but it has nineteen times as many people as that

Correct: state, place, area

Incorrect: country, Oregon, city, population, U.S.

26. In recent centuries, a total eclipse of the sun brought panic and gloom because the sun would totally disappear at midday. When you think about this starting phenomenon, it is no wonder that people were so

Correct: frightened, afraid, scared

27. To be part of the experimental team, they had to remove their everyday clothes, wash their hands and faces, and put on the white clothes from the glass container. It was utmost importance that when they entered the room, they were very

Correct: sterile, clean

Incorrect: quiet

Query: sanitary-Tell me another word.

28. It's nice to have a small car when you are trying to squeeze into a tiny parking place. That may be the major reason that they are so

Correct: popular

Incorrect: small, compact

29. In all of human history, less than a thousand individual comets have been recorded. Only a few hundred of these have made more than one passage by 
Correct: Earth, us

Incorrect: people, vessels, air, atmosphere, Congress, space, sun

30. Form the most impoverished hovels in the poorest hamlets of Scotland, dedicated teachers and ministers identify youth promise. Then they find a way for them to get

Correct: educated, education, schooling, scholarships

Incorrect: youth, jobs, even, food, homes, money, saved

Query: ahead, help, away, out-Tell me another word.

31. It rarely happens that a small particle lifted off the Earth's surface is found floating about the stratosphere. Such particles tend to be rained out before they reach that

Correct: level, height, altitude, layer

Incorrect: ground, sun, atmosphere, destination, earth, part, planet, shore, stratosphere, surface

Query: place, space, area, point-Tell me another word.

32. Today tour operators offer thousands of vacations to every continent. Be sure to read the brochures very carefully because different groups often create very different

$\overline{\text { Correct: }}$ trips, itineraries, packages, vacations

33. Parents have a secret source of delight that is closed to nonparenting adults. When the report from school comes for one of their children, they realize with a relief that rises to delight-thank heaven no one is reporting in this fashion about

Correct: me, us, parents, them

Incorrect: grades, behavior, children, failing, misbehavior, trouble

34. Observation of behavior when errors are made can lead to hypotheses regarding learning characteristics. Some people become so frustrated that their emotions cause them to quit. The rigid persist with a strategy that has

Correct: failed

Incorrect: stubbornness, prevailed, succeeded, patience, worked, persisted 


\title{
Appendix G
}

\author{
Similarities of Unknown Auditory-Answer EEG Vs. Auditory-Answer EEG from \\ Database
}

\section{LISTENING}

\%\%RESULTS WHEN RUNNING PATIENT 1 WITH RESPECT TO THE REST (8)

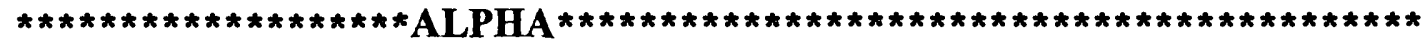

Energy Minimum Distance (ALPHA POS LEFT) of Subject 1 Vs Unknown $=1.000$ Energy Minimum Distance (ALPHA POS LEFT) of Subject 2 Vs Unknown $=2.000$ Energy Minimum Distance (ALPHA POS LEFT) of Subject 3 Vs Unknown $=2.000$ Energy Minimum Distance (ALPHA POS LEFT) of Subject 4 Vs Unknown $=3.000$ Energy Minimum Distance (ALPHA POS LEFT) of Subject 5 Vs Unknown $=4.000$ Energy Minimum Distance (ALPHA POS LEFT) of Subject 6 Vs Unknown $=2.000$ Energy Minimum Distance (ALPHA POS LEFT) of Subject 7 Vs Unknown $=1.000$ Energy Minimum Distance (ALPHA POS LEFT) of Subject 8 Vs Unknown $=3.000$

Energy Minimum Distance (ALPHA POS RIGHT) of Subject 1 Vs Unknown $=3.000$ Energy Minimum Distance (ALPHA POS RIGHT) of Subject 2 Vs Unknown $=2.000$ Energy Minimum Distance (ALPHA POS RIGHT) of Subject 3 Vs Unknown $=3.000$ Energy Minimum Distance (ALPHA POS RIGHT) of Subject 4 Vs Unknown $=3.000$ Energy Minimum Distance (ALPHA POS RIGHT) of Subject 5 Vs Unknown $=4.000$ Energy Minimum Distance (ALPHA POS RIGHT) of Subject 6 Vs Unknown $=3.000$ Energy Minimum Distance (ALPHA POS RIGHT) of Subject 7 Vs Unknown $=3.000$ Energy Minimum Distance (ALPHA POS RIGHT) of Subject 8 Vs Unknown $=3.000$

Energy Minimum Distance (ALPHA neg LEFT) of Subject 1 Vs Unknown $=3.000$ Energy Minimum Distance (ALPHA neg LEFT) of Subject 2 Vs Unknown $=3.000$ Energy Minimum Distance (ALPHA neg LEFT) of Subject 3 Vs Unknown $=9.000$ Energy Minimum Distance (ALPHA neg LEFT) of Subject 4 Vs Unknown $=5.000$ Energy Minimum Distance (ALPHA neg LEFT) of Subject 5 Vs Unknown $=11.000$ Energy Minimum Distance (ALPHA neg LEFT) of Subject 6 Vs Unknown $=9.000$ Energy Minimum Distance (ALPHA neg LEFT) of Subject 7 Vs Unknown $=2.000$ Energy Minimum Distance (ALPHA neg LEFT) of Subject 8 Vs Unknown $=5.000$

Energy Minimum Distance (ALPHA neg RIGHT) of Subject 1 Vs Unknown $=1.000$ Energy Minimum Distance (ALPHA neg RIGHT) of Subject 2 Vs Unknown $=1.000$ Energy Minimum Distance (ALPHA neg RIGHT) of Subject 3 Vs Unknown $=5.000$ Energy Minimum Distance (ALPHA neg RIGHT) of Subject 4 Vs Unknown $=7.000$ 
Energy Minimum Distance (ALPHA neg RIGHT) of Subject 5 Vs Unknown $=4.000$ Energy Minimum Distance (ALPHA neg RIGHT) of Subject 6 Vs Unknown $=1.000$ Energy Minimum Distance (ALPHA neg RIGHT) of Subject 7 Vs Unknown $=3.000$ Energy Minimum Distance (ALPHA neg RIGHT) of Subject 8 Vs Unknown $=4.000$

$\star \star \star \star \star \star \star \star \star \star \star \star \star \star \star \star \star \star \star \star \star \star$ BETA

Energy Minimum Distance (beta1 POS LEFT) of Subject 1 Vs Unknown $=5.000$ Energy Minimum Distance (beta1 POS LEFT) of Subject 2 Vs Unknown $=5.000$ Energy Minimum Distance (beta1 POS LEFT) of Subject 3 Vs Unknown $=7.000$ Energy Minimum Distance (beta1 POS LEFT) of Subject 4 Vs Unknown $=6.000$ Energy Minimum Distance (beta1 POS LEFT) of Subject 5 Vs Unknown $=6.000$ Energy Minimum Distance (beta1 POS LEFT) of Subject 6 Vs Unknown $=4.000$ Energy Minimum Distance (beta1 POS LEFT) of Subject 7 Vs Unknown $=1.000$ Energy Minimum Distance (beta1 POS LEFT) of Subject 8 Vs Unknown $=4.000$

Energy Minimum Distance (beta1 POS RIGHT) of Subject 1 Vs Unknown $=3.000$ Energy Minimum Distance (betal POS RIGHT) of Subject 2 Vs Unknown $=5.000$ Energy Minimum Distance (beta1 POS RIGHT) of Subject 3 Vs Unknown $=4.000$ Energy Minimum Distance (beta1 POS RIGHT) of Subject 4 Vs Unknown $=4.000$ Energy Minimum Distance (betal POS RIGHT) of Subject 5 Vs Unknown $=4.000$ Energy Minimum Distance (betal POS RIGHT) of Subject 6 Vs Unknown $=1.000$ Energy Minimum Distance (beta1 POS RIGHT) of Subject 7 Vs Unknown $=2.000$ Energy Minimum Distance (betal POS RIGHT) of Subject 8 Vs Unknown $=5.000$

Energy Minimum Distance (betal neg LEFT) of Subject 1 Vs Unknown $=9.000$ Energy Minimum Distance (beta1 neg LEFT) of Subject 2 Vs Unknown $=7.000$ Energy Minimum Distance (betal neg LEFT) of Subject 3 Vs Unknown $=10.000$ Energy Minimum Distance (betal neg LEFT) of Subject 4 Vs Unknown $=6.000$ Energy Minimum Distance (betal neg LEFT) of Subject 5 Vs Unknown $=8.000$ Energy Minimum Distance (betal neg LEFT) of Subject 6 Vs Unknown $=6.000$ Energy Minimum Distance (betal neg LEFT) of Subject 7 Vs Unknown $=5.000$ Energy Minimum Distance (beta1 neg LEFT) of Subject 8 Vs Unknown $=6.000$

Energy Minimum Distance (beta1 neg RIGHT) of Subject 1 Vs Unknown $=1.000$ Energy Minimum Distance (beta1 neg RIGHT) of Subject 2 Vs Unknown $=1.000$ Energy Minimum Distance (betal neg RIGHT) of Subject 3 Vs Unknown $=5.000$ Energy Minimum Distance (betal neg RIGHT) of Subject 4 Vs Unknown $=7.000$ Energy Minimum Distance (beta1 neg RIGHT) of Subject 5 Vs Unknown $=3.000$ Energy Minimum Distance (beta1 neg RIGHT) of Subject 6 Vs Unknown $=3.000$ Energy Minimum Distance (betal neg RIGHT) of Subject 7 Vs Unknown $=3.000$ Energy Minimum Distance (beta1 neg RIGHT) of Subject 8 Vs Unknown $=2.000$ 
Energy Minimum Distance (beta2 POS LEFT) of Subject 1 Vs Unknown $=3.000$ Energy Minimum Distance (beta2 POS LEFT) of Subject 2 Vs Unknown $=2.000$ Energy Minimum Distance (beta2 POS LEFT) of Subject 3 Vs Unknown $=5.000$ Energy Minimum Distance (beta2 POS LEFT) of Subject 4 Vs Unknown $=4.000$ Energy Minimum Distance (beta2 POS LEFT) of Subject 5 Vs Unknown $=1.000$ Energy Minimum Distance (beta2 POS LEFT) of Subject 6 Vs Unknown $=4.000$ Energy Minimum Distance (beta2 POS LEFT) of Subject 7 Vs Unknown $=3.000$ Energy Minimum Distance (beta2 POS LEFT) of Subject 8 Vs Unknown $=2.000$

Energy Minimum Distance (beta2 POS RIGHT) of Subject 1 Vs Unknown $=2.000$ Energy Minimum Distance (beta2 POS RIGHT) of Subject 2 Vs Unknown $=4.000$ Energy Minimum Distance (beta2 POS RIGHT) of Subject 3 Vs Unknown $=6.000$ Energy Minimum Distance (beta2 POS RIGHT) of Subject 4 Vs Unknown $=4.000$ Energy Minimum Distance (beta2 POS RIGHT) of Subject 5 Vs Unknown $=4.000$ Energy Minimum Distance (beta2 POS RIGHT) of Subject 6 Vs Unknown $=4.000$ Energy Minimum Distance (beta2 POS RIGHT) of Subject 7 Vs Unknown $=2.000$ Energy Minimum Distance (beta2 POS RIGHT) of Subject 8 Vs Unknown $=4.000$

Energy Minimum Distance (beta2 neg LEFT) of Subject 1 Vs Unknown $=11.000$ Energy Minimum Distance (beta2 neg LEFT) of Subject 2 Vs Unknown $=6.000$ Energy Minimum Distance (beta2 neg LEFT) of Subject 3 Vs Unknown $=8.000$ Energy Minimum Distance (beta2 neg LEFT) of Subject 4 Vs Unknown $=8.000$ Energy Minimum Distance (beta2 neg LEFT) of Subject 5 Vs Unknown $=7.000$ Energy Minimum Distance (beta2 neg LEFT) of Subject 6 Vs Unknown $=8.000$ Energy Minimum Distance (beta2 neg LEFT) of Subject 7 Vs Unknown $=5.000$ Energy Minimum Distance (beta2 neg LEFT) of Subject 8 Vs Unknown $=8.000$

Energy Minimum Distance (beta2 neg RIGHT) of Subject 1 Vs Unknown $=0.000$ Energy Minimum Distance (beta2 neg RIGHT) of Subject 2 Vs Unknown $=1.000$ Energy Minimum Distance (beta2 neg RIGHT) of Subject 3 Vs Unknown $=5.000$ Energy Minimum Distance (beta2 neg RIGHT) of Subject 4 Vs Unknown $=10.000$ Energy Minimum Distance (beta2 neg RIGHT) of Subject 5 Vs Unknown $=0.000$ Energy Minimum Distance (beta2 neg RIGHT) of Subject 6 Vs Unknown $=6.000$ Energy Minimum Distance (beta2 neg RIGHT) of Subject 7 Vs Unknown $=0.000$ Energy Minimum Distance (beta2 neg RIGHT) of Subject 8 Vs Unknown $=0.000$

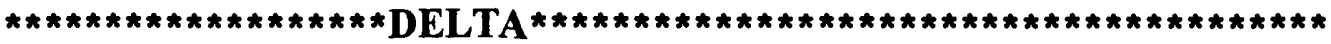

Energy Minimum Distance (delta POS LEFT) of Subject 1 Vs Unknown $=3.000$ Energy Minimum Distance (delta POS LEFT) of Subject 2 Vs Unknown $=1.000$ 
Energy Minimum Distance (delta POS LEFT) of Subject 3 Vs Unknown $=1.000$ Energy Minimum Distance (delta POS LEFT) of Subject 4 Vs Unknown $=2.000$ Energy Minimum Distance (delta POS LEFT) of Subject 5 Vs Unknown $=2.000$ Energy Minimum Distance (delta POS LEFT) of Subject 6 Vs Unknown $=1.000$ Energy Minimum Distance (delta POS LEFT) of Subject 7 Vs Unknown $=1.000$ Energy Minimum Distance (delta POS LEFT) of Subject 8 Vs Unknown $=2.000$

Energy Minimum Distance (delta POS RIGHT) of Subject 1 Vs Unknown $=3.000$ Energy Minimum Distance (delta POS RIGHT) of Subject 2 Vs Unknown $=2.000$ Energy Minimum Distance (delta POS RIGHT) of Subject 3 Vs Unknown $=1.000$ Energy Minimum Distance (delta POS RIGHT) of Subject 4 Vs Unknown $=1.000$ Energy Minimum Distance (delta POS RIGHT) of Subject 5 Vs Unknown $=1.000$ Energy Minimum Distance (delta POS RIGHT) of Subject 6 Vs Unknown $=3.000$ Energy Minimum Distance (delta POS RIGHT) of Subject 7 Vs Unknown $=2.000$ Energy Minimum Distance (delta POS RIGHT) of Subject 8 Vs Unknown $=2.000$

Energy Minimum Distance (delta neg LEFT) of Subject 1 Vs Unknown $=0.000$ Energy Minimum Distance (delta neg LEFT) of Subject 2 Vs Unknown $=0.000$ Energy Minimum Distance (delta neg LEFT) of Subject 3 Vs Unknown $=0.000$ Energy Minimum Distance (delta neg LEFT) of Subject 4 Vs Unknown $=0.000$ Energy Minimum Distance (delta neg LEFT) of Subject 5 Vs Unknown $=0.000$ Energy Minimum Distance (delta neg LEFT) of Subject 6 Vs Unknown $=0.000$ Energy Minimum Distance (delta neg LEFT) of Subject 7 Vs Unknown $=0.000$ Energy Minimum Distance (delta neg LEFT) of Subject 8 Vs Unknown $=3.000$

Energy Minimum Distance (delta neg RIGHT) of Subject 1 Vs Unknown $=0.000$ Energy Minimum Distance (delta neg RIGHT) of Subject 2 Vs Unknown $=2.000$ Energy Minimum Distance (delta neg RIGHT) of Subject 3 Vs Unknown $=0.000$ Energy Minimum Distance (delta neg RIGHT) of Subject 4 Vs Unknown $=5.000$ Energy Minimum Distance (delta neg RIGHT) of Subject 5 Vs Unknown $=0.000$ Energy Minimum Distance (delta neg RIGHT) of Subject 6 Vs Unknown $=18.000$ Energy Minimum Distance (delta neg RIGHT) of Subject 7 Vs Unknown $=0.000$ Energy Minimum Distance (delta neg RIGHT) of Subject 8 Vs Unknown $=0.000$

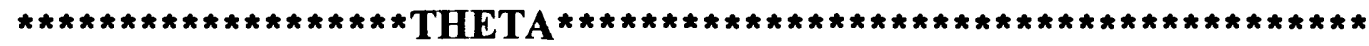

Energy Minimum Distance (theta POS LEFT) of Subject 1 Vs Unknown $=1.000$ Energy Minimum Distance (theta POS LEFT) of Subject 2 Vs Unknown $=1.000$ Energy Minimum Distance (theta POS LEFT) of Subject 3 Vs Unknown $=1.000$ Energy Minimum Distance (theta POS LEFT) of Subject 4 Vs Unknown $=2.000$ Energy Minimum Distance (theta POS LEFT) of Subject 5 Vs Unknown $=3.000$ Energy Minimum Distance (theta POS LEFT) of Subject 6 Vs Unknown $=1.000$ Energy Minimum Distance (theta POS LEFT) of Subject 7 Vs Unknown $=1.000$ 
Energy Minimum Distance (theta POS RIGHT) of Subject 1 Vs Unknown $=3.000$ Energy Minimum Distance (theta POS RIGHT) of Subject 2 Vs Unknown $=0.000$ Energy Minimum Distance (theta POS RIGHT) of Subject 3 Vs Unknown $=2.000$ Energy Minimum Distance (theta POS RIGHT) of Subject 4 Vs Unknown $=1.000$ Energy Minimum Distance (theta POS RIGHT) of Subject 5 Vs Unknown $=3.000$ Energy Minimum Distance (theta POS RIGHT) of Subject 6 Vs Unknown $=2.000$ Energy Minimum Distance (theta POS RIGHT) of Subject 7 Vs Unknown $=2.000$ Energy Minimum Distance (theta POS RIGHT) of Subject 8 Vs Unknown $=2.000$

Energy Minimum Distance (theta neg LEFT) of Subject 1 Vs Unknown $=8.000$ Energy Minimum Distance (theta neg LEFT) of Subject 2 Vs Unknown $=7.000$ Energy Minimum Distance (theta neg LEFT) of Subject 3 Vs Unknown $=7.000$ Energy Minimum Distance (theta neg LEFT) of Subject 4 Vs Unknown $=7.000$ Energy Minimum Distance (theta neg LEFT) of Subject 5 Vs Unknown $=10.000$ Energy Minimum Distance (theta neg LEFT) of Subject 6 Vs Unknown $=7.000$ Energy Minimum Distance (theta neg LEFT) of Subject 7 Vs Unknown $=7.000$ Energy Minimum Distance (theta neg LEFT) of Subject 8 Vs Unknown $=9.000$

Energy Minimum Distance (theta neg RIGHT) of Subject 1 Vs Unknown $=2.000$ Energy Minimum Distance (theta neg RIGHT) of Subject 2 Vs Unknown $=2.000$ Energy Minimum Distance (theta neg RIGHT) of Subject 3 Vs Unknown $=2.000$ Energy Minimum Distance (theta neg RIGHT) of Subject 4 Vs Unknown $=10.000$ Energy Minimum Distance (theta neg RIGHT) of Subject 5 Vs Unknown $=2.000$ Energy Minimum Distance (theta neg RIGHT) of Subject 6 Vs Unknown $=2.000$ Energy Minimum Distance (theta neg RIGHT) of Subject 7 Vs Unknown $=2.000$ Energy Minimum Distance (theta neg RIGHT) of Subject 8 Vs Unknown $=3.000$

Energy Minimum Distance (ALPHA POS LEFT) is 1 Minimum Distance (ALPHA POS LEFT) belongs to subjects 28

Energy Minimum Distance (ALPHA NEG LEFT) is 2 Energy Minimum Distance (ALPHA NEG LEFT) belongs to subject 8

Energy Minimum Distance (ALPHA POS RIGHT) is 2 Energy Minimum Distance (ALPHA POS RIGHT) belongs to subject 3

Energy Minimum Distance (ALPHA NEG RIGHT) is 1 Energy Minimum Distance (ALPHA NEG RIGHT) belongs to subjects 237 


\section{Unknown}

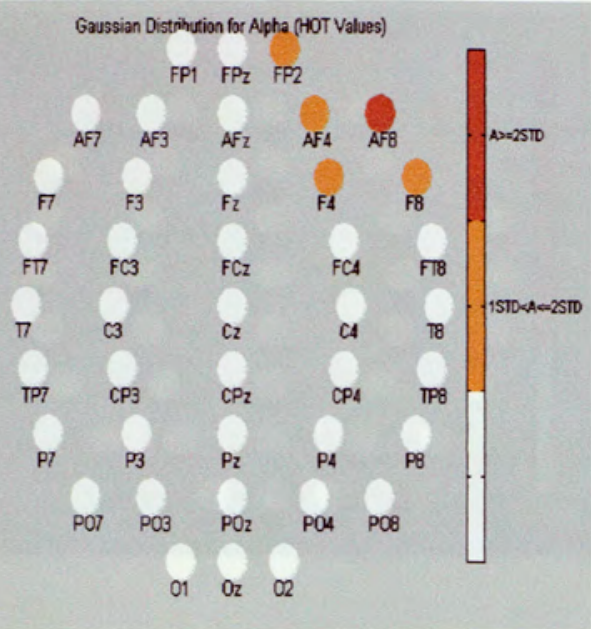

\section{Patient 2}

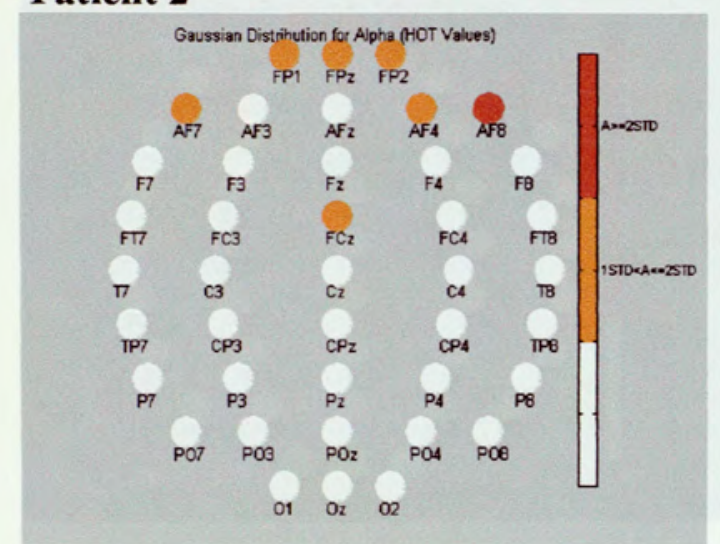

\section{Unknown}

Gaussian Distrihution for Alpha (Cold Values)

$\begin{array}{lll}F P 1 & F P & F P 2\end{array}$

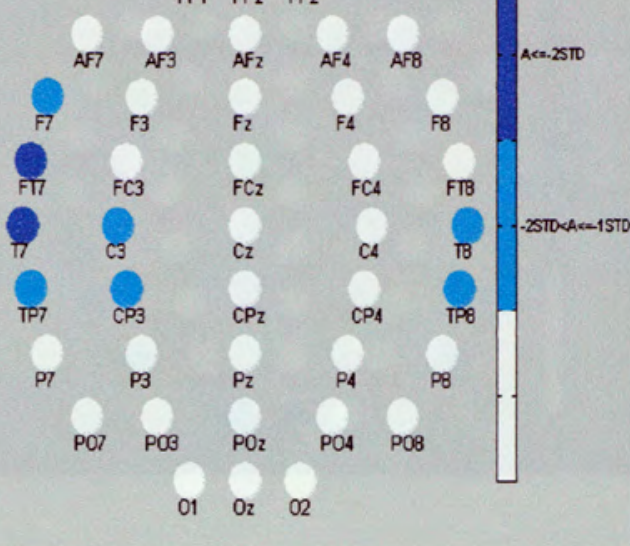

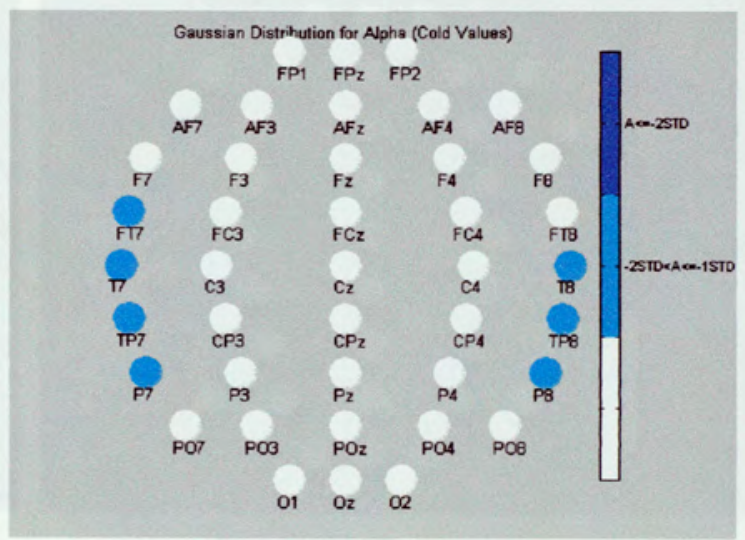

\section{Patient 8}
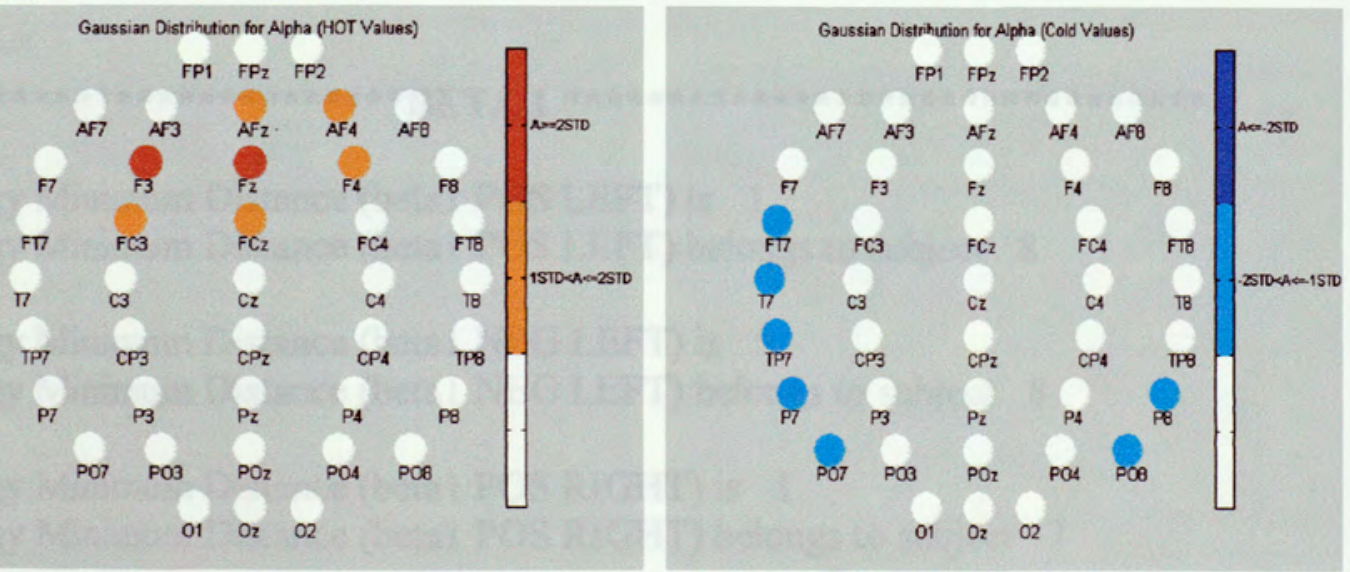


\section{Patient 3}
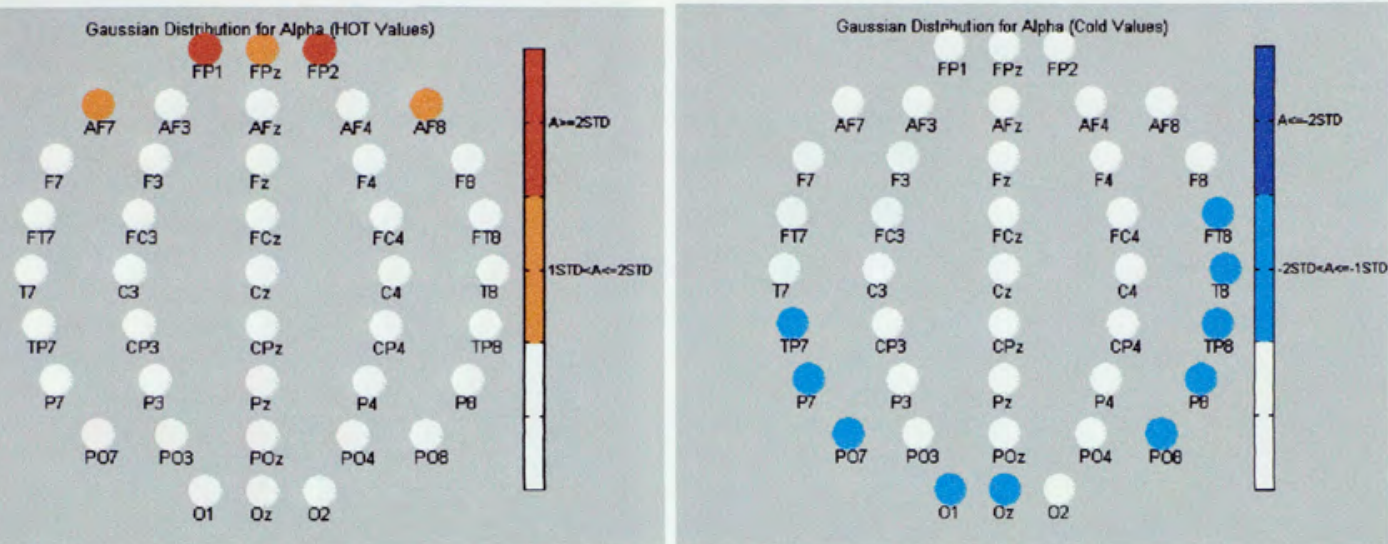

\section{Patient 7}
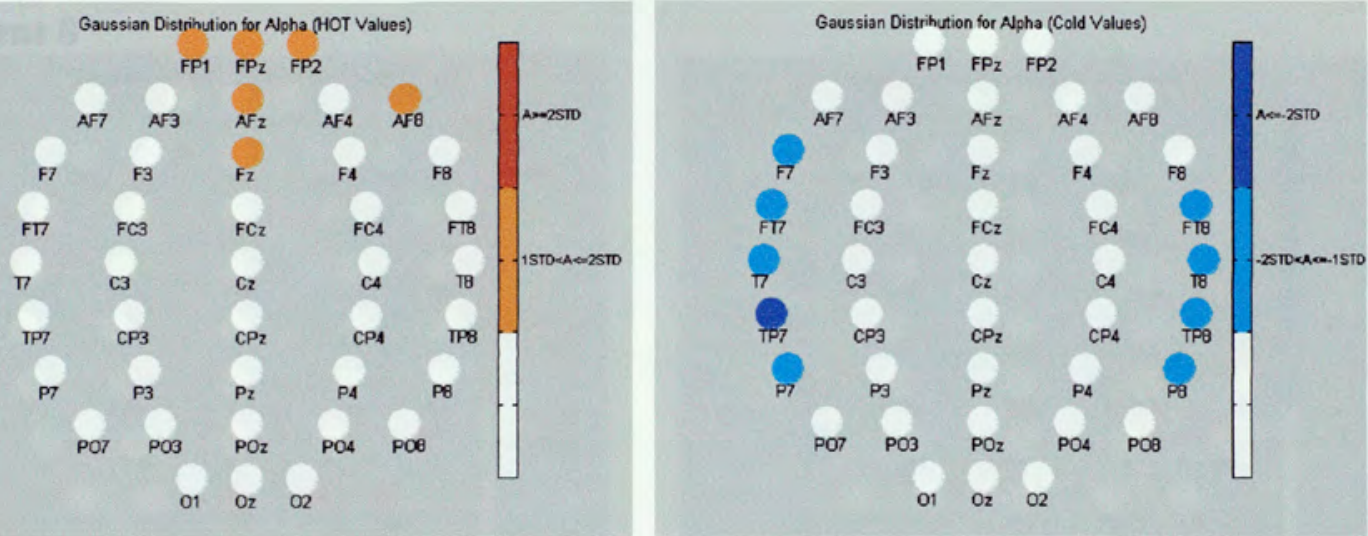

Energy Minimum Distance (beta1 POS LEFT) is 1 Energy Minimum Distance (betal POS LEFT) belongs to subject 8

Energy Minimum Distance (beta1 NEG LEFT) is 5 Energy Minimum Distance (beta1 NEG LEFT) belongs to subject 8

Energy Minimum Distance (betal POS RIGHT) is 1 Energy Minimum Distance (beta1 POS RIGHT) belongs to subject 7

Energy Minimum Distance (betal NEG RIGHT) is 1 Energy Minimum Distance (beta1 NEG RIGHT) belongs to subjects 23 


\section{Unknown}

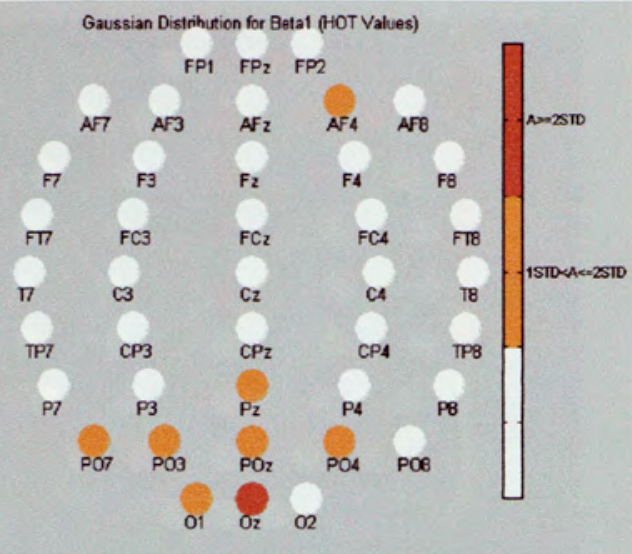

\section{Patient 8}

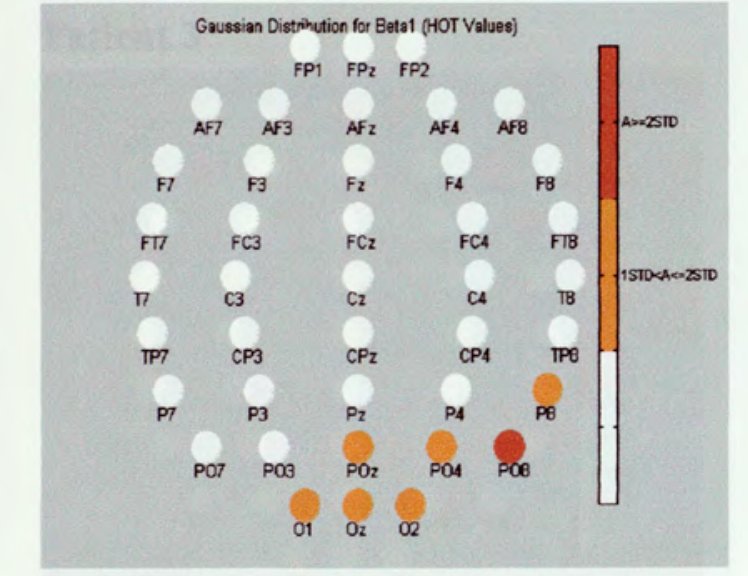

\section{Patient 7}

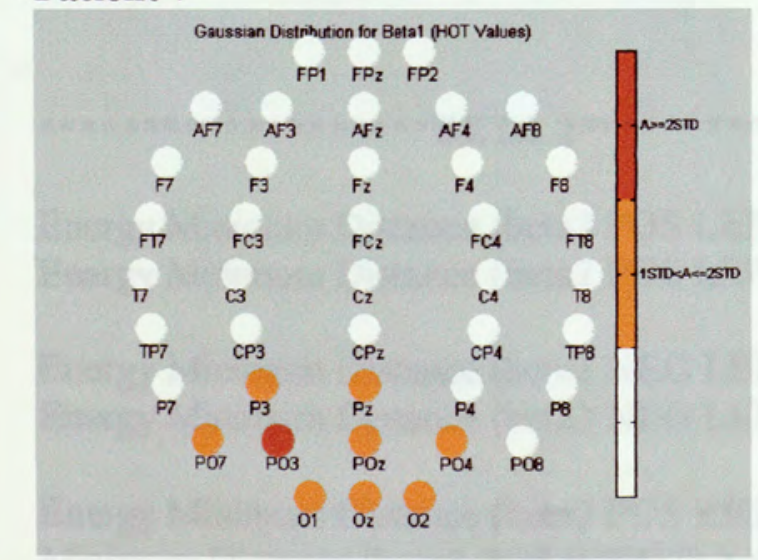

\section{Unknown}

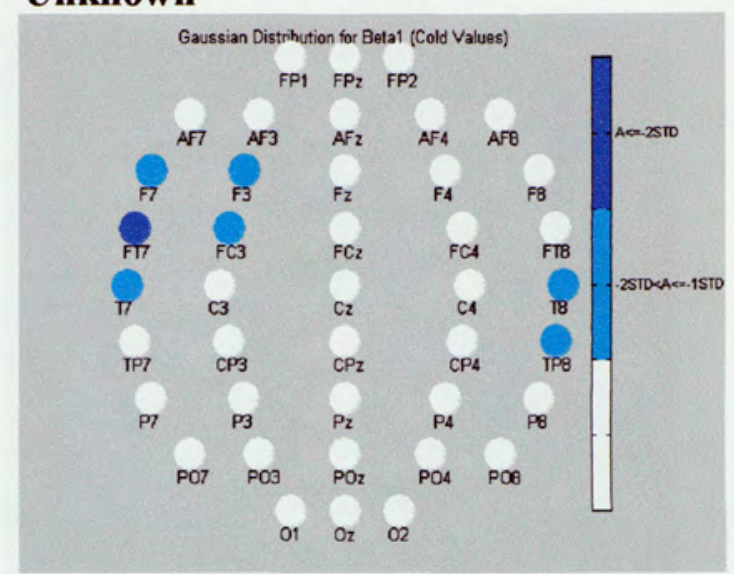

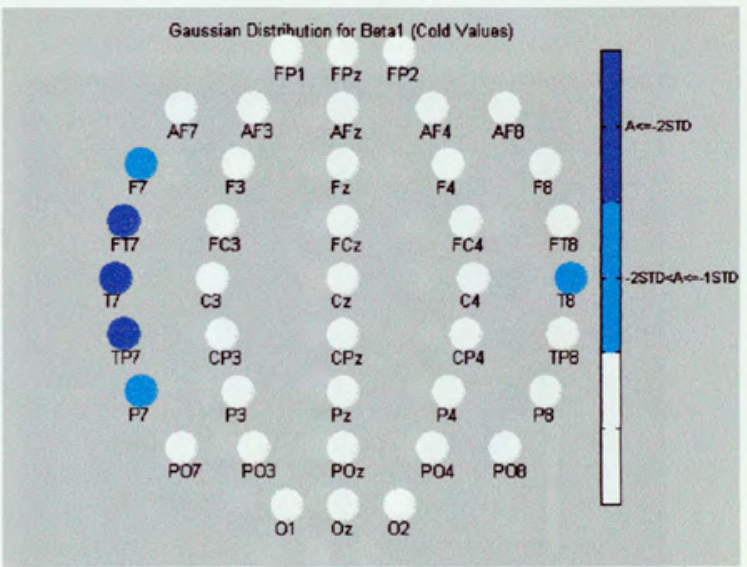

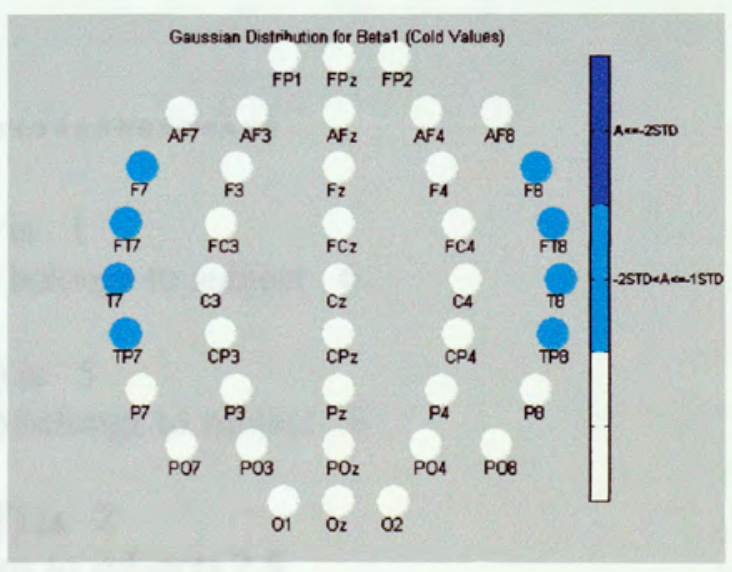


Patient 2
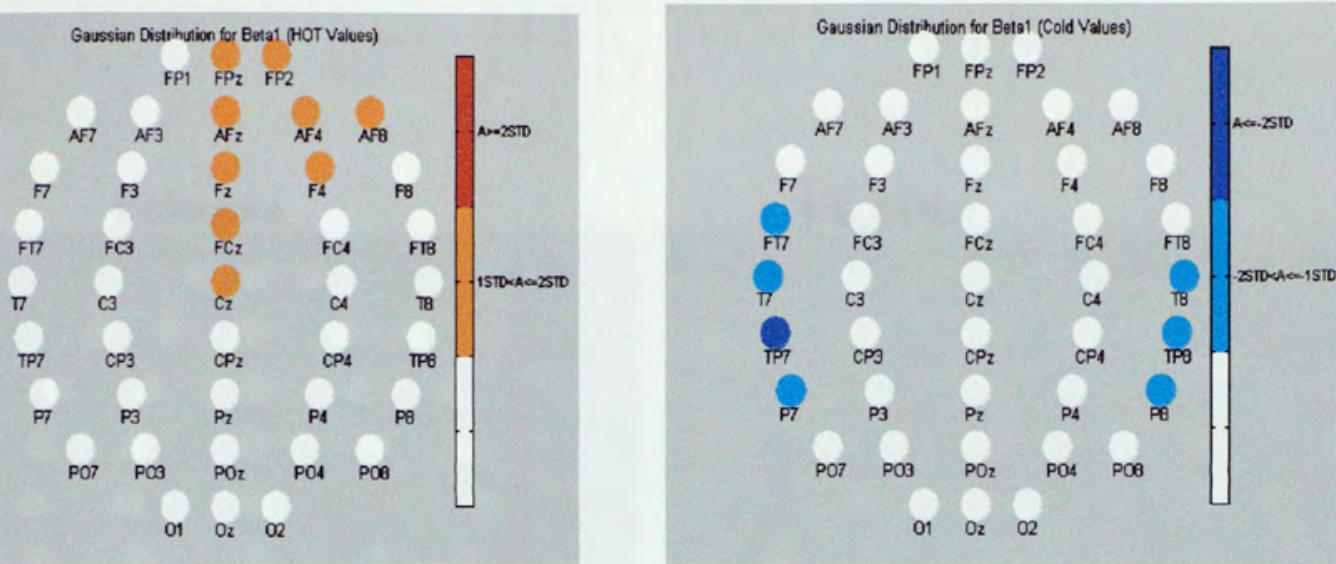

\section{Patient 3}
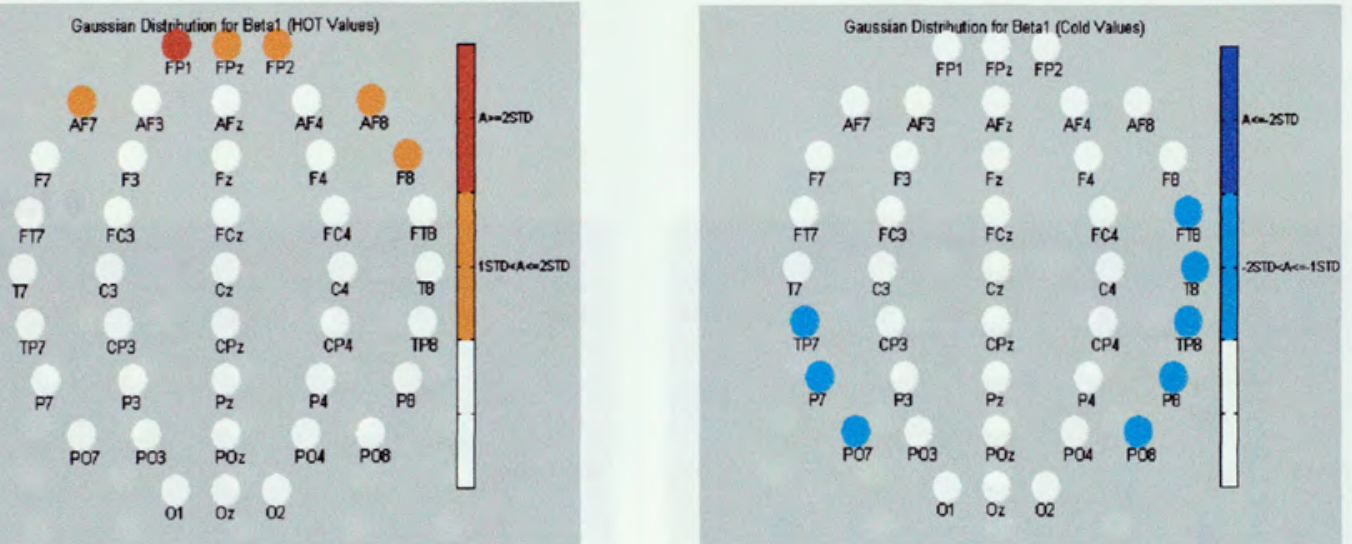

Energy Minimum Distance (beta2 POS LEFT) is 1 Energy Minimum Distance (beta2 POS LEFT) belongs to subject 6

Energy Minimum Distance (beta2 NEG LEFT) is 5 Energy Minimum Distance (beta2 NEG LEFT) belongs to subject 8

Energy Minimum Distance (beta2 POS RIGHT) is 2 Minimum Distance (beta2 POS RIGHT) belongs to subjects 28

Energy Minimum Distance (beta2 NEG RIGHT) is 0 
Energy Minimum Distance (beta2 NEG RIGHT) belongs to subjects 2689

\section{Unknown}

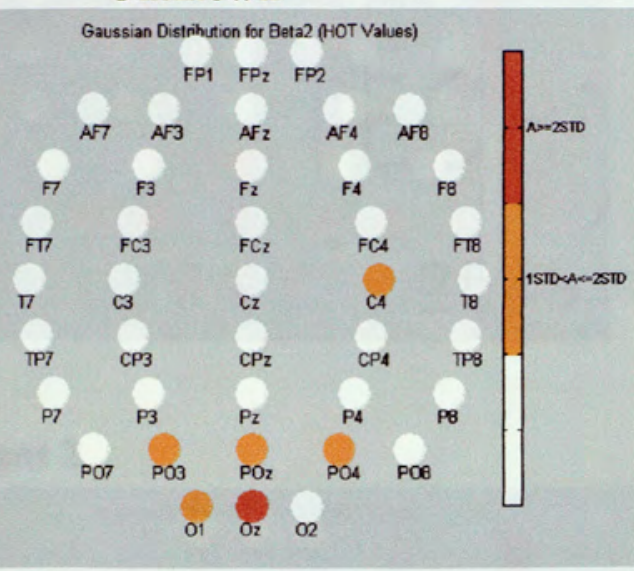

\section{Patient 6}

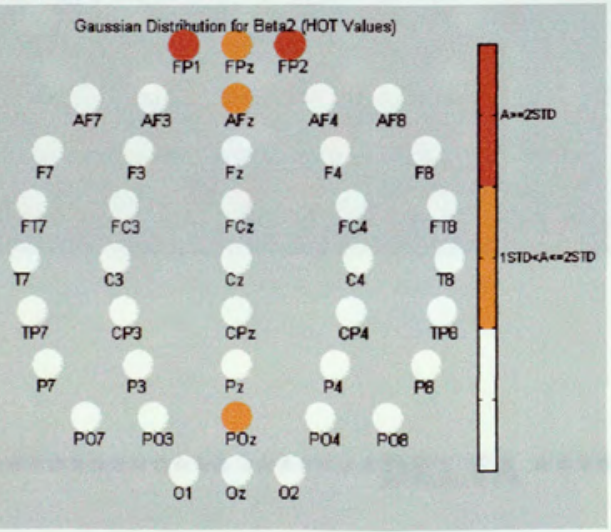

\section{Unknown}

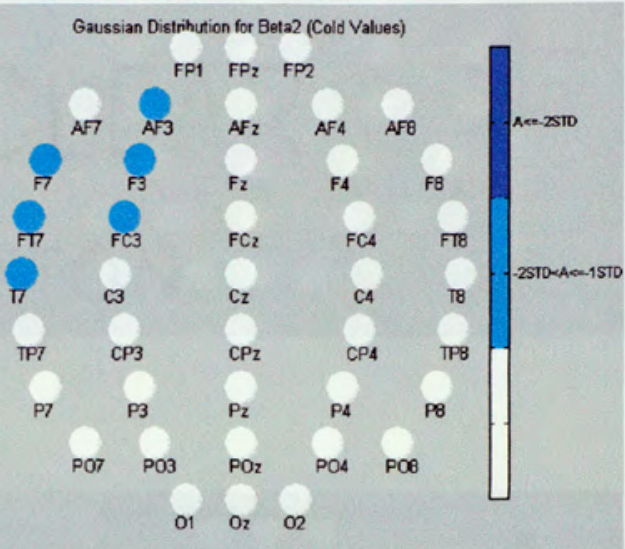




\section{Patient 8}
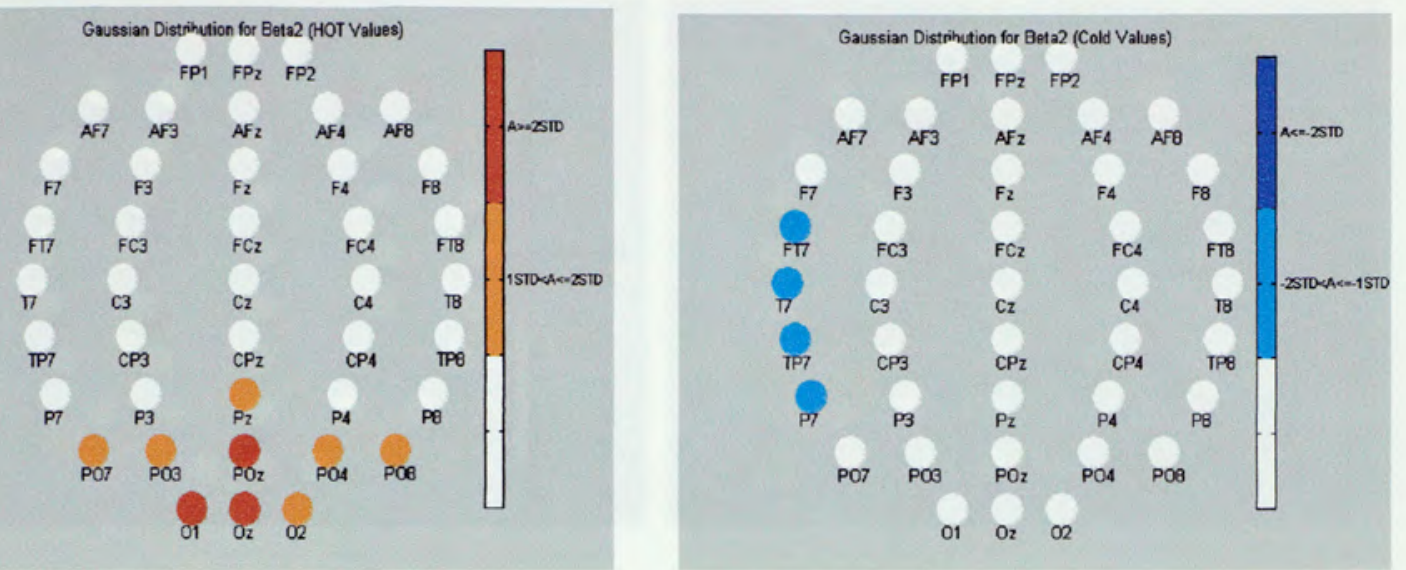

\section{Patient 2}
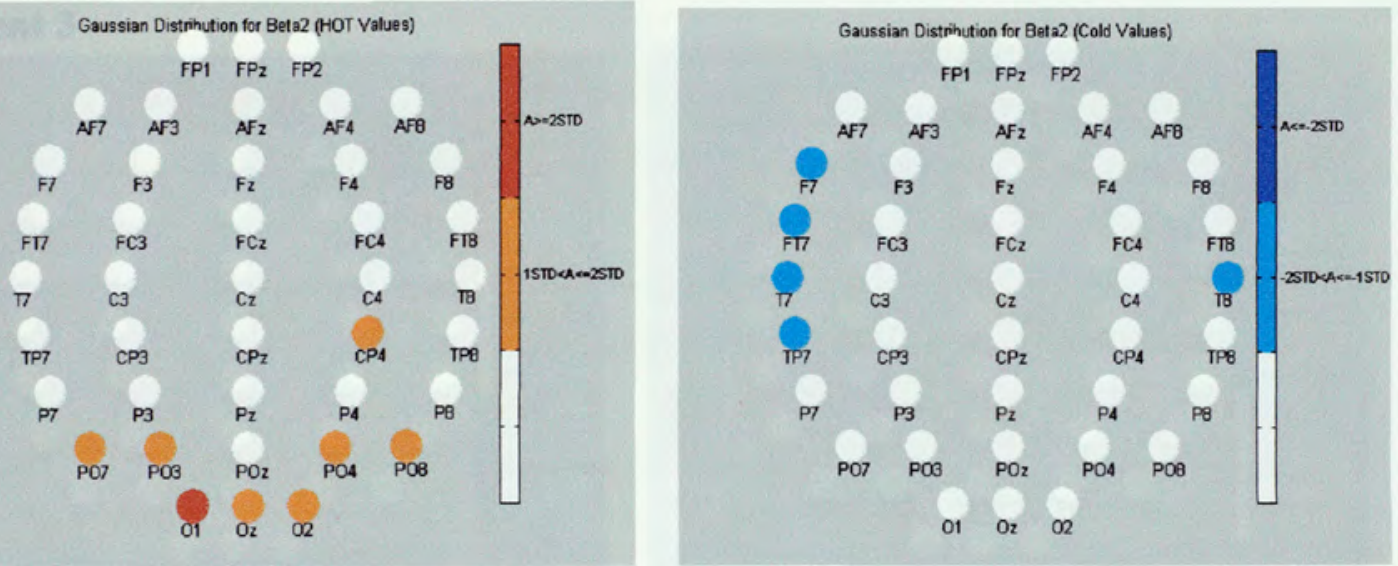

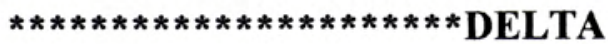

Energy Minimum Distance (delta POS LEFT) is 1

Minimum Distance (delta POS LEFT) belongs to subjects 3478

Energy Minimum Distance (delta NEG LEFT) is 0

Energy Minimum Distance (delta NEG LEFT) belongs to subjects 2345678

Energy Minimum Distance (delta POS RIGHT) is 1

Minimum Distance (delta POS RIGHT) belongs to subjects 456

Energy Minimum Distance (delta NEG RIGHT) is 0

Energy Minimum Distance (delta NEG RIGHT) belongs to subjects 24689 


\section{Unknown}

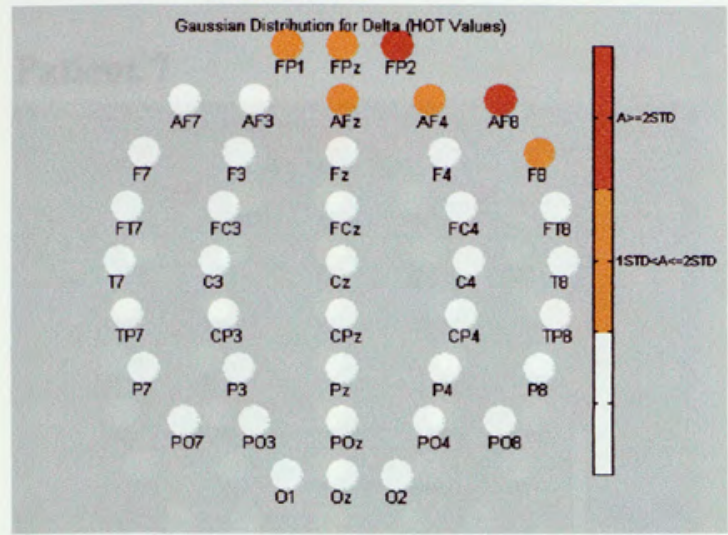

\section{Patient 3}

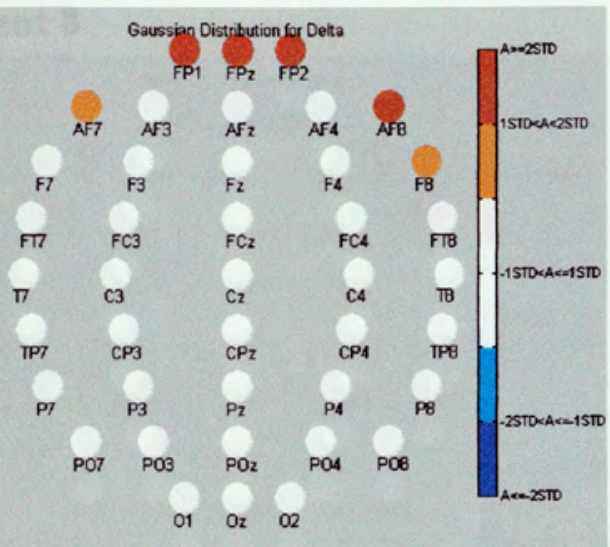

\section{Patient 4}

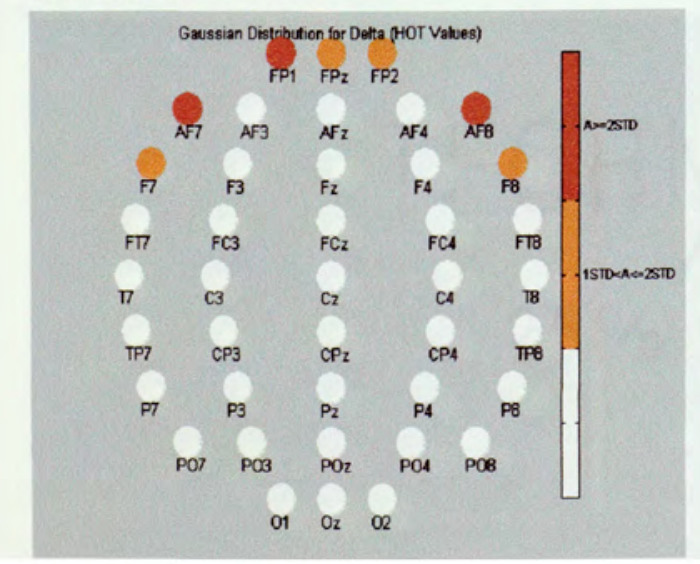

\section{Unknown}

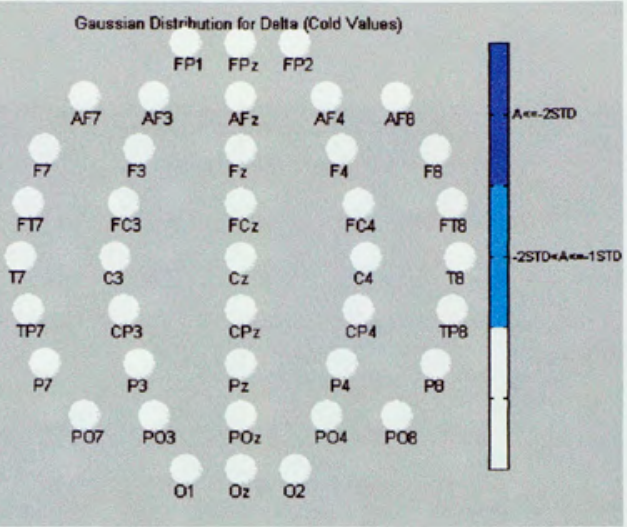

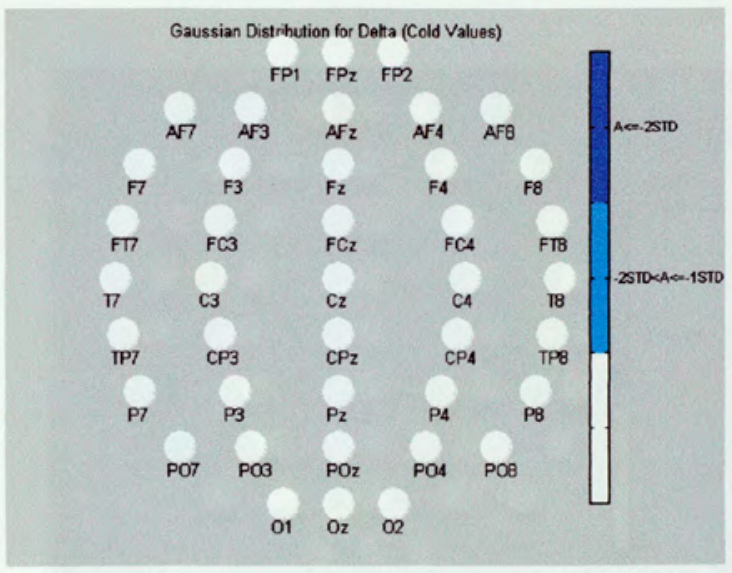

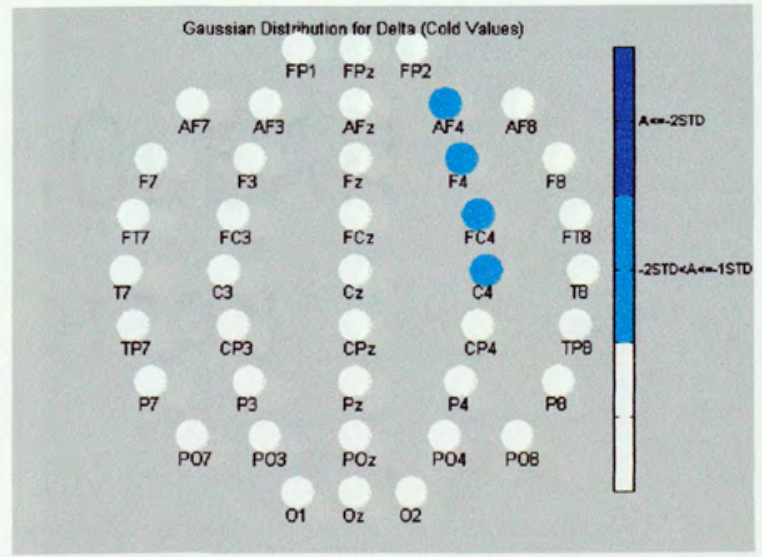




\section{Patient 7}

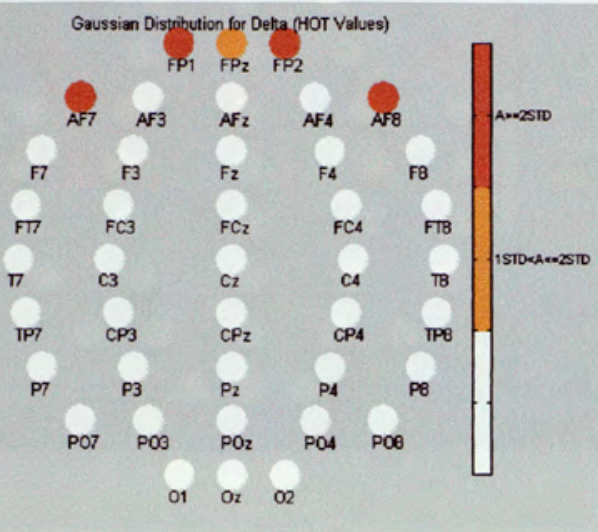

\section{Patient 8}

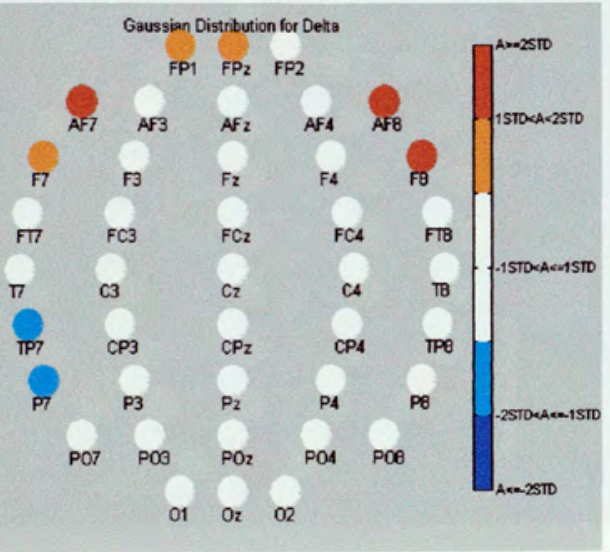

\section{Patient 2}

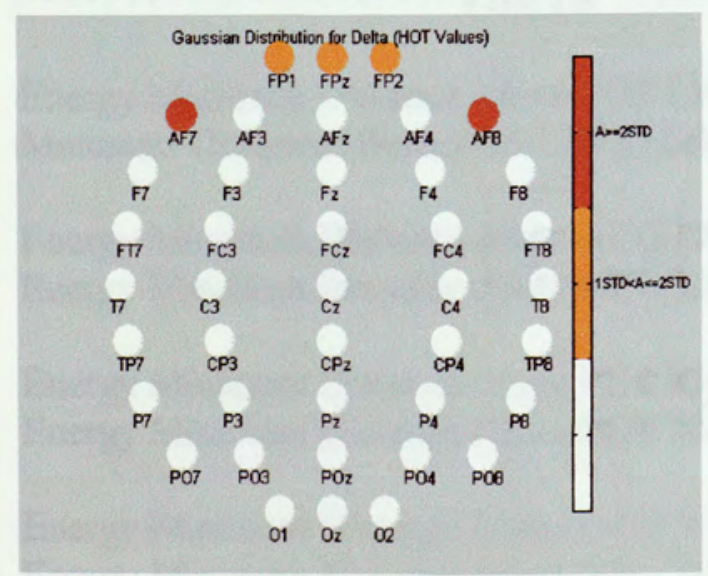

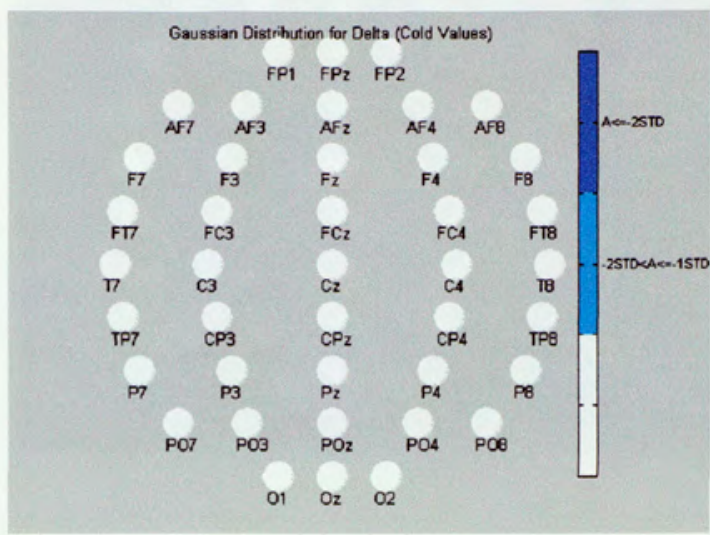

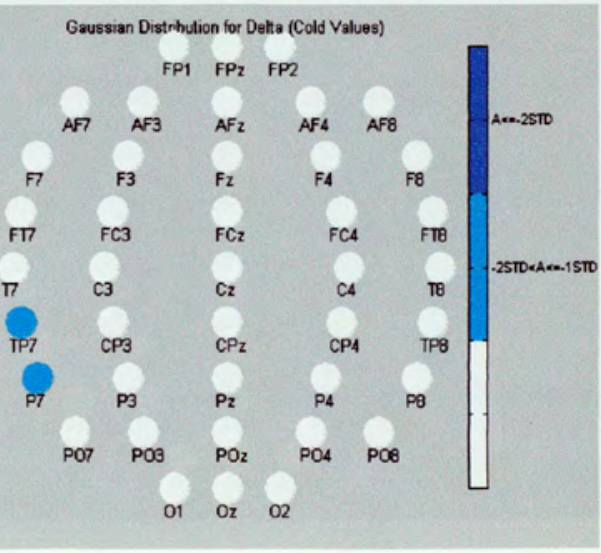

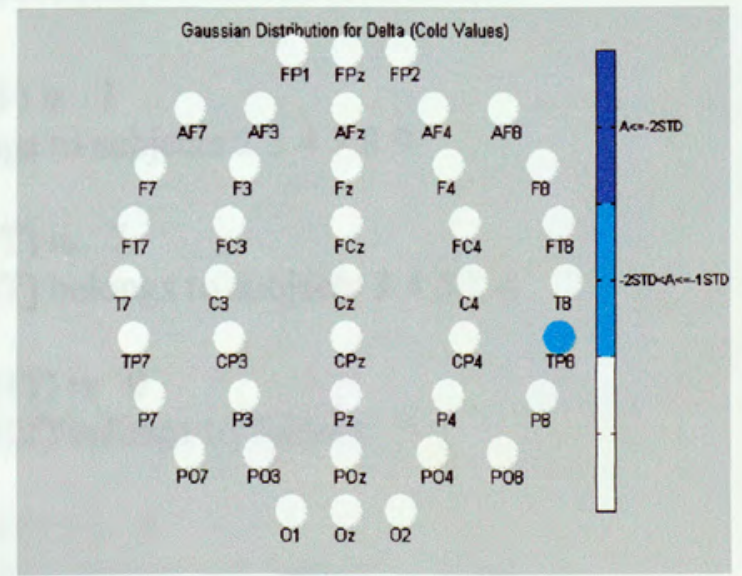



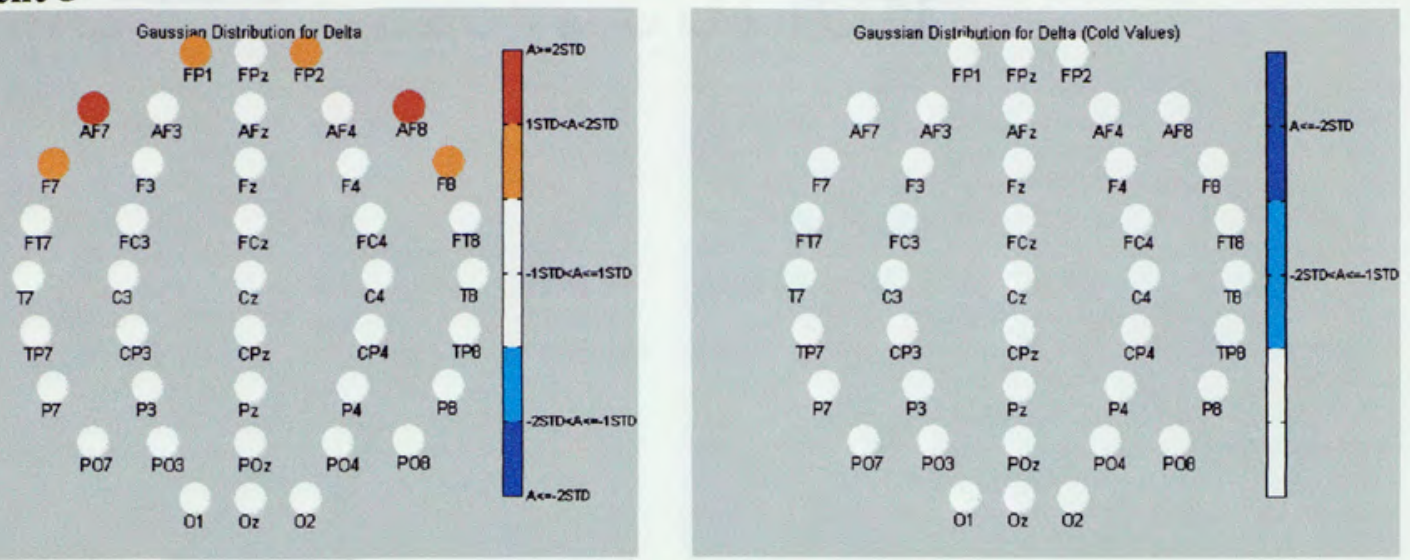

\section{Patient 6}
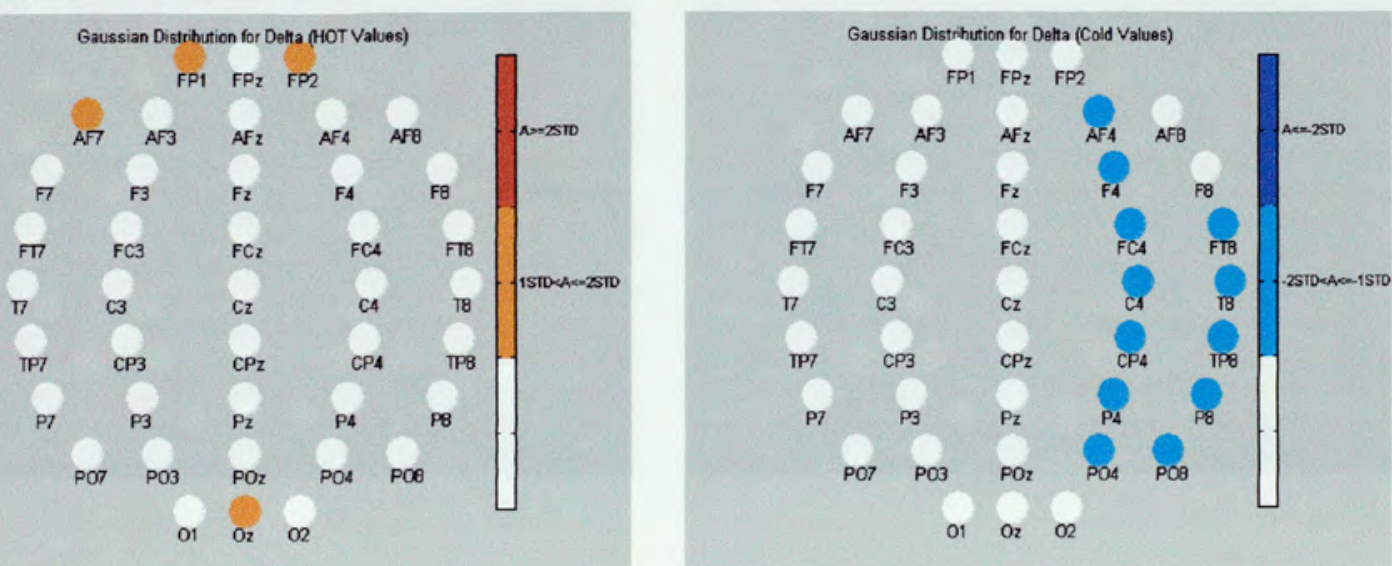

$* * * * * * * * * * * * * * * * * * * * *$ THETA

Energy Minimum Distance (theta POS LEFT) is 1

Minimum Distance (theta POS LEFT) belongs to subjects 234789

Energy Minimum Distance (theta NEG LEFT) is 7

Energy Minimum Distance (theta NEG LEFT) belongs to subjects 34578

Energy Minimum Distance (theta POS RIGHT) is 0

Energy Minimum Distance (theta POS RIGHT) belongs to subject 3

Energy Minimum Distance (theta NEG RIGHT) is 2

Energy Minimum Distance (theta NEG RIGHT) belongs to subjects 234678 


\section{Unknown}

Gaussian Distrihution for Theta. (HOT Values) $\begin{array}{lll}F P 1 & F P 2\end{array}$

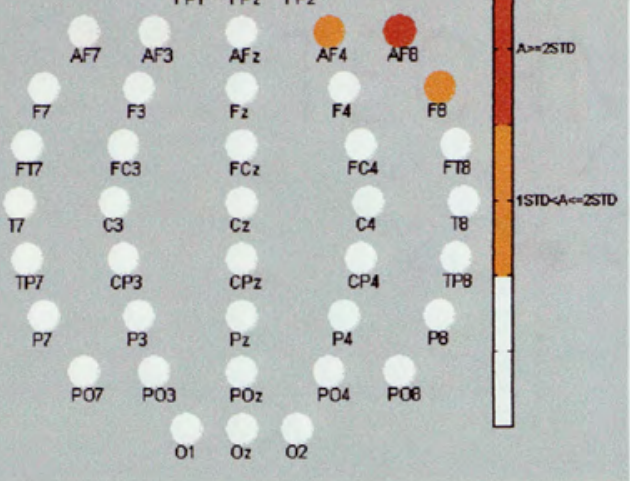

\section{Patient 2}

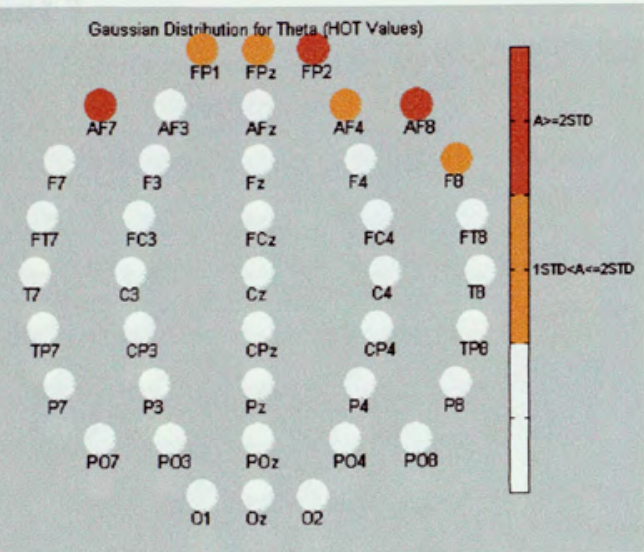

\section{Patient3}

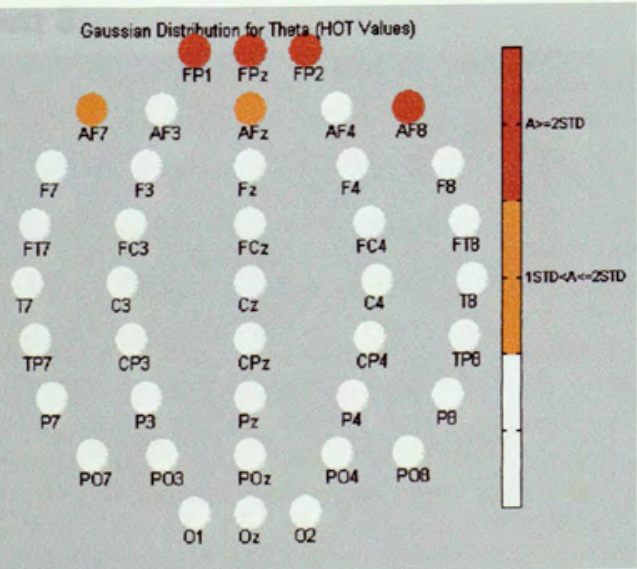

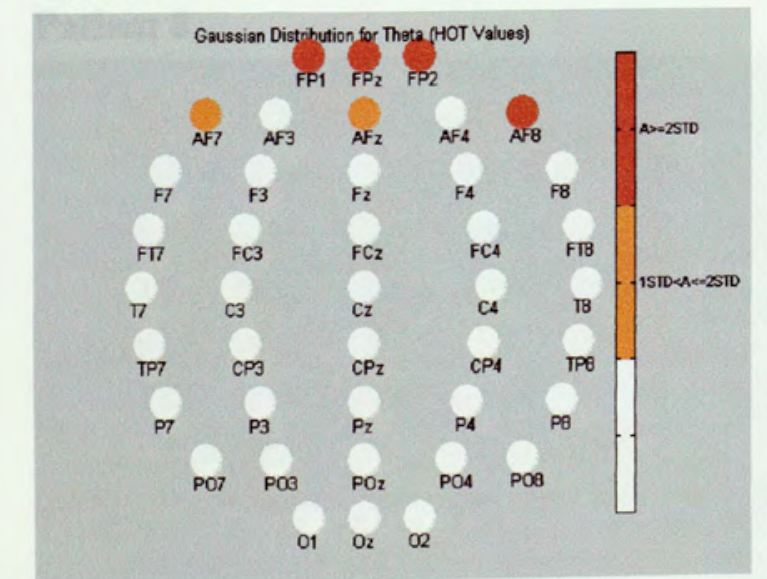

\section{Unknown}

Gaussian Distrihution for Theta (Cold Values) $\begin{array}{lll}F P 1 & F P z & F P 2\end{array}$

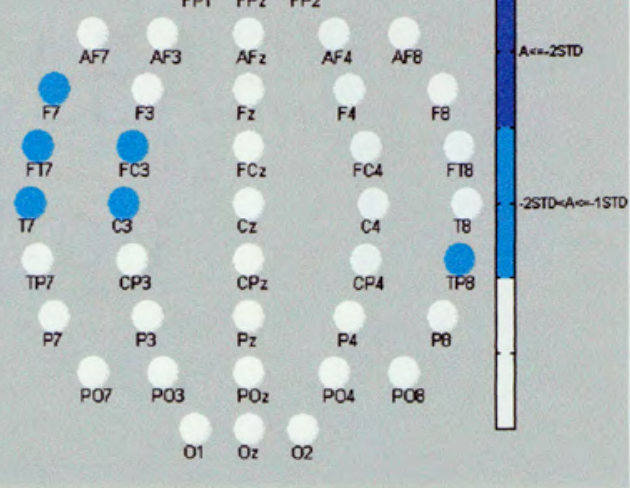

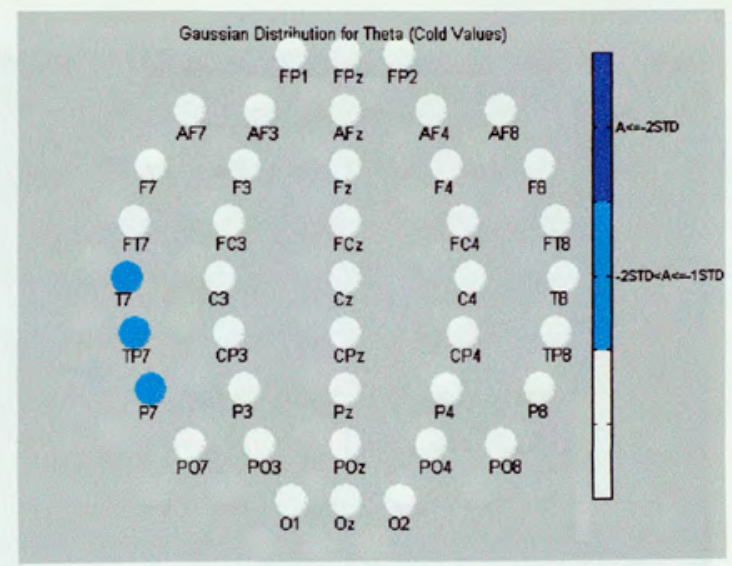

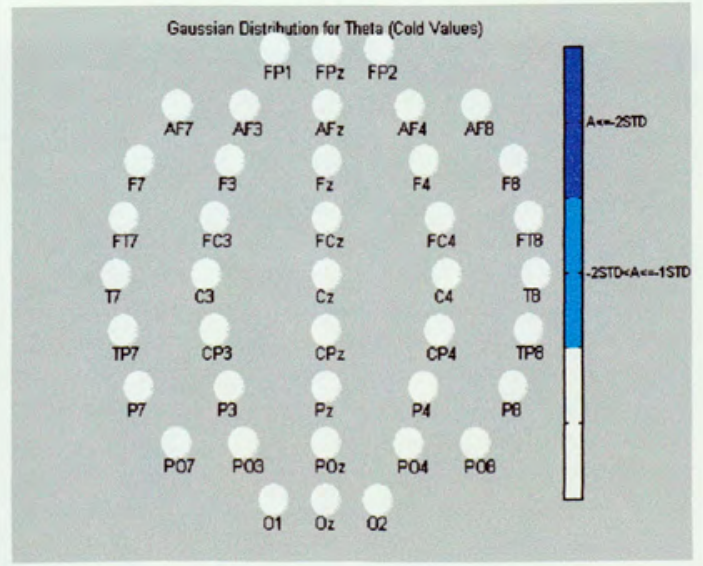




\section{Patient 4}
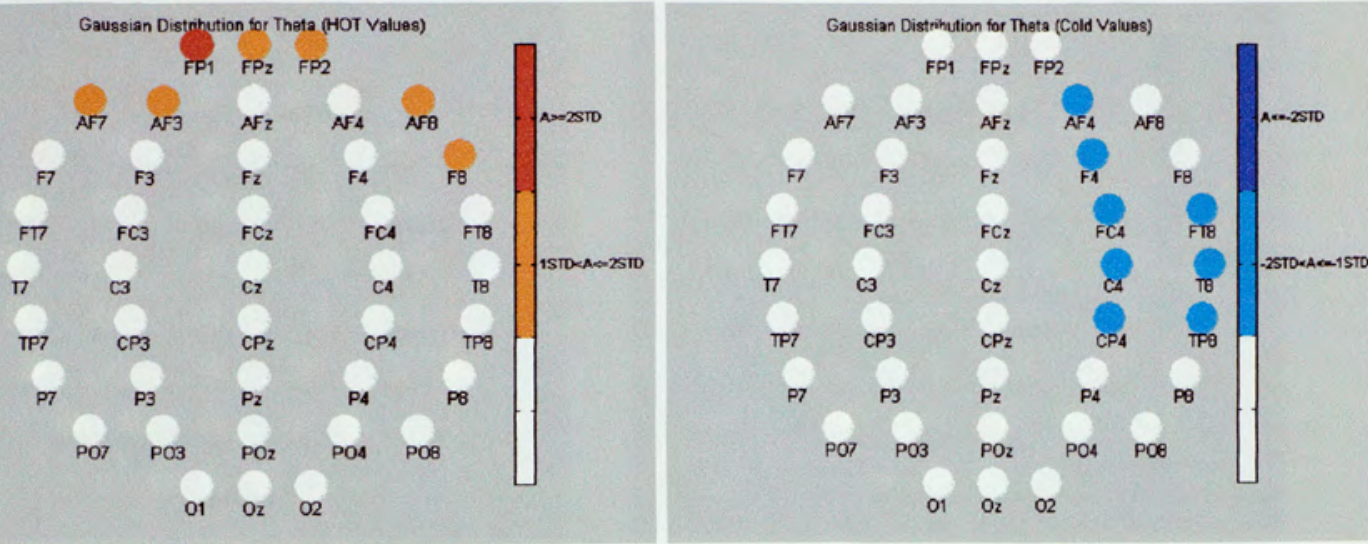

\section{Patient 7}
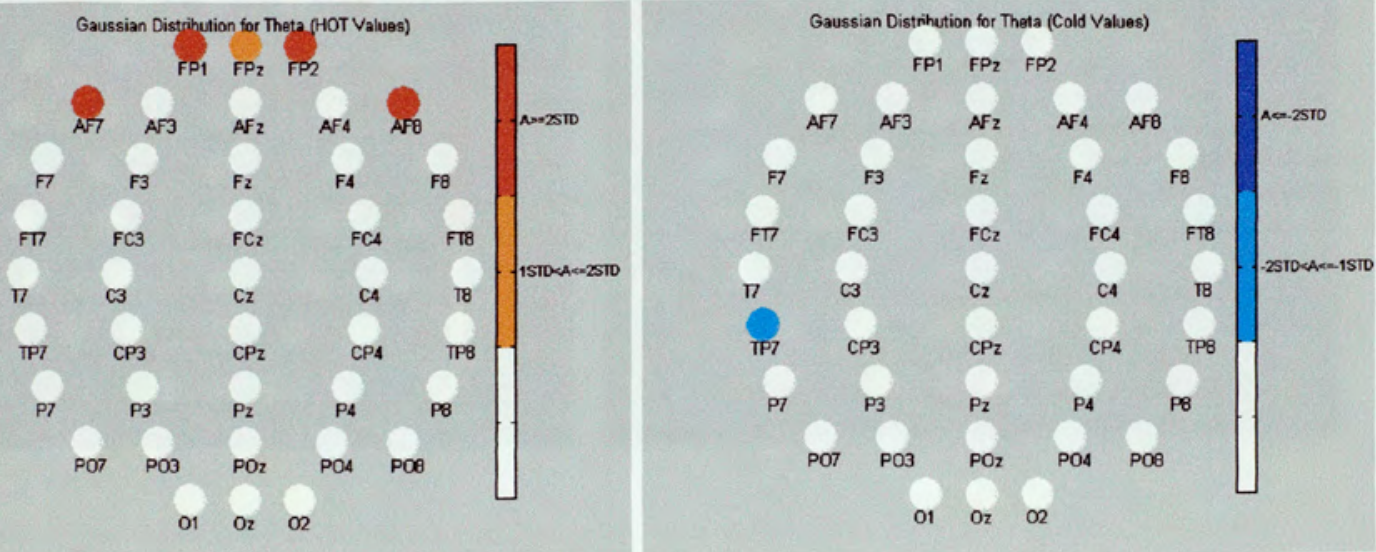

\section{Patient 8}
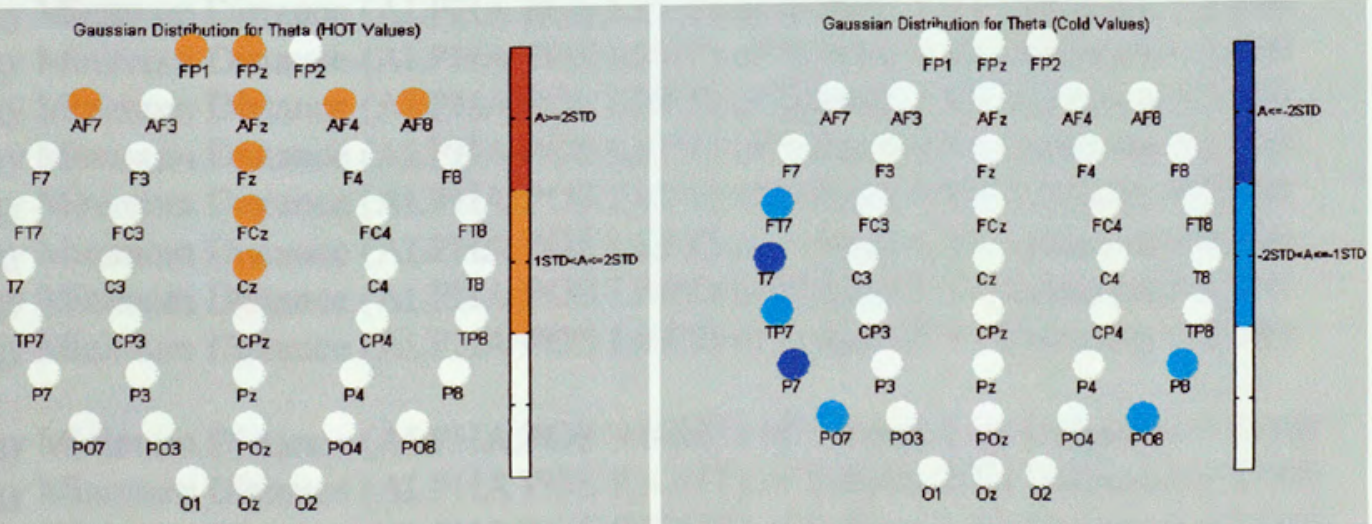


\section{Patient 5}
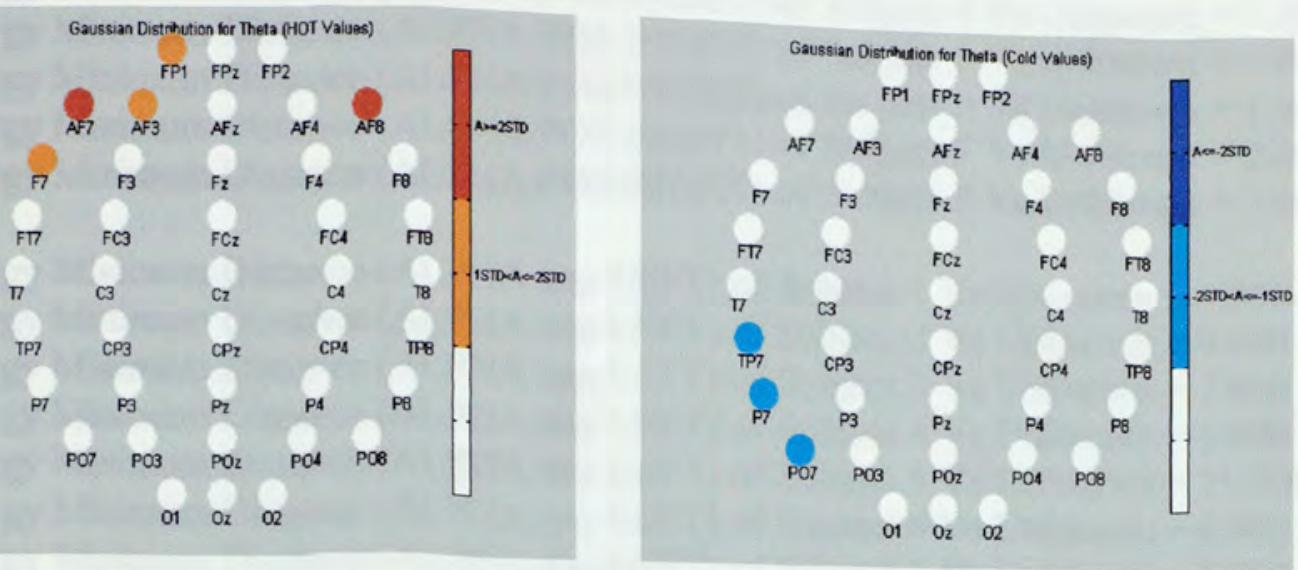

\section{Patient 6}
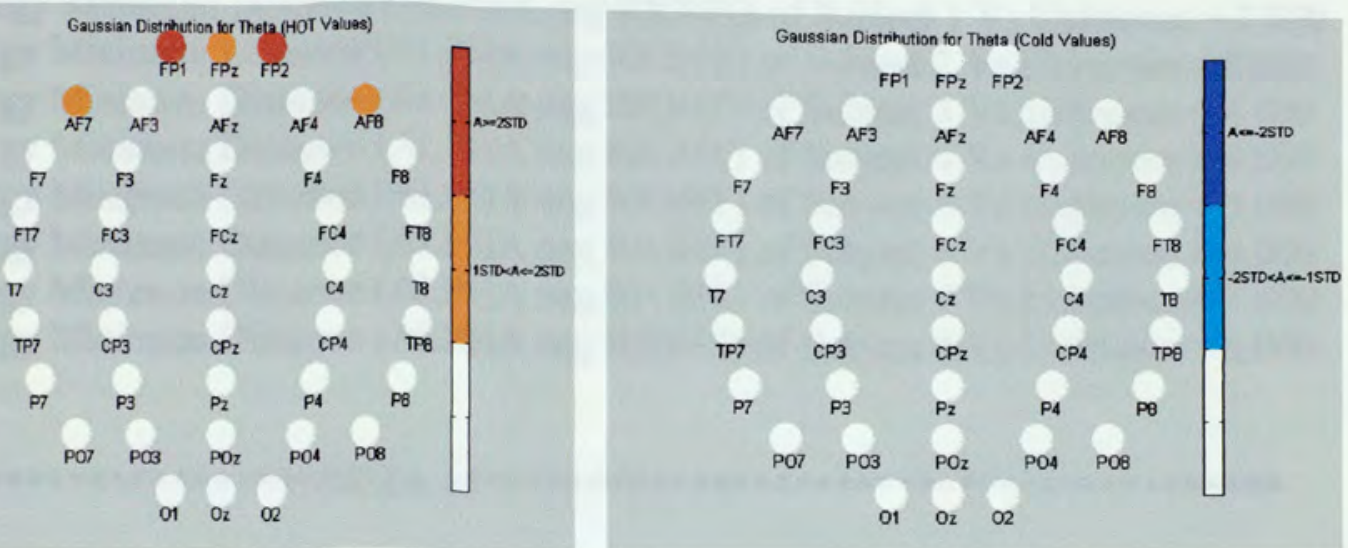

\section{Answer Results}

Energy Minimum Distance (ALPHA POS LEFT) of Subject 1 Vs Unknown $=1.000$ Energy Minimum Distance (ALPHA POS LEFT) of Subject 2 Vs Unknown $=1.000$ Energy Minimum Distance (ALPHA POS LEFT) of Subject 3 Vs Unknown $=1.000$ Energy Minimum Distance (ALPHA POS LEFT) of Subject 4 Vs Unknown $=1.000$ Energy Minimum Distance (ALPHA POS LEFT) of Subject 5 Vs Unknown $=3.000$ Energy Minimum Distance (ALPHA POS LEFT) of Subject 6 Vs Unknown $=0.000$ Energy Minimum Distance (ALPHA POS LEFT) of Subject 7 Vs Unknown $=3.000$ Energy Minimum Distance (ALPHA POS LEFT) of Subject 8 Vs Unknown $=2.000$

Energy Minimum Distance (ALPHA POS RIGHT) of Subject 1 Vs Unknown $=2.000$ Energy Minimum Distance (ALPHA POS RIGHT) of Subject 2 Vs Unknown $=2.000$ Energy Minimum Distance (ALPHA POS RIGHT) of Subject 3 Vs Unknown $=2.000$ 
Energy Minimum Distance (ALPHA POS RIGHT) of Subject 4 Vs Unknown $=1.000$ Energy Minimum Distance (ALPHA POS RIGHT) of Subject 5 Vs Unknown $=3.000$ Energy Minimum Distance (ALPHA POS RIGHT) of Subject 6 Vs Unknown $=1.000$ Energy Minimum Distance (ALPHA POS RIGHT) of Subject 7 Vs Unknown $=2.000$ Energy Minimum Distance (ALPHA POS RIGHT) of Subject 8 Vs Unknown $=3.000$

Energy Minimum Distance (ALPHA neg LEFT) of Subject 1 Vs Unknown $=4.000$ Energy Minimum Distance (ALPHA neg LEFT) of Subject 2 Vs Unknown $=4.000$ Energy Minimum Distance (ALPHA neg LEFT) of Subject 3 Vs Unknown $=7.000$ Energy Minimum Distance (ALPHA neg LEFT) of Subject 4 Vs Unknown $=3.000$ Energy Minimum Distance (ALPHA neg LEFT) of Subject 5 Vs Unknown $=11.000$ Energy Minimum Distance (ALPHA neg LEFT) of Subject 6 Vs Unknown $=6.000$ Energy Minimum Distance (ALPHA neg LEFT) of Subject 7 Vs Unknown $=3.000$ Energy Minimum Distance (ALPHA neg LEFT) of Subject 8 Vs Unknown $=7.000$ Energy Minimum Distance (ALPHA neg RIGHT) of Subject 1 Vs Unknown $=1.000$ Energy Minimum Distance (ALPHA neg RIGHT) of Subject 2 Vs Unknown $=0.000$ Energy Minimum Distance (ALPHA neg RIGHT) of Subject 3 Vs Unknown $=4.000$ Energy Minimum Distance (ALPHA neg RIGHT) of Subject 4 Vs Unknown $=8.000$ Energy Minimum Distance (ALPHA neg RIGHT) of Subject 5 Vs Unknown $=5.000$ Energy Minimum Distance (ALPHA neg RIGHT) of Subject 6 Vs Unknown $=6.000$ Energy Minimum Distance (ALPHA neg RIGHT) of Subject 7 Vs Unknown $=7.000$ Energy Minimum Distance (ALPHA neg RIGHT) of Subject 8 Vs Unknown $=6.000$

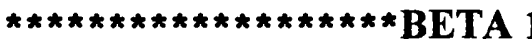

Energy Minimum Distance (beta1 POS LEFT) of Subject 1 Vs Unknown $=3.000$ Energy Minimum Distance (beta1 POS LEFT) of Subject 2 Vs Unknown $=3.000$ Energy Minimum Distance (beta1 POS LEFT) of Subject 3 Vs Unknown $=5.000$ Energy Minimum Distance (betal POS LEFT) of Subject 4 Vs Unknown $=3.000$ Energy Minimum Distance (betal POS LEFT) of Subject 5 Vs Unknown $=5.000$ Energy Minimum Distance (beta1 POS LEFT) of Subject 6 Vs Unknown $=4.000$ Energy Minimum Distance (beta1 POS LEFT) of Subject 7 Vs Unknown $=3.000$ Energy Minimum Distance (beta1 POS LEFT) of Subject 8 Vs Unknown $=2.000$

Energy Minimum Distance (beta1 POS RIGHT) of Subject 1 Vs Unknown $=4.000$ Energy Minimum Distance (betal POS RIGHT) of Subject 2 Vs Unknown $=5.000$ Energy Minimum Distance (beta1 POS RIGHT) of Subject 3 Vs Unknown $=4.000$ Energy Minimum Distance (betal POS RIGHT) of Subject 4 Vs Unknown $=7.000$ Energy Minimum Distance (beta1 POS RIGHT) of Subject 5 Vs Unknown $=5.000$ Energy Minimum Distance (beta1 POS RIGHT) of Subject 6 Vs Unknown $=6.000$ Energy Minimum Distance (beta1 POS RIGHT) of Subject 7 Vs Unknown $=5.000$ Energy Minimum Distance (betal POS RIGHT) of Subject 8 Vs Unknown $=7.000$

Energy Minimum Distance (beta1 neg LEFT) of Subject 1 Vs Unknown $=9.000$ 
Energy Minimum Distance (beta1 neg LEFT) of Subject 2 Vs Unknown $=4.000$ Energy Minimum Distance (betal neg LEFT) of Subject 3 Vs Unknown $=7.000$ Energy Minimum Distance (betal neg LEFT) of Subject 4 Vs Unknown $=6.000$ Energy Minimum Distance (betal neg LEFT) of Subject 5 Vs Unknown $=9.000$ Energy Minimum Distance (betal neg LEFT) of Subject 6 Vs Unknown $=6.000$ Energy Minimum Distance (betal neg LEFT) of Subject 7 Vs Unknown $=3.000$ Energy Minimum Distance (betal neg LEFT) of Subject 8 Vs Unknown $=5.000$

Energy Minimum Distance (beta1 neg RIGHT) of Subject 1 Vs Unknown $=1.000$ Energy Minimum Distance (betal neg RIGHT) of Subject 2 Vs Unknown $=1.000$ Energy Minimum Distance (betal neg RIGHT) of Subject 3 Vs Unknown $=2.000$ Energy Minimum Distance (betal neg RIGHT) of Subject 4 Vs Unknown $=7.000$ Energy Minimum Distance (betal neg RIGHT) of Subject 5 Vs Unknown $=1.000$ Energy Minimum Distance (betal neg RIGHT) of Subject 6 Vs Unknown $=2.000$ Energy Minimum Distance (betal neg RIGHT) of Subject 7 Vs Unknown $=3.000$ Energy Minimum Distance (beta1 neg RIGHT) of Subject 8 Vs Unknown $=1.000$

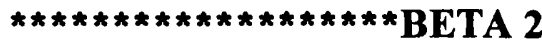

Energy Minimum Distance (beta2 POS LEFT) of Subject 1 Vs Unknown $=3.000$ Energy Minimum Distance (beta2 POS LEFT) of Subject 2 Vs Unknown $=2.000$ Energy Minimum Distance (beta2 POS LEFT) of Subject 3 Vs Unknown $=5.000$ Energy Minimum Distance (beta2 POS LEFT) of Subject 4 Vs Unknown $=3.000$ Energy Minimum Distance (beta2 POS LEFT) of Subject 5 Vs Unknown $=5.000$ Energy Minimum Distance (beta2 POS LEFT) of Subject 6 Vs Unknown $=5.000$ Energy Minimum Distance (beta2 POS LEFT) of Subject 7 Vs Unknown $=3.000$ Energy Minimum Distance (beta2 POS LEFT) of Subject 8 Vs Unknown $=2.000$

Energy Minimum Distance (beta2 POS RIGHT) of Subject 1 Vs Unknown $=5.000$ Energy Minimum Distance (beta2 POS RIGHT) of Subject 2 Vs Unknown $=5.000$ Energy Minimum Distance (beta2 POS RIGHT) of Subject 3 Vs Unknown $=8.000$ Energy Minimum Distance (beta2 POS RIGHT) of Subject 4 Vs Unknown $=5.000$ Energy Minimum Distance (beta2 POS RIGHT) of Subject 5 Vs Unknown $=6.000$ Energy Minimum Distance (beta2 POS RIGHT) of Subject 6 Vs Unknown $=5.000$ Energy Minimum Distance (beta2 POS RIGHT) of Subject 7 Vs Unknown $=6.000$ Energy Minimum Distance (beta2 POS RIGHT) of Subject 8 Vs Unknown $=6.000$

Energy Minimum Distance (beta2 neg LEFT) of Subject 1 Vs Unknown $=12.000$ Energy Minimum Distance (beta2 neg LEFT) of Subject 2 Vs Unknown $=5.000$ Energy Minimum Distance (beta2 neg LEFT) of Subject 3 Vs Unknown $=9.000$ Energy Minimum Distance (beta2 neg LEFT) of Subject 4 Vs Unknown $=8.000$ Energy Minimum Distance (beta2 neg LEFT) of Subject 5 Vs Unknown $=6.000$ Energy Minimum Distance (beta2 neg LEFT) of Subject 6 Vs Unknown $=11.000$ Energy Minimum Distance (beta2 neg LEFT) of Subject 7 Vs Unknown $=5.000$ 
Energy Minimum Distance (beta2 neg RIGHT) of Subject 1 Vs Unknown $=0.000$ Energy Minimum Distance (beta2 neg RIGHT) of Subject 2 Vs Unknown $=0.000$ Energy Minimum Distance (beta2 neg RIGHT) of Subject 3 Vs Unknown $=8.000$ Energy Minimum Distance (beta2 neg RIGHT) of Subject 4 Vs Unknown $=8.000$ Energy Minimum Distance (beta2 neg RIGHT) of Subject 5 Vs Unknown $=3.000$ Energy Minimum Distance (beta2 neg RIGHT) of Subject 6 Vs Unknown $=7.000$ Energy Minimum Distance (beta2 neg RIGHT) of Subject 7 Vs Unknown $=1.000$ Energy Minimum Distance (beta2 neg RIGHT) of Subject 8 Vs Unknown $=2.000$

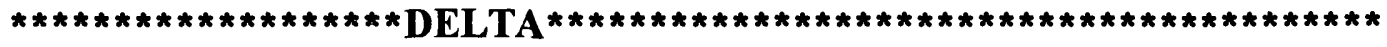

Energy Minimum Distance (delta POS LEFT) of Subject 1 Vs Unknown $=2.000$ Energy Minimum Distance (delta POS LEFT) of Subject 2 Vs Unknown $=1.000$ Energy Minimum Distance (delta POS LEFT) of Subject 3 Vs Unknown $=1.000$ Energy Minimum Distance (delta POS LEFT) of Subject 4 Vs Unknown $=2.000$ Energy Minimum Distance (delta POS LEFT) of Subject 5 Vs Unknown $=2.000$ Energy Minimum Distance (delta POS LEFT) of Subject 6 Vs Unknown $=1.000$ Energy Minimum Distance (delta POS LEFT) of Subject 7 Vs Unknown $=1.000$ Energy Minimum Distance (delta POS LEFT) of Subject 8 Vs Unknown $=2.000$

Energy Minimum Distance (delta POS RIGHT) of Subject 1 Vs Unknown $=3.000$ Energy Minimum Distance (delta POS RIGHT) of Subject 2 Vs Unknown $=0.000$ Energy Minimum Distance (delta POS RIGHT) of Subject 3 Vs Unknown $=2.000$ Energy Minimum Distance (delta POS RIGHT) of Subject 4 Vs Unknown $=1.000$ Energy Minimum Distance (delta POS RIGHT) of Subject 5 Vs Unknown $=2.000$ Energy Minimum Distance (delta POS RIGHT) of Subject 6 Vs Unknown $=4.000$ Energy Minimum Distance (delta POS RIGHT) of Subject 7 Vs Unknown $=2.000$ Energy Minimum Distance (delta POS RIGHT) of Subject 8 Vs Unknown $=3.000$

Energy Minimum Distance (delta neg LEFT) of Subject 1 Vs Unknown $=2.000$ Energy Minimum Distance (delta neg LEFT) of Subject 2 Vs Unknown $=2.000$ Energy Minimum Distance (delta neg LEFT) of Subject 3 Vs Unknown $=0.000$ Energy Minimum Distance (delta neg LEFT) of Subject 4 Vs Unknown $=2.000$ Energy Minimum Distance (delta neg LEFT) of Subject 5 Vs Unknown $=0.000$ Energy Minimum Distance (delta neg LEFT) of Subject 6 Vs Unknown $=0.000$ Energy Minimum Distance (delta neg LEFT) of Subject 7 Vs Unknown $=0.000$ Energy Minimum Distance (delta neg LEFT) of Subject 8 Vs Unknown $=1.000$

Energy Minimum Distance (delta neg RIGHT) of Subject 1 Vs Unknown $=0.000$ Energy Minimum Distance (delta neg RIGHT) of Subject 2 Vs Unknown $=0.000$ Energy Minimum Distance (delta neg RIGHT) of Subject 3 Vs Unknown $=0.000$ Energy Minimum Distance (delta neg RIGHT) of Subject 4 Vs Unknown $=7.000$ 
Energy Minimum Distance (delta neg RIGHT) of Subject 5 Vs Unknown $=0.000$ Energy Minimum Distance (delta neg RIGHT) of Subject 6 Vs Unknown $=18.000$ Energy Minimum Distance (delta neg RIGHT) of Subject 7 Vs Unknown $=0.000$ Energy Minimum Distance (delta neg RIGHT) of Subject 8 Vs Unknown $=0.000$

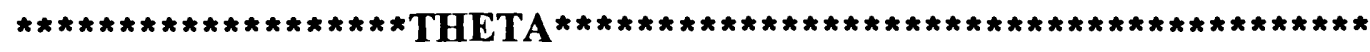

Energy Minimum Distance (theta POS LEFT) of Subject 1 Vs Unknown $=2.000$ Energy Minimum Distance (theta POS LEFT) of Subject 2 Vs Unknown $=1.000$ Energy Minimum Distance (theta POS LEFT) of Subject 3 Vs Unknown $=1.000$ Energy Minimum Distance (theta POS LEFT) of Subject 4 Vs Unknown $=3.000$ Energy Minimum Distance (theta POS LEFT) of Subject 5 Vs Unknown $=3.000$ Energy Minimum Distance (theta POS LEFT) of Subject 6 Vs Unknown $=1.000$ Energy Minimum Distance (theta POS LEFT) of Subject 7 Vs Unknown $=0.000$ Energy Minimum Distance (theta POS LEFT) of Subject 8 Vs Unknown $=1.000$

Energy Minimum Distance (theta POS RIGHT) of Subject 1 Vs Unknown $=3.000$ Energy Minimum Distance (theta POS RIGHT) of Subject 2 Vs Unknown $=2.000$ Energy Minimum Distance (theta POS RIGHT) of Subject 3 Vs Unknown $=2.000$ Energy Minimum Distance (theta POS RIGHT) of Subject 4 Vs Unknown $=2.000$ Energy Minimum Distance (theta POS RIGHT) of Subject 5 Vs Unknown $=2.000$ Energy Minimum Distance (theta POS RIGHT) of Subject 6 Vs Unknown $=1.000$ Energy Minimum Distance (theta POS RIGHT) of Subject 7 Vs Unknown $=2.000$ Energy Minimum Distance (theta POS RIGHT) of Subject 8 Vs Unknown $=3.000$

Energy Minimum Distance (theta neg LEFT) of Subject 1 Vs Unknown $=3.000$ Energy Minimum Distance (theta neg LEFT) of Subject 2 Vs Unknown $=3.000$ Energy Minimum Distance (theta neg LEFT) of Subject 3 Vs Unknown $=3.000$ Energy Minimum Distance (theta neg LEFT) of Subject 4 Vs Unknown $=2.000$ Energy Minimum Distance (theta neg LEFT) of Subject 5 Vs Unknown $=3.000$ Energy Minimum Distance (theta neg LEFT) of Subject 6 Vs Unknown $=3.000$ Energy Minimum Distance (theta neg LEFT) of Subject 7 Vs Unknown $=3.000$ Energy Minimum Distance (theta neg LEFT) of Subject 8 Vs Unknown $=4.000$

Energy Minimum Distance (theta neg RIGHT) of Subject 1 Vs Unknown $=0.000$ Energy Minimum Distance (theta neg RIGHT) of Subject 2 Vs Unknown $=0.000$ Energy Minimum Distance (theta neg RIGHT) of Subject 3 Vs Unknown $=0.000$ Energy Minimum Distance (theta neg RIGHT) of Subject 4 Vs Unknown $=8.000$ Energy Minimum Distance (theta neg RIGHT) of Subject 5 Vs Unknown $=3.000$ Energy Minimum Distance (theta neg RIGHT) of Subject 6 Vs Unknown $=2.000$ Energy Minimum Distance (theta neg RIGHT) of Subject 7 Vs Unknown $=2.000$ Energy Minimum Distance (theta neg RIGHT) of Subject 8 Vs Unknown $=0.000$ 
Energy Minimum Distance (ALPHA POS LEFT) is 0.000

Energy Minimum Distance (ALPHA POS LEFT) belongs to subject 7

Energy Minimum Distance (ALPHA NEG LEFT) is 3

Energy Minimum Distance (ALPHA NEG LEFT) belongs to subjects 58

Energy Minimum Distance (ALPHA POS RIGHT) is 1

Minimum Distance (ALPHA POS RIGHT) belongs to subjects 57

Energy Minimum Distance (ALPHA NEG RIGHT) is 0

Energy Minimum Distance (ALPHA NEG RIGHT) belongs to subject 3

\section{BETA 1}

Energy Minimum Distance (betal POS LEFT) is 2

Energy Minimum Distance (betal POS LEFT) belongs to subject 9

Energy Minimum Distance (betal NEG LEFT) is 3

Energy Minimum Distance (beta1 NEG LEFT) belongs to subject 8

Energy Minimum Distance (beta1 POS RIGHT) is 4

Minimum Distance (beta1 POS RIGHT) belongs to subjects 24

Energy Minimum Distance (betal NEG RIGHT) is 1

Energy Minimum Distance (betal NEG RIGHT) belongs to subjects 2369

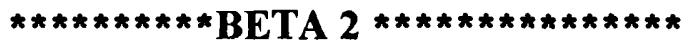

Energy Minimum Distance (beta2 POS LEFT) is 2

Minimum Distance (beta2 POS LEFT) belongs to subjects 39

Energy Minimum Distance (beta2 NEG LEFT) is 5

Energy Minimum Distance (beta2 NEG LEFT) belongs to subjects 38

Energy Minimum Distance (beta2 POS RIGHT) is 5

Minimum Distance (beta2 POS RIGHT) belongs to subjects 2357 
Energy Minimum Distance (beta2 NEG RIGHT) is 0

Energy Minimum Distance (beta2 NEG RIGHT) belongs to subjects 23

$\star \star \star * \star * \star \star * * *$ DELTA

Energy Minimum Distance (delta POS LEFT) is 1

Minimum Distance (delta POS LEFT) belongs to subjects 3478

Energy Minimum Distance (delta NEG LEFT) is 0

Energy Minimum Distance (delta NEG LEFT) belongs to subjects 4678

Energy Minimum Distance (delta POS RIGHT) is 0

Energy Minimum Distance (delta POS RIGHT) belongs to subject 3

Energy Minimum Distance (delta NEG RIGHT) is 0

Energy Minimum Distance (delta NEG RIGHT) belongs to subjects 234689

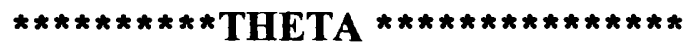

Energy Minimum Distance (theta POS LEFT) is 0

Energy Minimum Distance (theta POS LEFT) belongs to subject 8

Energy Minimum Distance (theta NEG LEFT) is 2

Energy Minimum Distance (theta NEG LEFT) belongs to subject 5

Energy Minimum Distance (theta POS RIGHT) is 1

Energy Minimum Distance (theta POS RIGHT) belongs to subject 7

Energy Minimum Distance (theta NEG RIGHT) is 0

Energy Minimum Distance (theta NEG RIGHT) belongs to subjects 2349 